\title{
TOTAL SYNTHESIS OF THE PROPOSED STRUCTURE OF ALDINGENIN B
}

\author{
Colin Oliver Hughes
}

A dissertation submitted to the faculty of the University of North Carolina at Chapel Hill in partial fulfillment of the requirements for the degree of Doctor of Philosophy in the Department of Chemistry

Chapel Hill

2012

\author{
Approved by: \\ Michael Crimmins \\ Jeff Johnson \\ Wei You \\ Joe Templeton \\ Maurice Brookhart
}


(c) 2012

Colin Oliver Hughes

ALL RIGHTS RESERVED 


\begin{abstract}
COLIN OLIVER HUGHES: Total Synthesis of the Proposed Structure of Aldingenin B

(Under the direction of Michael T. Crimmins)
\end{abstract}

The first enantioselective total synthesis of the proposed structure of aldingenin $B$ is reported in sixteen longest linear steps from known compounds. The stereochemistry at C5 and C6 were established by an asymmetric acetal aldol. Following a ring-closing metathesis, a selective, substrate-controlled hydrogen bondmediated dihydroxylation provided control of the C2 and C3 stereocenters. Other key reactions include a cycloketalization, a bromoetherification, and two cerium trichloride promoted nucleophilic additions. Discrepancies in the spectroscopic data of the synthetic and natural material led to the conclusion that the structure of the natural sample was misassigned. 
To everyone and everything who made this possible. 


\section{ACKNOWLEDGEMENTS}

Traditional:

l'd like to thank the guy who made this all possible, Michael Crimmins. I'd also like to thank members of my committee, especially Wei You for being all-around awesome, in the Eddie Izzard-the-universe-not-a-hot-dog sense of the word. Many thanks also to Jeff Johnson, Dave Nicewicz, and Simon Meek. Additionally, l'd like to thank F. Dean Toste, Dennis Hopper, and Ahamindra Jain.

I'd like to thank Drs. Marc ter Horst and Sohrab Habibi for help with spectroscopic samples. l'd also like to thank the $600 \mathrm{MHz}$ NMR, without which none of this work would be possible.

Thanks are due to João H. G. Lago and Professor Greg Dudley for spectral data. Without their help this project would have been much more difficult at the end.

I have learned much from my labmates throughout the years, so thanks are in order to people I learned from, including Aaron Smith, Pat McDougall, Luke Zuccarello, Michael Ellis, Dee Jacobs, Mariam Shamszad, Adam Azman, Jason Stevens, Mark Mans, Tim Martin, Phil Williams, Lizzy O'Bryan, Anne-Marie Roe Dechert-Schmidt, Anita Matteson, Christie Stauffer, and Dan Carper. Special thanks to "Dee", Mariam "Ahamszad", Adam-the-Azman, Jay-the-cray-cray, Mark "the" Mans, Timmy!, AMDS, Anita, and Dan for friendship.

Special thanks to Mark Mans, Adam Azman, Dee Jacobs, Dan Carper and Tim Martin for various proof-reading throughout the years. I appreciate it. 
To my GFABFAM Mark Mans, thanks for being a wonderful friend and always being there for me. I could not have made it through the first five years of grad school without your friendship and support through all the hardship.

To Puja, thanks for being awesome, in the Wei You sense. Without you I could not have made it through the last year.

Will.i.am style acknowledgements (thanking things for which I am thankful, but which most people take for granted, thus making it seem disingenuous to cynical readers):

Special thanks are due to Cosmic Cantina, for providing nutritious and nonsleep inducing lunches in exchange for only $\$ 3.30$.

l'd like to thank my longest-tenured roommate $($ and +1$)$ Nathan Westcott for mostly being a good guy, other than all the times he insisted on asking me how research was going. Perhaps he was only trying to vicariously live the *real ${ }^{*}$ gradschool life through me. Thanks are also due to Shrinivas Krishian, Jennifer See, Kathryn deKrafft and Dale Wilger for being great roommates by ever asking how my research was going.

I owe a debt of gratitude to the Student Health Services and the hospital for treatment of various ailments throughout my time here.

Thanks to all the family-members and teachers who told me I wasn't good enough to go to college. I enjoy proving people wrong.

Thanks to the sun, without which most life would not be possible. No food, light, plants, daytime, or warmth. 
l'd like to thanks the Department of Education for a GAANN fellowship. I'd also like to thanks the creators of ChemDraw, SciFinder, MS Word, the internet, and Kenan Labs. I also would like to thanks all the janitors, maintenance people, and others who ensure this place is able to run.

I'd like to thank the tax-payers of the United States of America, North Carolina, and California for paying for my education. I also need to thank all chemists past and present and all previous scientists for discovering the tools I used both in research and life. Furthermore, I thank everyone who had the foresight to prioritize discovery and knowledge. Without people like them, we'd all be living in caves in the south of France.

l'd also like to thank everyone who made my clothes, food, soap, purified my water, undertook public health initiatives, built my apartments, put money in my bank account, supplied electricity, made music I enjoy, increased my knowledge, provided cell phone service, invented or provided sports/games/entertainment, and in general anyone who contributed to my or others well-being. 


\section{TABLE OF CONTENTS}

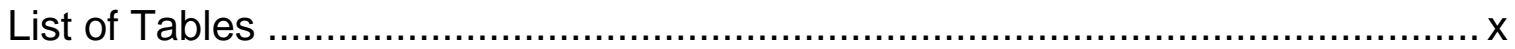

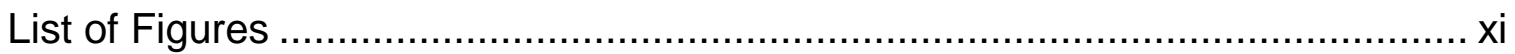

List of Schemes .......................................................................................

List of Abbreviations.............................................................................

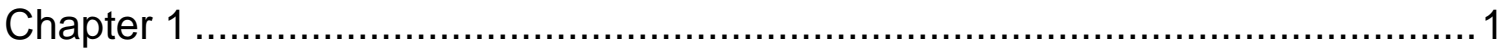

A. Secondary metabolites of Laurencia species ........................................ 1

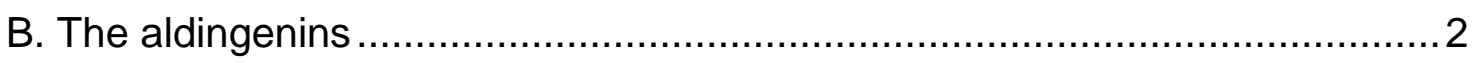

C. Aldingenin B

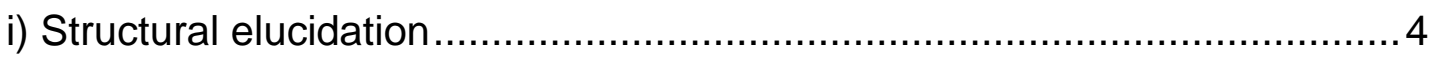

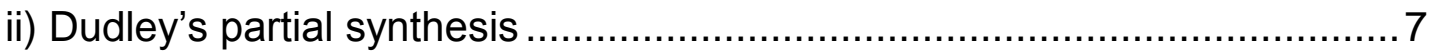

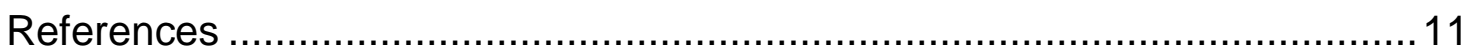

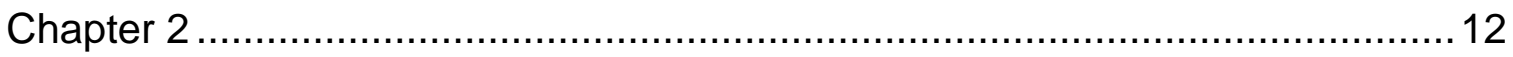

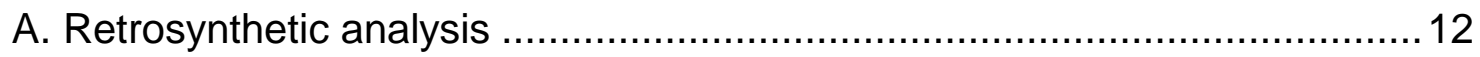

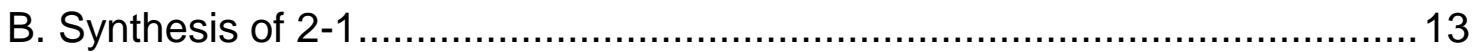

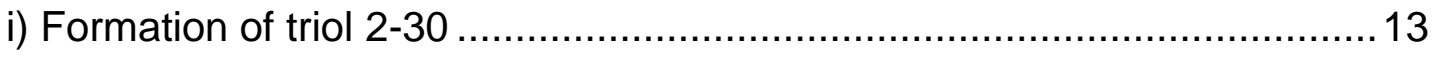

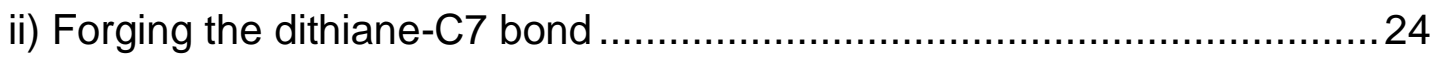

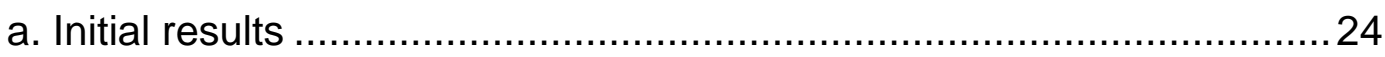


b. The utilization and role of cerium as an additive.

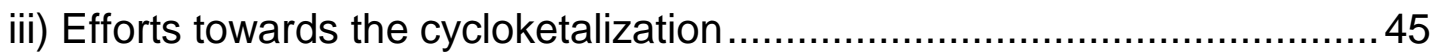

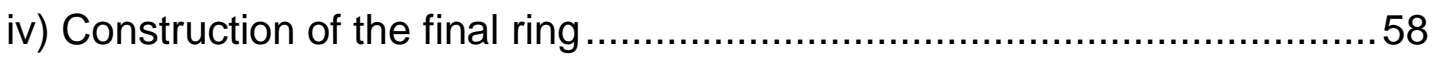

C. Comments on the misassignment of the structure of the natural product and evidence for the synthesis of the proposed structure 64

i) Spectral differences between synthetic 2-1 and assigned (natural) 2-1 ...66

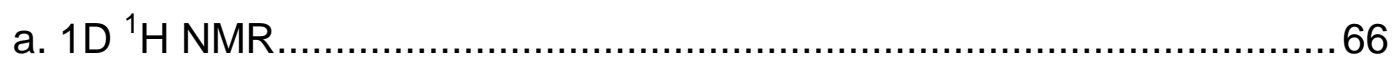

b. $\mathrm{H} 5 / \mathrm{H} 6$ coupling and ramifications for splitting patters on $\mathrm{H} 5$................72

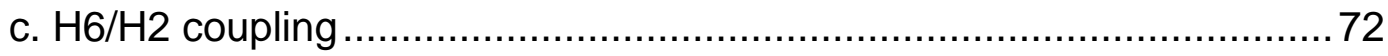

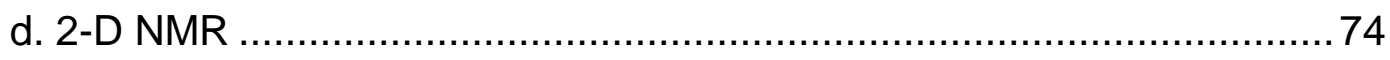

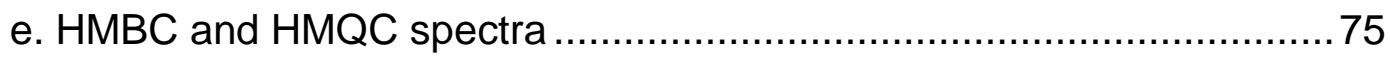

f. Review of identification of selected structures ................................... 76

D. Attempts to synthesize the actual structure of aldingenin B .....................83

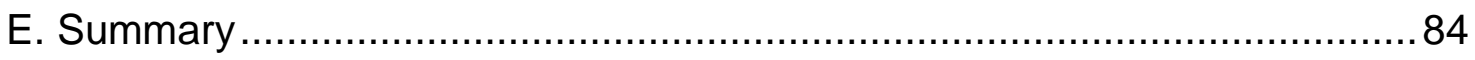

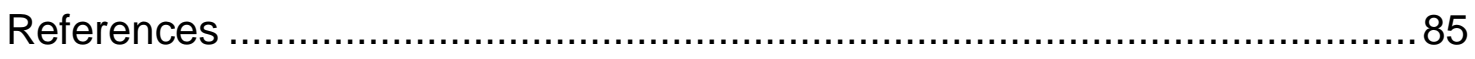

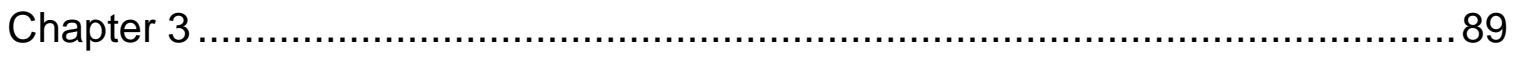

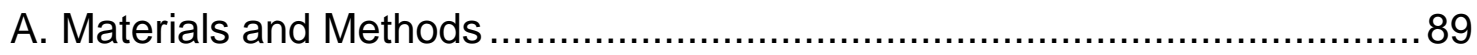

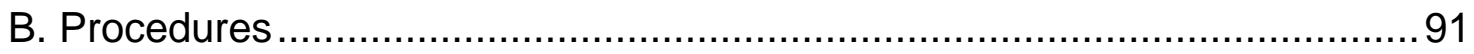

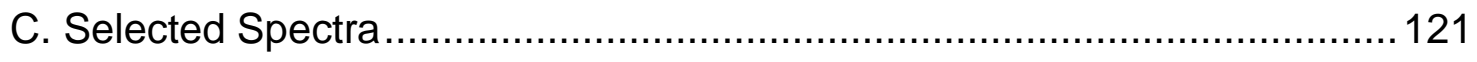




\section{LIST OF TABLES}

Table 1.1 NMR of aldingenin B 5

Table 2.1 Dihydroxylation conditions 19

Table 2.2 The additive $\mathrm{CeCl}_{3}$ proves useful in cerium

promoted carbonyl additions 35

Table 2.3 Various known methods for drying cerium . 36

Table 2.4 Comparison of ${ }^{1} \mathrm{H},{ }^{13} \mathrm{C}$ NMR assignments between natural and synthetic 2-1 65

Table 2.5 HMBC data, authors claim, what the data shows, and comparison to synthetic sample 


\section{LIST OF FIGURES}

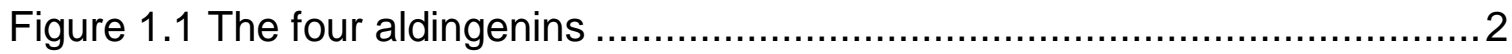

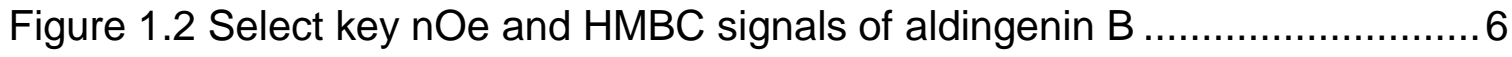

Figure 1.3 Determination of absolute configuration........................................

Figure 2.1 Speculated favored transition state in acetal aldol .........................16

Figure 2.2 From which face will the oxidant approach? ................................ 18

Figure 2.3 Select reactions illustrative of Donohoe's findings .........................20

Figure 2.4 Hydrogen-bonding model of syn-dihydroxylation ...........................21

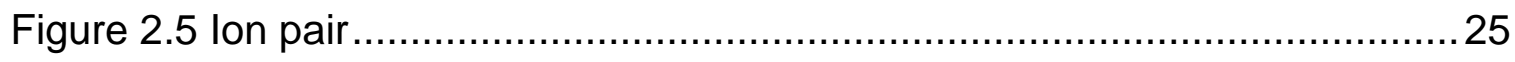

Figure 2.6 Potential literature identification of problem/solution ........................29

Figure 2.7 Brief survey of cerium promoted nucleophilic addition reactions .......30

Figure 2.8 Two methods of utilizing cerium for carbonyl additions.....................31

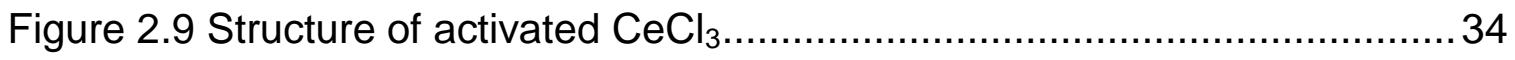

Figure 2.10 Carbinol range of natural sample ............................................6

Figure 2.11 Carbinol range of selected synthetic tricyclic compounds ...............68

Figure 2.12 Three tricycles synthesized by Dudley and co-workers and ${ }^{1} \mathrm{H}$ NMR data for $\mathrm{H} 6 / \mathrm{H} 2$ and comparison to $2-132 / 2-131 / 2-144$

Figure 2.13 Select key COSY and NOESY correlations of synthetic $2-1 \ldots \ldots \ldots \ldots .74$ 
Figure 2.14 Summary of key evidence against Lago's assignment

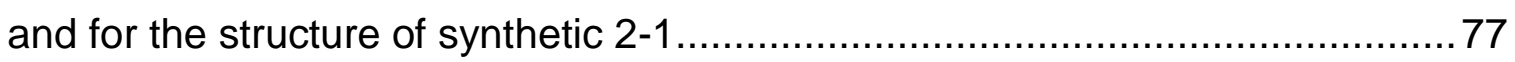

Figure 2.15 Sampling of select observed NMR data compared to unobserved data, to weaken arguments against assigned structures.................78 


\section{LIST OF SCHEMES}

Scheme 1.1 Proposed biosynthesis of aldingenin A ..................................... 3

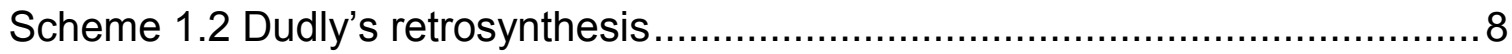

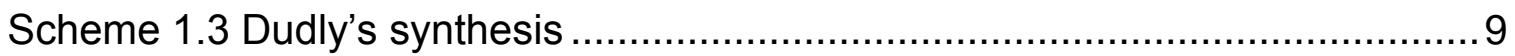

Scheme 1.4 Cycloketalization to form core of aldingenin B ..........................10

Scheme 2.1 Retrosynthetic scheme …................................................ 13

Scheme 2.2 Synthesis of dibenzyl acetal 2-9 …...................................... 14

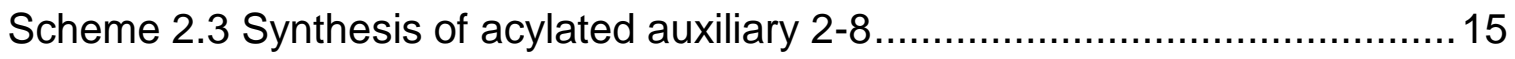

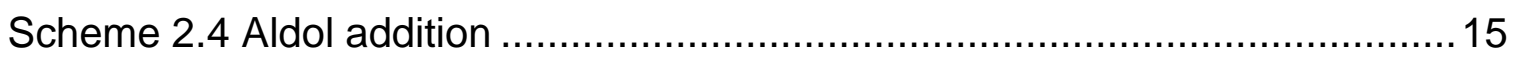

Scheme 2.5 Synthesis of alcohol 2-29 ................................................... 17

Scheme 2.6 Stereoselective dihydroxylation ….........................................22

Scheme 2.7 Determination of stereochemistry …….....................................23

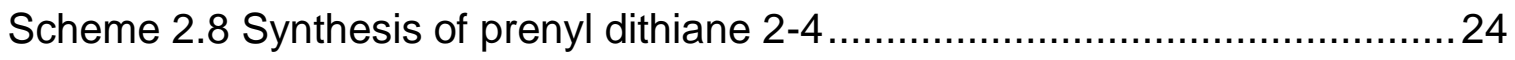

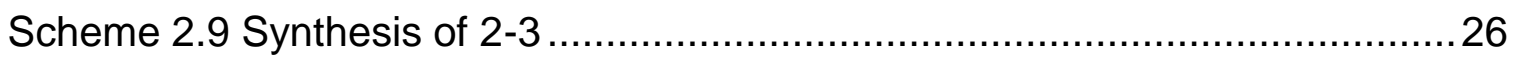

Scheme 2.10 Acetonide protection and attempted dithiane addition .................27

Scheme 2.11 Addition of 1,3 dithiane to aldehyde $2-59 \ldots \ldots \ldots \ldots \ldots \ldots \ldots \ldots \ldots \ldots \ldots . .28$

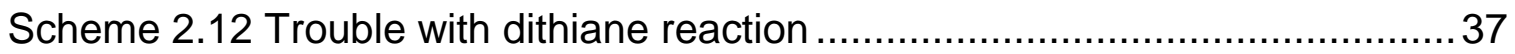

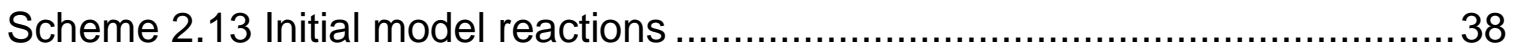


Scheme 2.14 Inconsistent result utilizing anhydrous $\mathrm{CeCl}_{3}$

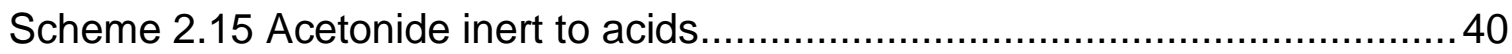

Scheme 2.16 Synthesis of dimethylcyclopentane …..................................... 41

Scheme 2.17 Diol protected as cyclopentylidene ketal ..................................42

Scheme 2.18 A successful new development............................................. 45

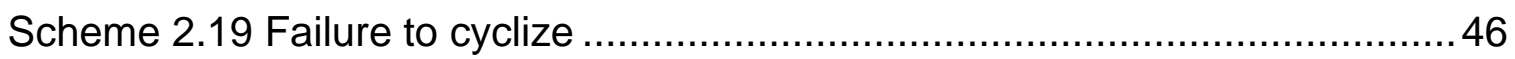

Scheme 2.20 Failed attempts to cyclize ..................................................... 47

Scheme 2.21 Dithiane removal without olefin migration ................................ 48

Scheme 2.22 Undesired over cyclization .................................................... 49

Scheme 2.23 Attempt to cyclize diketone ..................................................... 49

Scheme 2.24 Attempts to cyclize with acetate protection ...............................50

Scheme 2.25 Is THP formation a necessary precondition to cycloketalization? .50

Scheme 2.26 hypothetical route to aldingenin B …....................................52

Scheme 2.27 Potential model studies ........................................................ 53

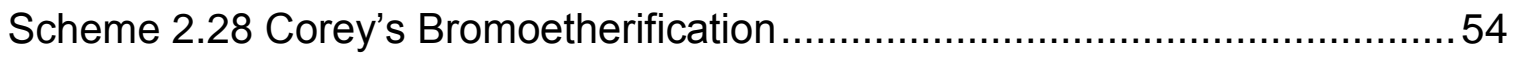

Scheme 2.29 Failure to re-form bromo-THP prior to cycloketalization.................55

Scheme 2.30 Testing the success if olefin not present ...................................56

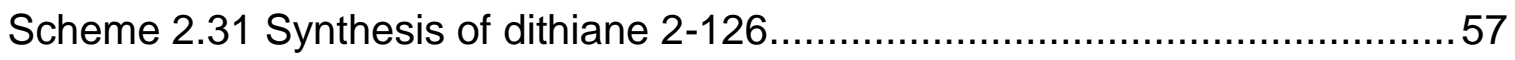

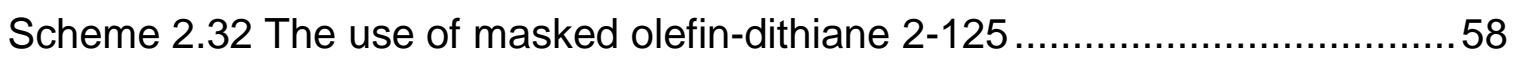

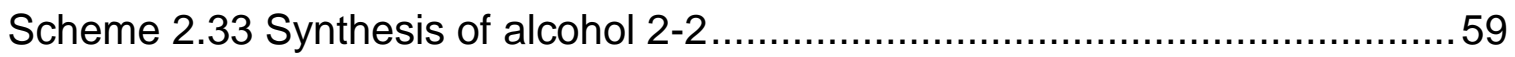


Scheme 2.34 Formation of prenyl 2-131 through cross-metathesis.

Scheme 2.35 Attempt to circumvent Wittig troubles......................................61

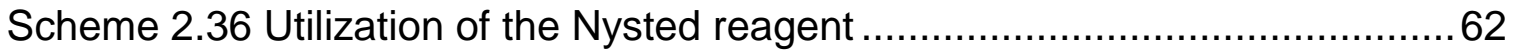

Scheme 2.37 Potential pathways to form elimination product $2-139 \ldots \ldots \ldots \ldots \ldots \ldots . . .62$

Scheme 2.38 Cerium trichloride to prevent elimination...................................63

Scheme 2.39 Completion of the final ring and protecting group removal...........64

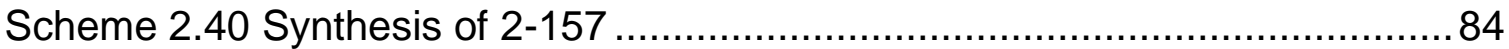




\section{LIST OF ABBREVIATIONS}

\begin{tabular}{|c|c|}
\hline$A c$ & Acetyl \\
\hline $\mathrm{Bn}$ & Benzyl \\
\hline BRSM & Based on recovered starting material \\
\hline $\mathrm{Bu}$ & Butyl \\
\hline COSY & Correlation spectroscopy \\
\hline CSA & Camphorsulfonic acid \\
\hline DABCO & 1,4-diazabicyclo[2.2.2]octane \\
\hline DBU & 1,8-diazabicyclo[5.4.0]undec-7-ene \\
\hline DIBAL & Diisobutyl aluminum hydride \\
\hline DMAP & 4-Dimethylaminopyridine \\
\hline DMF & $\mathrm{N}, \mathrm{N}$-dimethylformamide \\
\hline DMP & Dess-Martin Periodinane \\
\hline DMSO & Dimethylsulfoxide \\
\hline Et & Ethyl \\
\hline G2 & Grubbs $2^{\text {nd }}$ generation catalyst \\
\hline HMBC & Heteronuclear multiple-bond correlation \\
\hline HMQC & Heteronuclear multiple-quantum correlation \\
\hline HMPA & Hexamethylphosphoramide \\
\hline$i-\operatorname{Pr}$ & Isopropyl \\
\hline LDA & Lithium diisopropylamide \\
\hline LiHMDS & Lithium hexamethyldisilazide \\
\hline
\end{tabular}




\begin{tabular}{|c|c|}
\hline $\mathrm{Me}$ & Methyl \\
\hline NBS & $\mathrm{N}$-Bromosuccinimide \\
\hline NCS & $\mathrm{N}$-Chlorosuccinimide \\
\hline NMO & $\mathrm{N}$-methylmorpholine oxide \\
\hline NMR & Nuclear Magnetic Resonance \\
\hline $\mathrm{nOe}$ & Nuclear Overhauser effect \\
\hline NOESY & Nuclear Overhauser effect spectroscopy \\
\hline PCC & Pyridinium chlorochromate \\
\hline $\mathrm{Ph}$ & Phenyl \\
\hline PIFA & Phenyliodonium bis(trifluoroacetate) \\
\hline PMB & p-Methoxybenzyl \\
\hline $\mathrm{PPh}_{3}$ & Triphenylphosphine \\
\hline PPTS & Pyridinium $p$-toluenesulfonate \\
\hline PTSA & $p$-toluenesulfonic acid \\
\hline Pyr. & Pyridine \\
\hline $\mathrm{rt}$ & Room temperature \\
\hline TBAF & Tetrabutylammonium fluoride \\
\hline TBCO & tetrabromocyclohexadienone \\
\hline TBS & $t$-Butyldimethylsilyl \\
\hline TES & Triethylsilyl \\
\hline Tf & Trifluoromethanesulfonyl \\
\hline THF & Tetrahydrofuran \\
\hline THP & Tetrahydropyran \\
\hline
\end{tabular}


TIPS Triisopropylsilyl

TMEDA $\quad N, N, N^{\prime}, N^{\prime}$-tetramethylethylenediamine

TMS Trimethylsilyl

Ts $\quad p$-Toluenesulfonyl

TPAP tetra- $n$-propylammonium perruthenate 


\section{CHAPTER ONE}

\section{A. Secondary metabolites of Laurencia species}

The red algae constituting the genus Laurencia were first reported by the prolific algal taxonomist J. V. Lamouroux in $1813 .{ }^{1}$ Nearly 140 years later a secondary metabolite of this genus was isolated for the first time, sparking a fertile interest in these molecules. ${ }^{1}$ To date, more than 500 secondary metabolites from Laurencia species have been isolated, including aldingenin B.

These metabolites demonstrate immense structural diversity and a vast number of halogenated compounds are known and are classified into two groups: terpenoids, (sesquiterpenoid being the most numerous, followed by diterpenoids, and triterpenoids) and $\mathrm{C}_{15}$ acetogenins.

Due to the large number and great similarity of species of Laurencia, algal samples of Laurencia are easily misidentified. ${ }^{2}$ Natural product isolation can prove helpful in clarifying confusing taxonomy, as most species of Laurencia display distinct secondary metabolites. The presence of a certain metabolite in one sample of Laurencia can be used to make taxonimional distinctions if another similar sample displays an absence of that metabolite. In one example, three samples of (previously identified as) Laurencia pacifica proved to be three separate species. ${ }^{2 a}$ 


\section{B. The aldingenins.}

The brominated bisabolene derivatives in the aldingenin family were all isolated as secondary metabolites from a sample of red algae (identified as $L$. aldingensis) isolated off the coast of Castlehanos, in the Brazilian state of Espirito Santo in 1995. Brazilian professor João Henrique G. Lago and co-workers at the Universidad de São Paulo used a portion of this algal material to isolate aldingenin A (1-1), the structure of which they disclosed in $2005 .^{3 a}$ Three years later, aldingenin B (1-2), C (1-3), and D (1-4) were reported (Figure 1.1). ${ }^{3 b}$ To date no total syntheses of the aldingenins have been reported.

Given the confused taxonomy of Laurencia seaweeds, and the findings of $L$. aldingensis in a separate ocean on another continent half-way around the globe, it is possible that the seaweed from which aldingenin B was isolated was a related, but separate species than Laurencia aldingensis.

Figure 1.1: The four aldingenins.

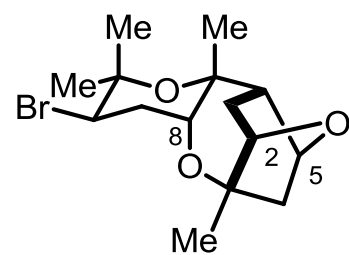

aldingenin $A$

1-1

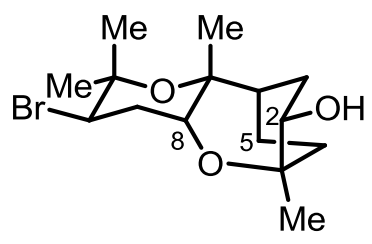

aldingenin $C$

1-3

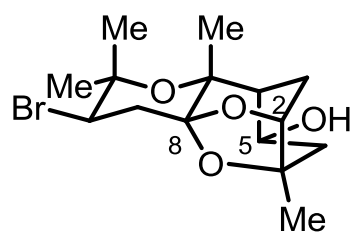

aldingenin $B$

1-2

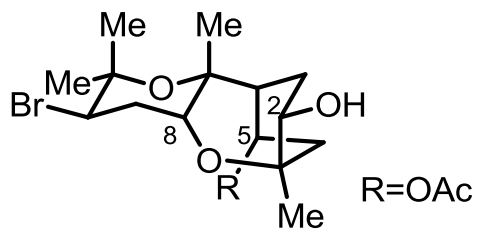

aldingenin $D$

1-4 
Lago and coworkers proposed a biosynthesis starting with a-bisabolene 1-5 (Scheme 1.1). Oxidation of C-8/C-7 and C-2/C-3 olefins followed by nucleophilic attack by bromide at C-11, C-10, C-8, and C-2 yields the tetra-brominated derivative 1-7. The tricycle 1-10 is made by intramolecular etherification on C-11 and C-2. Bromide elimination followed by successive ether ring formation produces aldingenin A. Presumably aldingenin $B, C$, and $D$ are made through a similar pathway.

\section{Scheme 1.1: Proposed biosynthesis of aldingenin A.}
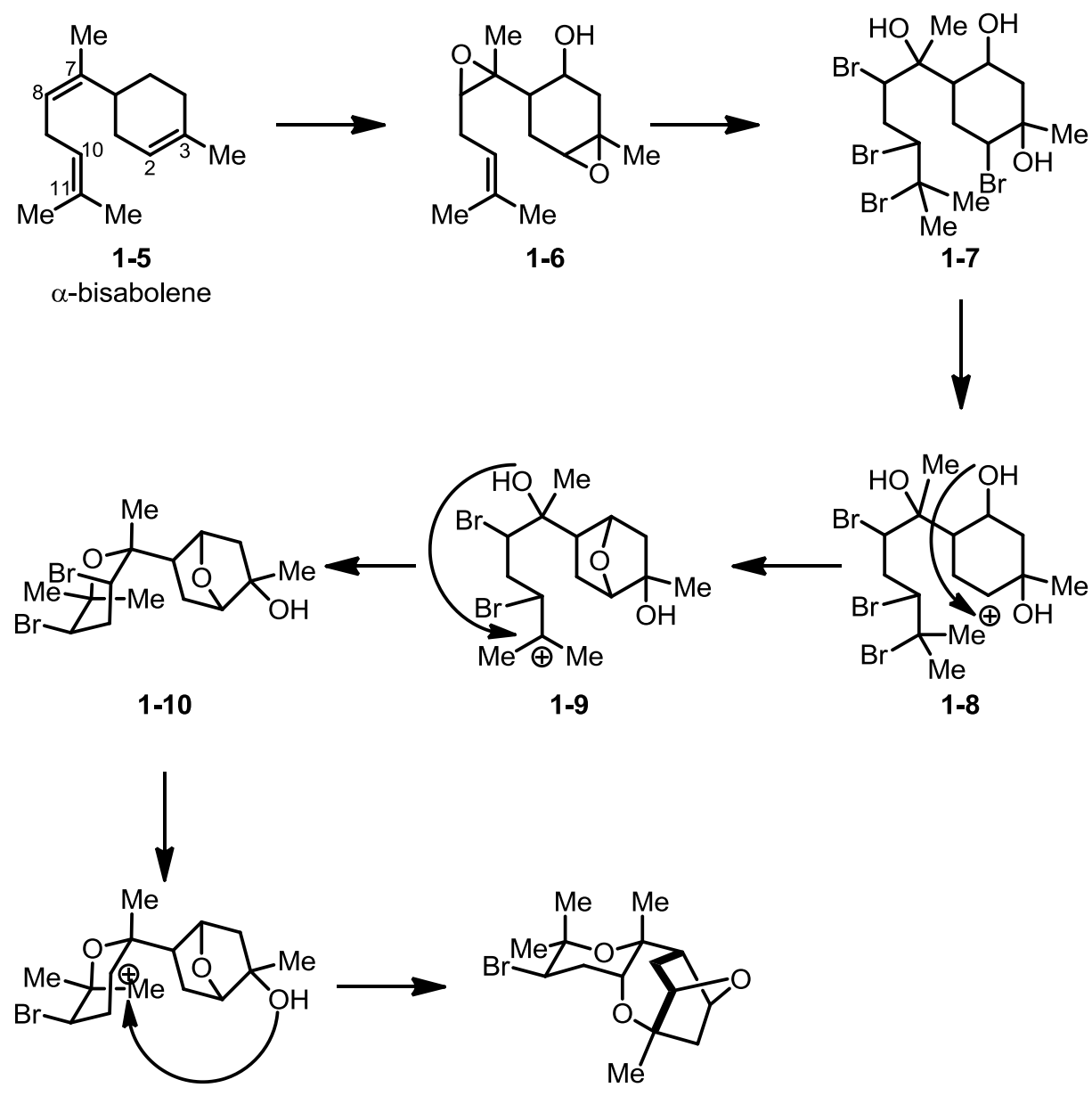

1-11

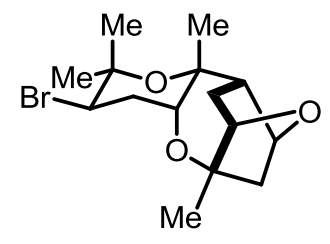

1-1

aldingenin $A$ 


\section{Aldingenin B}

Along with aldingenin $\mathrm{C}$ and $\mathrm{D}$, as well as cholesterol and palmitic acid, aldingenin B was isolated by column chromatography from a sample of $L$. aldingensis. Aldingenin $\mathrm{B}$ is the only member of the aldingenin family which contains a cyclic acetal. Additionally, it possesses a rich molecular architecture, possessing a tetracyclic framework containing 7 stereocenters, 4 of which are contiguous, and a brominated tetrahydropyran.

\section{i) Structural elucidation.}

The structure of aldingenin b was assigned based on extensive spectroscopic analysis, including ${ }^{1} \mathrm{H}$ NMR, ${ }^{13} \mathrm{C}$ NMR, COSY, NOESY, HMQC, HMBC, DEPT-90, DEPT-135, IR, and mass-spectral analysis. The $\mathrm{m} / \mathrm{z}$ of 346.0748 implied the molecular formula $\mathrm{C}_{15} \mathrm{H}_{23} \mathrm{O}_{4} \mathrm{Br}$ with four degrees of unsaturation (m/z calculated for $\mathrm{C}_{15} \mathrm{H}_{23} \mathrm{O}_{4} \mathrm{Br}=346.0780$ ). This molecular formula was supported by the presence of 15 signals in the ${ }^{13} \mathrm{C}$ NMR spectrum. DEPT-90 and DEPT-135 experiments indicated that four of the carbons were methyl, three methylene, four methine, and four nonprotonated carbons. The presence of an alcohol was indicated based on the observation of a broad band at $3450 \mathrm{~cm}^{-1}$ in the IR spectrum. 


\section{Table 1.1: NMR data for aldingenin B}

$\begin{array}{llll} & { }^{1} \mathrm{H} \text { NMR of } & & { }^{13} \mathrm{C} N M R \text { of } \\ \mathrm{H} & \text { Natural Sample } & \mathrm{C} & \text { Natural Sample } \\ \text { No. } & { }_{\mathrm{C}_{6} \mathrm{D}_{6}, 500 \mathrm{MHz}} & \text { No. } & \mathrm{C}_{6} \mathrm{D}_{6}, 150 \mathrm{MHz} \\ 1 \alpha & 1.65 m & 1 & 31.3\left(\mathrm{CH}_{2}\right) \\ 1 \beta & & 2 & 60.3(\mathrm{CH}) \\ 2 & 3.99 d d(9.6,6.3) & 3 & 69.3(\mathrm{C}) \\ 4 \beta & 1.92 d d(14.5,9.6) & 4 & 44.3\left(\mathrm{CH}_{2}\right) \\ 4 \alpha & 2.16 d d(14.5,4.7) & 5 & 68.9\left(\mathrm{CH}^{2}\right) \\ 5 & 3.86 d d d(9.6,8.4,4.7) & 6 & 47.8\left(\mathrm{CH}^{2}\right) \\ 6 & 1.44 d d(9.0,8.4) & 7 & 78.5(\mathrm{C}) \\ 9 \alpha & 1.72 d d(13.5,3.5) & 8 & 107.0(\mathrm{C}) \\ 9 \beta & 2.19 t(13.5) & 9 & 39.5\left(\mathrm{CH}_{2}\right) \\ 10 & 4.17 d d(13.5,3.5) & 10 & 52.7\left(\mathrm{CH}^{2}\right) \\ 12 & 1.36 s & 11 & 76.2(\mathrm{C}) \\ 13 & 1.49 s & 12 & 29.6\left(\mathrm{CH}_{3}\right) \\ 14 & 1.19 s & 13 & 23.2\left(\mathrm{CH}_{3}\right) \\ 15 & 1.57 s & 14 & 22.2\left(\mathrm{CH}_{3}\right) \\ & & 15 & 30.7\left(\mathrm{CH}_{3}\right) \\ & & & \end{array}$

The skeleton of aldingenin B was assigned based on analogy to known compounds and various $2 \mathrm{D}$ NMR experiments. Similarity between the ${ }^{1} \mathrm{H}$ NMR spectra of aldingenin $B(1-2)$ and aldingenin A (1-1) suggested related structural features between the two molecules. COSY analysis indicated that $\mathrm{H} 10-\mathrm{H} 9 \alpha / \beta$ were adjacent, as were $\mathrm{H} 2-\mathrm{H} 1 \alpha / \beta$, as was the string of $\mathrm{H} 6-\mathrm{H} 5-\mathrm{H} 4 \alpha / \beta$ (Figure 1.2). No comment was made on any $\mathrm{H} 6-\mathrm{H} 1$ COSY signal, nor the lack of the seemingly unmatched coupling constant of $9.0 \mathrm{~Hz}$ for $\mathrm{H} 6$ (Table 1.1). The NOESY spectrum displayed correlations between H10-Me12, H10-H9a, Me13-H9ß, Me13-Me14, Me15-H2, Me15-H4ß, and $\mathrm{H} 4 \alpha-\mathrm{H} 5$. The authors took the lack of an $\mathrm{H} 4 \beta-\mathrm{H} 5$ nOe 
signal to imply an $S$ configuration at C5. HMBC signals were used to confirm the structural assignment.

Figure 1.2: Select key COSY, NOESY, and HMBC signals
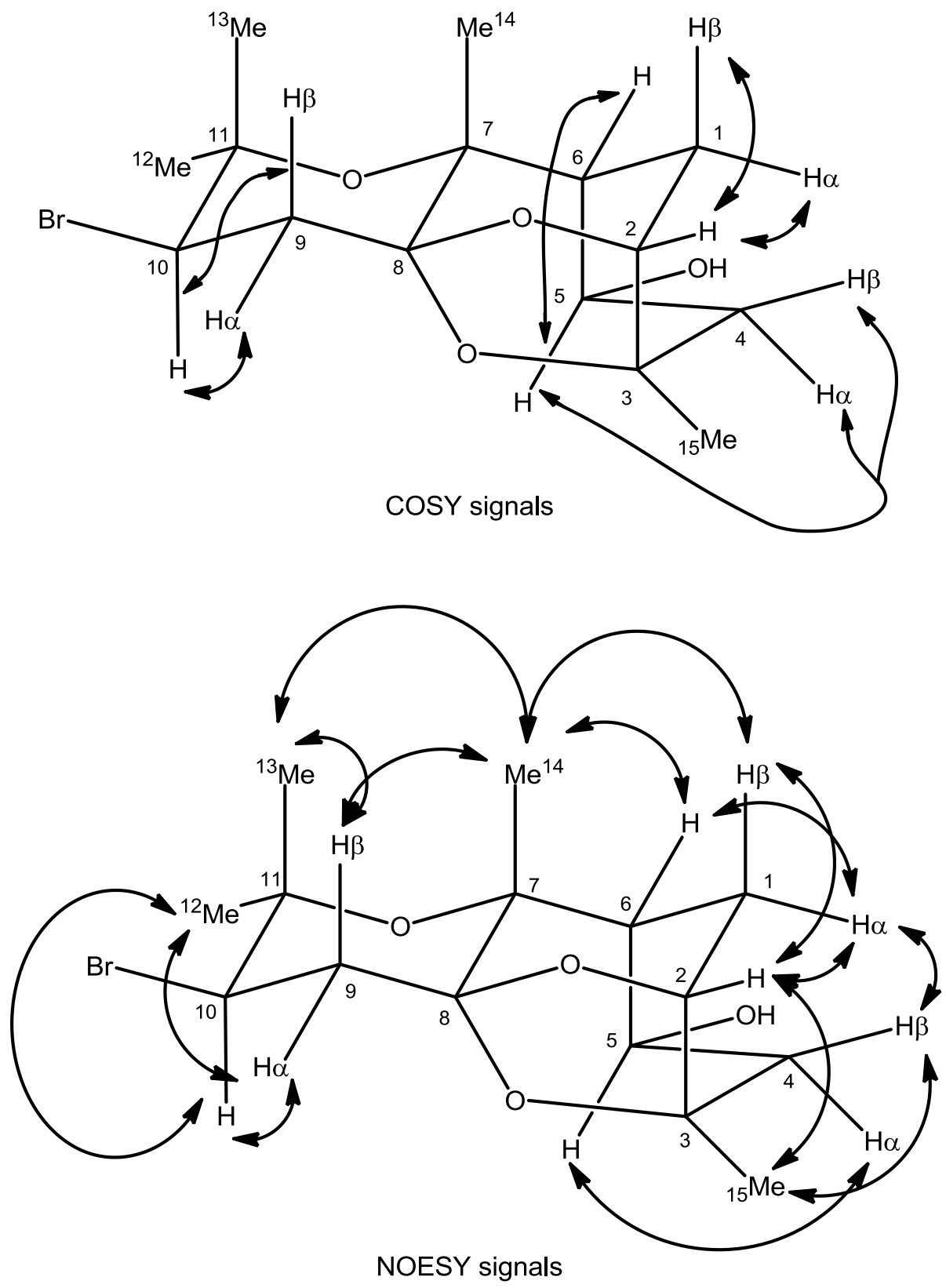


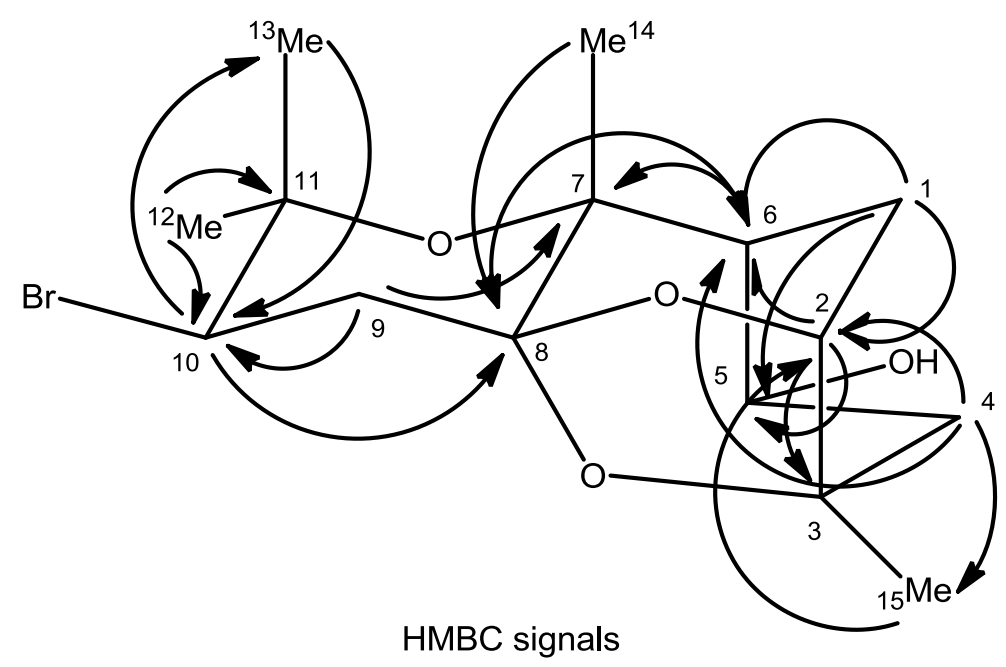

The absolute configuration was assigned based on biogenetic consideration, specifically on the assumption that the aldingenins must have the same stereochemistry in the bromated ether ring as the related laucapyranoid B (1-12), a secondary metabolite of the seaweed Laurencia caespitosa (Figure 1.3).

Figure 1.3: Determination of absolute configuration.

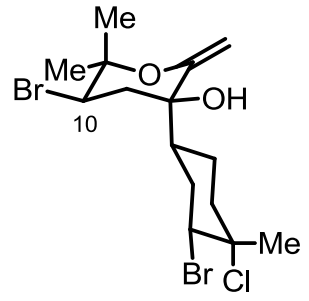

laucapyranoid B

1-12

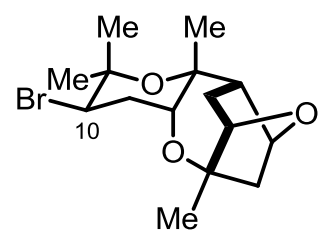

aldingenin $A$

1-1

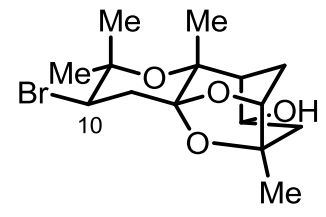

aldingenin $B$

1-2

\section{ii) Dudley's partial synthesis.}

Professor Greg Dudley and co-workers' retrosynthesis involved formation of tricyclic keto-ketal 1-13 (Scheme 1.2). ${ }^{4}$ Formation of this intermediate through diketone 1-14 was dismissed due to fears of tautomerization, which would potentially compromise the stereochemistry of C6 as well as lead to elimination of the protected 
C5 alcohol in 1-15. Instead, their efforts were directed towards the synthesis of alkyne 1-16.

Scheme 1.2: Dudley's retrosynthesis.

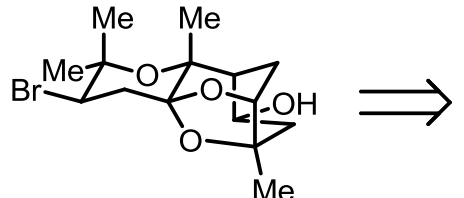

$1-2$

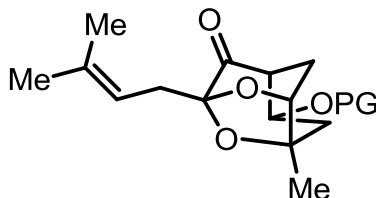

1-13

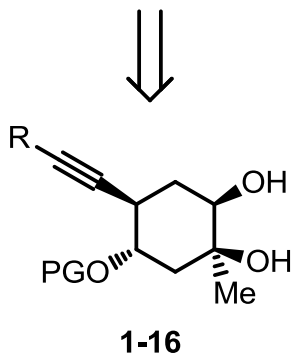

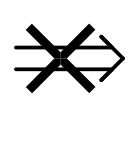

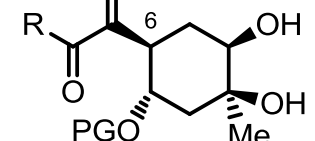

1-14

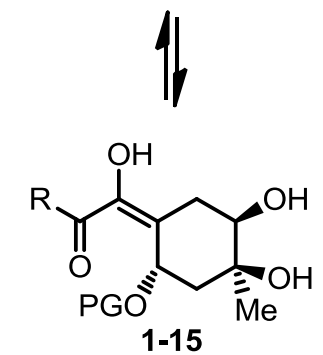

The synthesis of a model system of alkyne 1-16 $(R=M e)$ commenced by formation of cyclohexadienyl acid 1-19 through a Diels-Alder reaction between propiolic acid 1-17 and isoprene 1-18 (Scheme 1.3). The acid was then converted to the methyl ether, followed by Sharpless dihydroxylation of the electron-rich olefin to provide diol 1-20. This diol was then protected as acetonide 1-21, but following $\mathrm{LiAlH}_{4}$ reduction, hydroboration-oxidation proved sub-optimal due to formation of a mixture of isomers. The protecting group was altered, to form bis-TBS ether 1-23. Following $\mathrm{LiAlH}_{4}$ reduction of the methyl ester, hydroboration-oxidation yielded diol 1-24 as a single isomer. Following p-methoxybenzylidene acetal formation with anisaldehyde dimethyl acetal, the acetal was treated with $i-\mathrm{Bu}_{2} \mathrm{Al}-\mathrm{H}$ to afford protected secondary alcohol 1-25. The primary alcohol was converted to terminal alkyne 1-27 by oxidation to the aldehyde, followed by exposure to the Ohira- 
Bestmann reagent (1-26). The terminal alkyne was methylated, and the TBS ethers were removed to produce alkyne-diol 1-28.

\section{Scheme 1.3: Dudly's synthesis.}
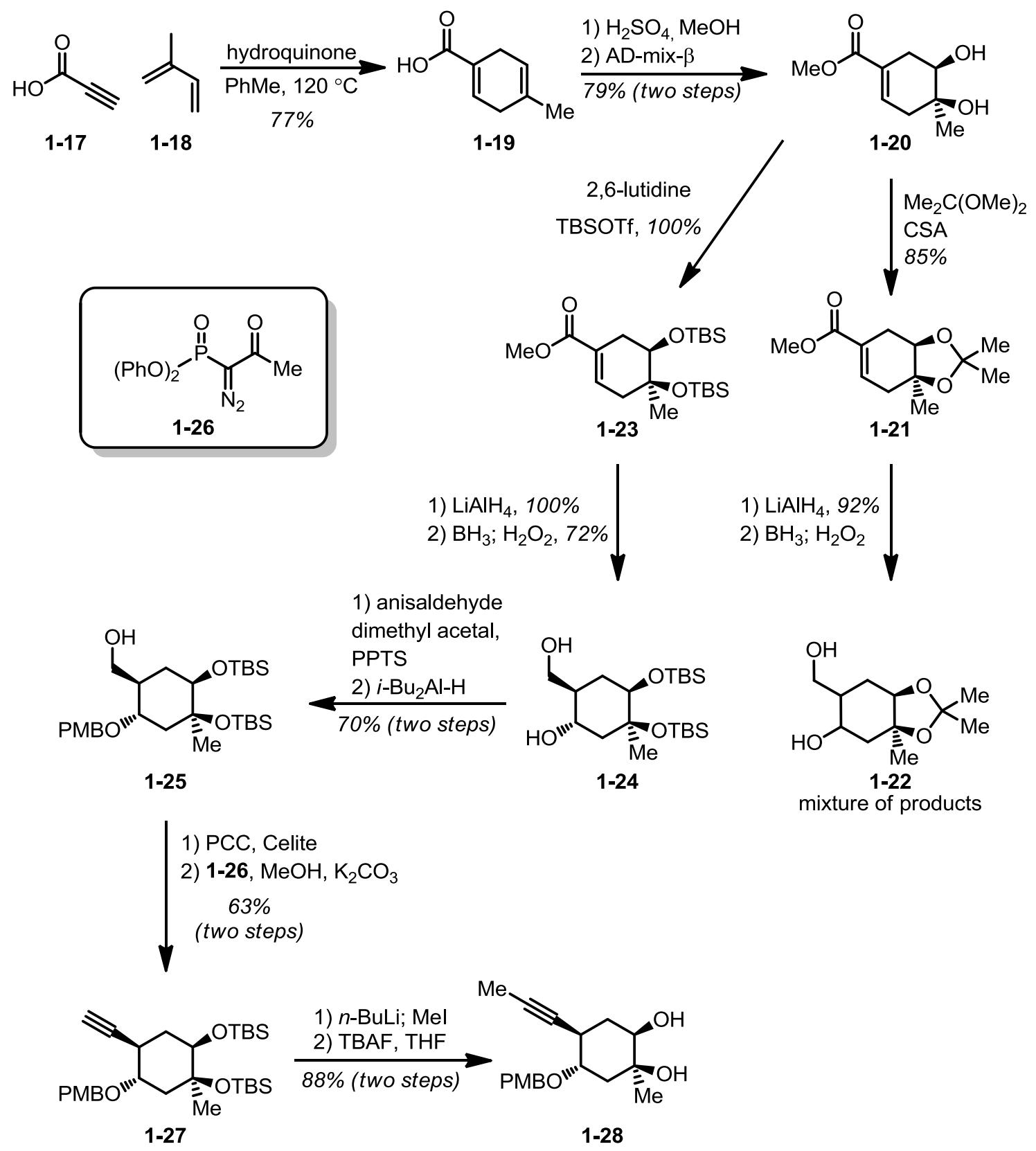

As the installation of an $\alpha$-keto-acetal without the in-situ formation of an $\alpha$ keto-ketone (i.e. diketone 1-14) was desired, prudent utilization of a reagent that 
promotes cyclization to the ketal while promoting alkyne oxidation was prioritized. The combination of ammonium peroxydisulfate and diphenyl diselenide (1-29) was selected on this basis (Scheme 1.4). When alkyne-diol 1-28 was subjected to these conditions, the desired ketal $1-34$ was formed in $52 \%$ yield, presumably by the mechanism shown. After coordination of the alkyne with the active selenium oxidant 1-30, the secondary alcohol attacks to form vinylselenide 1-32. Another oxyselenylation then occurs, resulting in seleno-ketal 1-33, which upon hydrolysis forms the desired tricyclic compound 1-34.

\section{Scheme 1.4: Cycloketalization to form core of aldingenin B.}
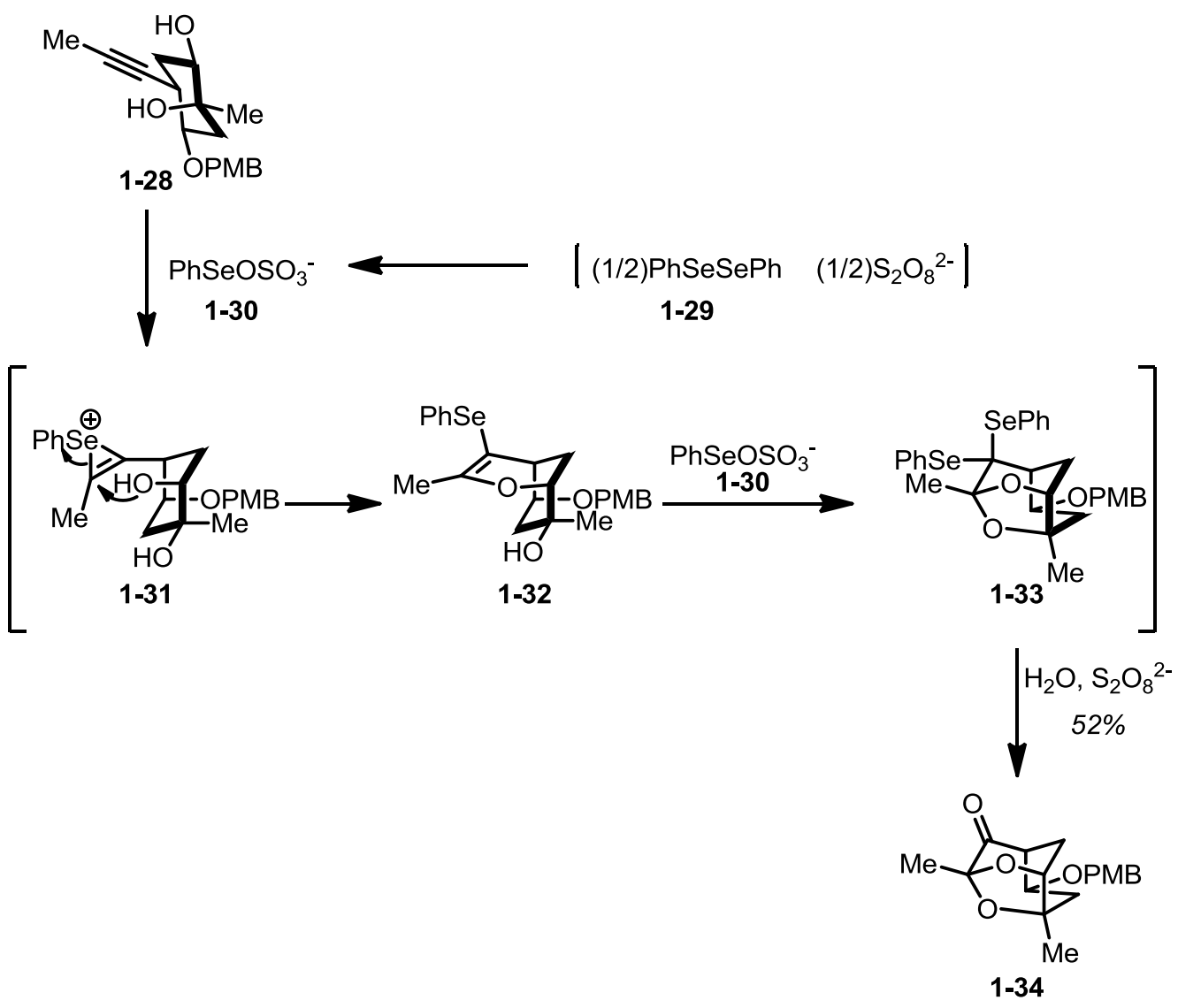


\section{References}

1) (a) Marine Natural Products; Scheuer, P. J., Ed.; Academic: New York, 1978; Vol. .1 (b) Marine Natural Products; Scheuer, P. J.; Ed.; Academic: New York, 1983; Vol. 5.

2) (a) Fenical, W.; Norris, J. N. Journal of Phycology 1975, 11, 104. (b) Fenical, W. Journal of Phycology 1975, 11, 245. (c) Masuda, M.; Abe, T.; Suzuki, T.; Suzuki, M. Phycologia 1996, 35, 550.

3) (a) de Carvalho, L. R.; Fujii, M. T.; Roque, N. F.; Kato, M. J.; Lago, J. H. G. Tetrahedron Lett. 2003, 44, 2637. (b) de Carvalho, L. R.; Fujii, M. T.; Roque, N. F.; Lago, J. H. G. Phytochemistry 2006, 67, 1331.

4) Yang, J.; Tummatorn, J.; Slegeris, R.; Tlais, S. F.; Dudley, G. B. Org. Lett. 2011, 13, 2065. 


\section{CHAPTER 2}

\section{THE TOTAL SYNTHESIS OF THE PROPOSED STRUCTURE OF ALDINGENIN B}

\section{A. Retrosynthetic analysis.}

The original retrosynthetic analysis envisioned aldingenin $\mathrm{B}(\mathbf{2 - 1})$ arising from a combination of a late stage bromo-etherification and secondary alcohol deprotection of tricyclic acetal 2-2 (Scheme 2.1). The acetal 2-2 would be obtained from cycloketalization of dithiane 2-3. This dithiane would result from nucleophilic addition of the anion of dithiane $\mathbf{2 - 4}$ to aldehyde $2-5$, the C2/C3 syn-oxygenation of which would be installed via a syn-dihydroxylation of appended cyclohexene 2-6. Aldehyde 2-6 could be formed through two pathways. In one, olefin 2-6 would be made through a ring closing metathesis of ester 2-10, the result of a Frater-Seebach alkylation $^{1}$ of ester 2-11. This ester would be formed through an acetate aldol between acylated mesityl-containing auxiliary ${ }^{2}$ 2-13 and 3-methyl-3-butenal 2-12. In the second, 2-6 would be formed through a ring closing metathesis of aldol adduct 27, which would come from an acetal aldol addition ${ }^{3}$ of acylated auxiliary 2-8 with dibenzyl acetal 2-9, which would be made from 3-methyl-3-butenal 2-12. 
Scheme 2.1: Retrosynthetic scheme.
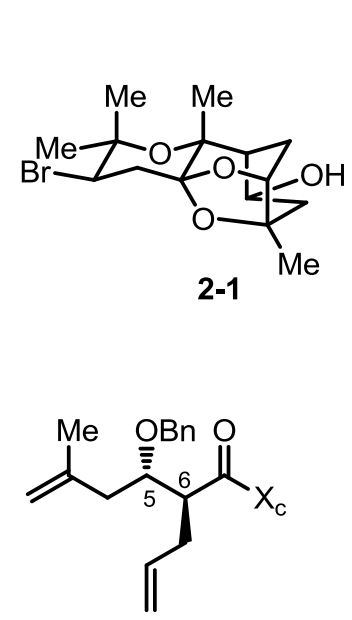

2-7<smiles>C=CCCC(=O)N1C(=S)SC[C@H]1C(C)C</smiles><smiles>C=C(C)CC(OCc1ccccc1)OCc1ccccc1</smiles>

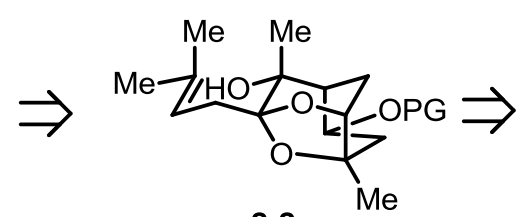

2-2<smiles>CC1=CC[C@@H](C=O)[C@H](O[PbH])C1</smiles>

2-6<smiles>CCCC</smiles><smiles>C=CC[C@@H](C(=O)OC)[C@@H](O)CC(=C)C</smiles><smiles>CC(C)=CCC1([C@@H](O)[C@@H]2C[C@H](O)[C@@](C)(O)C[C@H]2OC(=O)OCc2ccccc2)SCCCS1</smiles>

$\Downarrow$<smiles>CC(C)=CCC1SCCCS1</smiles>

2-10<smiles>C=C(C)CC([CH2+])=O</smiles><smiles>CC(=O)N1C(=S)SC[C@H]1c1c(C)cc(C)cc1C</smiles>

$\downarrow$

\section{B. Synthesis of 2-1.}

(i) Formation of Triol 2-30

For the acetal aldol route to be viable, an efficient synthesis to access dibenzyl acetal 2-9 was needed, a potentially non-trivial task due to the possibility of undesired olefin migration during reactions involving aldehyde 2-12. Fortunately, 
prior research in this laboratory has developed a method for the clean formation of $\beta, \gamma$-unsaturated aldehydes by way of an oxidative cleavage of a vicinal homoallylic diol. ${ }^{4}$ The homoallylic diol necessary for the formation of the aldehyde 2-12 was formed through an ultrasonic irradiation-promoted, tin-mediated Barbier reaction between methallyl iodide (2-14) and glyoxal (2-15) (Scheme 2.2). The resulting vicinal diol 2-16 was then cleaved to 3-methyl-3-butenal (2-12) with sodium periodate in the presence of a $1: 1(v: v)$ mixture of methylene chloride and $\mathrm{pH} 4$ buffer to avoid olefin isomerization to the conjugated enal. This $\beta, \gamma$-unsaturated aldehyde was subjected to gentle, non-isomerizing acetalization conditions developed by Noyori, ${ }^{5}$ producing dibenzyl acetal 2-9 in good yield.

\section{Scheme 2.2: Synthesis of dibenzyl acetal 2-9.}<smiles>C=C(C)CI</smiles>

2-14<smiles>O=CC(F)F</smiles>

2-15

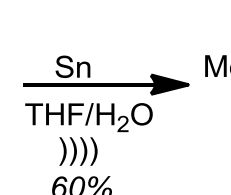

$60 \%$<smiles>C=C(C)CC(O)C(O)CC(=C)C</smiles>

2-16

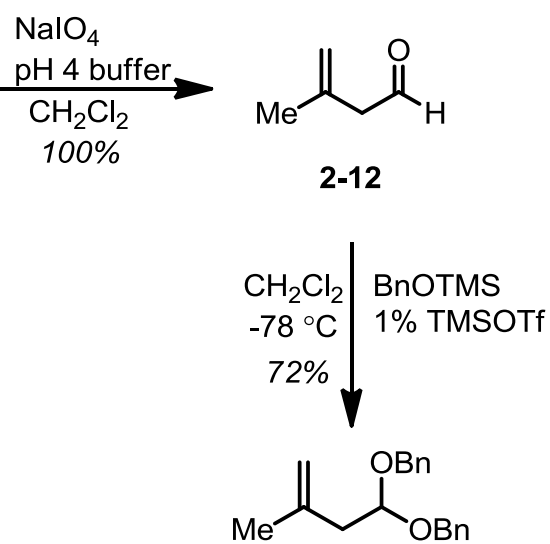

2-9

The acylated auxiliary 2-8 was obtained starting with 4-pentenoic acid 2-17 (Scheme 2.3). After acid chloride 2-18 was formed, it was added dropwise into a cold solution of anion 2-20, which after workup and column chromatography afforded desired acylated auxiliary 2-8. 


\section{Scheme 2.3: Synthesis of acylated auxiliary 2-8.}

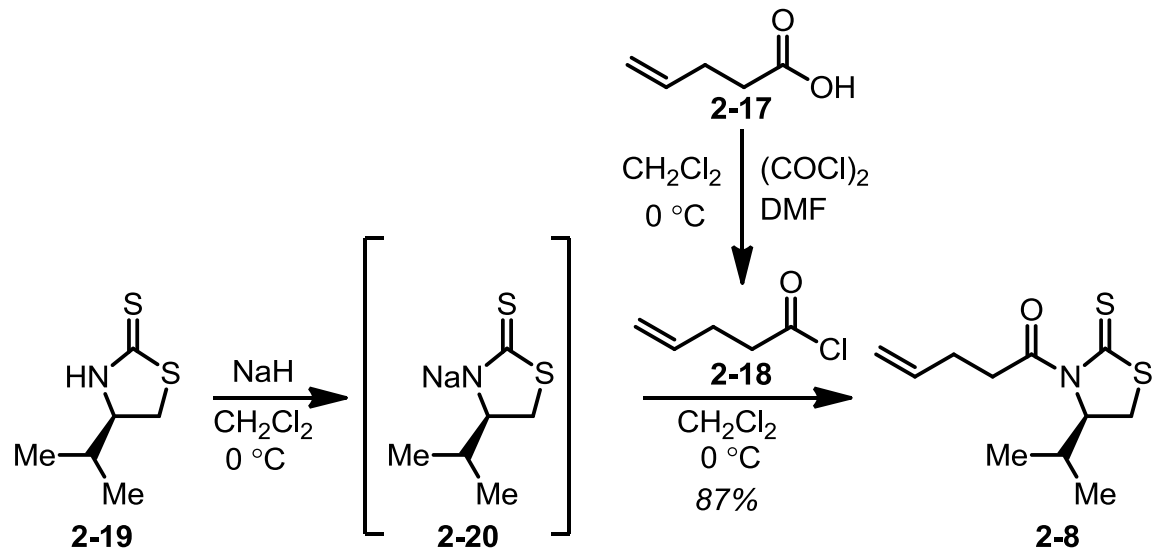

With all the necessary coupling components in hand, the aldol addition was performed proceeding in moderate yield and decent selectivity (Scheme 2.4).

\section{Scheme 2.4: Aldol addition.}

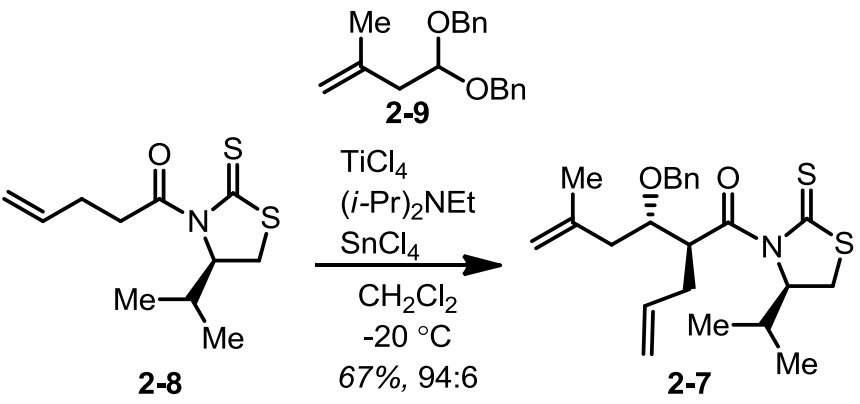

It is speculated ${ }^{3}$ that the diastereoselectivity of this acetal aldol addition is due to the open transition state $\mathbf{2 - 2 1}$; the $\alpha$-stereocenter is set by steric effects, and the $\beta$-stereocenter is determined primarily by electronic factors (Figure 2.1). ${ }^{6}$ Once the dibenzyl acetal is mixed with the Lewis acidic $\mathrm{SnCl}_{4}$, oxocarbenium ion $\mathbf{2 - 2 2}$ is formed. This electrophile is appropriate for an $S_{N} 1$ type process in which it approaches chelated chloro-titanium Z-enolate 2-23 from the least hindered face (the Si face, as shown), under the assumption that the unfavorable steric interactions between the substituents of the oxocarbenium ion and the auxiliary must 
be minimized. The formation of major diastereomer 2-7 can be rationalized through an antiperiplanar arrangement of the oxocarbenium ion, which minimizes dipoledipole interactions as compared to the disfavored transition state 2-24.

Figure 2.1: Speculated favored transition state in acetal aldol.

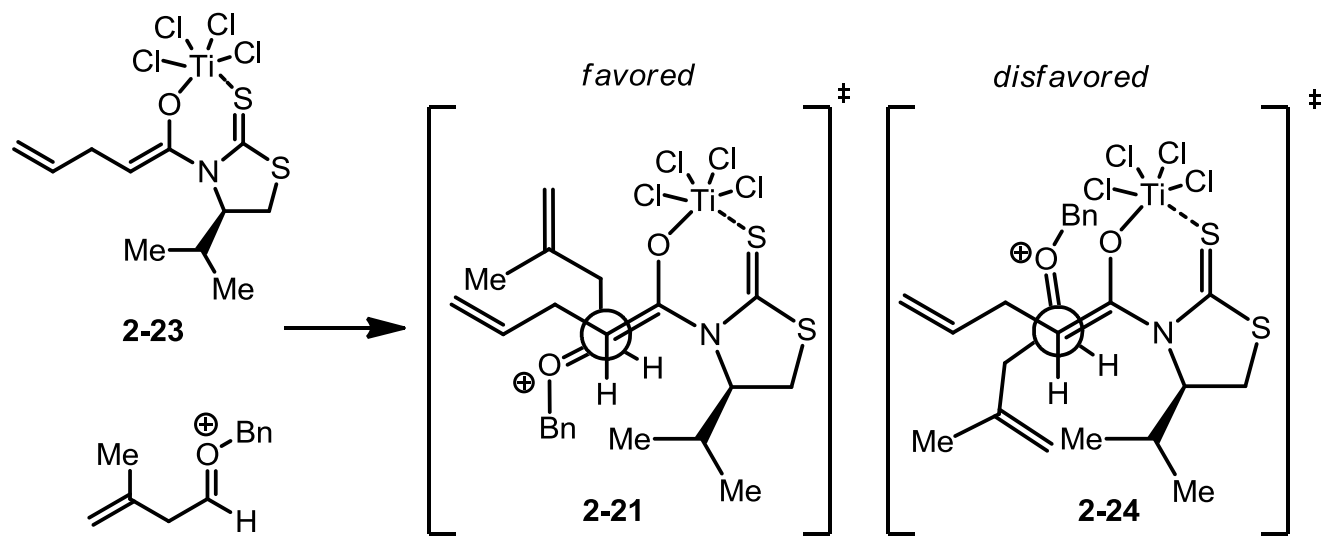

2-22

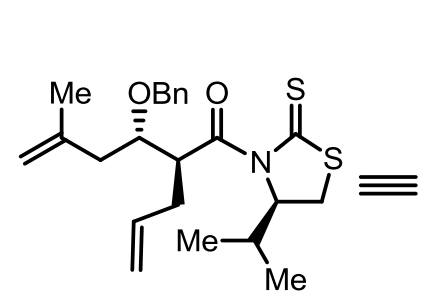

2-7

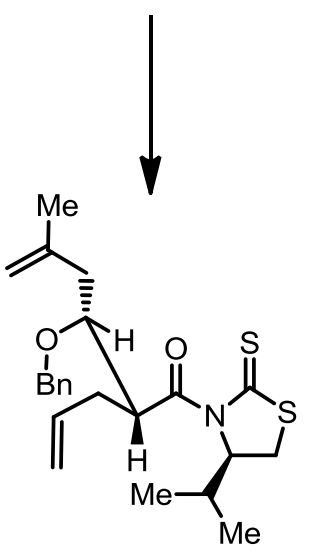

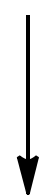

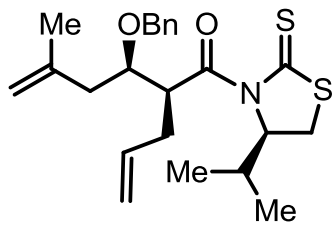

2-25

With the necessary aldol adduct 2-7 in hand, attention was turned to forming aldehyde-diol 2-5. After reductive removal of the auxiliary and formation of aldehyde 2-26 with $(i-\mathrm{Bu})_{2} \mathrm{AlH}$, the diene was subjected to a catalytic amount of Grubb's second generation catalyst ${ }^{7}(2-27)$, yielding cyclohexenal 2-6 through a ring-closing metathesis. However, when subjected to Upjohn dihydroxylation conditions ${ }^{8}$ (catalytic $\mathrm{OsO}_{4}, \mathrm{NMO}$ ), only decomposition of starting material was observed, perhaps as a result of the prolonged reaction times (up to 7 days) needed to ensure 
complete consumption of the trisubstituted olefin starting material. As the aldehyde functionality was suspected in the decomposition of the starting material, it was deemed prudent to target a reduced analogue of the aldehyde, alcohol 2-29. This product was achieved by a $\mathrm{LiBH}_{4}$ reduction of aldol adduct $\mathbf{2 - 7}$ to diene $\mathbf{2 - 2 8}$, followed by subjection to RCM conditions.

\section{Scheme 2.5: Synthesis of alcohol 2-29.}<smiles>C=CC[C@H](CC(=C)C)[C@H](CC(C)C)C(=O)N1C(=S)SC[C@H]1C(C)C</smiles>

2-7

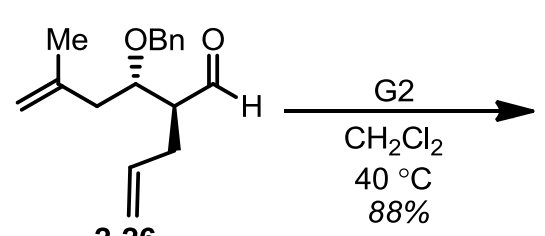

2-26<smiles>C[C@H]1CC[C@@H](C=O)[C@H](Cc2ccccc2)C1</smiles>

$\mathrm{LiBH}_{4}, \mathrm{MeOH}, 0^{\circ} \mathrm{C}$ $\mathrm{Et}_{2} \mathrm{O}, 85 \%$<smiles>C=CC[C@H](CO)[C@@H](CC(=C)C)OCC</smiles>

2-28

G2, $\mathrm{CH}_{2} \mathrm{Cl}_{2}$ $40{ }^{\circ} \mathrm{C}, 90 \%$<smiles>C[N+]1=CC[C@@H](CO)[C@H](OBr)C1</smiles>

2-29
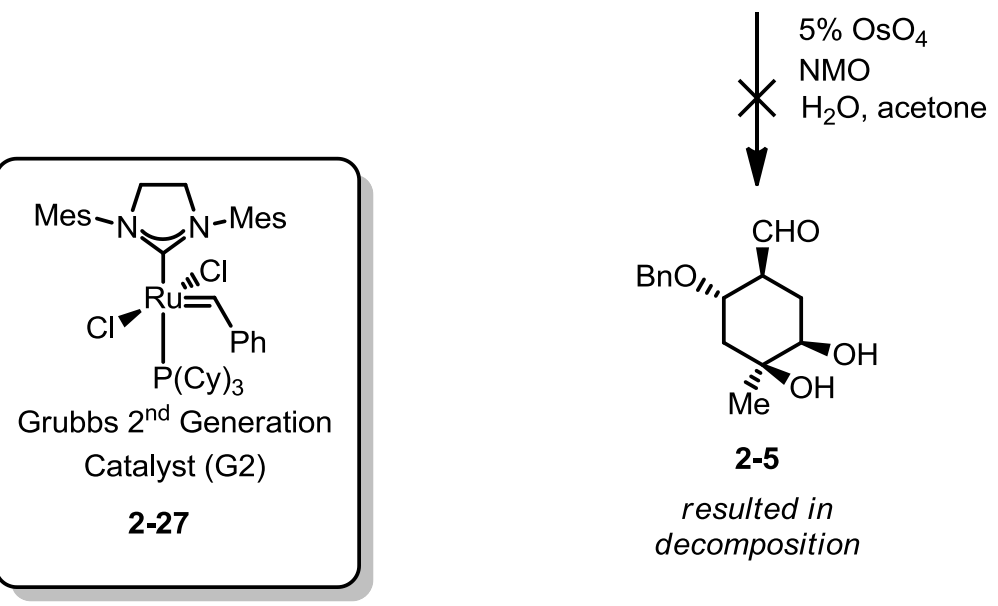<smiles>C[C@]1(O)C[C@@H](Br)[C@@H](C=O)C[C@H]1O</smiles>

2-5

resulted in decomposition

At this stage, it was unclear from which face of trisubstituted olefin 2-29 the oxidizing agent would approach, or indeed which cyclohexene conformer would be 
more reactive (Figure 2.2). Simply by consulting models it was difficult to envision a high degree of diastereoselectivity arising during this key transformation.

\section{Figure 2.2: From which face will the oxidant approach?}
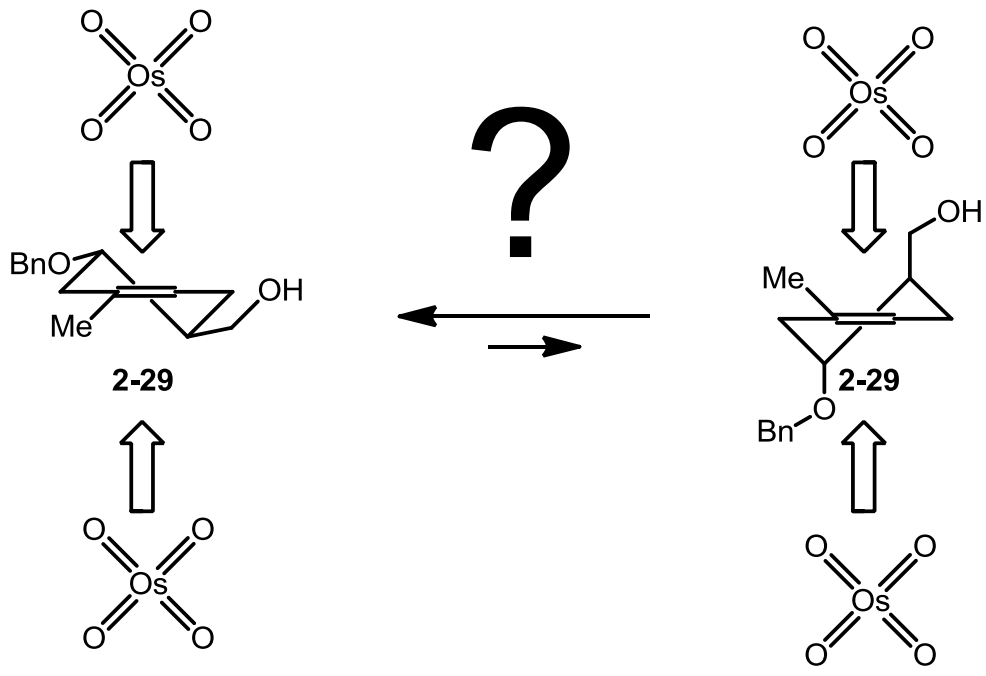

Initial attempts utilized standard Upjohn conditions (Table 2.1, entry 1), which after extensive reaction time (five days) led to an inseparable 3:1 mixture of major/minor isomers, as determined by ${ }^{1} \mathrm{H}-\mathrm{NMR}$ spectral analysis. At this time, however, the stereochemistry of the major and minor isomers was unknown. It is known that addition of an amine base enhances the reactivity of $\mathrm{OsO}_{4},{ }^{9}$ which was clearly desirable in this case. In order to diminish reaction times, various amine bases were screened as additives. Pyridine and 1,4-diazabicyclo[2.2.2]octane (DABCO, 2-32) were tested, and both appeared to hasten the formation of product, and led to a greater yield, although the 3:1 ratio of major/minor isomers remained unchanged. As these diastereomeric triols could not be separated, nor could the acetonide protected versions be separated, a Sharpless asymmetric dihydroxylation was investigated. Both $A D$-mix $\beta$ and AD-mix $\alpha^{10}$ were tested on trisubstituted olefin 2-29. According to literature precedent, AD-mix $\beta$ should have provided the desired 
isomer, and indeed it did prove most promising; though implied, the structure of the major isomer remained unconfirmed.

\section{Table 2.1: Dihydroxylation conditions.}
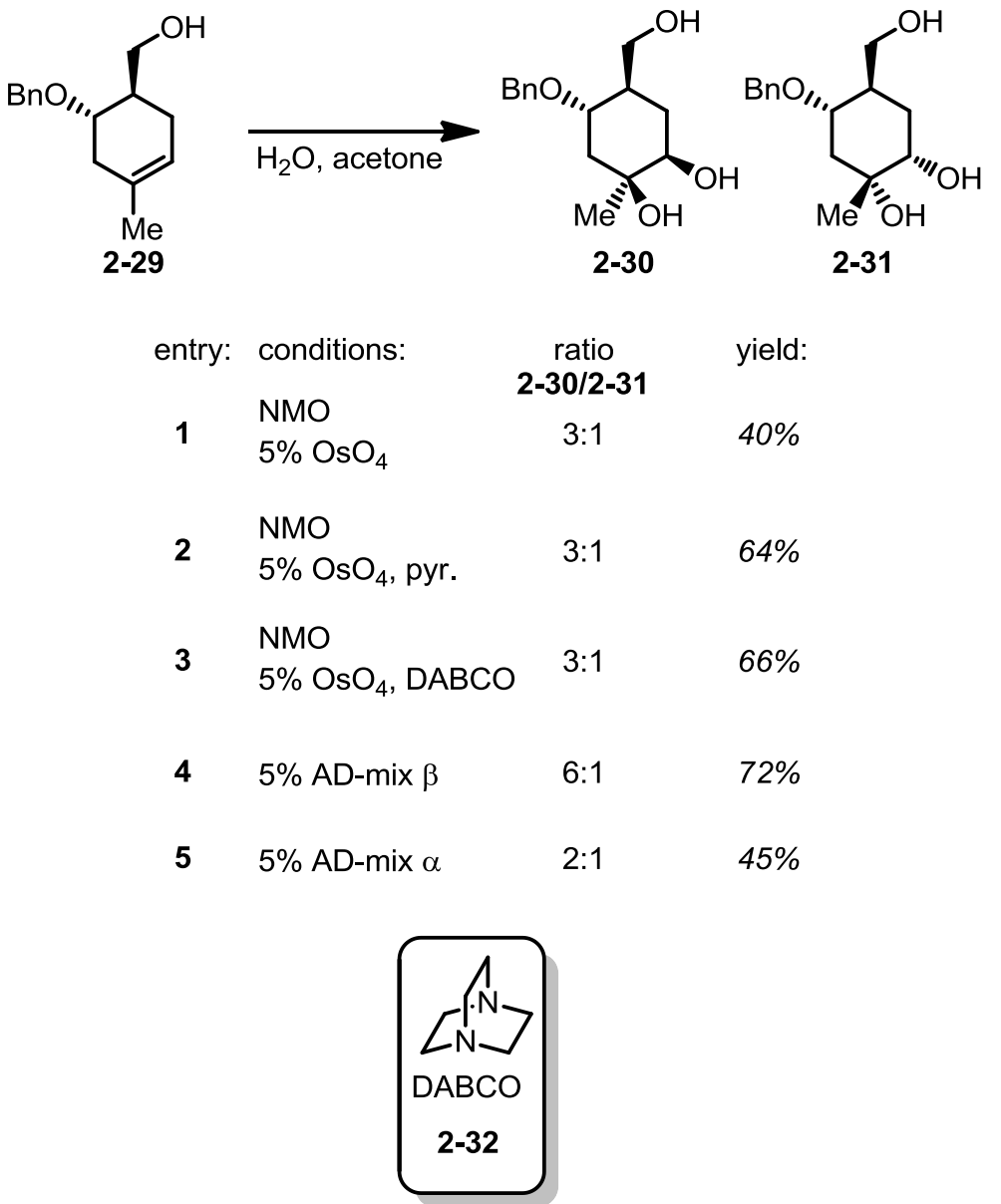

Seeking to harness the architectural features of olefin $\mathbf{2 - 2 9}$, attention was turned to the work of Timothy Donohoe on the directed dihydroxylation of allylic and homoallylic alcohols. It is well established that under Upjohn conditions the oxidant approaches the olefin from the opposite face as the allylic alcohol. ${ }^{11}$ Professor Donohoe identified a gap in the synthetic methodology, and developed a method to overturn this facial bias (Figure 2.3). ${ }^{12}$ 
Figure 2.3: Select reactions illustrative of Donohoe's findings. ${ }^{12}$

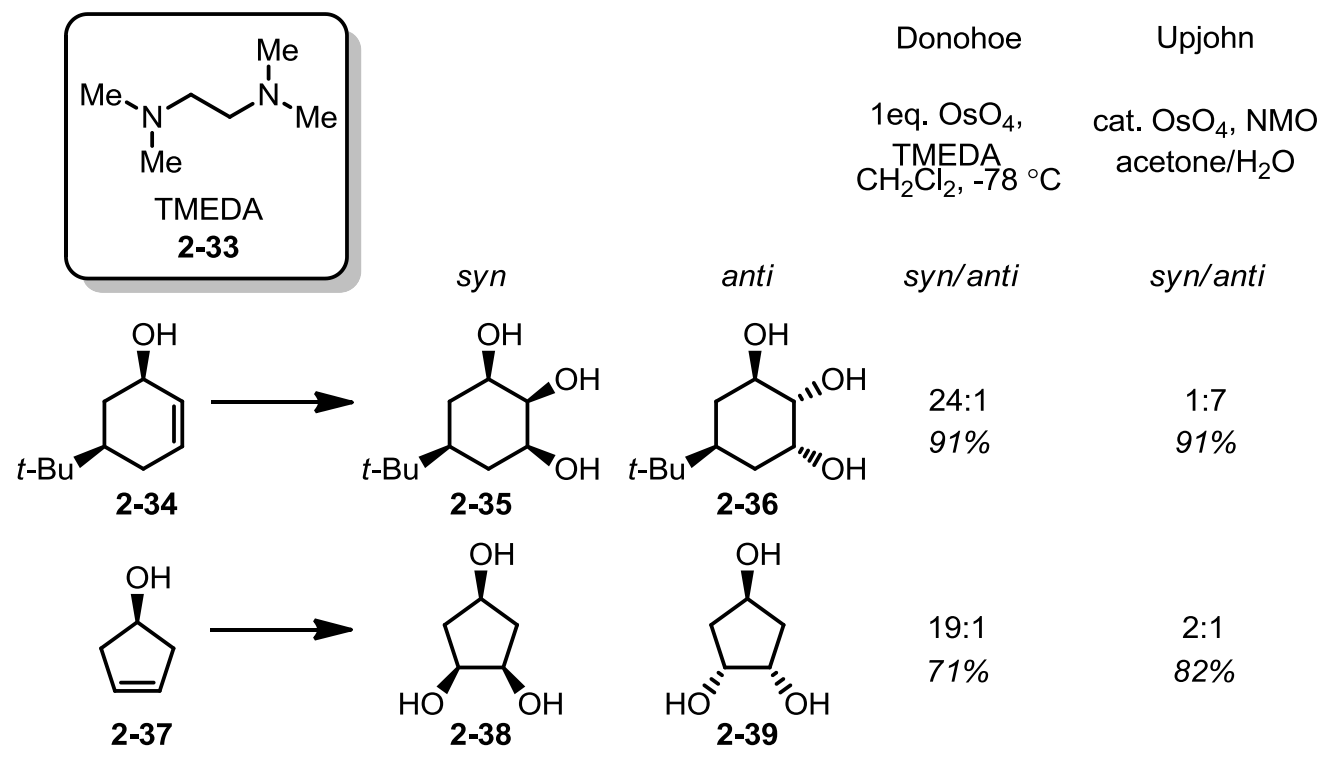

Donohoe postulates that a diamine, such as tetramethylethylenediamine (TMEDA) 2-33 binds with osmium, forming a formal 20-electron complex which reacts with olefins at a rate 10,000 times greater than $\mathrm{OsO}_{4}$ alone. This electron-rich complex causes the oxo ligands to become more Lewis basic, and thus more apt to participate in hydrogen-bonding with the proton of the adjacent alcohol. This hydrogen-bonding transition state $\mathbf{2 - 4 1}$ can then direct the bulky oxidizing agent to the same face of the allylic or homoallylic alcohol, even if it is the more sterically encumbered face of the olefin (Figure 2.4). The resulting osmate ester 2-42 is very stable and stubborn to turnover, thus necessitating the use of one full equivalent of $\mathrm{OsO}_{4}$. Once the reaction is judged to be complete, the osmate ester is hydrolyzed, either using (neutral) sodium sulfite heated at reflux, acidic methanol, or with (basic) excess ethylenediamine, to provide triol 2-43. 
Figure 2.4: Hydrogen-bonding model of syn-dihydroxylation. ${ }^{12}$
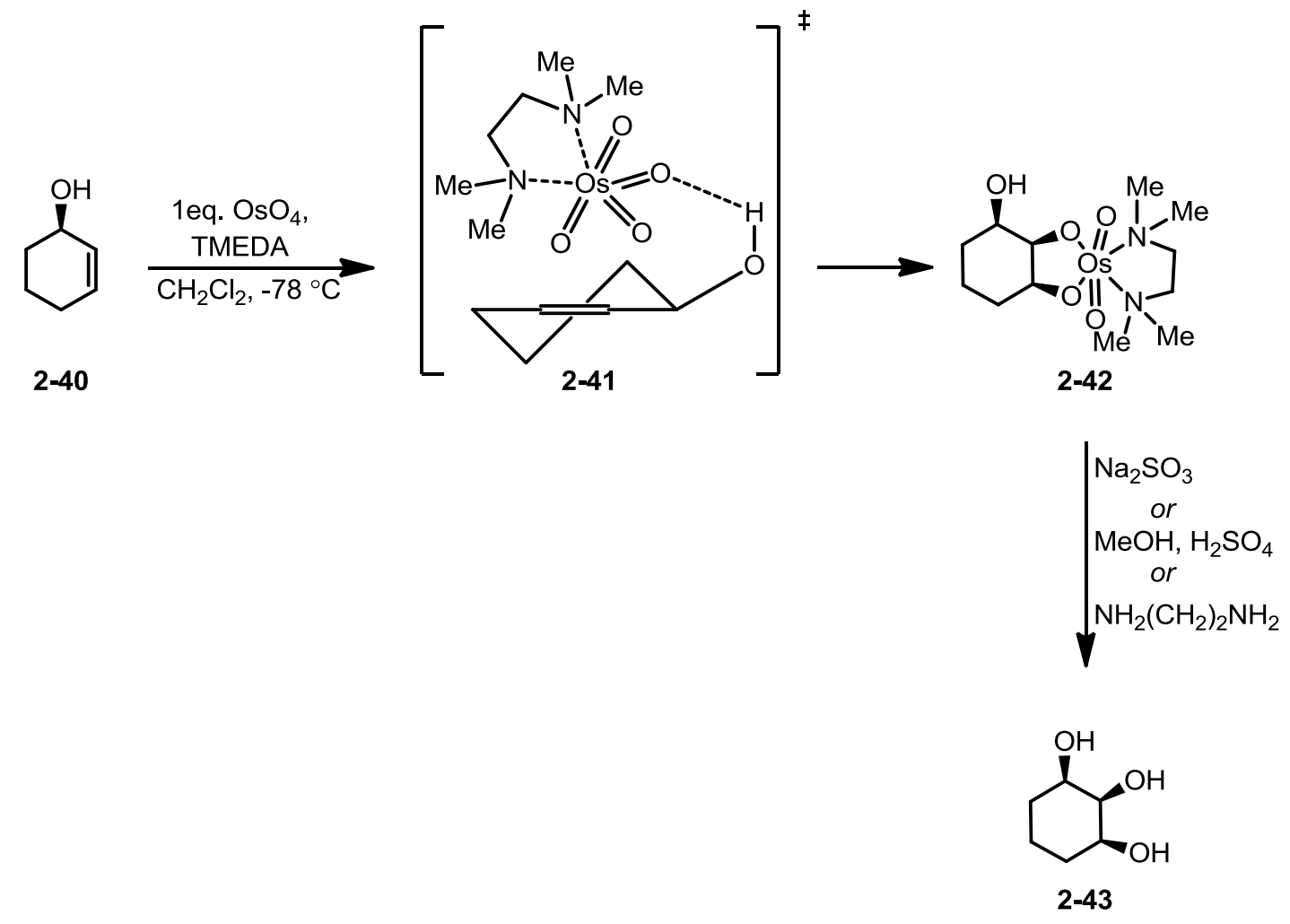

It was not initially obvious whether this methodology would work on the required substrate, as only the directing effects of allylic (alcohol 1 carbon away from olefin), and homoallylic (alcohol 2 carbons away from olefin) alcohols were known. The directing possibilities of an alcohol 3 carbons away from an olefin were unprecedented and uncommented upon in the literature. Despite this uncertainty, it was inviting to ponder whether or not the directing conditions would prove fruitful in the desired chemistry. Pleasingly, under Donohoe's conditions (method A) the desired triol 2-30 was produced as the only isomer and in $72 \%$ yield after workup with ethylene diamine to avoid any loss of the very polar product in the aqueous layer (Scheme 2.6). 


\section{Scheme 2.6: Stereoselective dihydroxylation.}

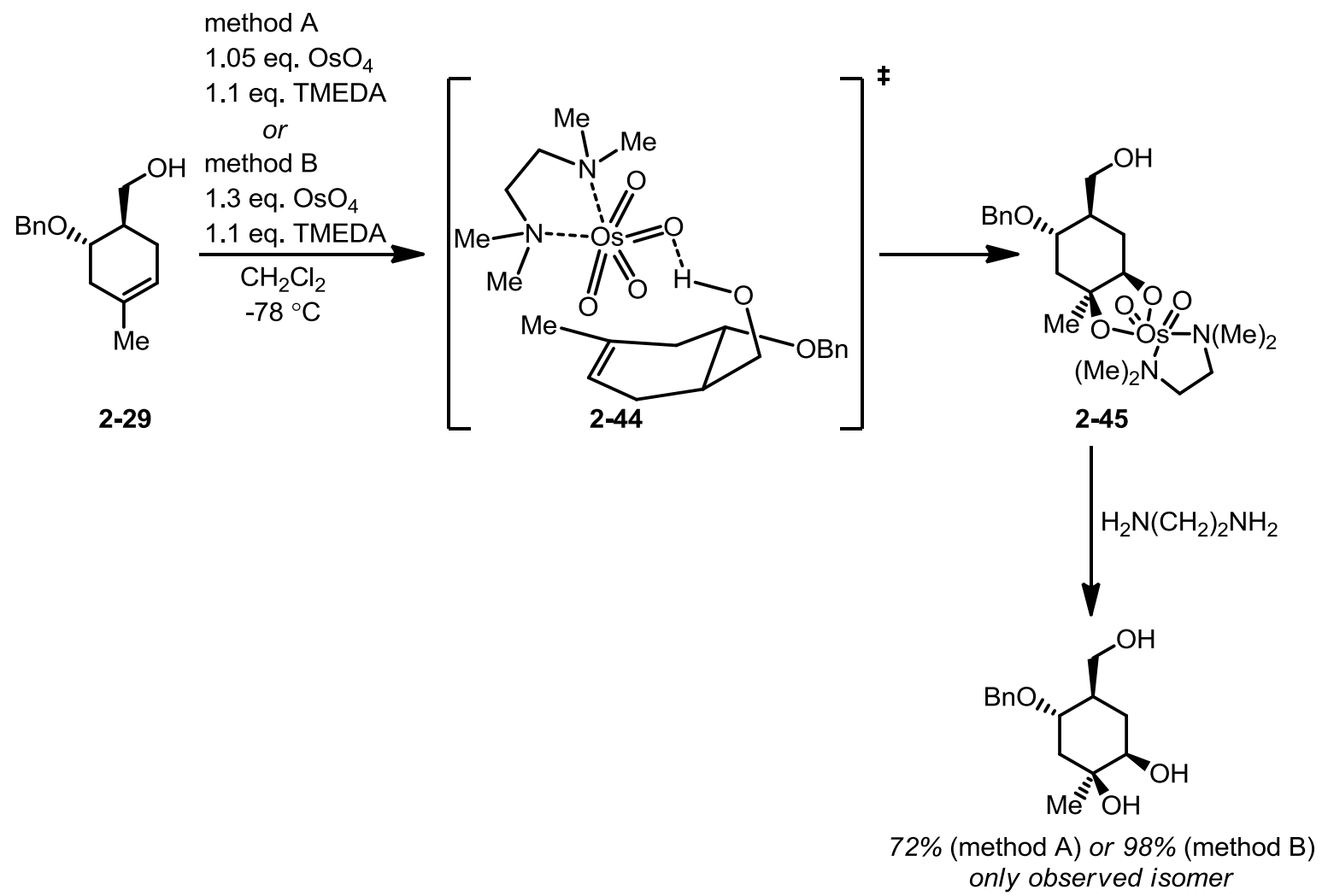

2-30

Ever vigilant in seeking to increase efficiencies of reactions, the color of the septum inside the flask was noted: black. Based on the fact that $\mathrm{OsO}_{4}$ readily sublimes and is converted to a form which is black, it was presumed that the darkened septum inside the flask was coated in osmium. Importantly, this was osmium which was not participating in the dihydroxylation reaction, meaning that 1.05 equivalents of $\mathrm{OsO}_{4}$ were not in solution, but rather a lesser amount was participating in the desired bond forming event. As the yield was roughly $30 \%$ less than theoretical, roughly $30 \%$ more $\mathrm{OsO}_{4}$ was added to the reaction (Scheme 2.6, method $\mathrm{B}$ ). It was speculated that any "free" $\mathrm{OsO}_{4}$ in solution would not be problematic, as up to 1.1 equivalents of the $\mathrm{OsO}_{4}$ would be converted to the 10,000 times more reactive $\mathrm{OsO}_{4} /$ TMEDA complex, and any non-ligated $\mathrm{OsO}_{4}$ would not 
oxidize the olefin to any meaningful extent (vide supra). This $24 \%$ increase in $\mathrm{OsO}_{4}$ loading led to a $36 \%$ increase in yield ( $26 \%$ increase compared to theoretical), for a $98 \%$ yield of triol $2-30 .^{13}$

The stereochemistry of the newly formed diol was determined by rigidifying it as a cyclic carbonate, followed by protecting the primary alcohol to form acetate 246 to clearly determine ${ }^{1} \mathrm{H}$ NMR spectrum signals (Scheme 2.7). COSY and nOe data suggested the desired isomer was formed, and the lack of signals between $\mathrm{H} 5$ to both Me15 and to $\mathrm{H} 2$, and the presence of an $\mathrm{H} 2$ to $\mathrm{H} 6$ signal, though weak, indicated this compound was the correct isomer.

\section{Scheme 2.7: Determination of stereochemistry.}
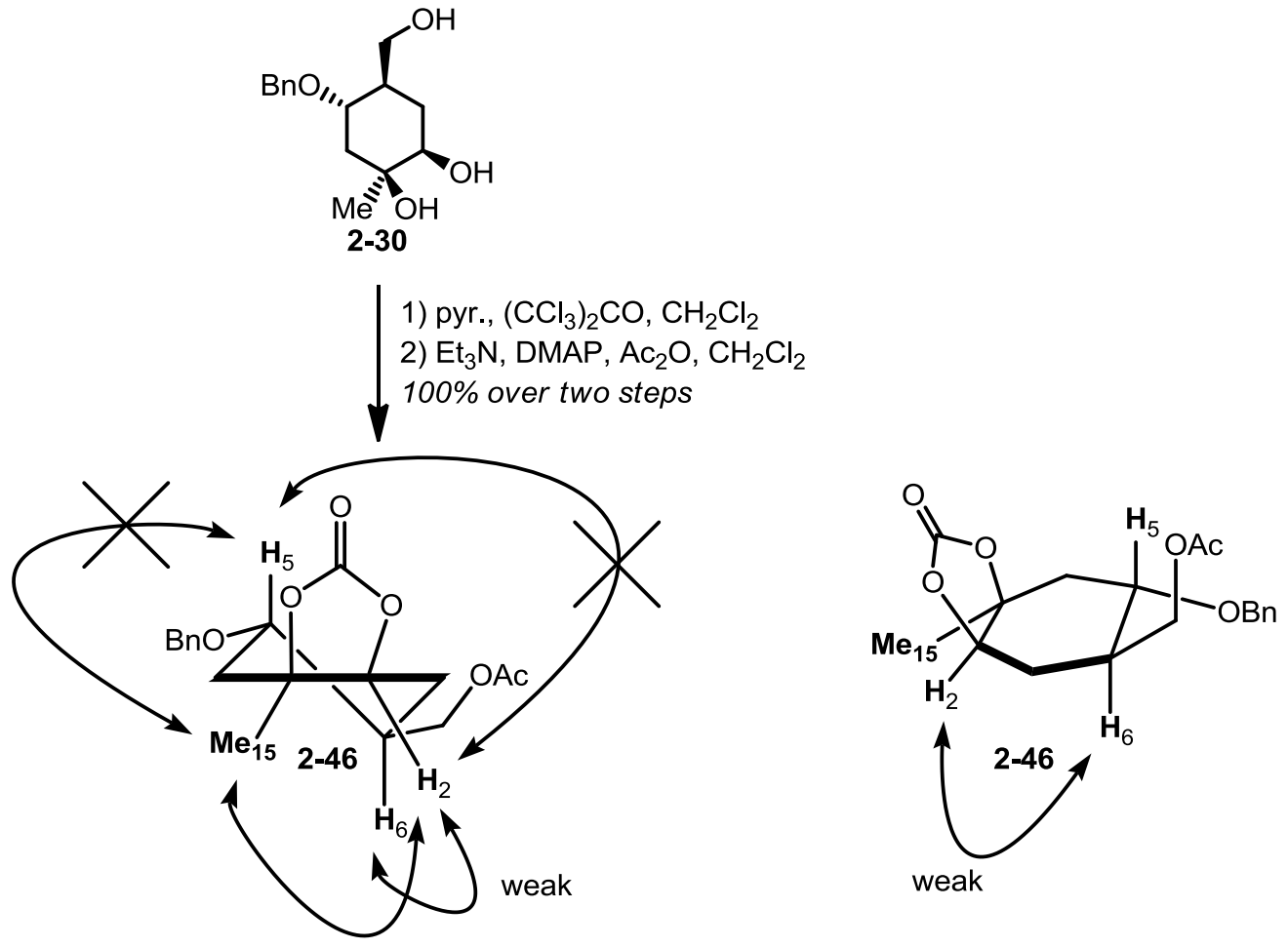


\section{(ii) Forging the dithiane-C7 bond}

a. Initial results

The next focus of the synthesis was the installation of a prenyl dithiane to form dithiane 2-3. As installations of dithianes are often achieved through nucleophilic addition $^{14}$ of a metalated dithiane to an aldehyde, ample amounts of

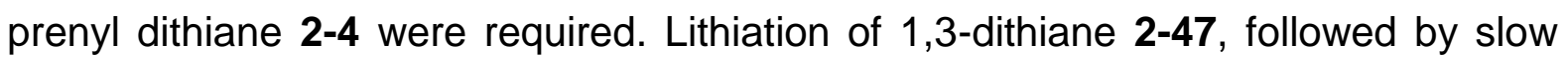
addition of prenyl bromide 2-48 produced an inseparable 1:1 mixture of desired prenyl dithiane 2-4, and isomeric dithiane 2-50. Upon identification of the corrupting compound 2-50 it was speculated that this by-product arouse due to an $S_{N} 2$ ' type addition.

\section{Scheme 2.8: Synthesis of prenyl dithiane 2-4.}

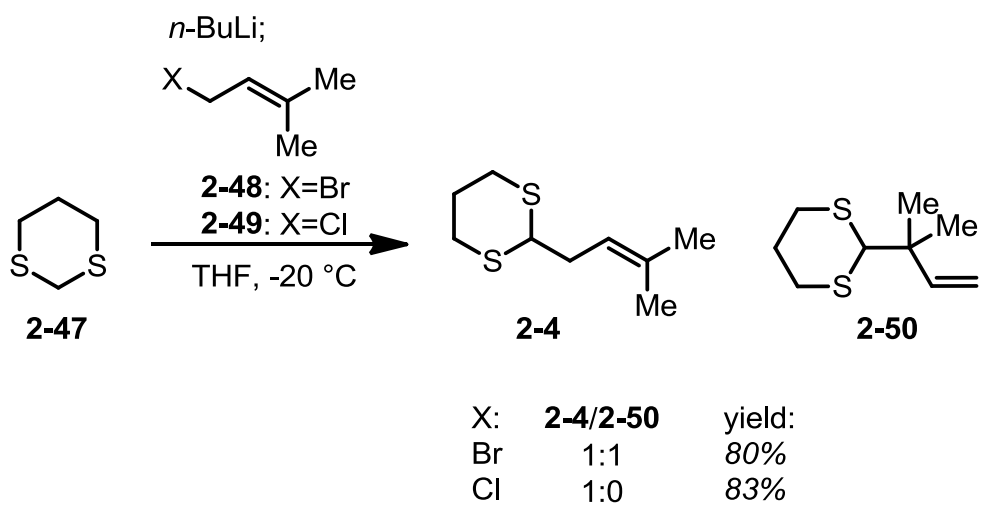

Consultation of lan Flemings' elegant book, "Frontier Orbitals and Organic Chemical Reactions" 15 yielded an important insight to this problem. According to the text, there is little evidence for a completely concerted $S_{N} 2$ ' type reaction; the text goes on to theorize that the reaction proceeds through initial formation of an ion-pair 2-52 (Figure 2.5). If one accepts that the existence of ion-pair 2-52 is a necessary precondition for formation of isomeric dithiane 2-50, then suppressing $S_{N} 2$ ' simply becomes a matter of suppressing formation of ion-pair 2-52. If the degree to which 
this ion-pair is in solution depends on leaving group ability on prenyl-halogen 2-51, it is logical to assume a worse leaving group than bromide (i.e. $\mathrm{Cl}^{-}$) would shift the equilibrium more in favor of 2-4.

Figure 2.5: Ion pair. ${ }^{15}$

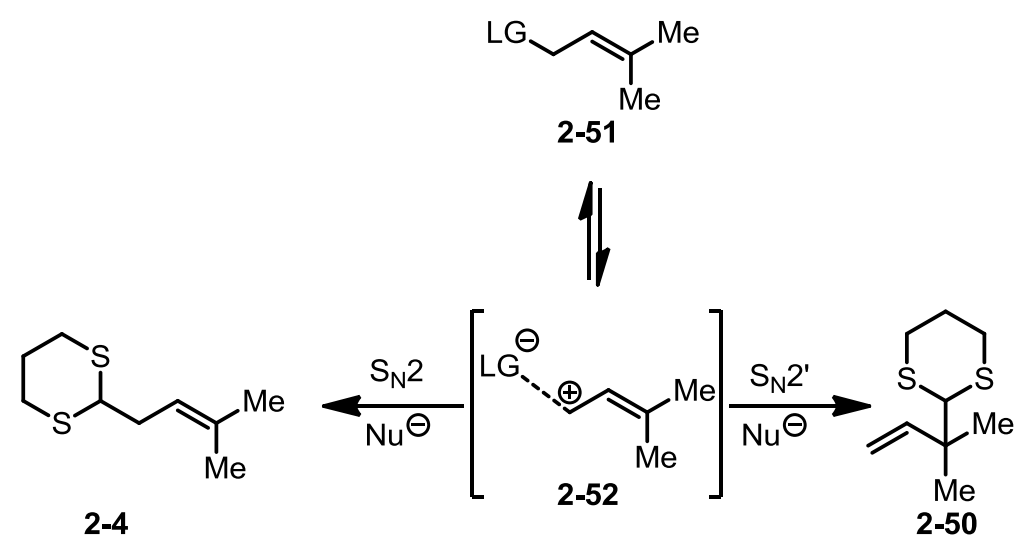

Semi-reproduced from pg. 72 of "Frontier Orbitals and Organic Chemical Reactions"15

This line of thinking, though not necessarily correct, did lead to the desired outcome. By changing the dithiane coupling partner from prenyl bromide 2-48 to prenyl chloride 2-49, the pathway producing undesired dithiane 2-50 was halted, allowing for the sole formation of desired prenyl dithiane $\mathbf{2 - 4}$ in $83 \%$ yield.

With one coupling partner available for the formation of dithiane 2-3, the next task towards this goal was the conversion of the $\mathrm{C} 7$ carbon (primary alcohol) into an electrophilic form. Several conditions selective for the oxidation of a primary alcohol in the presence of a secondary alcohol were attempted; ${ }^{16}$ however all led to unsatisfactory results. When Dess-Martin periodinane $(D M P)^{17}$ 2-53 was utilized in the reaction, the desired aldehyde was isolated, albeit in highly variable yields.

With the requisite coupling partners in hand, reaction conditions to forge the C7-C8 bond were explored. Unfortunately, the addition of lithiated prenyl dithiane 254 to aldehyde $2-5$ proceeded in only $10 \%$ yield. Further muddling hopes for this 
pathway was the finding that all attempts to induce an oxidative cyclization of dithiane 2-3 to tricyclic acetal 2-57 with phenyliodine bis-trifluoroacetate (PIFA) ${ }^{18}$ 256 led to decomposition of the starting material.

\section{Scheme 2.9: Synthesis of 2-3.}

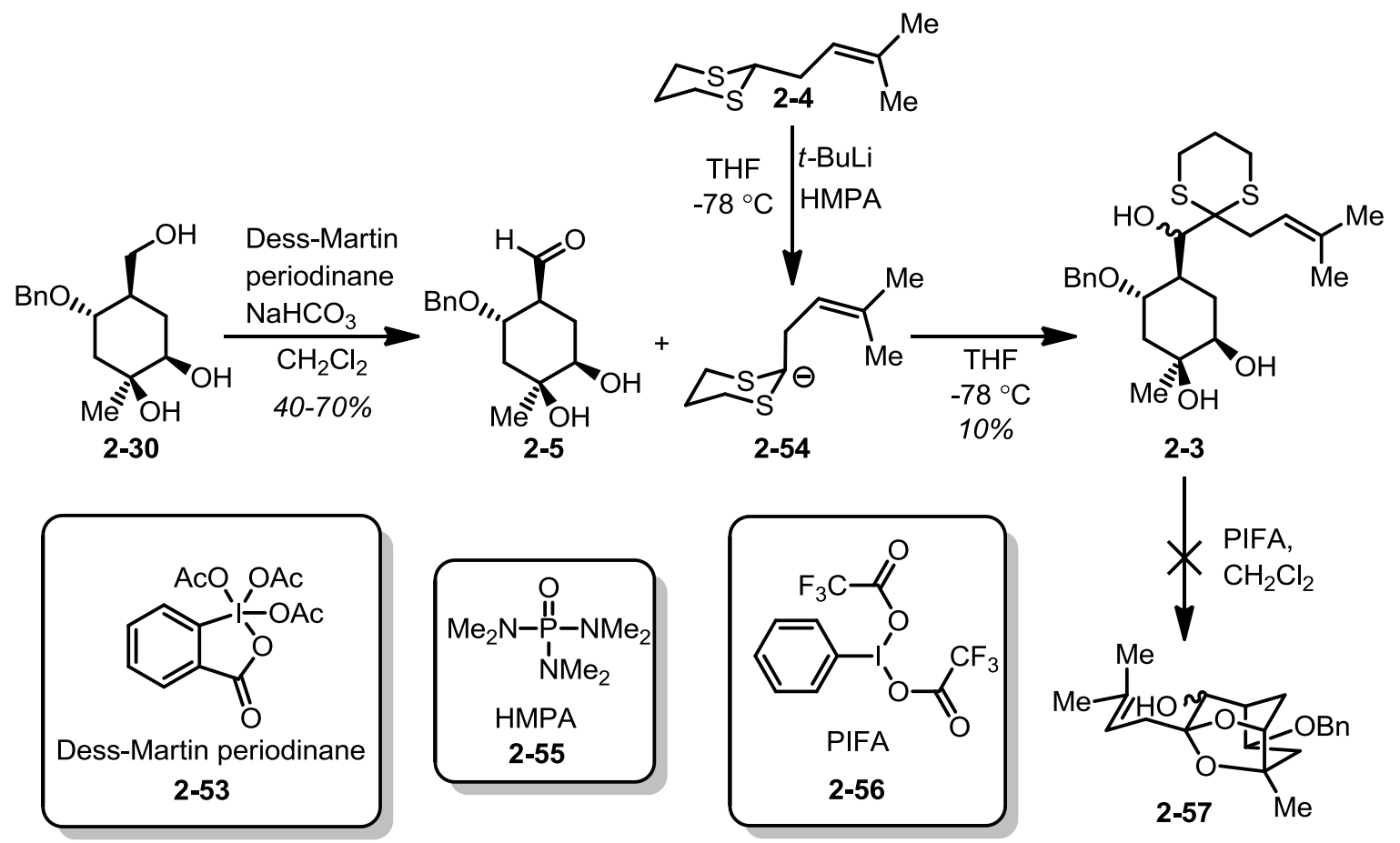

As a sizeable amount of dithiane $\mathbf{2 - 3}$, or an analogue thereof was required for the synthesis, attention was turned to maximizing the yield. The attempted selective DMP oxidation of triol 2-30 was suboptimal due to inconsistent yields as a result of oxidation of the secondary alcohol, and it was theorized that protection of the diol would eliminate this problem. An acid-labile acetonide was selected as the protecting group of choice. This acetonide 2-58 was installed in an operationally simple manner with the use of $p$-toluenesulfonic acid (PTSA) and 2,2-dimethoxy propane (Scheme 2.10). With the diol protected, a Swern oxidation ${ }^{19}$ was utilized to form aldehyde 2-59. Possibly as a result of the added steric bulk of the acetonide in 
2-59, lithiated dithiane addition did not produce desired alcohol 2-60, and in fact led to decomposition of the aldehyde.

Scheme 2.10: Acetonide protection and attempted dithiane addition.

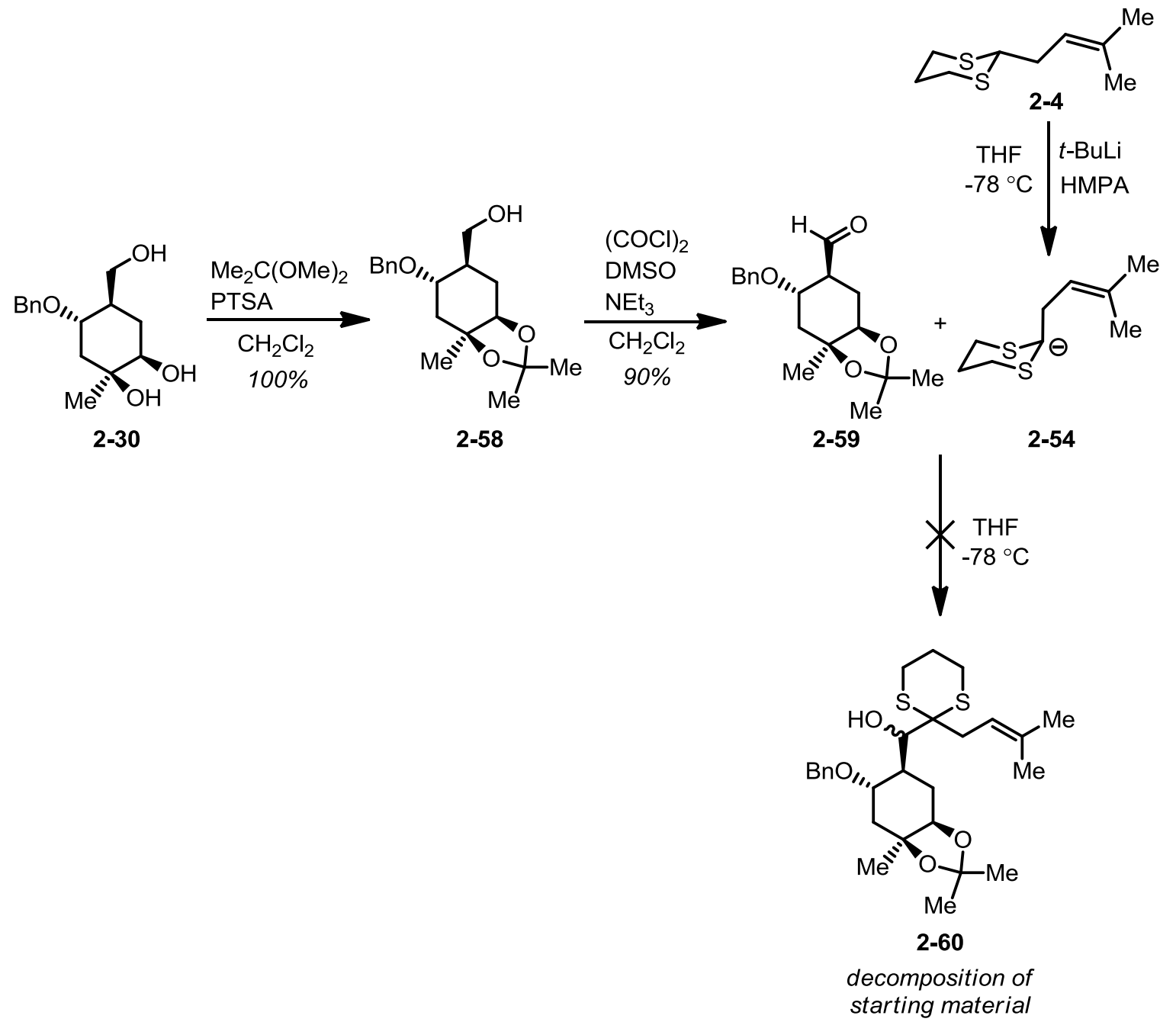

Since it was initially presumed that prenyl dithiane 2-4 did not add to protected aldehyde 2-59 due to the added steric bulk, a logical work-around to synthesize 2-60 was to install a smaller dithiane on aldehyde $2-59$, then attempt to append the new dithiane with a prenyl group. Addition of lithiated 1,3-dithiane 2-47 to aldehyde 2-59 proceeded in low yield. Unfortunately, all efforts to prenylate dithiane 2-61 to form 2-60 were met with no reaction (Scheme 2.11). 


\section{Scheme 2.11: Addition of 1,3 dithiane to aldehyde 2-59.}

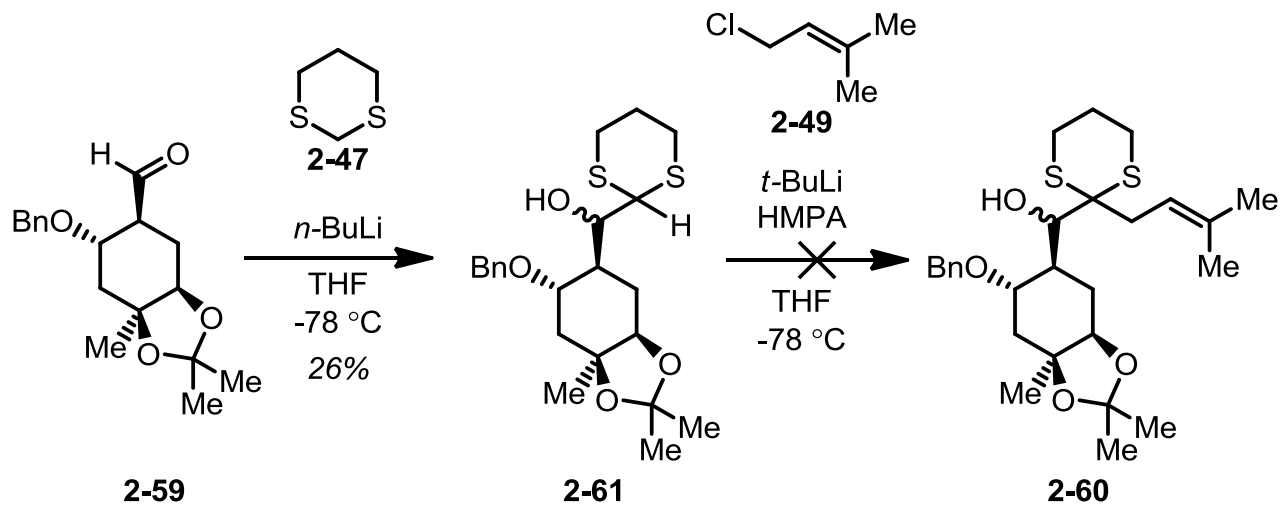

b. The utilization and role of cerium as an additive

A search of the dithiane literature provided potential insight as to the problem of decomposition observed during the prenyl-dithiane addition to aldehyde $2-59$, as well as a possible solution. In Smith's synthesis of spongistatin, ${ }^{20}$ the coupling of dithiane 2-62 with an aldehyde (2-63) possessing functionality reminiscent of aldehyde 2-59 to provide product 2-64 proved impossible without the addition of cerium trichloride (Figure 2.6). It was theorized this was due to the presence of the acidic a-proton on aldehyde 2-63, which once deprotonated could lead to the decomposition of the compound. This insight focused their attention to the addition of cerium trichloride, which is known to suppress enolization of carbonyls and favor nucleophilic addition. As cerium and its preparation proved to play an integral role in the synthesis, a further comment on the topic is warranted. 
Figure 2.6: Potential literature identification of problem/solution. ${ }^{20}$
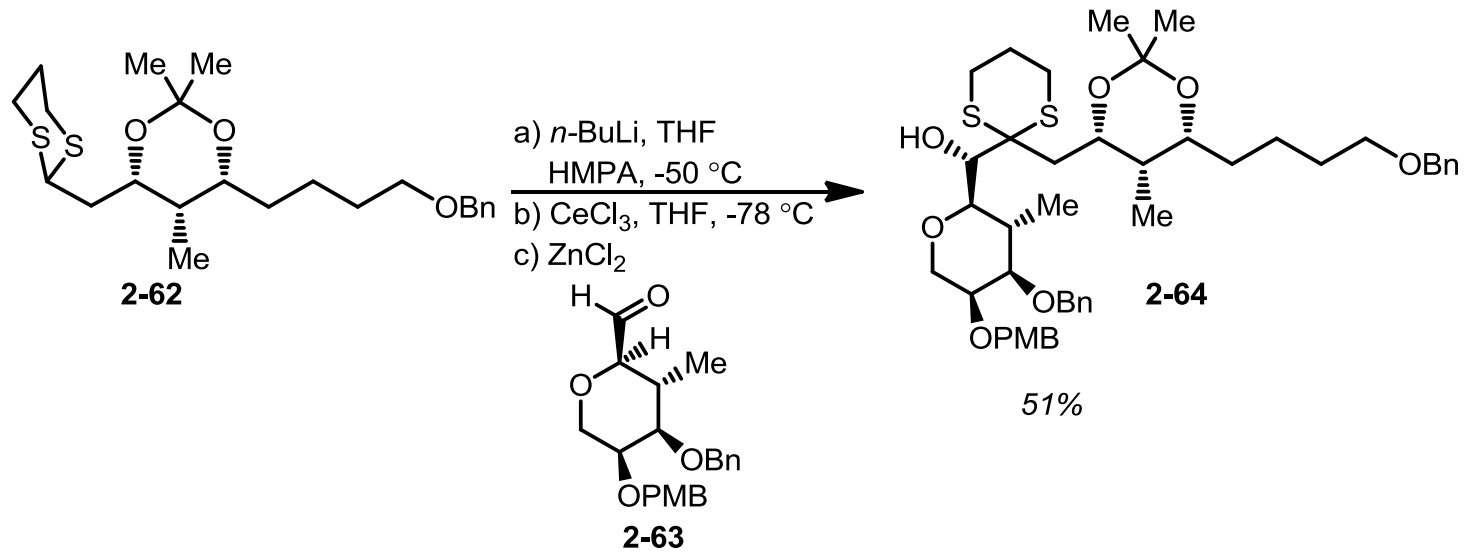

Cerium is the most abundant of the lanthanide metals, and its inorganic salts are commercially available at modest cost. ${ }^{21}$ Cerium, especially in the form of the trichloride salt, has gained much interest in the synthetic community for the preparation of organocerium reagents for addition reactions to carbonyl compounds. Due to the oxophilic nature of cerium, the use of these reagents avoids undesired reactions such as enolization, reduction (by $\beta$-hydride transfer), and conjugate addition which can result from the use of the corresponding organometallic (organolithium and Grignard) reagents, increasing the yield of desired carbonyl addition products (Figure 2.7). 
Figure 2.7: Brief survey of cerium promoted nucleophilic addition reactions. ${ }^{22}$
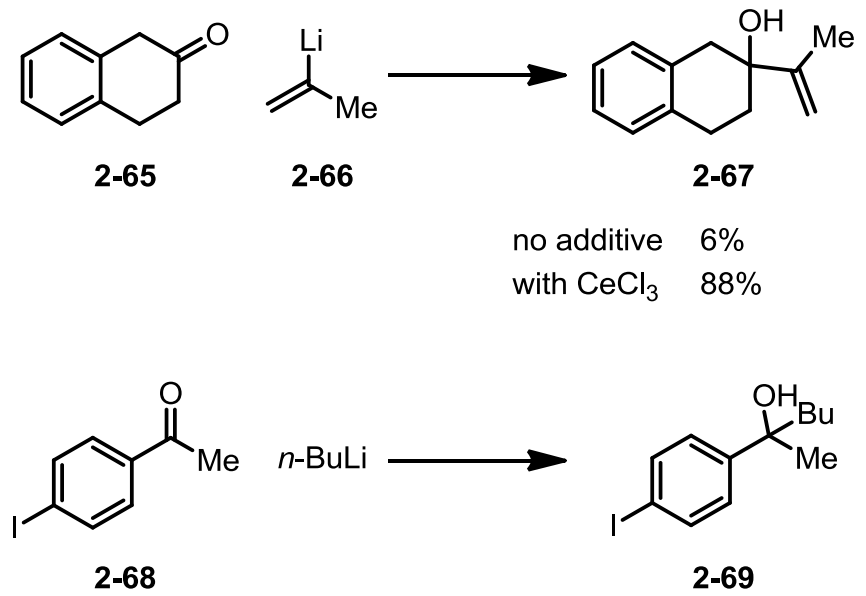

no additive $33 \%$ with $\mathrm{CeCl}_{3} \quad 98 \%$

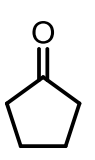

2-70

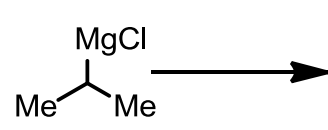

2-71

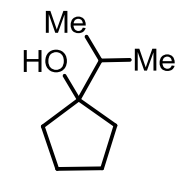

2-72

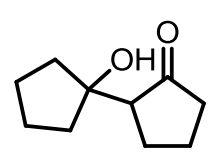

2-73

no additive $\quad 3 \% \quad 88 \%$

with $\mathrm{CeCl}_{3} \quad 72-94 \% \quad$ trace

In 1984, Imamoto and co-workers ${ }^{22}$ were the first to recognize that the lowered basicity and high oxophilicity of organocerium reagents could be utilized within the context of carbonyl addition chemistry. This lab pioneered the two main experimental methods of utilizing cerium for nucleophilic addition to carbonyls (Figure 2.8). Both methods require "anhydrous" $\mathrm{CeCl}_{3}$, which was prepared by heating $\mathrm{CeCl}_{3} \cdot 7 \mathrm{H}_{2} \mathrm{O}$ under vacuum at $140{ }^{\circ} \mathrm{C}$.

In one method of utilizing cerium for nucleophilic addition (method A), the $\mathrm{CeCl}_{3}$ is stirred in THF until the formation of a suspension of $\mathrm{CeCl}_{3} \cdot \mathrm{THF}$ complex is achieved. This can be accomplished through prolonged stirring times, heating at 
reflux, or the use of ultrasonic irradiation. The organocerium reagent is then formed by the addition of the Grignard or alkyllithium reagent at cold temperatures.

In method $\mathrm{B}$, the carbonyl compound is stirred in THF with anhydrous $\mathrm{CeCl}_{3}$ for a period of time (normally $1 \mathrm{~h}$ ), after which the Grignard reagent is slowly added. This method of activating the $\mathrm{CeCl}_{3}$ requires less time to complete due to the higher Lewis basicity of the carbonyl oxygen (compared to the oxygen atom in THF), allowing for facile complexation with $\mathrm{CeCl}_{3}$.

Figure 2.8: Two methods of utilizing cerium for carbonyl additions. ${ }^{23}$

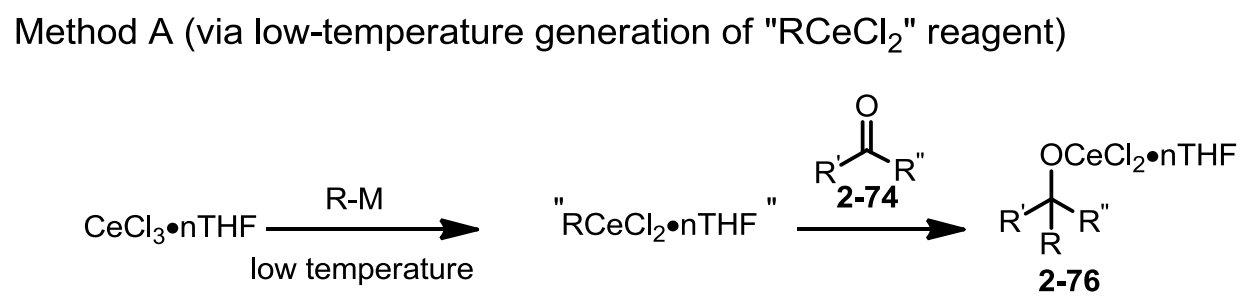

Method B (via initial complexation of the ketone with $\mathrm{CeCl}_{3}$ )

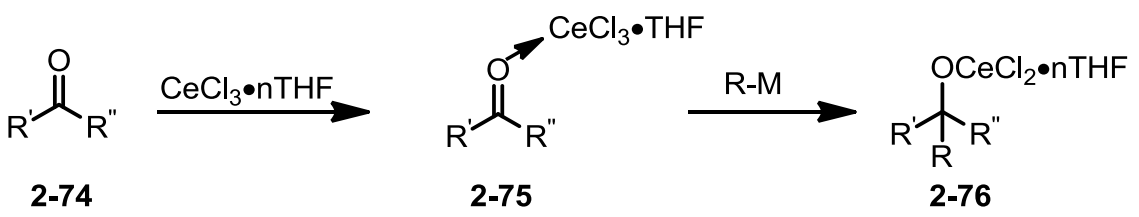

Imamoto's method of drying $\mathrm{CeCl}_{3}$ still remains popular in the synthetic community today, no doubt due to its inclusion in the Encyclopedia of Reagents for Organic Synthesis. ${ }^{24}$ However, in 1996 Professor William Evans ${ }^{25}$ and co-workers reported that this method of drying does not produce anhydrous $\mathrm{CeCl}_{3}$, but rather forms a polymeric monohydrate with the elemental composition of $\left[\mathrm{CeCl}_{3}\left(\mathrm{H}_{2} \mathrm{O}\right)\right]_{n}$. The implications of this publication were that all or most of previous reported uses of "anhydrous $\mathrm{CeCl}_{3}$ " were inaccurate, and organocerium reagents formed using $\mathrm{CeCl}_{3}$ dried via this process should be more accurately written as $\left[\mathrm{CeCl}_{3}\left(\mathrm{H}_{2} \mathrm{O}\right)\right]_{n} / \mathrm{RM}$ 
( $\mathrm{M}=\mathrm{Mg} / \mathrm{Li}$ ) rather than " $\mathrm{CeCl}_{3} / \mathrm{RM}$ " or " $\mathrm{CeCl}_{2} \mathrm{R}$." It is speculated that if $\left[\mathrm{CeCl}_{3}\left(\mathrm{H}_{2} \mathrm{O}\right)\right]_{n}$ is treated with excess $\mathrm{RLi}$, it may form " $\mathrm{CeCl}_{3} / \mathrm{RM}$ ", but $\mathrm{MOH}$ or $\mathrm{M}_{2} \mathrm{O}$ may also be present in solution which has the potential to affect certain sensitive reactions. Another likely form of the organocerium reagent is $\left[\mathrm{CeCl}_{a} \mathrm{R}_{b}(\mathrm{OH})_{c} \mathrm{O}_{d} \mathrm{Li}_{e}\right]_{f}$, based on the knowledge that lanthanide metal complexes often have high coordination numbers. The authors clarify that their discovery in no way diminished the effectiveness of the reagent, and in fact speculate that the use of truly anhydrous $\mathrm{CeCl}_{3}$ could produce exceptional chemistry. ${ }^{25}$

Immediately after the disclosure by the Evans group, Professor Dimitrov and co-workers published a report on an improved method of drying $\mathrm{CeCl}_{3}$, though an analysis of the $\mathrm{CeCl}_{3}$ prepared this way was not tested for the presence of water. In this elegant manuscript, they set the groundwork for future research using cerium salts to promote nucleophilic carbonyl chemistry. Amongst their key findings for working with $\mathrm{CeCl}_{3}$ :

Drying procedure: It was found that heating $\mathrm{CeCl}_{3}$ in the presence of water above $90^{\circ} \mathrm{C}$ hydrolyzed the metal chloride, forming $\mathrm{HCl}$ and oxychlorides of the type $\mathrm{Ce}(\mathrm{OH}) \mathrm{Cl}_{2}$ and $\mathrm{Ce}(\mathrm{OCl}) \mathrm{H}_{2} \mathrm{O}$. To avoid formation of these byproducts, at least $80 \%$ of the water needs to be removed at a temperature below $90{ }^{\circ} \mathrm{C}$.

Activation of the ketones: The $\mathrm{CeCl}_{3}$-THF solution and the carbonyl electrophile need to be mixed and stirred at room temperature until the ketone 
is successfully activated. The time of this activation depends on the quality of the $\mathrm{CeCl}_{3}$.

Addition of the organometallic reagent: Certain organometallic reagents (especially those having $\beta$-hydrides) decompose upon exposure with $\mathrm{CeCl}_{3}$. The use of cold temperatures can mitigate this effect.

Catalytic activity: Catalytic use of $\mathrm{CeCl}_{3}$ is possible, perhaps indicating an alkoxide species of the type $(\mathrm{RO})_{3} \mathrm{Ce}$ is formed during the reaction.

The term "activated $\mathrm{CeCl}_{3}$ " has come to be understood ${ }^{26}$ as the formation of $\left[\mathrm{CeCl}(\mu-\mathrm{Cl})_{2}(\mathrm{THF})_{2}\right]_{\mathrm{n}}$, a complex with one chloride in an axial position and two chlorides in bridging positions (Figure 2.9). This is in contrast to the structure of the polymeric hydrate $\left[\mathrm{CeCl}_{3}\left(\mathrm{H}_{2} \mathrm{O}\right)\right]_{n}$, in which all the chlorine atoms are in bridging positions. Terminal chlorides are more reactive ${ }^{27}$ than the bridging chlorides, and it is hypothesized that these terminal chlorides account for the ability of the activated $\mathrm{CeCl}_{3}$ to undergo the transmetalation/substitution reaction more readily than nonactivated $\mathrm{CeCl}_{3}$. Although various forms of an organocerium reagent are invoked, there does not appear to be a consensus as to the actual form. This species has been postulated to exist as an -ate complex, but also the sigma bound complex has been proposed. ${ }^{26}$ 
Figure 2.9: Structure of activated $\left.\mathrm{CeCl}_{3} ; \mathrm{CeCl}(\mu-\mathrm{Cl})_{2}(\mathrm{THF})_{2}\right]_{\mathrm{n}}{ }^{26}$

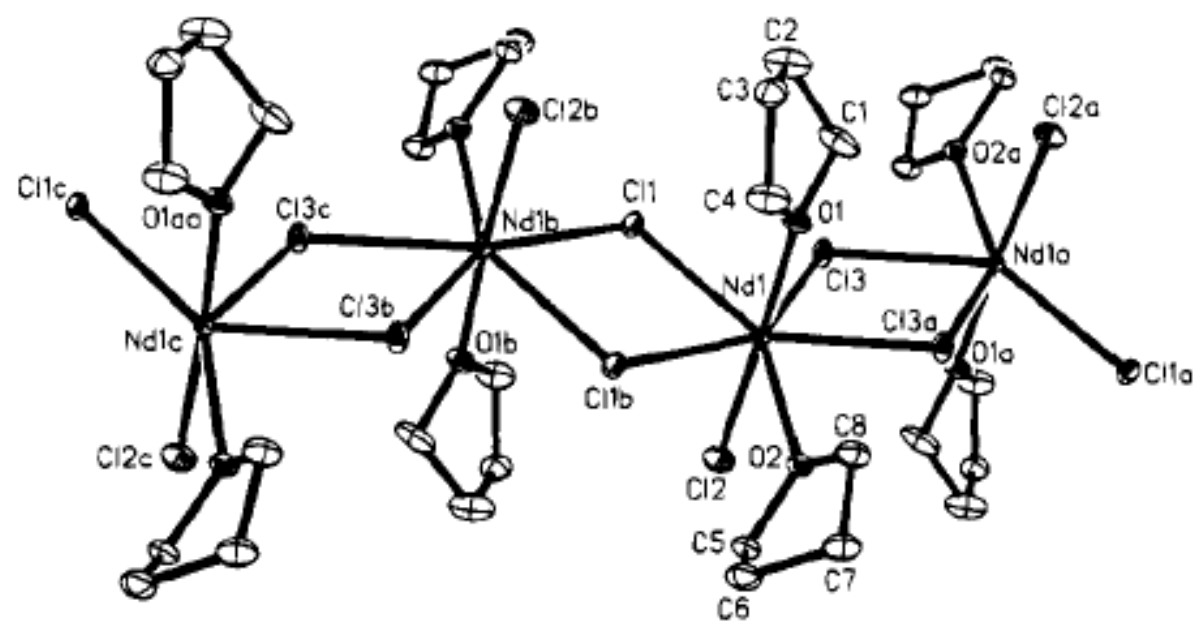

Copied from reference 26. Depicts $\left[\mathrm{NdCl}(\mu-\mathrm{Cl})_{2}(\mathrm{THF})_{2}\right]_{\mathrm{n}}$, a complex which is isostructural to $\left[\mathrm{CeCl}(\mu-\mathrm{Cl})_{2}(\mathrm{THF})_{2}\right]_{n}$

In $2006 \mathrm{Knochel}^{28}$ published a series of papers on the preparation and use of $\mathrm{CeCl}_{3} \cdot 2 \mathrm{LiCl}$ as a superior cerium source for carbonyl chemistry. This reagent displays greater activity compared to prior methods of drying $\mathrm{CeCl}_{3}$ due to the enhanced solubility in THF it displays, presumably due to increased polarity of the THF induced by the presence of $\mathrm{LiCl}$ (Table 2.2). ${ }^{29}$ 


\section{Table 2.2: The additive $\mathrm{LiCl}$ proves useful in cerium-promoted carbonyl additions. $^{28}$}

iPrMgCl

2-71<smiles>CCOC(=O)c1ccc(C(C)Cl)cc1</smiles>

2-77<smiles>O=C(Cc1ccccc1)Cc1ccccc1</smiles>

2-78<smiles>CC(C)C1(O)CCCC1</smiles>

2-72 $\begin{array}{ccc}\begin{array}{c}\text { Yield } \\ \text { without }\end{array} & \text { Yield with } & \text { Yield with } \\ \text { additives } & \mathrm{CeCl}_{3} & \mathrm{CeCl}_{3} \cdot 2 \mathrm{LiCl}\end{array}$ additives

$3-5 \% \quad 72 \%^{\mathrm{a}} 80 \%^{\mathrm{b}} \quad 94 \%$

$39 \%$

$11 \%^{\mathrm{a}}$

$91 \%$<smiles>CCOC(=O)c1ccc(C(O)(Br)c2ccccc2)cc1</smiles>

2-79<smiles>CCOC(=O)c1ccc([N+](=O)[O-])c([N+](=O)[O-])c1</smiles>

2-80<smiles>CC(=O)c1ccccc1</smiles>

2-81<smiles>CCOC(=O)c1ccc(C(C)(O)c2ccccc2)c([N+](=O)[O-])c1</smiles>

$0 \%$

$2-82$
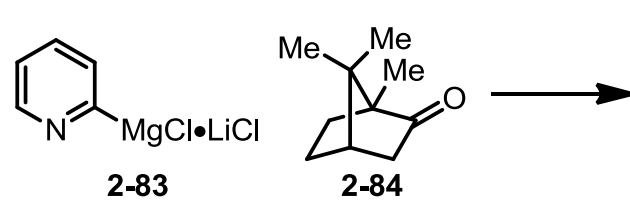<smiles>CC1(C)C2CCC1(C)C(O)(c1ccccn1)C2</smiles>

$17 \%$

$53 \%^{a}$

$92 \%$

$a=$ Drying method of Imamoto $b=$ Drying method of Dimitrov 


\section{Table 2.3: Various reported methods for drying cerium.}

\begin{tabular}{|c|c|c|c|c|}
\hline Starting with & $\begin{array}{c}\text { Temperature } \\
\left({ }^{\circ} \mathrm{C}\right)\end{array}$ & $\begin{array}{l}\text { Total Time } \\
\text { (hours) }\end{array}$ & $\begin{array}{l}\text { Pressure } \\
(\mathrm{mm} \mathrm{Hg})\end{array}$ & Reference \\
\hline $\mathrm{CeCl}_{3} \bullet 7 \mathrm{H}_{2} \mathrm{O}$ & 23 to 140 & 12 & 0.1 & 22 \\
\hline $\mathrm{CeCl}_{3} \cdot 7 \mathrm{H}_{2} \mathrm{O}$ & 23 to 140 slowly & 40 & 0.001 & 23 \\
\hline $\mathrm{CeCl}_{3} \bullet 7 \mathrm{H}_{2} \mathrm{O}$ & 23 to 275 slowly & 199 & 50 & $26 b$ \\
\hline $\mathrm{CeCl}_{3} \bullet 7 \mathrm{H}_{2} \mathrm{O}+2 \mathrm{LiCl}$ & 23 to 140 slowly & 32 & 0.01 & 28 \\
\hline $\mathrm{CeCl}_{3}+2 \mathrm{LiCl}^{*}$ & 23 to 140 & 48 & $0.8-9.5$ & This work \\
\hline
\end{tabular}

With the insight of Smith's work (vide supra), attention was turned to the formation of an organocerium reagent (Scheme 2.12). The use of "anhydrous" $\mathrm{CeCl}_{3}$ prepared by the Imamoto procedure led to an improvement over the cerium free reaction, in that aldehyde 2-59 did not decompose, but no product was formed. Reactions were run with the same batch of " $\mathrm{CeCl}_{3}$ " while modifying reaction times, temperatures, equivalents, titration with $t$-BuLi,${ }^{24}$ and the use of differing forms of butyllithium, ([1.6] $n$-Buli and [1.7] $t$-BuLi), all to no avail. 


\section{Scheme 2.12: Trouble with dithiane reaction.}

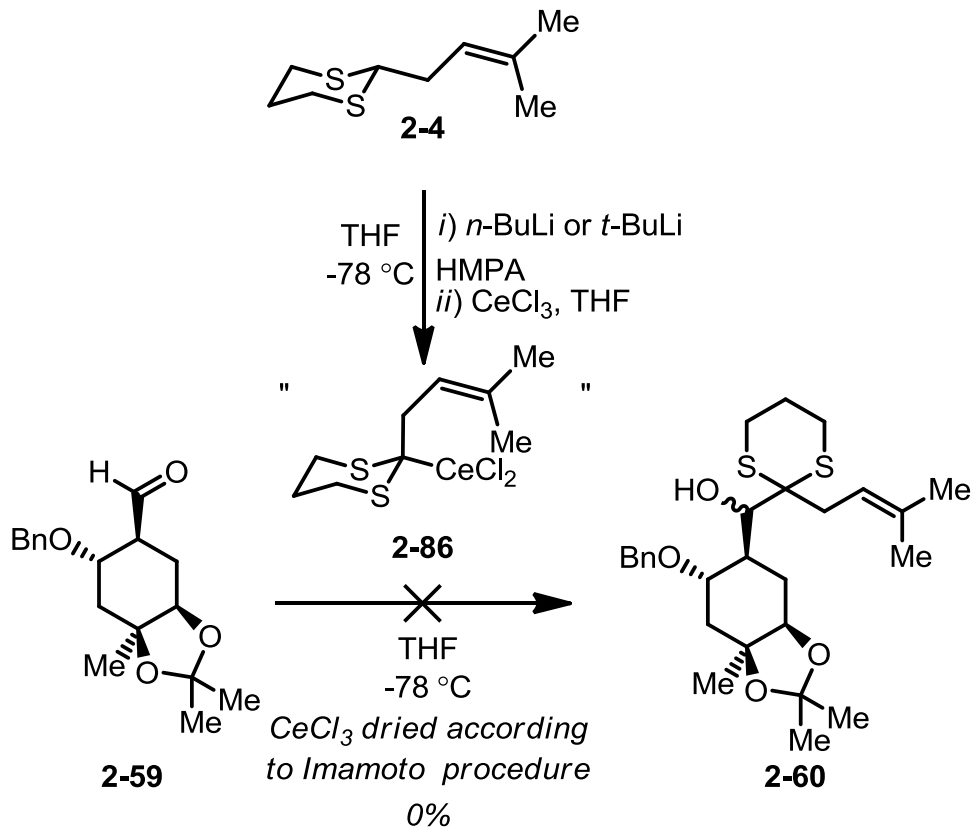

Test reactions were conducted with prenyl dithiane 2-4 and isobutyraldehyde (2-87) as the electrophile (Scheme 2.13). Oddly, the reaction run without $\mathrm{CeCl}_{3}$ performed better ( $85 \%$ yield) than the reaction run with $\mathrm{CeCl}_{3}(0 \%$ yield), indicating the quality of "dried" cerium was inadequate; hence the method of drying the cerium reagent was insufficient. 


\section{Scheme 2.13: Initial model reactions.}

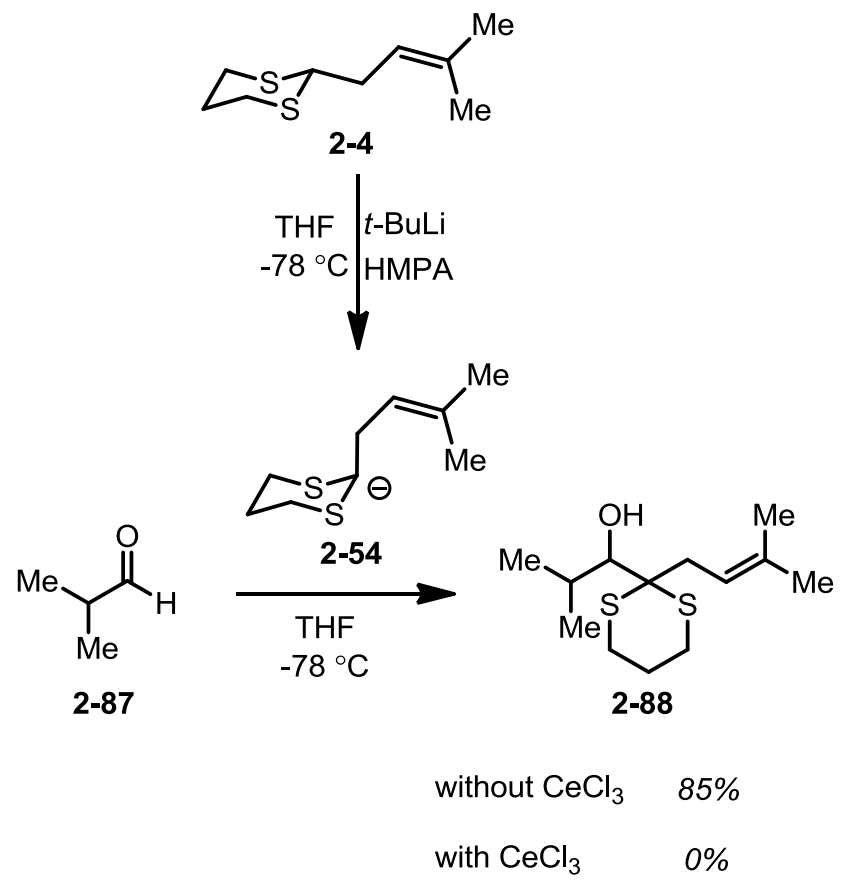

In the optimistic hope that the future of this work would be furthered by obtaining high quality cerium, the breadth of the search extended beyond the peerreviewed scientific literature and to the inorganic chemists in Kenan Labs in Professor Maurice Brookhart's lab. During the time of the cerium investigations it was learned that a post-doctoral researcher, Dr. Marc D. Walter, produced a batch of $\mathrm{CeCl}_{3}$ by a procedure analogous to known procedures for drying other metal chlorides, such as $\mathrm{FeCl}_{3}$ and $\mathrm{AlCl}_{3} \cdot{ }^{30}$ In this procedure, the metal-chloride-hydrate (i.e. $\mathrm{FeCl}_{3} \bullet n \mathrm{H}_{2} \mathrm{O}$ or $\mathrm{AlCl}_{3} \cdot n \mathrm{H}_{2} \mathrm{O}$ ) is combined with $\mathrm{SOCl}_{2}$ and heated at reflux for several days. The $\mathrm{SOCl}_{2}$ reacts with any water producing gasses $\mathrm{SO}_{2}$ and $\mathrm{HCl}$, and also has the benefit of converting any metal oxychlorides to the metal-chloride. When complete (monitored by the lack of generation of gases) the excess $\mathrm{SOCl}_{2}$ is removed under reduced pressure and the $\mathrm{MCl}_{3}$ is heated under vacuum. Dr. Walter graciously provided his method of preparing anhydrous $\mathrm{CeCl}_{3}$, which was attempted 
and utilized in the test reaction of prenyl dithiane and isobutyraldehyde, leading to a $90 \%$ yield. This batch of anhydrous material was then utilized with the desired system, which led to no reaction (Scheme 2.14). The reaction was repeated on a small scale, using a portion of the formed ceriated dithiane for a side-by-side test reaction on isobutyraldehyde. Oddly, both of these reactions provided product. This reaction was then repeated a third time on the desired substrate, and the product was obtained in $38 \%$ yield. This type of inconsistency is unfortunately normal ${ }^{31}$ for $\mathrm{CeCl}_{3}$ promoted reactions, and it was unclear if the quality of the cerium itself was to blame, or another factor such as atmospheric humidity or quality of reagents.

\section{Scheme 2.14: Inconsistent result utilizing anhydrous $\mathrm{CeCl}_{3}$.}

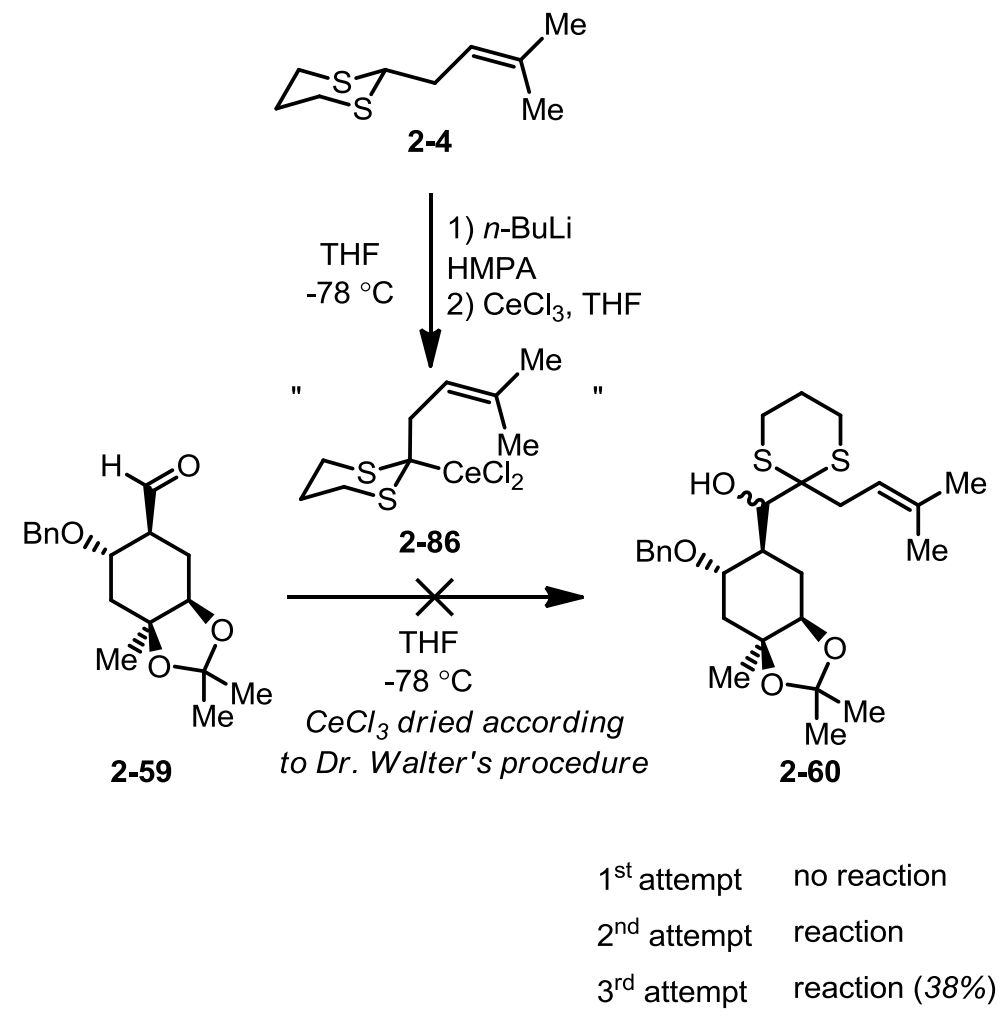

Although questions remained as to the reproducibility of the dithiane addition, an adequate amount of dithiane 2-60 was obtained to pursue the synthesis of 
aldingenin $\mathrm{B}$. The removal of the acetonide protecting group to obtain triol 2-3 was deemed necessary to pursue the intramolecular ketalization to tricycle 2-89. Unfortunately, all efforts to remove the acetonide with various acids resulted in no reaction and recovered starting material (Scheme 2.15).

\section{Scheme 2.15: Acetonide inert to acids.}
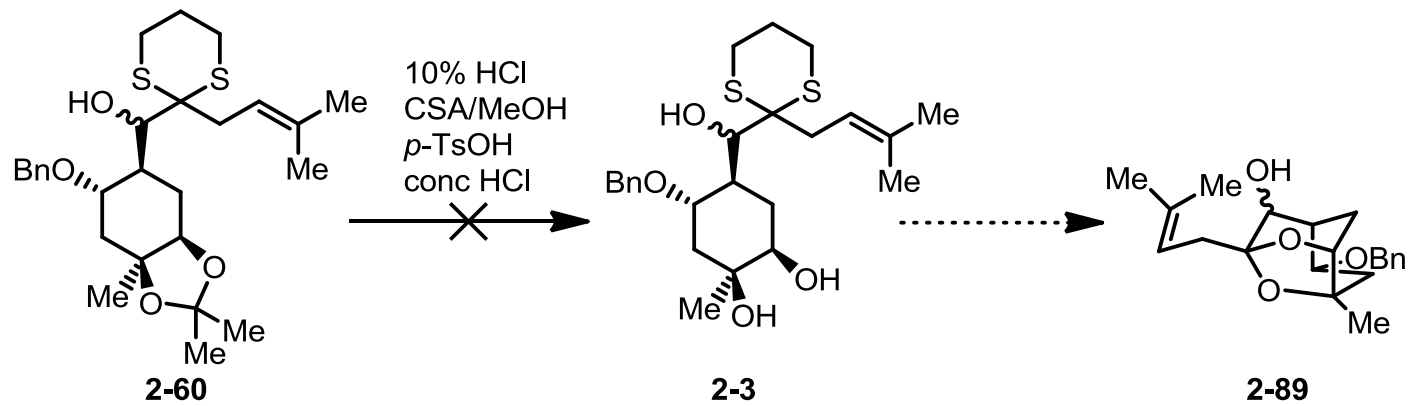

It was obvious that a more acid-labile protecting group was necessary. At first the use of various orthoesters were explored, but difficulties were encountered due to side reactions involving the primary alcohol of triol 2-30. Eventually the use of the more acid-labile (compared to an acetonide) cyclopentylidene ketal was chosen as a suitable protecting group. The precursor for this ketal, 1,1-dimethoxycyclopentane 290 could be efficiently produced from cyclopentanone 2-70 and trimethyl orthoformate (Scheme 2.16). ${ }^{32}$ 


\section{Scheme 2.16: Synthesis of dimethylcyclopentane.}

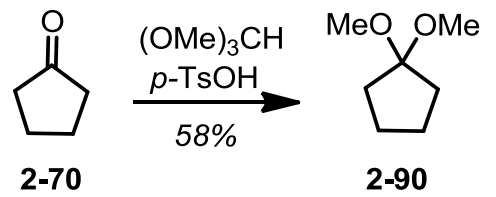

The cyclopentylidene ketal 2-91 was made from triol 2-30 with great efficiency, with a simple shake of the reaction mixture in $10 \%$ aqueous $\mathrm{HCl}$ needed to remove the methoxy cyclopentane from the primary alcohol (Scheme 2.17). Depending on the scale of the reaction, the primary alcohol was then subjected to Swern or TPAP/NMO ${ }^{33}$ oxidation conditions (elimination and epimerization was observed during larger Swern oxidation), and the resulting aldehyde was combined with the ceriated dithiane, leading to product formation in $32 \%$ yield, $6 \%$ below the corresponding acetonide. This material was then screened with various acids, resulting in no reaction. Upon exposure of TFA, complete decomposition of the starting material was observed. Supplies of dithiane 2-93 had been depleted, necessitating the synthesis of more. Further attempts to repeat the cerium reaction proved fruitless, resulting in no reaction. 
Scheme 2.17: Diol protected as cyclopentylidene ketal.

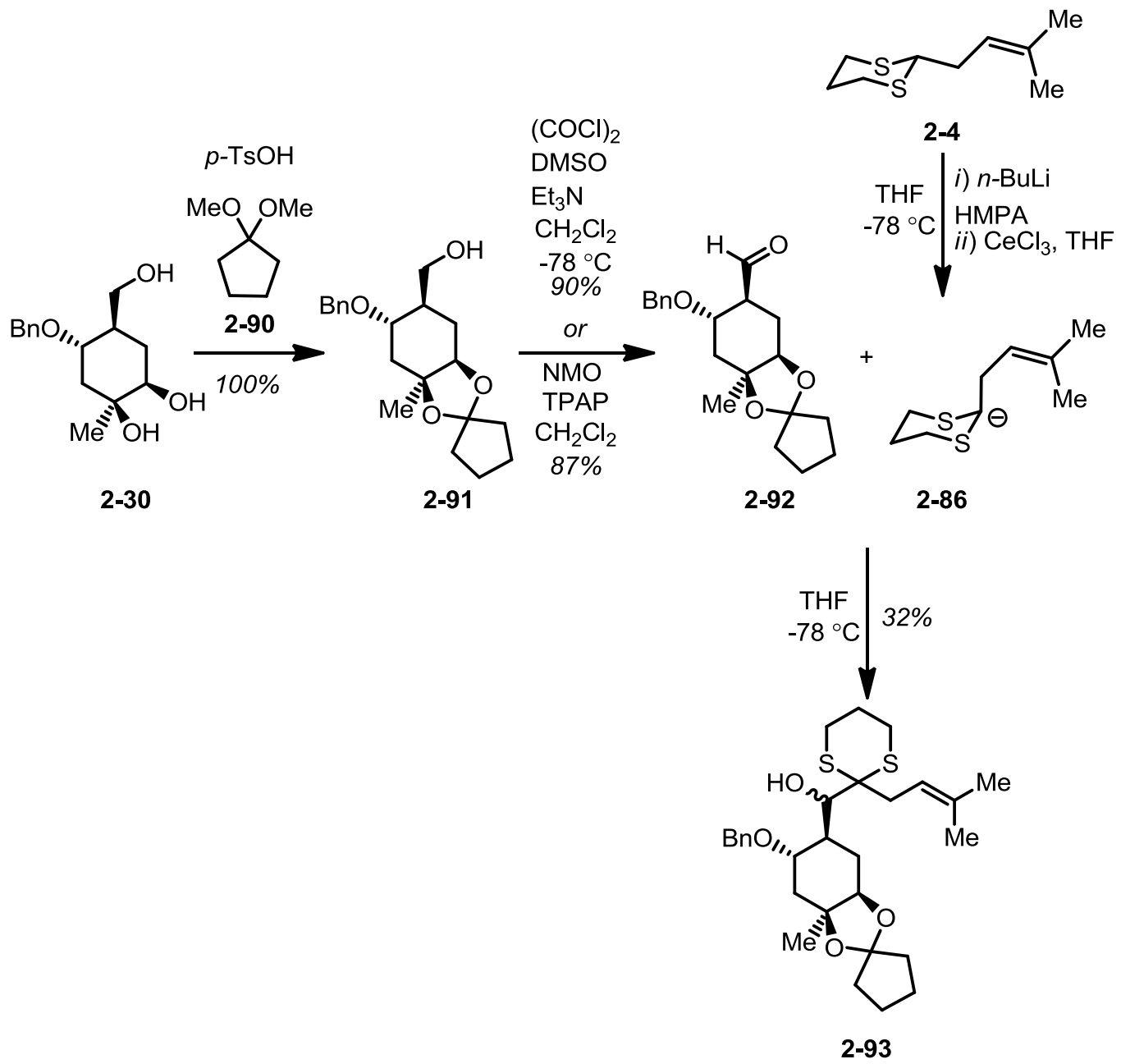

Based upon observations that reactions involving the use of $\mathrm{CeCl}_{3}$ prepared according to Dr. Walter's procedure proved very inconsistent, a new consistently competent preparation of $\mathrm{CeCl}_{3}$ was sought. The method of Dimitrov proved attractive. After following the recipe for "slow-dried" $\mathrm{CeCl}_{3}$, the cerium was covered in THF and subjected to ultrasonic irradiation to aid in the formation of activated $\mathrm{CeCl}_{3}$. However, use of $\mathrm{CeCl}_{3}$ prepared this way resulted in no reaction. In Trost's total synthesis of pseudolaric acid $\mathrm{B}^{31}$ the addition of all liquids at $-78{ }^{\circ} \mathrm{C}$ proved essential (i.e. any warming in the cannula ruined the reaction, necessitating steps be 
taken to keep the liquids cool in the cannula). This suggestion was added to the growing list of "cerium tips and hints". Before this course of action was taken, it was deemed necessary to use this batch of cerium in the standard test reaction with isobutyraldehyde (2-87). Unsurprisingly, the reaction failed. It was speculated that a micro-leak existed in the glovebox in which the dried cerium was stored, leading to some formation of the hydrate. As a precautionary measure against the possibility of hydrates, the cerium was re-heated immediately prior to use. Half of the time this strategy proved effective in test reactions, and half the time this strategy met with failure. Variables such as deprotonation time, heating temperature, method of purification of the dithiane, and heating time were all varied, to maddeningly inconsistent results; a result which proved successful one day failed the next.

Next, efforts were directed towards the formation of $\mathrm{CeCl}_{3} \cdot 2 \mathrm{LiCl}$. The oil pumps readily available for use were inadequate to exactly replicate the Knochel procedure ${ }^{34}$ so a modified version of this procedure developed in Trost's lab was explored. ${ }^{31} \mathrm{~A}$ solution of $\mathrm{CeCl}_{3} \cdot 2 \mathrm{LiCl}$ in THF prepared this way was utilized in the desired system, leading to no reaction. Several test reactions utilizing simple aldehydes were attempted with this solution, most working extremely well, once more indicating that aldehyde $2-92$ is uniquely sensitive to the quality of the $\mathrm{CeCl}_{3}$ employed.

The next wave of attempts to coerce the reaction into working involved a combination of many prior procedures. It was determined that three factors correlated (though very weakly) to success in the dithiane addition. One factor was the use of 2.5 M n-BuLi as base. The second factor was the use of cerium trichloride 
prepared utilizing $\mathrm{SOCl}_{2}$. The third factor correlating to a successful reaction was the use of freshly prepared cerium trichloride. Cerium salt stored in the glove box for longer than a day, even if dried at $140^{\circ} \mathrm{C}$ under vacuum immediately prior to use, was never successful.

With this knowledge, and knowledge gained through the literature, a 1:2 (mole/mole) mixture of $\mathrm{CeCl}_{3} \cdot \mathrm{H}_{2} \mathrm{O}$ and $\mathrm{LiCl}$ were combined with $\mathrm{SOCl}_{2}$ and heated at reflux for two days. After removal of $\mathrm{SOCl}_{2}$, the white powder was heated under high vacuum $(0.8 \mathrm{mmHg})$ at $140^{\circ} \mathrm{C}$ for $16 \mathrm{~h}$, followed by addition of anhydrous THF. Additionally, the Schlenk flask was fitted with a reflux condenser and after the addition of anhydrous THF the solution was heated at reflux overnight. This solution was employed in the reaction, and after the formation of a promising TLC spot, the reaction was prematurely halted, and product was collected in $20 \%$ yield! The method of drying has since been refined, and the aldehyde is now pre-mixed in a solution of $\mathrm{CeCl}_{3} \cdot 2 \mathrm{LiCl}$ for one hour prior to addition of the ceriated dithiane (Scheme 2.18). 


\section{Scheme 2.18: A successful new development.}

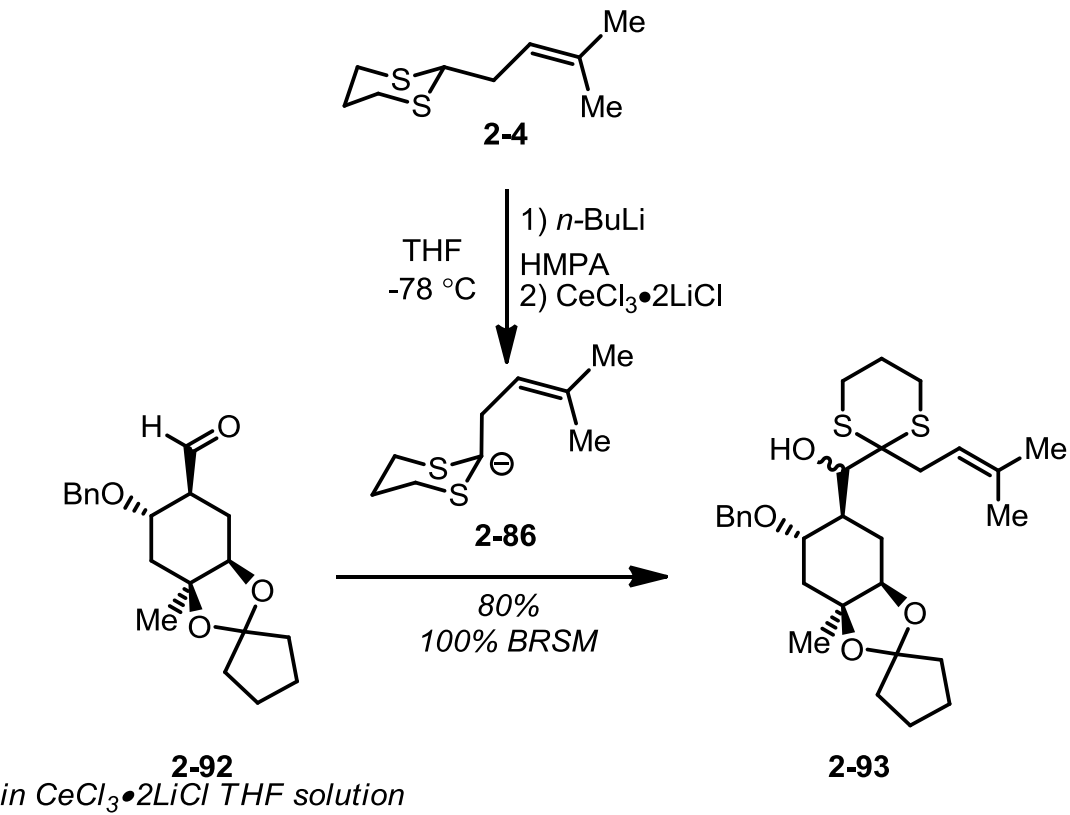

All subsequent cerium promoted dithiane addition reactions run with $\mathrm{CeCl}_{3} \cdot 2 \mathrm{LiCl}$ prepared this way have consistently provided product in high yields. Given the following three factors 1) importance of cerium trichloride promoted carbonyl additions, 2) known inconsistencies with cerium promoted reactions ${ }^{31}$ and 3) difficulties encountered attempting to procure truly anhydrous $\mathrm{CeCl}_{3}{ }^{25}$ this method of formation of $\mathrm{CeCl}_{3} \cdot 2 \mathrm{LiCl}$ has the potential to be of great importance to the synthetic community.

(iii) Efforts towards the cycloketalization

Once dithiane 2-93 was in hand, efforts were focused on the deprotection of the cyclopentylidene ketal. CSA was found to be the most effective acid, yielding the desired triol 2-3 in 47\% yield with no recovered starting material (Scheme 2.19). Dithianes in the presence of a diol are known to cyclize to ketals under the influence 
of certain reagents such as $\mathrm{Phl}\left(\mathrm{CO}_{2} \mathrm{CF}_{3}\right)_{2}(\mathrm{PIFA})$ and $\mathrm{Hg}\left(\mathrm{ClO}_{4}\right)_{2}{ }^{18,20}$ These reactions are often run in the presence of base to prevent undesired acid promoted reactions. Conditions such as $\mathrm{Phl}\left(\mathrm{CO}_{2} \mathrm{CF}_{3}\right)_{2}$ in $\mathrm{SrCO}_{3}, \mathrm{Phl}\left(\mathrm{CO}_{2} \mathrm{CF}_{3}\right)_{2}$ in $\mathrm{pH} 6$ buffer, and $\mathrm{Hg}\left(\mathrm{ClO}_{4}\right)_{2}$ with organic and inorganic bases were all tested. No desired product was observed, nor was any carbonyl compound found, and all conditions led to the loss of starting material.

\section{Scheme 2.19: Failure to cyclize.}

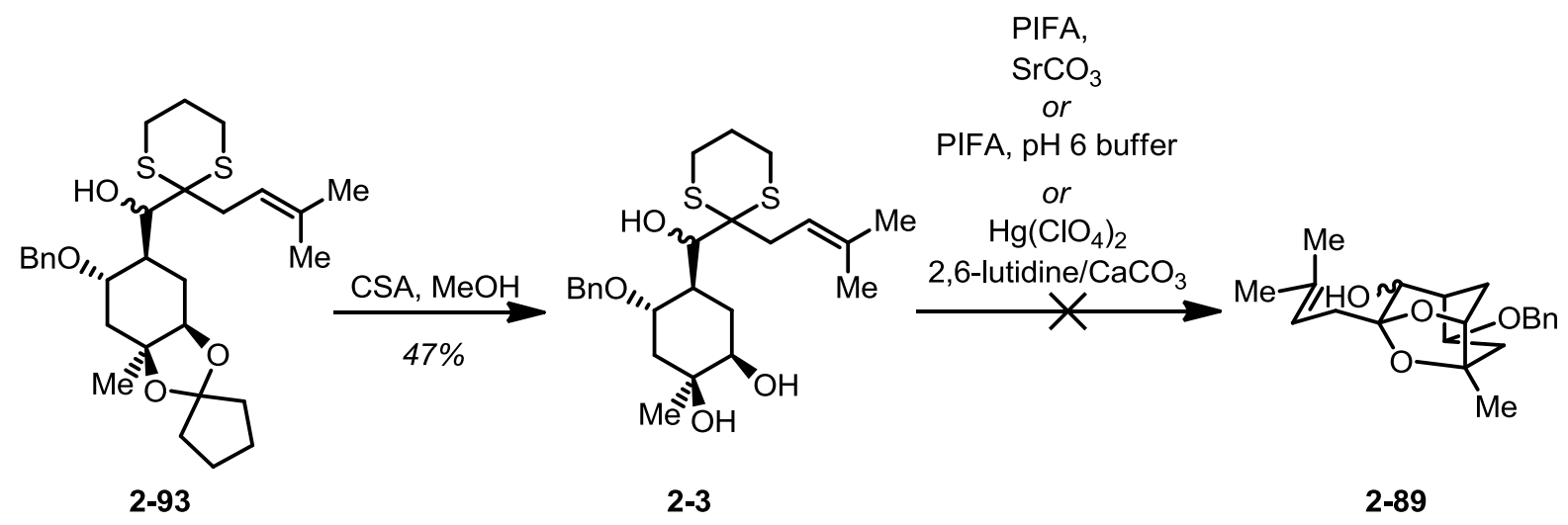

The mild conditions $\mathrm{AgNO}_{3} / \mathrm{NCS}$ are known to deprotect dithianes; ${ }^{35}$ these conditions proved better than any other conditions employed, though the succinimide byproduct co-eluted with the desired product making purification difficult. When the quenched reaction mixture was agitated with $10 \% \mathrm{HCl}$ to acid-wash the succinimide out of the organic layer, the product was isolated in only a $14 \%$ yield (Scheme 2.20). 


\section{Scheme 2.20: Failed attempts to cyclize.}
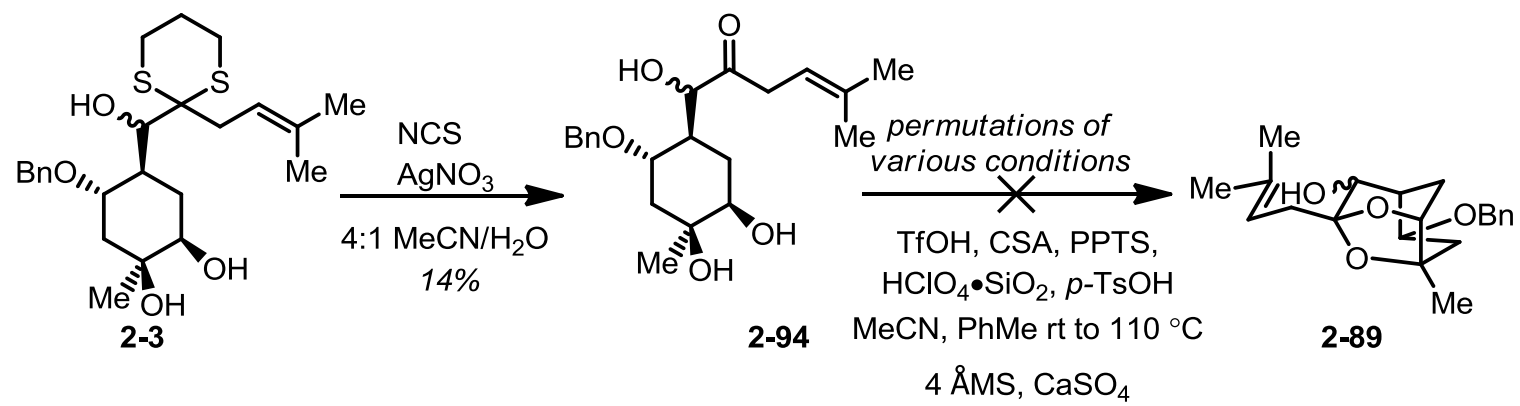

A variety of acidic conditions were screened with triol 2-94 to promote the desired ketalization. $\mathrm{TfOH}, \mathrm{CSA}, \mathrm{HClO}_{4} \cdot \mathrm{SiO}_{2}{ }^{36}$ and PPTS were all attempted, to no avail. Desiccants were added to the mixture with the hope that the removal of water would drive the reaction by Le Chatelier's principle. Heating the reaction to reflux was also attempted, but all attempts were met with failure (Scheme 2.20).

Efforts were refocused to determine if a switch in the order of operations from 1) removal of cyclopentylidene ketal 2) conversion of the dithiane to carbonyl then 3) cycloketalization to 1) conversion of the dithiane to carbonyl 2) removal of cyclopentylidene ketal 3) cycloketalization, would produce any difference in success in the forward progression of the synthesis. Given past difficulties utilizing $\mathrm{Hg}\left(\mathrm{ClO}_{4}\right)_{2}$ in $\mathrm{MeCN} / \mathrm{H}_{2} \mathrm{O}$ to convert dithiane 2-3 to ketone 2-94, it was a great surprise that brief exposure $(<10 \mathrm{~s})$ of a $0{ }^{\circ} \mathrm{C}$ mixture of 2-93 and $\mathrm{CaCO}_{3}$ with $\mathrm{Hg}\left(\mathrm{ClO}_{4}\right)_{2}$ in $\mathrm{THF} / \mathrm{H}_{2} \mathrm{O}$ afforded desired hydroxy ketone $2-95$ in $23 \%$ yield with the excess starting material recovered (it should be noted that the identical reaction run in wet $\mathrm{MeCN}$ resulted in decomposition of starting material). When repeated with longer reaction times (ca. $30 \mathrm{~s}$ ) with the hope of increasing the yield, the formation of undesired olefin isomer 2-96 was detected (Scheme 2.21). Presumably this undesired product resulted from an acid promoted event, and as the $\mathrm{CaCO}_{3}$ mixture seemed to be heterogeneous, it 
was speculated that the selection of a more soluble base would prevent pockets of localized acid in solution which could isomerize the olefin. Thus, the base 2,6lutidine was selected to supplement the acid-suppression efforts. Delightfully, even upon extended reaction times (ca. $50 \mathrm{~s}$ ) this base mixture proved successful in suppressing olefin migration.

\section{Scheme 2.21: Dithiane removal without olefin migration.}
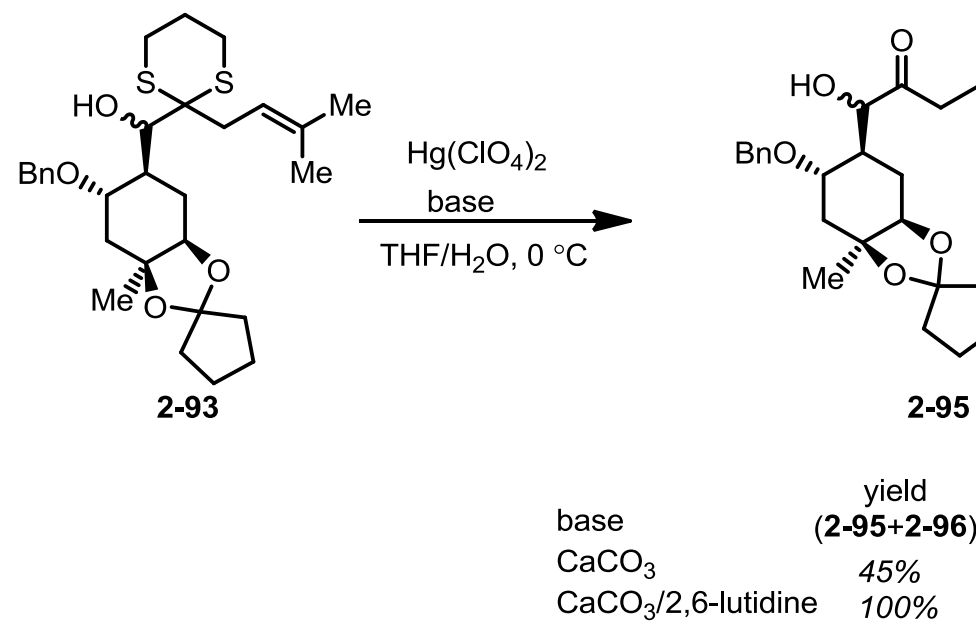

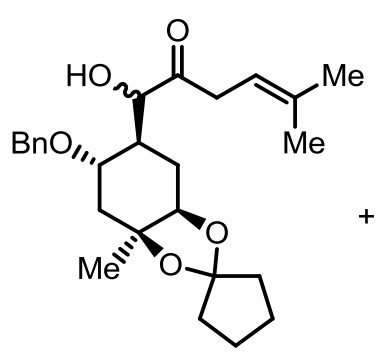

2-95

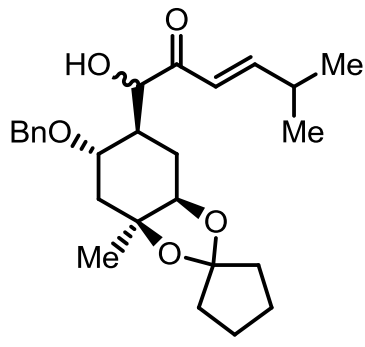

2-96

With the necessary non-conjugated olefin in hand, the one-pot cyclopentylidene removal/cycloketalization was attempted (Scheme 2.22). Following literature precedent, ${ }^{37}$ hydroxy ketone 2-95 was treated with one equivalent of $\mathrm{HClO}_{4}$ in $\mathrm{CH}_{2} \mathrm{Cl}_{2}$. It was expected that exposure of 2-95 to acid would cleanly deliver hydroxy ketal 2-89. Surprisingly, the product was actually that of tetrahydropyran ketal 2-97, presumably resulting from intramolecular $C 7$ hydroxyl trapping of the insitu formed tertiary carbocation at $\mathrm{C} 11$ as well as the desired cyclopentylidene removal/cycloketalization. With the goal of preventing the undesired etherification, various mild acids including acetic acid, PPTS, and $10 \% \mathrm{HCl}_{(\text {aq.) }}$ were screened, all 
leading to no reaction. The iron ${ }^{(\mathrm{III})}$ complex $\mathrm{FeCl}_{3}{ }^{38}$ was also screened as a ketalizing agent, though this too afforded the undesired over-cyclized product 2-97.

\section{Scheme 2.22: Undesired over cyclization.}

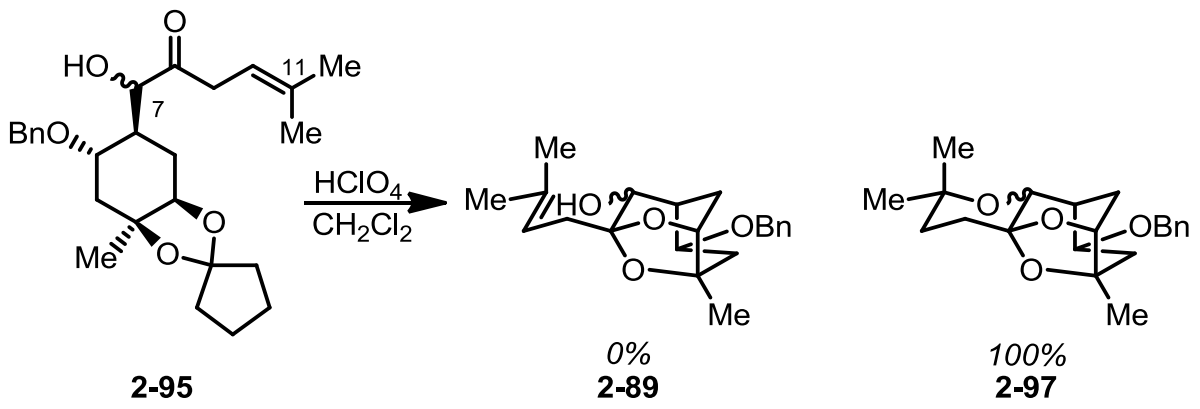

To circumvent the hydroxyl group acting as a nucleophile, the alcohol was oxidized to diketone 2-98 (Scheme 2.23). It was hypothesized that acid-promoted cyclization would then lead to desired intermediate 2-99 on the synthetic route, awaiting axial methyl attack. Unfortunately, when this diketone was treated with acid, the only result was decomposition of starting material.

\section{Scheme 2.23: Attempt to cyclize diketone.}

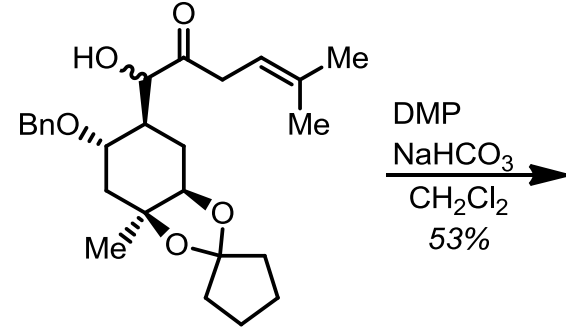

2-95

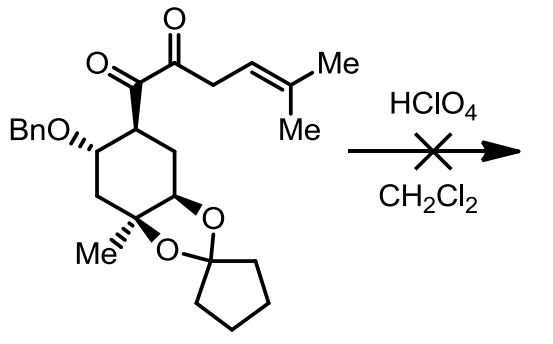

2-98

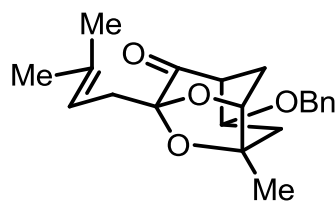

2-99

It was speculated that acetate protection of the secondary alcohol would prevent any ether ring formation under acidic conditions while still allowing cycloketalization. ${ }^{37}$ Again all efforts were met with failure as the acetate protected ketone 2-100 not only failed to cyclize, but also failed to undergo removal of the 
cyclopentylidene ketal. Attempts to force the reaction by heating at reflux resulted in decomposition of the starting material (Scheme 2.24).

Scheme 2.24: Attempts to cyclize with acetate protection.<smiles>C=C(C)[R5](C)(C(C)=O)C(C)=O</smiles>

2-95<smiles>CC(=O)O[C@H](C(=O)CC=C(C)C)[C@H]1C[C@H](OCc2ccccc2)[C@H](Cc2ccccc2)C[C@]1(C)O</smiles>

2-100

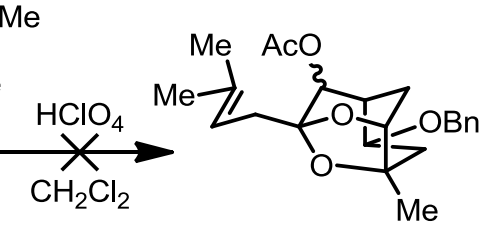

2-101

The observation that acetate protected ketone $\mathbf{2 - 1 0 0}$ failed to cyclize possibly indicated one of two things: that the acetate effected a conformational change which renders the compound inert to acid, or formation of the THP ring is a necessary precondition for cyclopentylidene loss/cycloketalization to occur (Scheme 2.25).

Scheme 2.25: Is THP formation a necessary precondition to cycloketalization?

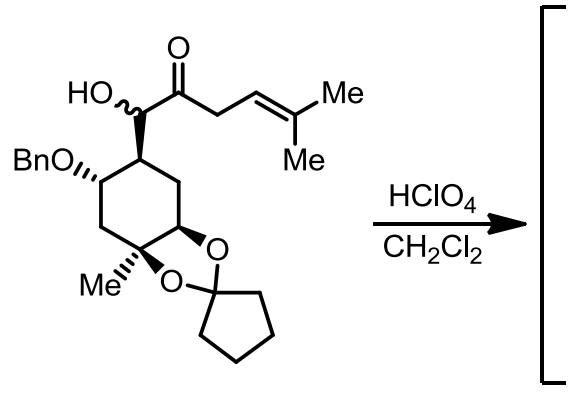

2-94

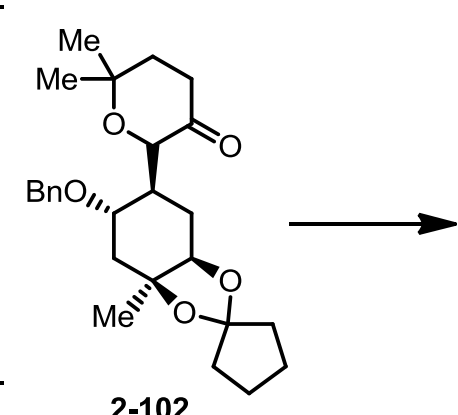

2-102
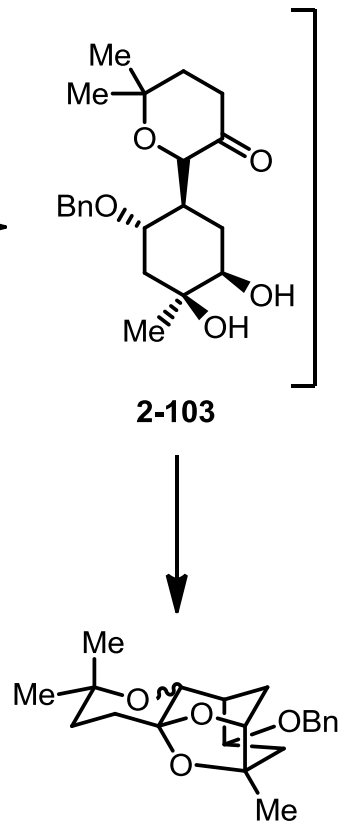

2-97

$100 \%$ 
If indeed THP formation was a necessary condition for cycloketalization, there existed the possibility to capitalize upon this fact. It was anticipated that after initial formation of the brominated THP ring, the necessary conformational change would be induced to allow cycloketalization in the presence of acid to lead to the penultimate compound in the proposed synthesis.

To first perform this bromo-etherification/cycloketalization sequence, the C-7 stereochemistry and the C-14 methyl would need to be set. After consultation of models, based on both chelate and Felkin-Ahn analysis, this seemed possible to accomplish by treatment of keto-dithiane 2-104 with a methyl anion (Scheme 2.26). This tertiary hydroxy-dithiane 2-105 could then be treated with an electrophilic bromine source to induce bromo-etherification, which could be followed by conversion of dithiane 2-106 to ketone 2-108. Alternatively, tertiary hydroxy-dithiane 2-105 could be converted to ketone 2-107, followed by treatment with a bromine source to yield bromo-ether 2-108, giving the synthetic plan a modicum of flexibility. This $\beta$-bromo ketone could then be treated with acid to induce the desired cycloketalization to complete the skeleton of aldingenin B (2-109). 
Scheme 2.26: Hypothetical route to aldingenin B.
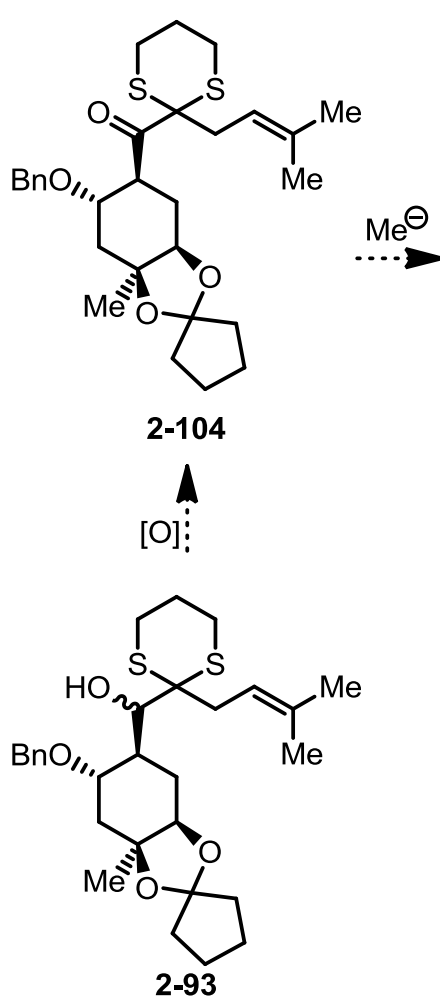

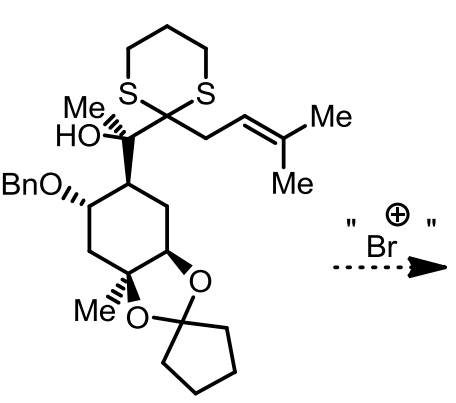

2-105

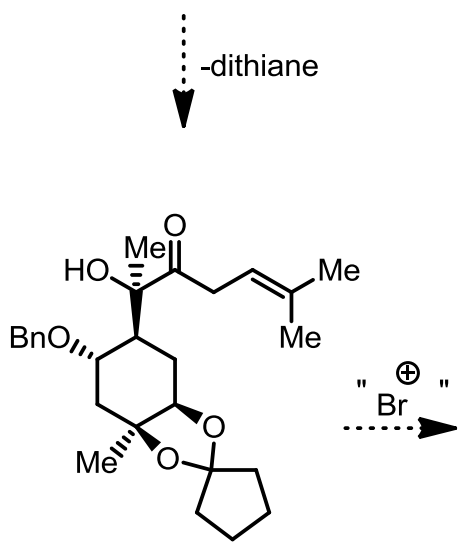

2-107

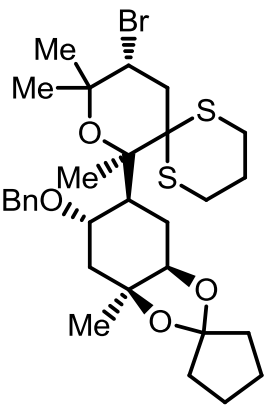

2-106
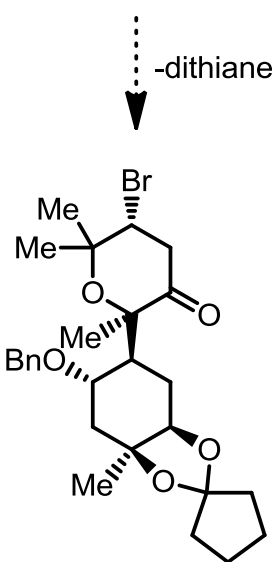

2-108
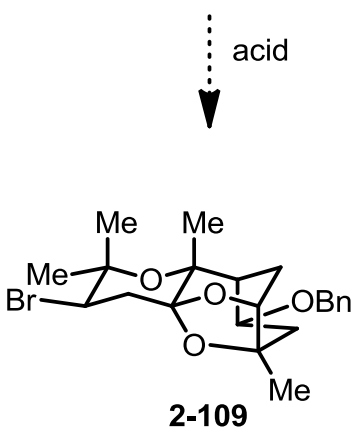

The concern of an undesired acid-promoted $\beta$-elimination of the bromine to the enone was dissipated after a literature search unearthed several examples of ketal formation in the presence of $\beta$-bromines. ${ }^{39}$

While a potentially interesting synthetic plan, the desire to limit the loss of the valuable resource of time necessitated the use of a model study (Scheme 2.27). It 
was reasoned that if previously synthesized hydroxy dithiane 2-93 (differing from 2105 by a C7 methyl group) could undergo manipulation to bromo-ketone 2-111, followed by successful cycloketalization, then studies would be directed to the route outlined in the scheme above.

\section{Scheme 2.27: Potential model studies.}

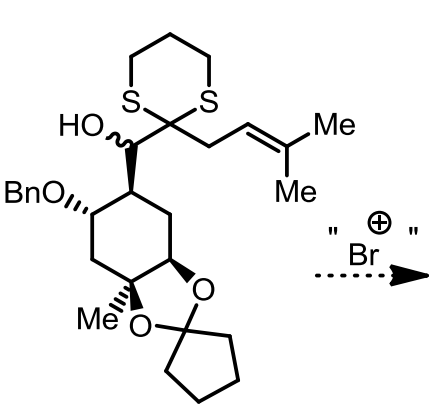

$2-93$

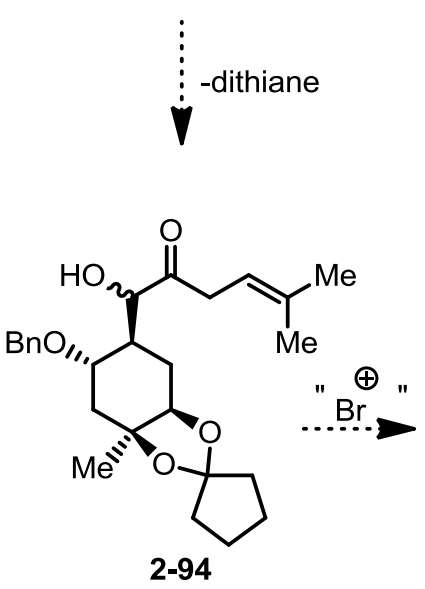

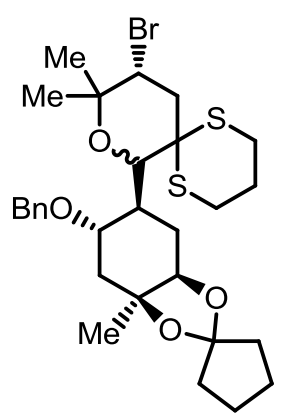

2-110
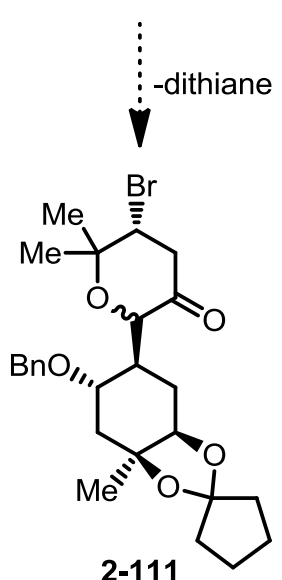

2-111

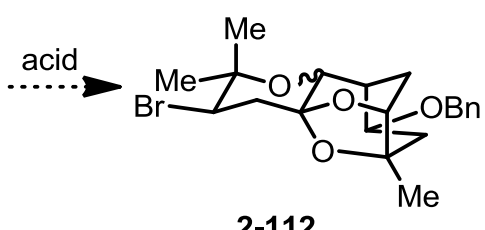

2-112

As the bromo-etherification was slated to play a pivotal role in the synthesis of aldingenin $\mathrm{B}$, prudent selection of brominating conditions was necessary. In the synthesis of brominated THP systems, such as the one present in aldingenin $B$, an interesting choice of reagent has often been selected. TBCO (2-113), $(2,4,4,6$ tetrabromocyclohexadieneone) is known ${ }^{39,40}$ to favor a higher ratio bromotetrahydropyrans to bromo-tetrahydrofurans as compared to other brominating reagents, such as NBS. 
In E. J. Corey's synthesis of Laurencia metabolite venustatriol, ${ }^{41}$ the highest yield after extensive optimization of reaction conditions of the desired THP 2-115 was $26 \%$ (Scheme 2.28 ). This low yield results presumably due to developing $1,3-$ diaxial interactions of the methyls, a moiety also contained within aldingenin B, disfavoring THP 2-115, and favoring THF 2-116.

\section{Scheme 2.28: Corey's bromoetherification.}

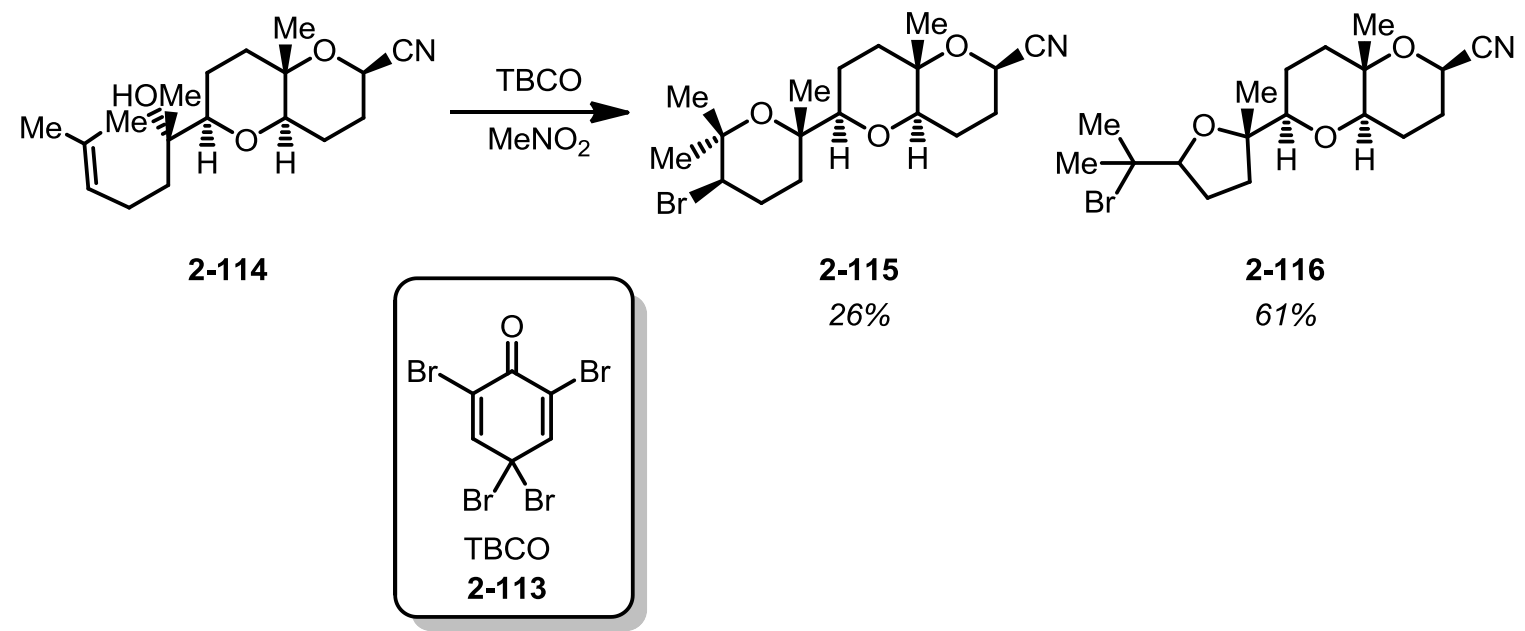

With this knowledge of the literature, hydroxy ketone 2-95 was treated with TBCO in $\mathrm{MeNO}_{2}$ (Scheme 2.29). This reaction failed to deliver the desired compound. Due to the flexibility of the route, dithiane 2-93 was treated with TBCO, leading to a mixture including THP 2-110. However, when this compound was treated with a variety of dethiolating agents, only decomposition of starting material was observed. 
Scheme 2.29: Failure to pre-form bromo-THP 2-111 prior to cycloketalization.<smiles></smiles>

2-95

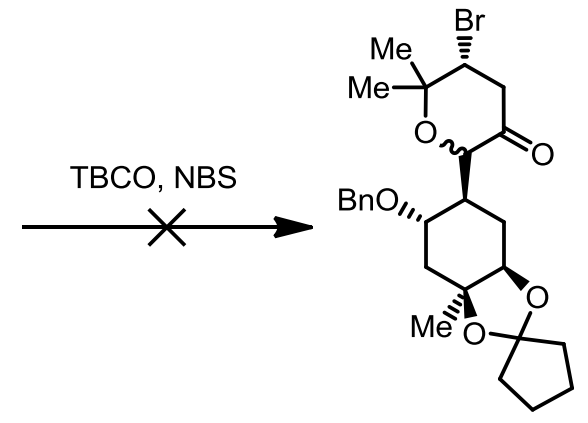

$2-111$

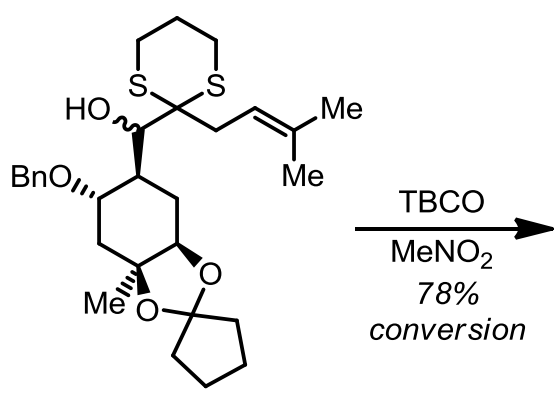

2-93

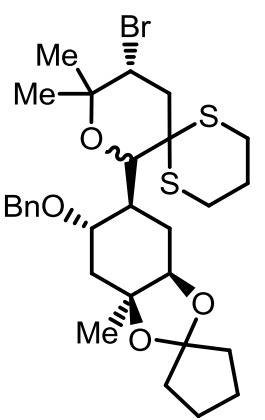

$2-110$

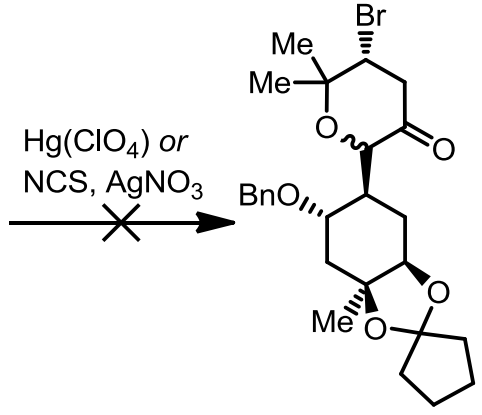

2-111

At this point, it was necessary to determine if a conformational effect was solely responsible for induction of cyclization. As a control study, saturated dithiane 2-118 was quickly synthesized from cerium promoted nucleophilic addition of dithiane 2-117 to aldehyde 2-92 in $81 \%$ yield (Scheme 2.30). Dithiane removal afforded saturated hydroxy ketone 2-119, which when treated with $\mathrm{HClO}_{4}$ cleanly afforded cyclized product 2-120 in quantitative yield. 


\section{Scheme 2.30: Saturated control experiment.}

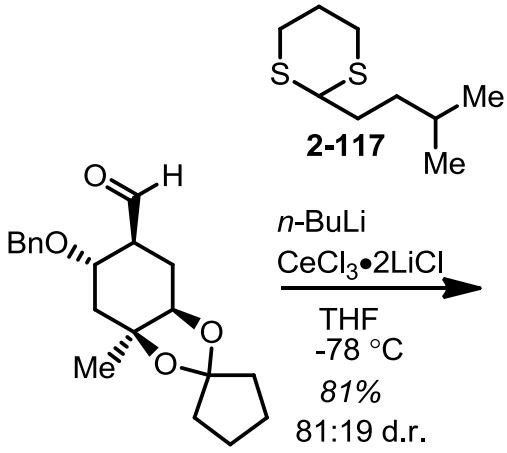

2-92

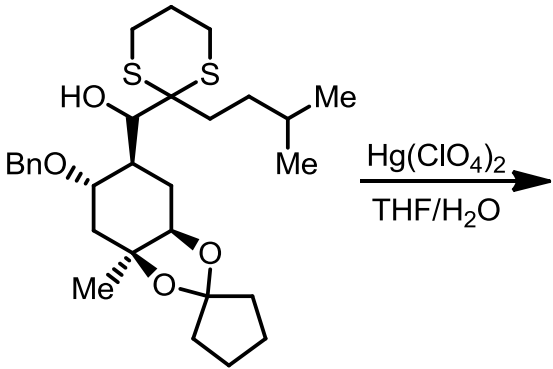

2-118<smiles>CC(C)CCC(=O)C(O)[C@H]1C[C@H](OCc2ccccc2)[C@]2(C)C[C@@H](Cc3ccccc3)OC3(CCCC3)O[C@]12C</smiles>

2-119

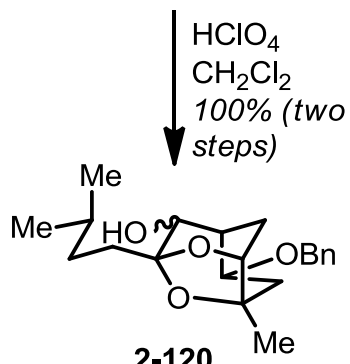

This result indicated that initial formation of a THP was not a necessary precondition for cycloketalization to occur. As the presence of the C-10/C-11 olefin in hydroxy ketone 2-94 was not needed at this point in the synthesis, and the existence of the olefin at this stage only complicated synthetic labors, studies were directed towards the synthesis of an analogue of dithiane 2-93 with a masked olefin as a way to circumvent the problems.

The analogue 2-126 was targeted, the parent dithiane 2-125 of which was made through a known procedure. ${ }^{42}$ Ethyl propiolate 2-121 was combined with sodium ethoxide and propane-1,3-dithiol (2-122), yielding ester 2-123 (Scheme 2.31). Ester 2-123 was subjected to reducing conditions to furnish alcohol 2-124, which was then exposed to silylating conditions to produce masked (revealed via deprotection/oxidation/alkene formation) olefin dithiane 2-125. 
Scheme 2.31: Synthesis of dithiane 2-126.

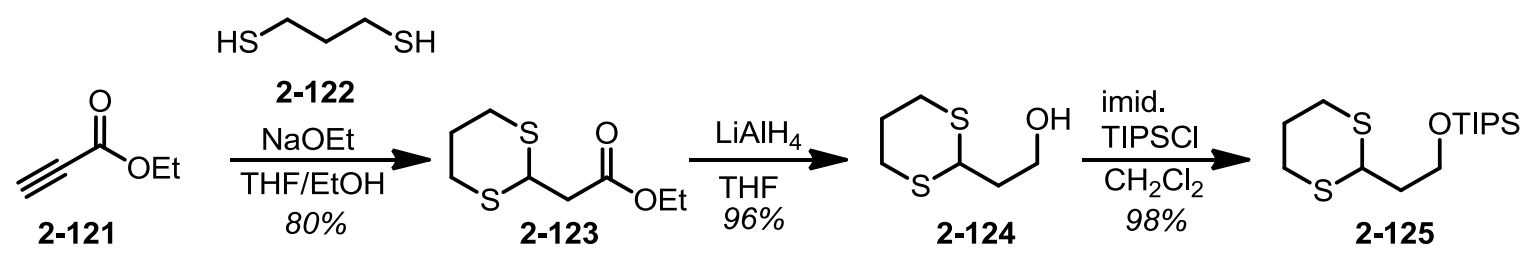

Dithiane 2-125 was lithiated and combined with a solubilized solution of cerium trichloride, followed by addition of a solution of aldehyde 2-92 in a $\mathrm{CeCl}_{3} \cdot 2 \mathrm{LiCl} / \mathrm{THF}$ solution, producing dithiane 2-126 (Scheme 2.32). This dithiane was converted to carbonyl 2-127 utilizing $\mathrm{Hg}\left(\mathrm{ClO}_{4}\right)_{2}$ as before, which when exposed to perchloric acid unexpectedly and serendipitously shed the silyl ether in addition to the cyclopentylidene and cyclized to 1,4-diol 2-128. 
Scheme 2.32: The use of masked olefin-dithiane 2-125.

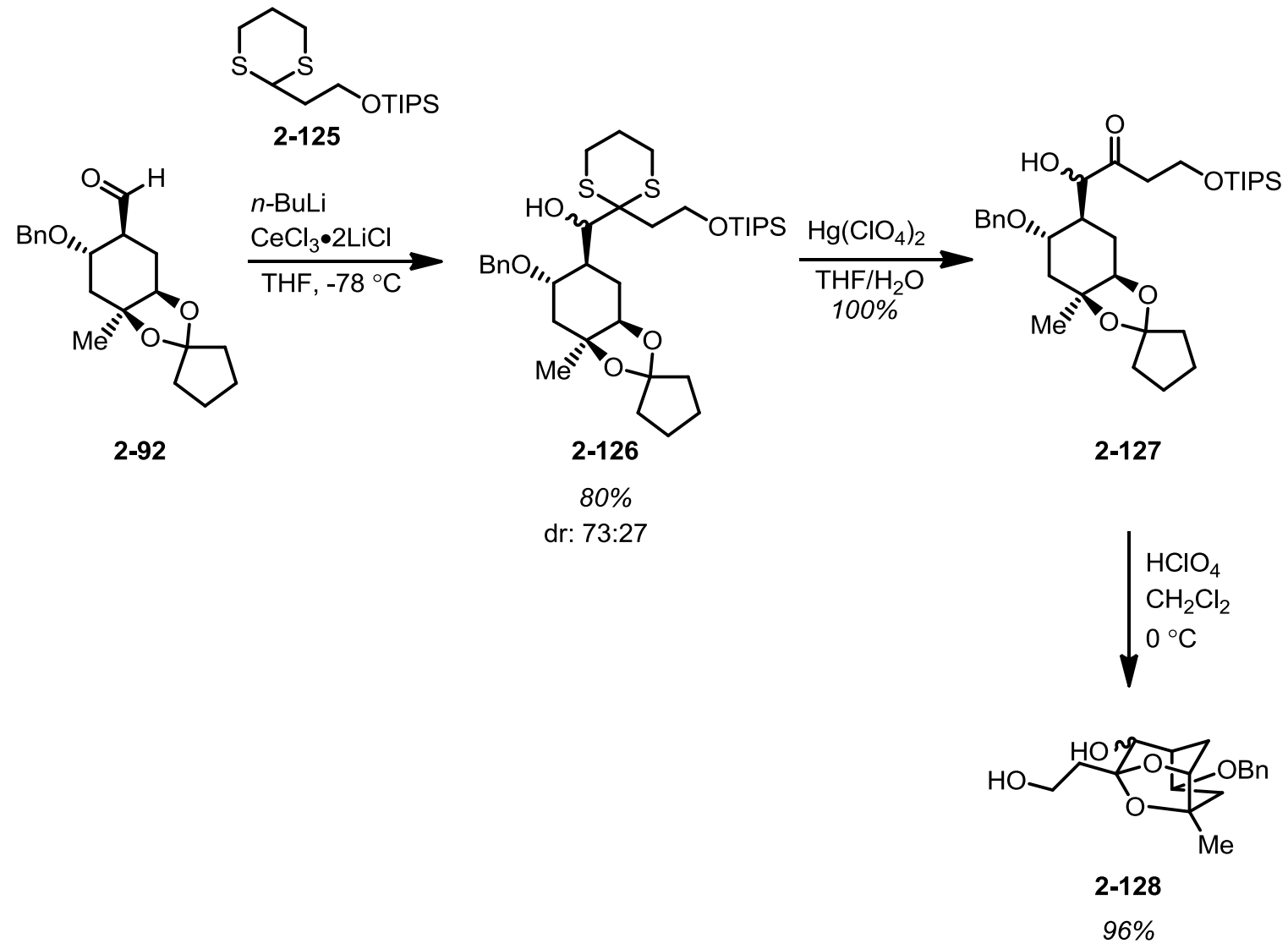

(iv) Construction of the final ring

This fortuitous product had the potential to reduce the longest linear step count by two (removing a deprotection and oxidation). Allaying concerns of lactonization, bis-oxidation under Swern conditions provided keto-aldehyde 2-129 (Scheme 2-33). Exploiting the hindered steric environment of the ketone, exposure of aldehyde 2-129 to isopropylidene triphenylphosphorane (2-130), formed the desired trisubstituted olefin 2-131. Axial methyl lithium addition provided C9 elimination products as well as alcohol $\mathbf{2 - 2}$ in low yield (17\%) with the necessary stereochemistry at C7, as confirmed by nOe and COSY $2 \mathrm{D}{ }^{1} \mathrm{H}-\mathrm{NMR}$ spectroscopy. 


\section{Scheme 2.33: Synthesis of alcohol 2-2.}

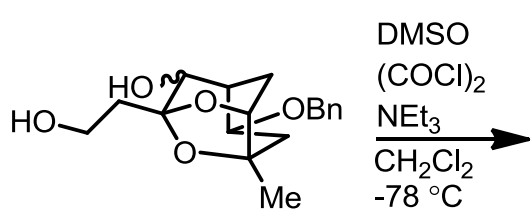

2-128

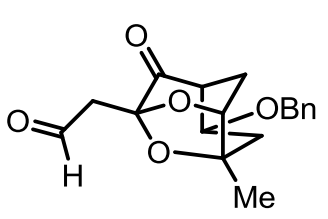

2-129

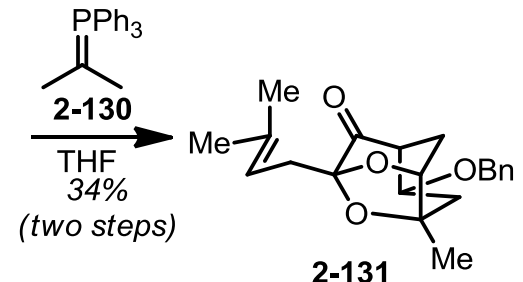

$2-131 \mathrm{Me}$

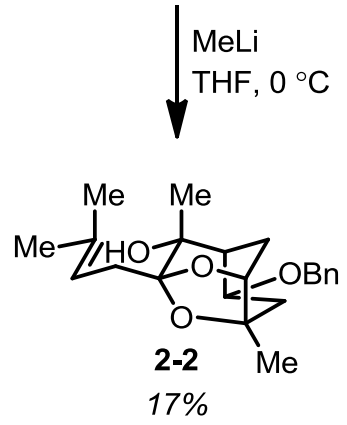

Unfortunately, attempts to procure sufficient advanced material for further study was hindered by inconsistent and debilitating yields in the cycloketalization, the Wittig reaction, and the axial methyl addition.

Larger scale reactions $(>\sim 20 \mathrm{mg})$ the cycloketalization often resulted in unidentified products and little to none of the desired diol. It was hypothesized that incomplete mixing of the aqueous-organic biphase was responsible for this failure. The problem of incomplete mixing derailing a ketalization had previously been observed in this lab during the total synthesis of Milbemycin $\beta_{3},{ }^{43}$ and was overcome by exposing the biphasic $\mathrm{CH}_{2} \mathrm{Cl}_{2} / \mathrm{H}_{2} \mathrm{O}$ solution to ultrasonic irradiation in order to maximize mixing. This strategy was adopted and allowed for the consistent formation of diol 2-128 in high yields (Scheme 2.34). 


\section{Scheme 2.34: Formation of prenyl 2-131 through cross-metathesis.}
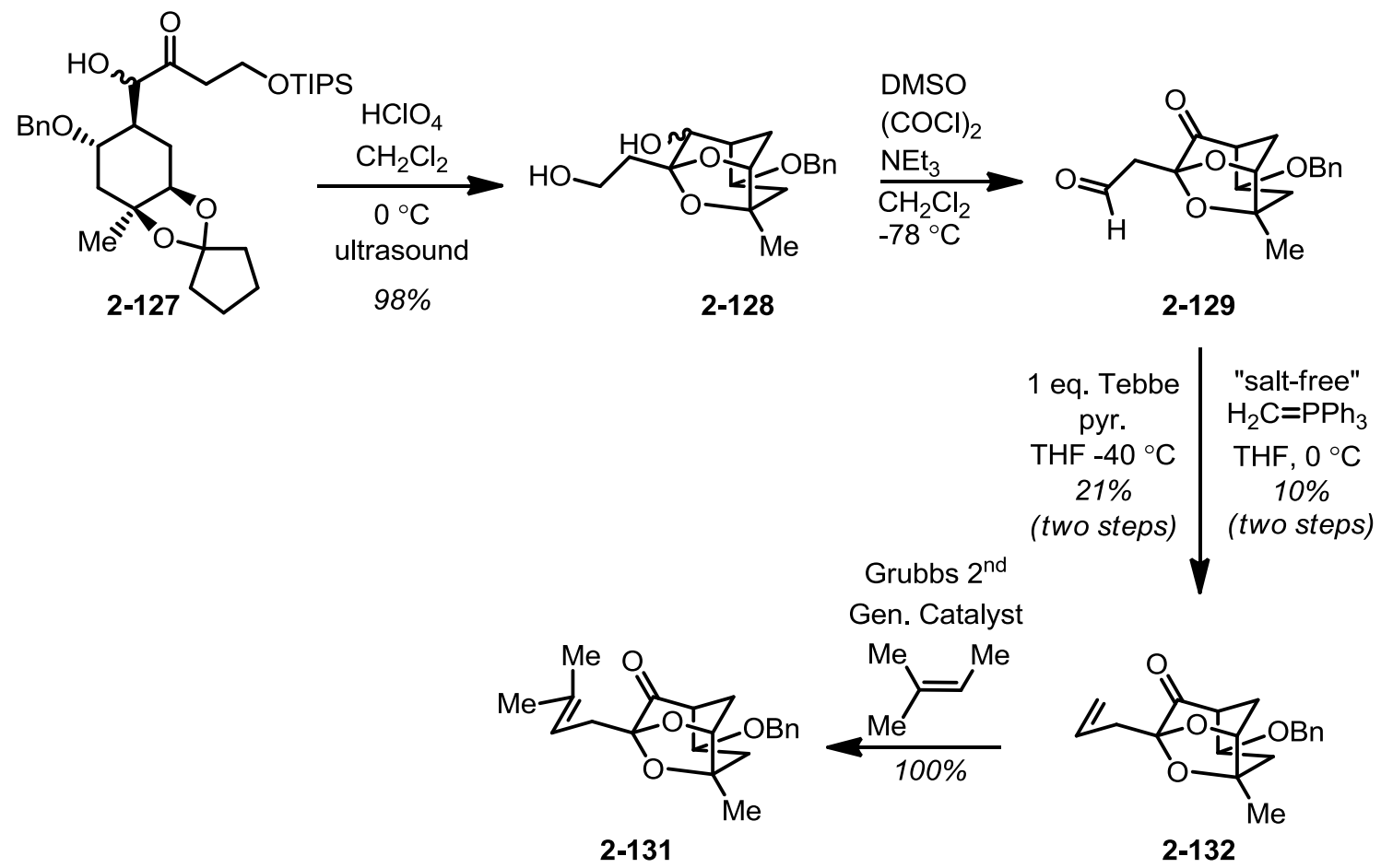

The troubling Wittig proved more challenging to solve. Attempts were made to overcome low (often $0 \%$ ) Wittig yields by changing equivalents, purity of the salt, ${ }^{43}$ base, and salt conditions, ${ }^{44}$ to no avail. An alternate strategy was explored to form a terminal olefin, with which a cross-metathesis could be performed to install the prenyl group. Methylenations with both the methylene Wittig (salt, and salt-free versions) and Tebbe reagent formed the desired terminal olefin 2-132, albeit in low yields. This olefin cleanly underwent cross-metathesis in neat 2-methyl-2-butene by the method of Grubbs ${ }^{46}$ to yield the trisubstituted olefin 2-131.

It was postulated that two factors could negatively affect the methylenation. One, perhaps the $\mathrm{C} 7$ ketone was adversely affecting the reactions. Two, perhaps elimination at C9 was leading to decomposition. 
The hypothesis that the presence of the $\mathrm{C} 7$ ketone was responsible for the low yielding olefinations was tested by quickly synthesizing aldehyde 2-136 which when combined with the "salt-free" methylene Wittig reagent led to decomposition (Scheme 2.35).

\section{Scheme 2.35: Attempt to circumvent Wittig troubles.}

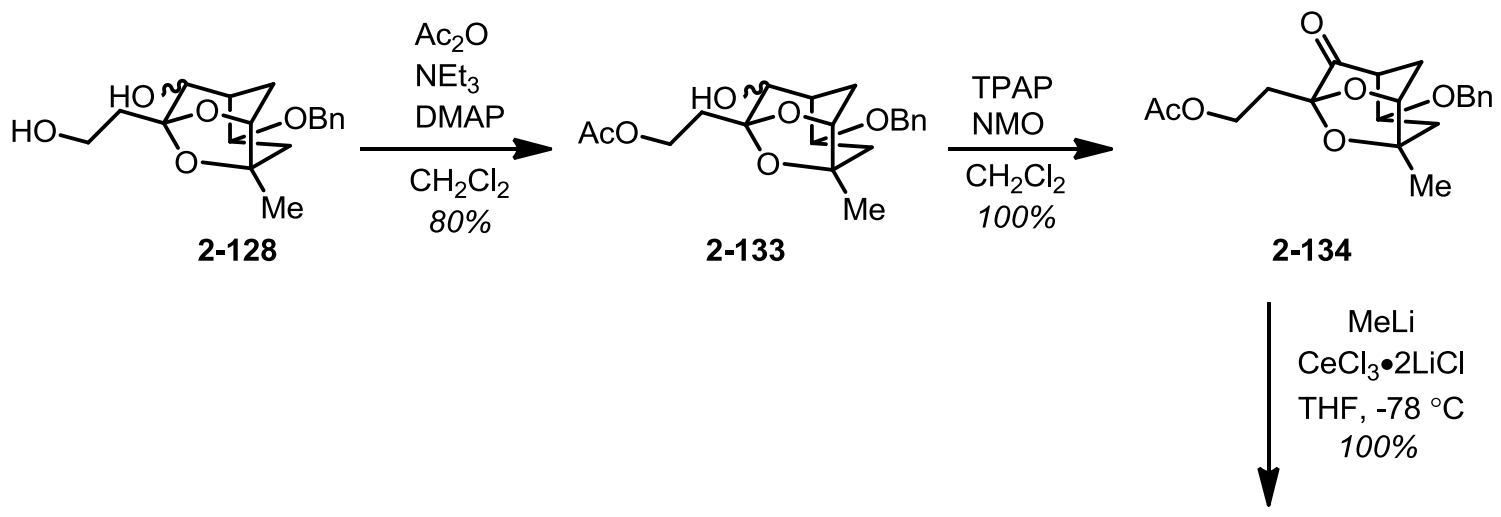

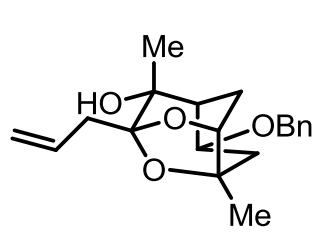

2-137

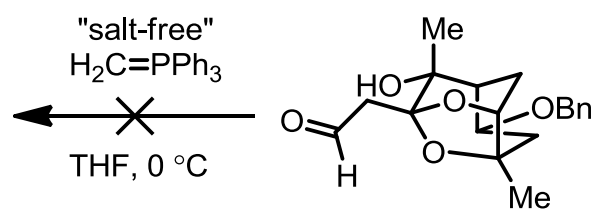

2-136

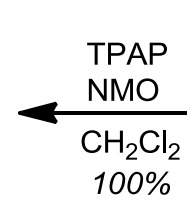

00\%

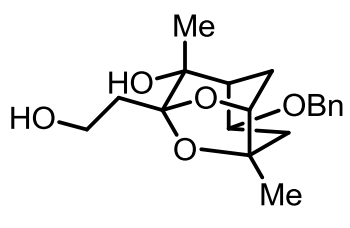

2-135

The hypothesis that the basic nature of the olefination reagents attempted (Tebbe/Wittig) was causing an elimination event which led to decomposition was tested by the selection of an electrophilic methylenation reagent. Initially, the electrophilic Lombardo reagent ${ }^{47}$ was selected, however Professor Simon Meek suggested utilizing the superficially similar - and commercially available - Nysted reagent (2-138), ${ }^{48}$ which is known to be chemoselective for aldehydes in the presence of ketones when $\mathrm{BF}_{3} \cdot \mathrm{OEt}_{2}$ is utilized in the reaction in lieu of $\mathrm{TiCl}_{4}{ }^{49}$ Though neither the mechanism nor the active species is known, (and thus the 
electrophilicity/nucleophilicity of the active species remains unclear), the Nysted reagent did lead to an improved yield of terminal olefin 2-132 (Scheme 2.36).

\section{Scheme 2.36: Utilization of the Nysted reagent.}
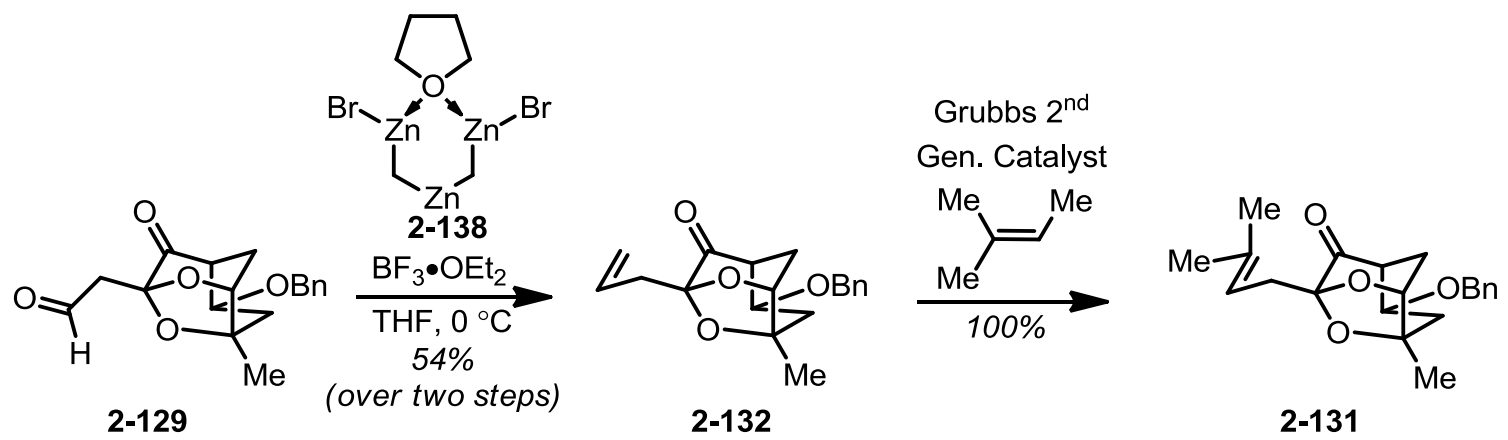

The axial methyl addition to the $\mathrm{C} 7$ ketone was re-explored in the hopes of improving the yield. It was observed that addition of MeLi to carbonyl 2-131 led to desired alcohol 2-2 as a minor product, the major product being diene 2-140. Two pathways could be proposed for the formation of this major product, either elimination of $\mathrm{H} 9$ by methyl anion or the $\mathrm{C} 7$ alkoxide formed after initial methyl addition forming 2-139 (Scheme 2.37).

Scheme 2.37: Potential pathways to form elimination product 2-140.

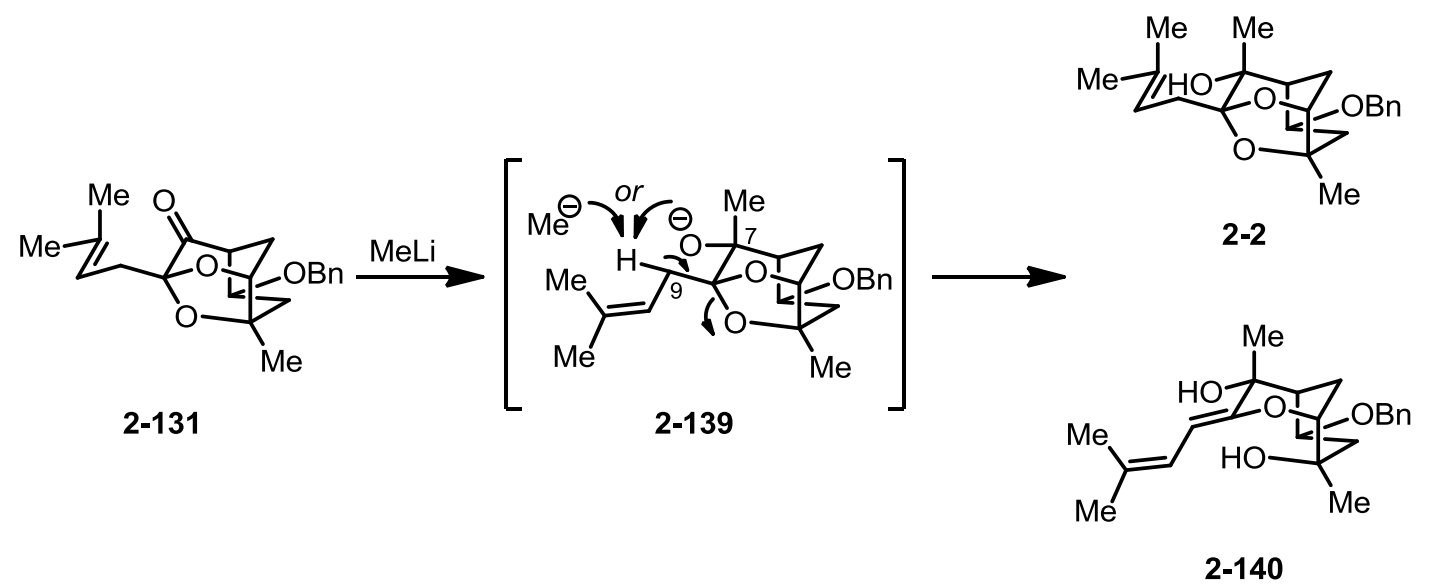

As before when a nucleophilic addition resulted in undesired elimination, the additive cerium trichloride was tested (Scheme 2.38). When the ketone was pre- 
complexed with $\mathrm{CeCl}_{3} \cdot 2 \mathrm{LiCl}$ and MeLi was added (method $\mathrm{B}$, vide supra), the only product observed was the elimination product 2-140. It was speculated that utilization of one equivalent of $\mathrm{MeLi}$ in conjunction with $\mathrm{CeCl}_{3} \cdot 2 \mathrm{LiCl}$ would avoid the formation of the elimination product. Interestingly, when the MeLi was pre-mixed with a THF solution of $\mathrm{CeCl}_{3} \cdot 2 \mathrm{LiCl}$ (method $\mathrm{A}$, vide supra) before addition to a solution of ketone 2-131 in $\mathrm{THF} / \mathrm{CeCl}_{3} \cdot 2 \mathrm{LiCl}$, the only product was the desired alcohol $2-2$, even when a large excess of the methylating agent was utilized, indicating (at least in this case) divergent reactivity of the two methods.

\section{Scheme 2.38: Cerium trichloride to prevent elimination.}

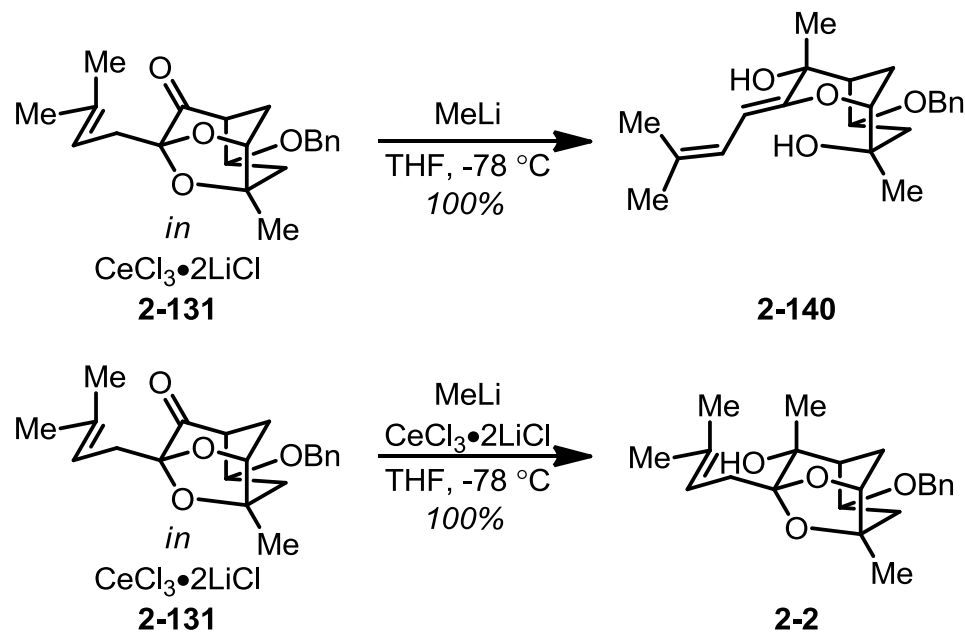

When alcohol 2-2 was treated with TBCO (2-113) in the dark, a mixture of the desired tetrahydropyran $\mathbf{2 - 1 4 1}(21 \%)$ and undesired tetrahyrdofurans (30\%) resulted, only separable by the use of HPLC (Scheme 2.39). The desired THP was identified by the characteristic coupling constants of 4.2 and $13.2 \mathrm{~Hz}$ of the newly formed $d d$ at $4.3 \mathrm{ppm}$, data characteristic of an axial proton on the carbon bearing the bromine atom in a tetrahydropyran $(\mathrm{H} 10) .{ }^{50}$ Additional confirmation came from several new expected NOESY correlations on the THP (H10-Me12, H9ß-Me13/14, 
Me13-Me14), as well as the expected (and previously observed) tricyclic nOe correlations. The benzyl protecting group was easily removed through palladiummediated hydrogenation to provide the assigned structure of aldingenin $B$ in 16 steps and $2.7 \%$ overall yield. Unfortunately, the ${ }^{1} \mathrm{H}$ NMR and ${ }^{13} \mathrm{C}$ NMR spectra of this material did not match the NMR spectra of the natural sample (Table $2.4 ;{ }^{1} \mathrm{H}$ NMR, ${ }^{13} \mathrm{C}$ NMR, COSY, HMBC, and HMQC spectra graciously provided by Professor João H. G. Lago upon request), raising the question of whether the structure of the natural sample was misassigned and/or if synthetic 2-1 and/or previous structures along the synthetic pathway were misidentified.

Scheme 2.39: Completion of the final ring and protecting group removal.

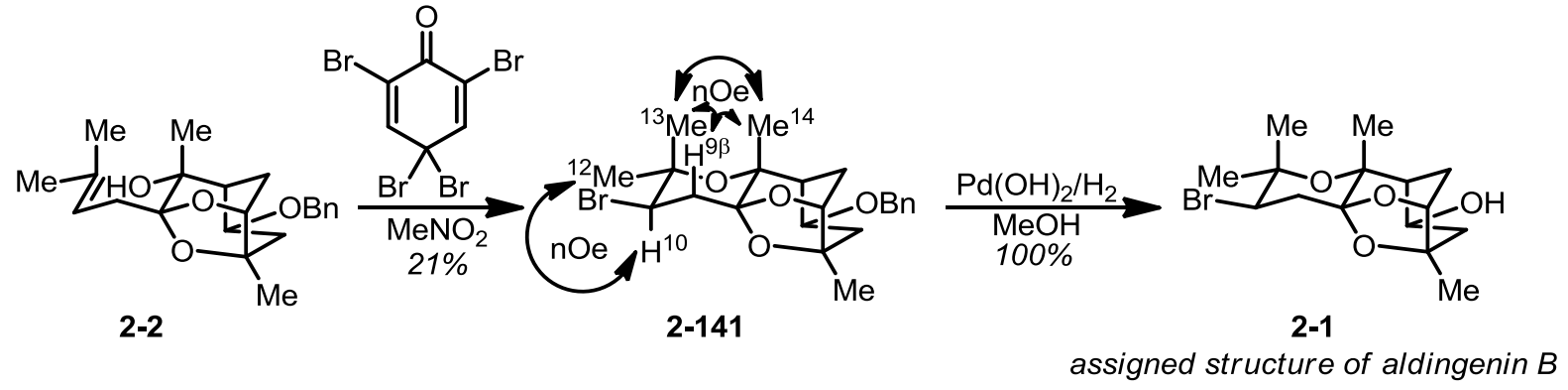

\section{Comments on the misassignment of the structure of the natural product and evidence for the synthesis of the proposed structure.}




\section{Table 2.4: Comparison of ${ }^{1} \mathrm{H},{ }^{13} \mathrm{C}$ NMR assignments between natural and}

\section{synthetic 2-1.}

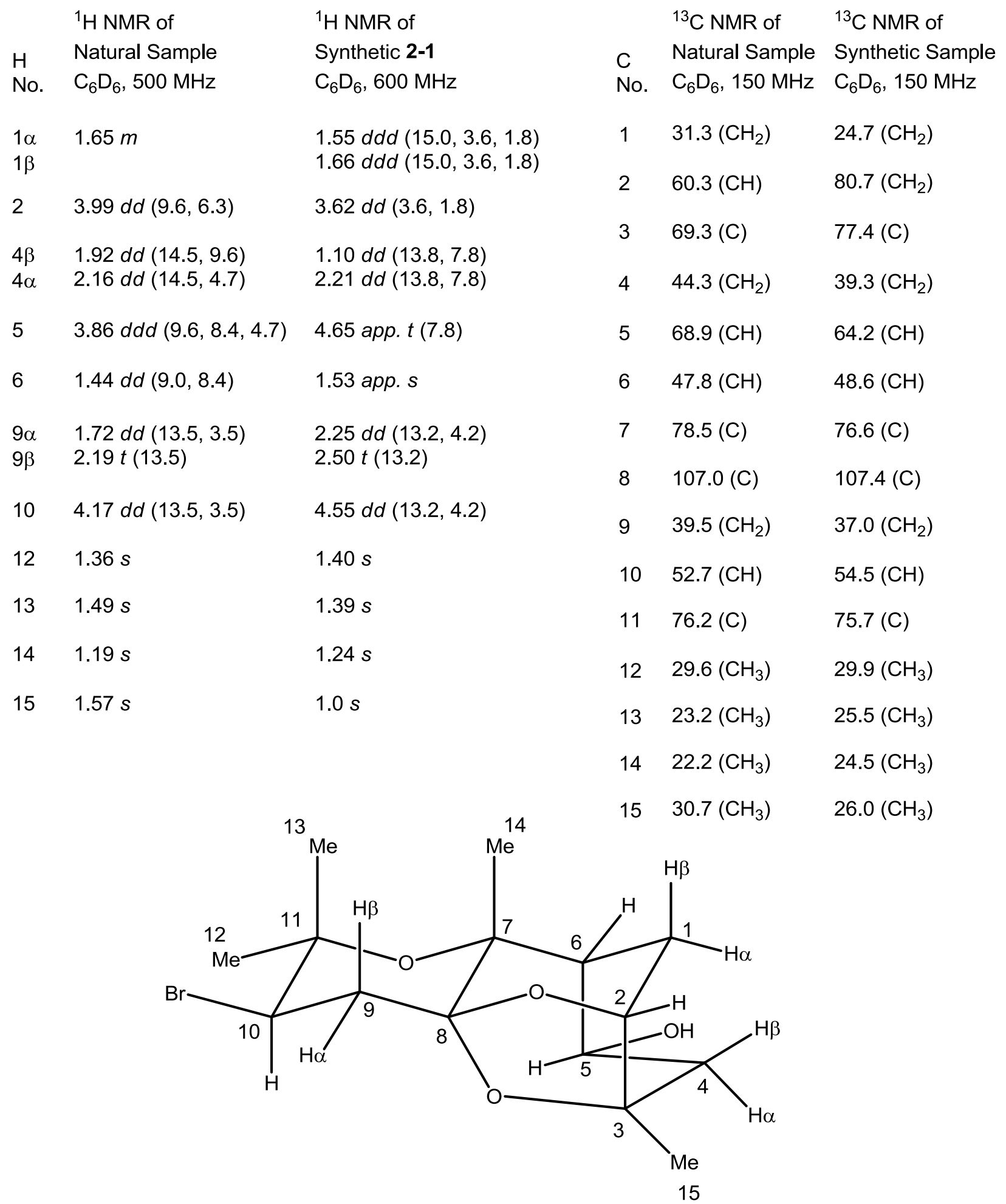


(i) Spectral differences between synthetic 2-1 and assigned (natural) 2-1

Inspection of the various NMR spectra of synthetic 2-1 and aldingenin B reveal several differences in the spectra of the natural sample and the synthetic sample. Additionally, the reported spectra of the natural sample and the expected spectra of the assigned structure bear some inconsistencies. Four key spectral signals stand out and call into question the validity of the assigned structure from the natural sample. Discussion below will focus on the $\mathrm{H} 2, \mathrm{H} 5, \mathrm{H} 6$ and $\mathrm{C} 2$ resonances in the ${ }^{1} \mathrm{H}$ NMR and argue in defense of the thesis that the assigned structure was synthesized and the mismatch of spectra is due to the misassignment of the structure of the natural sample.

a) $1 \mathrm{D}{ }^{1} \mathrm{H}$ NMR spectra

The most obvious ${ }^{1} \mathrm{H}$ NMR spectral difference between synthetic 2-1 and the natural sample is in the carbinol range ( 3-5 ppm). Both the splitting patterns and chemical shifts of $\mathrm{H} 5$ and $\mathrm{H} 2$ are significantly different in the two spectra (Figure 2.10, Figure 2.11). The $\mathrm{H} 5$ signal in the natural sample is a $d d d$ at $3.86 \mathrm{ppm}$; in the synthetic sample it is an apparent $t$ at $4.6 \mathrm{ppm}$ (both in $\mathrm{C}_{6} \mathrm{D}_{6}$ ). More interesting is the case of $\mathrm{H} 2$. The isolation chemists report this signal as a $d d(J=9.6,6.3 \mathrm{~Hz})$ at 3.99 ppm in the isolation paper for aldingenin B, compared to the observation of a $d d(\mathrm{~J}=$ 3.6, $1.8 \mathrm{~Hz}$ ) at $3.62 \mathrm{ppm}$ for synthetic 2-1. Visual inspection of the full ${ }^{1} \mathrm{H}$ NMR spectrum of the natural product reveals a much more interesting picture. Absent any exotic higher-order coupling, the splitting pattern of $\mathrm{H} 2$ is clearly not a $d d$. It most closely resembles a triplet centered amongst a doublet; however it integrates at one proton thus eliminating the possibility of the peak being two overlapping protons. 
Furthermore, the peak assigned as $\mathrm{H} 2$ also possesses outer wings which are not satellite peaks since there is a complete absence of similar wings on any other peaks in the spectra. This is a truly puzzling coupling pattern for which no clear rational exists. Another ${ }^{1} \mathrm{H}$ NMR spectral peak which differs significantly is the signal for H6. The reported assignment is a dd with coupling constants of 9.0 and $8.4 \mathrm{~Hz}$ (coupled to $\mathrm{H} 5$ and, presumably, $\mathrm{H} 1$ ). In the synthetic spectra it is an apparent singlet, though it may have a very small coupling. 
Figure 2.10: Carbinol range of natural sample.

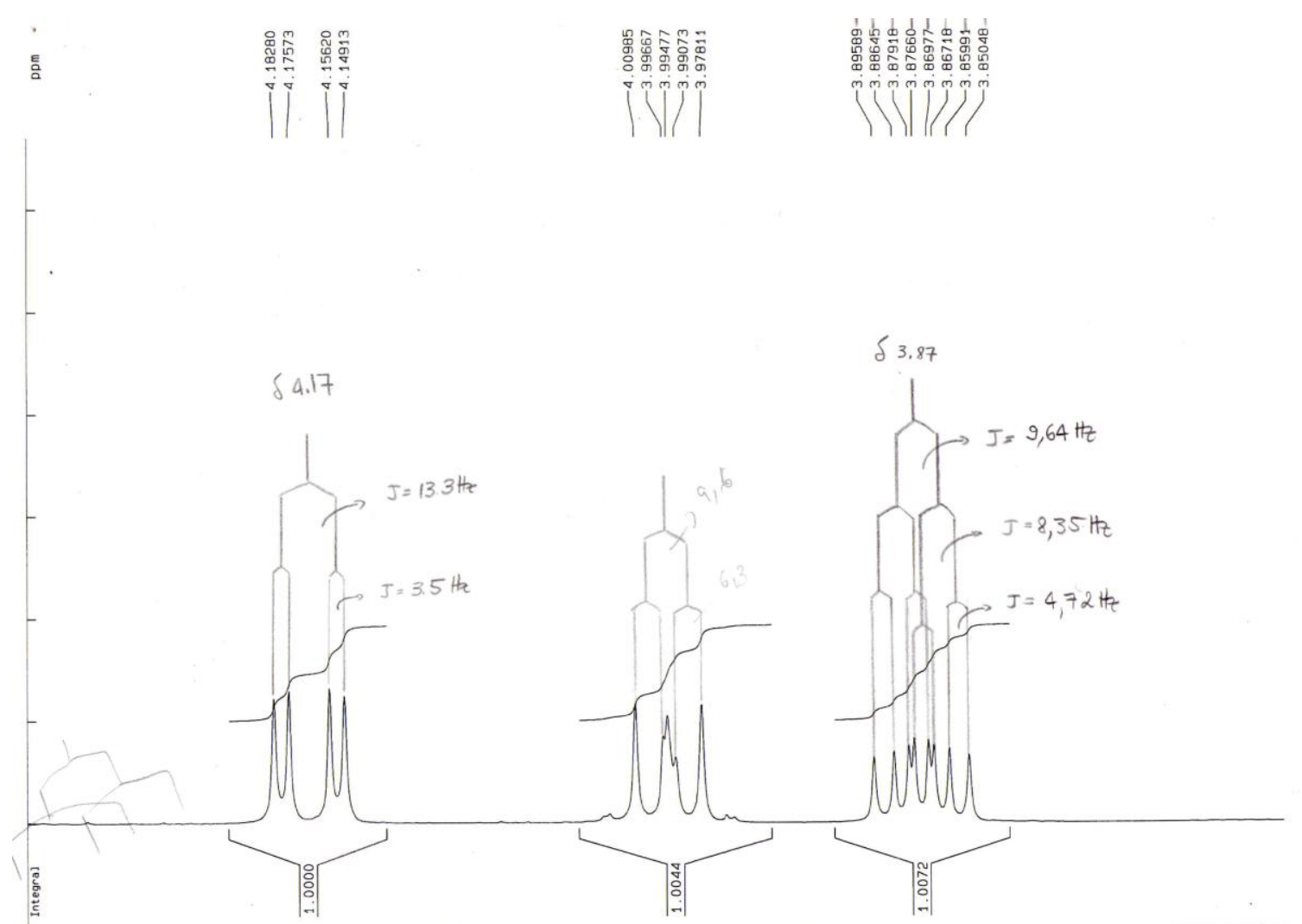

Figure 2.11: Carbinol range of selected synthetic tricyclic compounds.

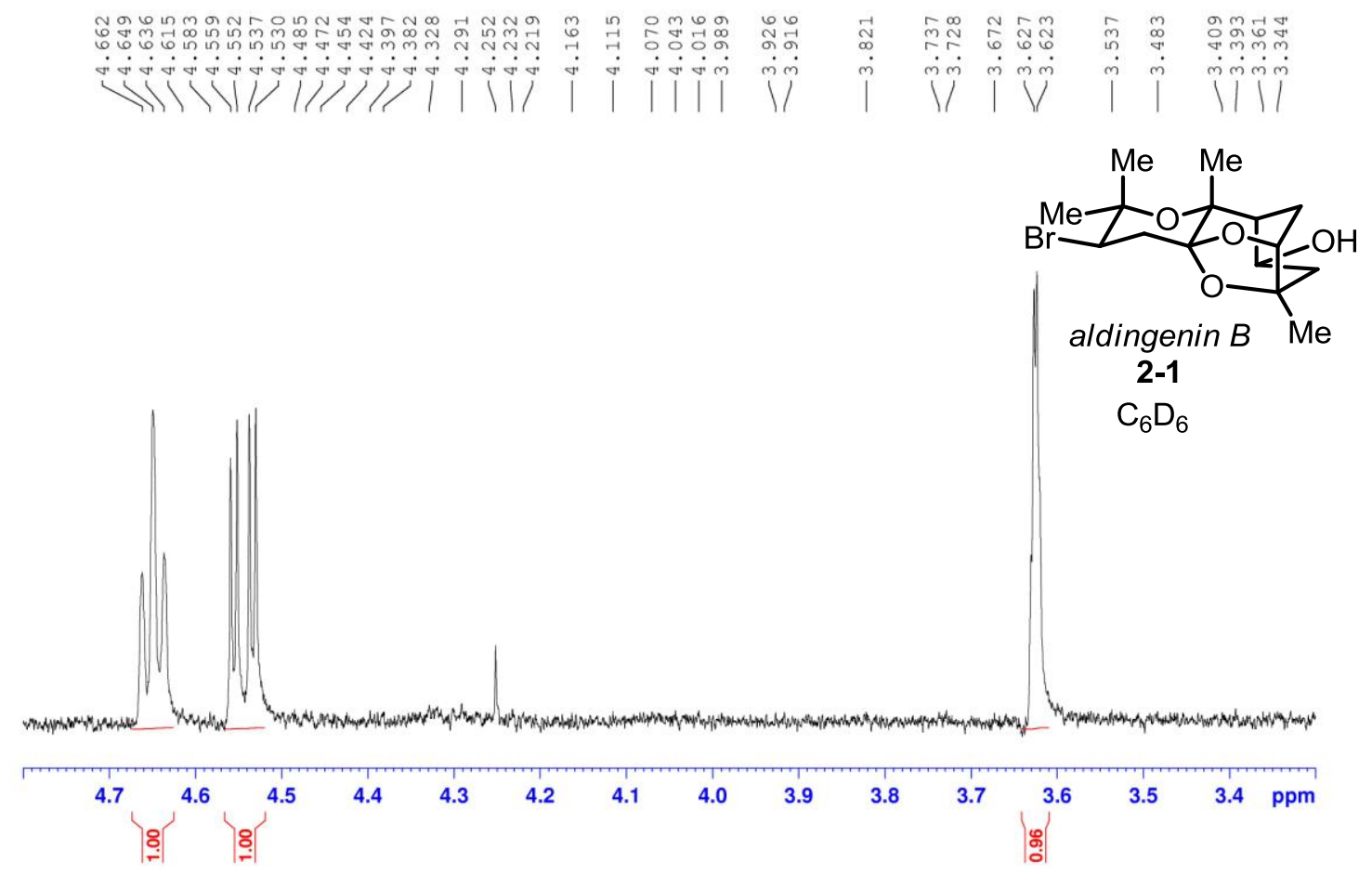




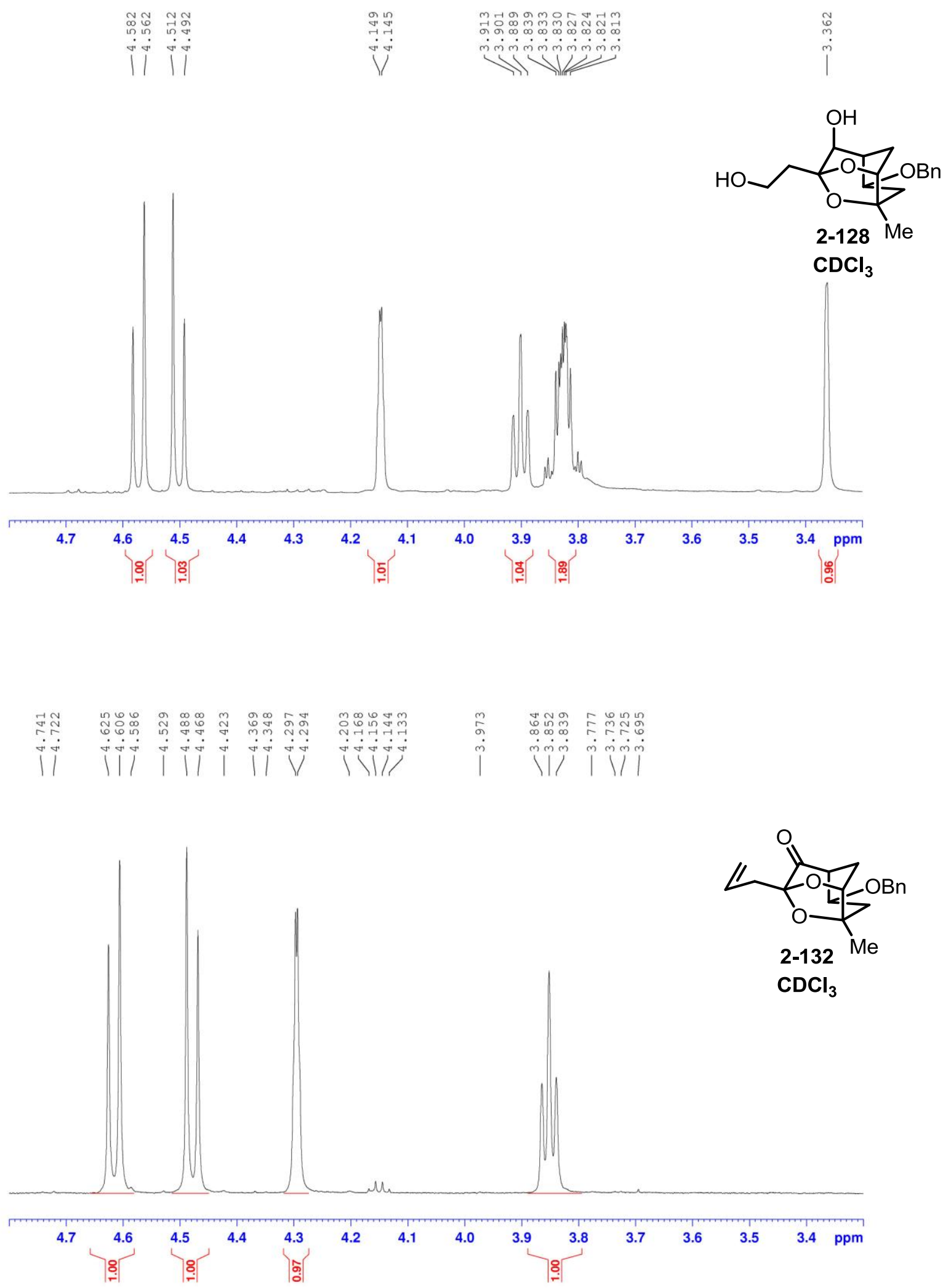




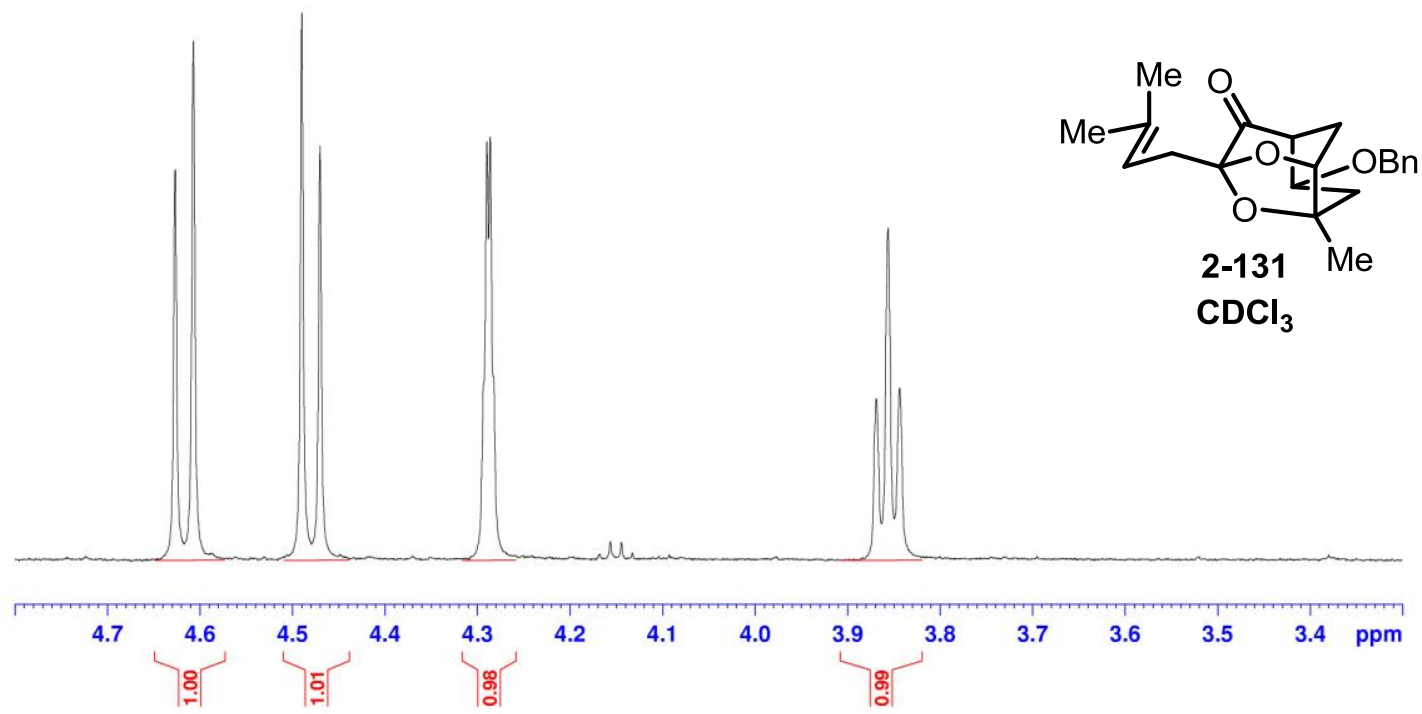
$\mathrm{CDCl}_{3}$
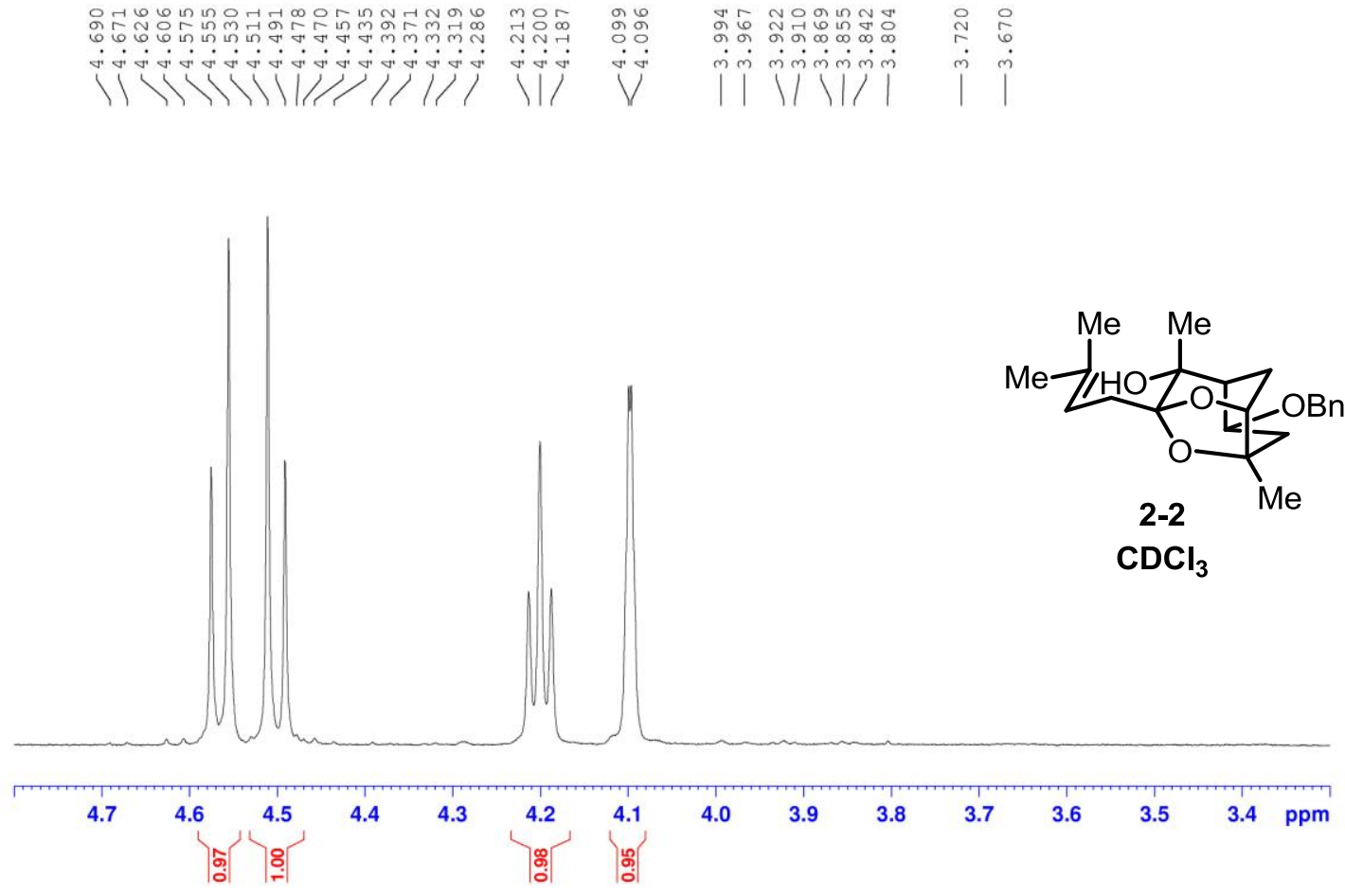

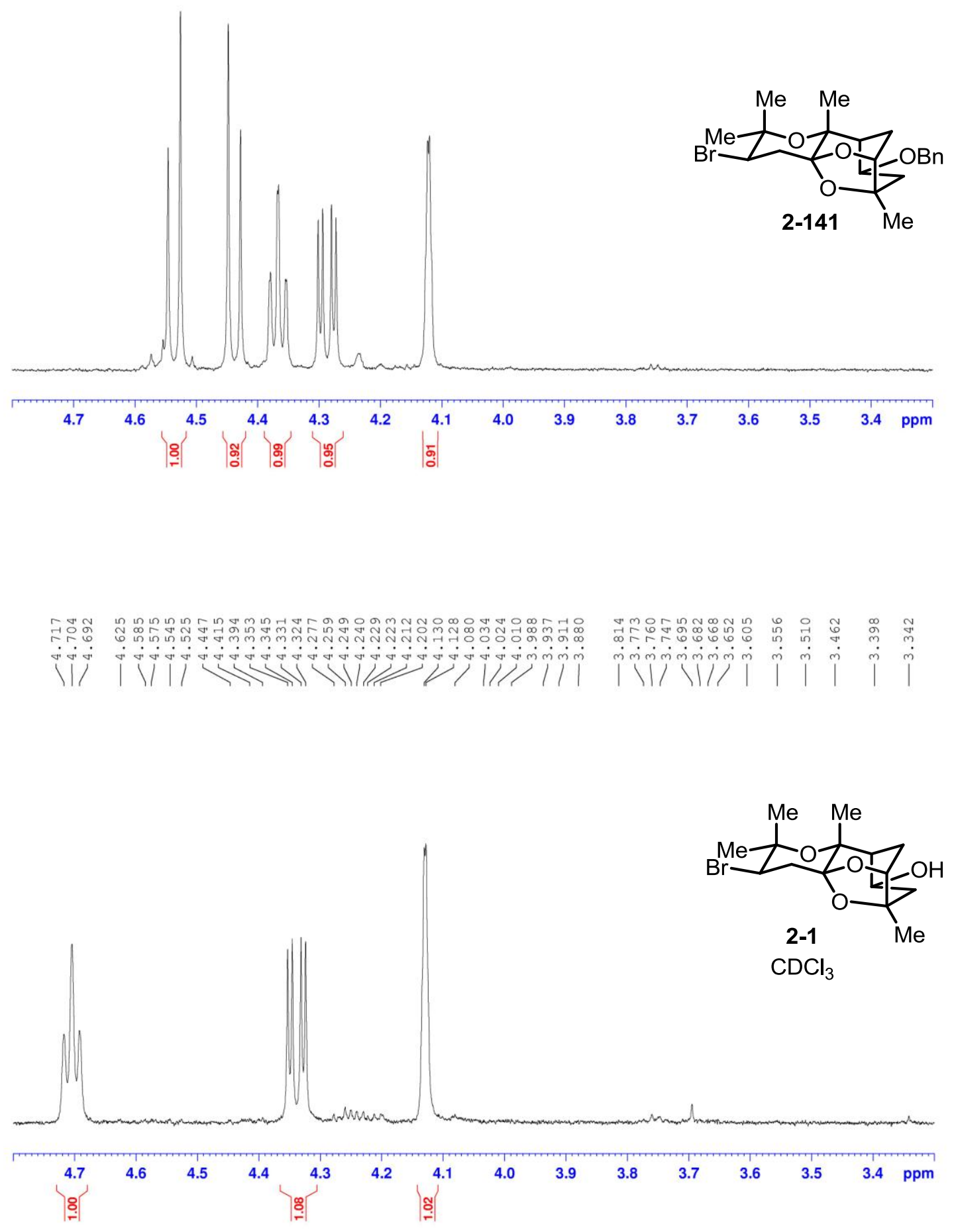
b) $\mathrm{H} 6 / \mathrm{H} 5$ coupling and ramifications for the splitting pattern of $\mathrm{H} 5$

Visual inspection of both physical and computer models of 2-1 reveals the $\mathrm{H} 6-\mathrm{H} 5$ dihedral angle to be $90^{\circ}\left( \pm 2^{\circ}\right)$. Given that the Karplus equation/curve predicts a low to nonexistent $(<2 \mathrm{~Hz})$ coupling between such vicinally orthogonal protons, immediate questions are raised about the validity of the structural assignment given the $\mathrm{H} 5$ signal as a $d d d(J=9.6,8.4,4.7 \mathrm{~Hz})$ considering the claimed coupling between $\mathrm{H} 6-\mathrm{H} 5$ at $8.4 \mathrm{~Hz}$. The expected splitting pattern of the $\mathrm{H} 5$ signal should be an app. $t$, $d d$, or at best, a $d d d$ with one small $(<2 \mathrm{~Hz})$ coupling constant. It is noteworthy that $\mathrm{H} 5$ in synthetic $\mathbf{2 - 1}$ is an apparent $t$, and there is no detected $\mathrm{H} 5-\mathrm{H} 6$ splitting in the COSY spectrum, further strengthening the argument that synthetic efforts were successful in creating 2-1.

c) $\mathrm{H} 6$ and $\mathrm{H} 2$ couplings

The signal for the bridgehead protons $\mathrm{H} 6$ and $\mathrm{H} 2$ also deserve further comment. Given the small coupling constants of cyclohexane equatorial protons ( 2$3 \mathrm{~Hz}),{ }^{51}$ and the small coupling constants of similar bridgehead protons in general (adamantane bridgehead coupling: $2.6 \mathrm{~Hz}^{52}$ ), it is very unlikely that both $\mathrm{H} 6$ and $\mathrm{H} 2$ would have two large coupling constants as reported by the isolation chemists (9.0, 8.4 and 9.6, 6.3 Hz respectively). More likely, the signals for $\mathrm{H} 6$ and $\mathrm{H} 2$ would have 1,2 , or 3 very small couplings (from W-coupling), consistent with what is observed in the spectra of synthetic 2-1.

Further strengthening the argument that the signals for $\mathrm{H} 6$ and $\mathrm{H} 2$ should resemble singlets is the work of Professor Greg Dudley at Florida State University (Figure 2.12). In published work on the synthesis of the tricyclic core of aldingenin 
$\mathrm{B},{ }^{53}$ the ${ }^{1} \mathrm{H}$ NMR signal for $\mathrm{H} 6$ on ketone 2-142 appears as a singlet at $2.93 \mathrm{ppm}$ while the signal for $\mathrm{H} 2$ appears as a singlet at $4.26 \mathrm{ppm}$, which is consistent with the spectra displayed by herein reported tricycles 2-132 (H6: br. s, 2.97 ppm, H2: d, $J=$ $1.8 \mathrm{~Hz}, 4.29 \mathrm{ppm}$ ) and 2-131 (H6: br. s, 2.96 ppm, H2: d, J = 2.4 Hz, 4.29 ppm) (Figure 2.12). Professor Dudley kindly shared spectral data on previouslyundisclosed tricycles 2-143 and 2-144, both of which display similar resonance for $\mathrm{H6}$, data which again strengthens the claim that, at the very least, the syntheses of tricycles 2-132, 2-131 and 2-145 ${ }^{54}$ were successful.

Figure 2.12: Three tricycles synthesized by Dudley and co-workers and ${ }^{1} \mathrm{H}$ NMR data for $\mathrm{H} 6 / \mathrm{H} 2$ and comparison to 2-132/2-131/2-145.

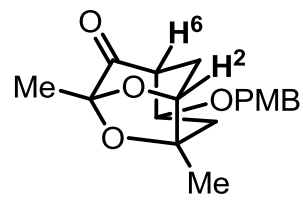

2-142

H6: br. s, 2.93 ppm $\mathrm{H} 2: s, 4.26 \mathrm{ppm}$

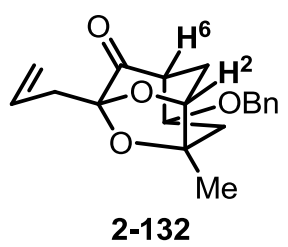

H6: br. s, 2.97 ppm H2: $d, J=1.8 \mathrm{~Hz}, 4.29 \mathrm{ppm}$

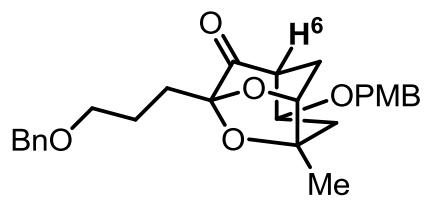

2-143

H6: br. s, 2.98 ppm

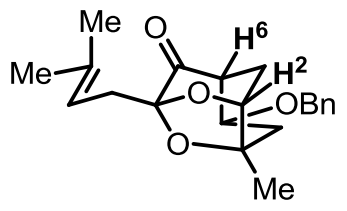

2-131

H6: br. s, 2.96 ppm $\mathrm{H} 2: d, J=2.4 \mathrm{~Hz}, 4.29$ ppm

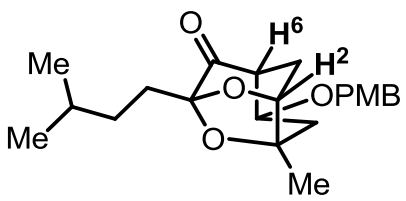

2-144

H6: br. s, 2.91 ppm $\mathrm{H} 2: d, J=2.2 \mathrm{~Hz}, 4.23 \mathrm{ppm}$

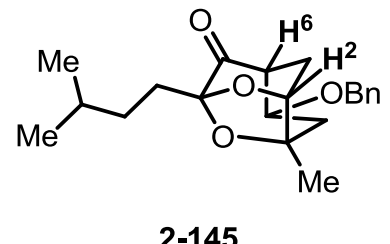

H6: br. s, 2.92 ppm $\mathrm{H} 2: d, J=1.8 \mathrm{~Hz}, 4.24$ ppm 


\section{d) 2-D NMR}

COSY and NOESY spectra also support the assigned structure of synthetic 21 (Figure 2.13). COSY spectra show strong correlations between $\mathrm{H} 5-\mathrm{H} 4 \beta, \mathrm{H} 5-\mathrm{H} 4 \alpha$, $\mathrm{H} 10-\mathrm{H} 9 \beta, \mathrm{H} 10-\mathrm{H} 9 \alpha, \mathrm{H} 2-\mathrm{H} 1 \alpha, \mathrm{H} 9 \alpha-\mathrm{H} 9 \beta, \mathrm{H} 4 \beta-\mathrm{H} 4 \alpha$, and $\mathrm{H} 1 \alpha-\mathrm{H} 1 \beta$, as would be

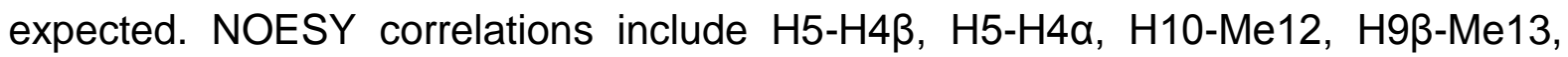

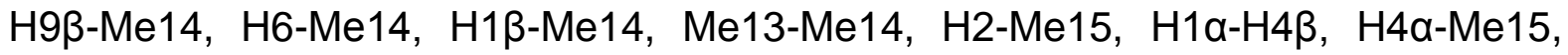
$\mathrm{H} 4 \beta-\mathrm{Me} 15, \mathrm{H} 10-\mathrm{H} 9 \beta$, and $\mathrm{H} 10-\mathrm{H} 9 \alpha$, as would be expected. Comparisons to the COSY and NOESY spectra of the natural sample are difficult due to the nonavailability of the NOESY, and the poor quality of the provided COSY spectra. The isolation paper claims all the COSY correlations found in the synthetic sample, with the addition of $\mathrm{H} 6-\mathrm{H} 5$, however it remains unclear how these were determined if the data provided was indeed the data the authors utilized in their structural elucidation (see Natural Sample COSY on p. 199-201).

Figure 2.13: Select key COSY (top) and NOESY (bottom) correlations of synthetic 2-1.

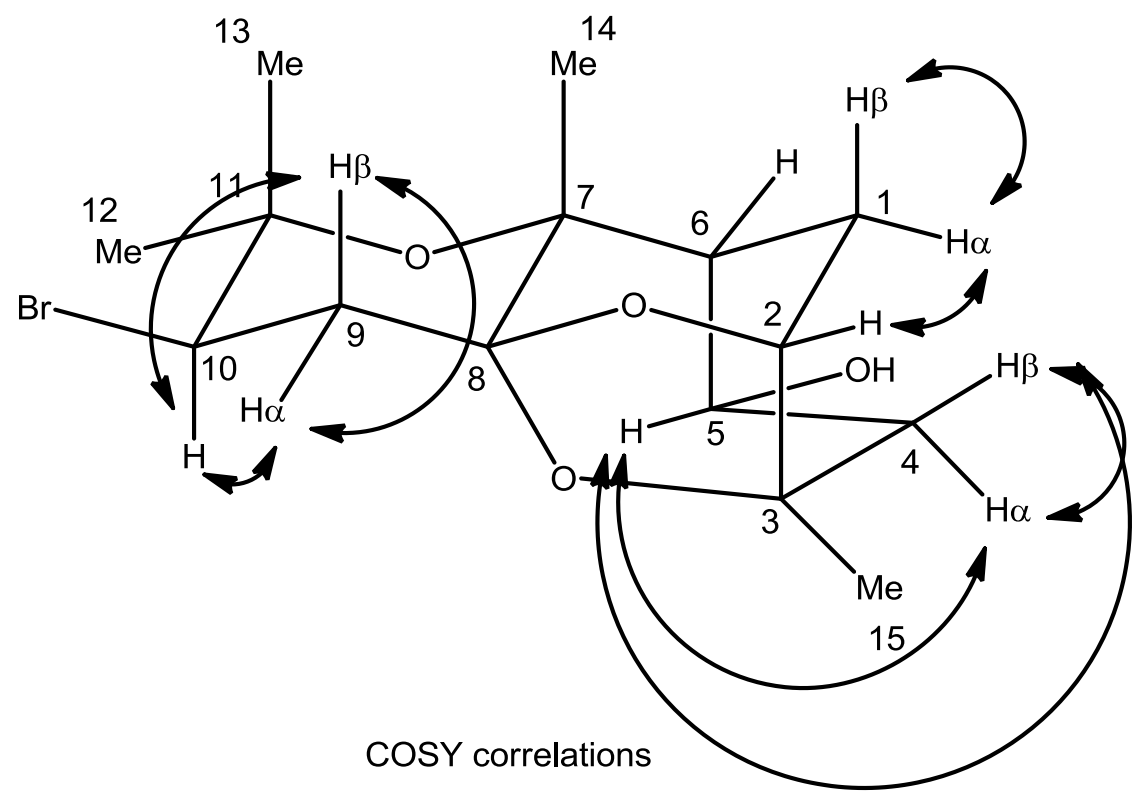




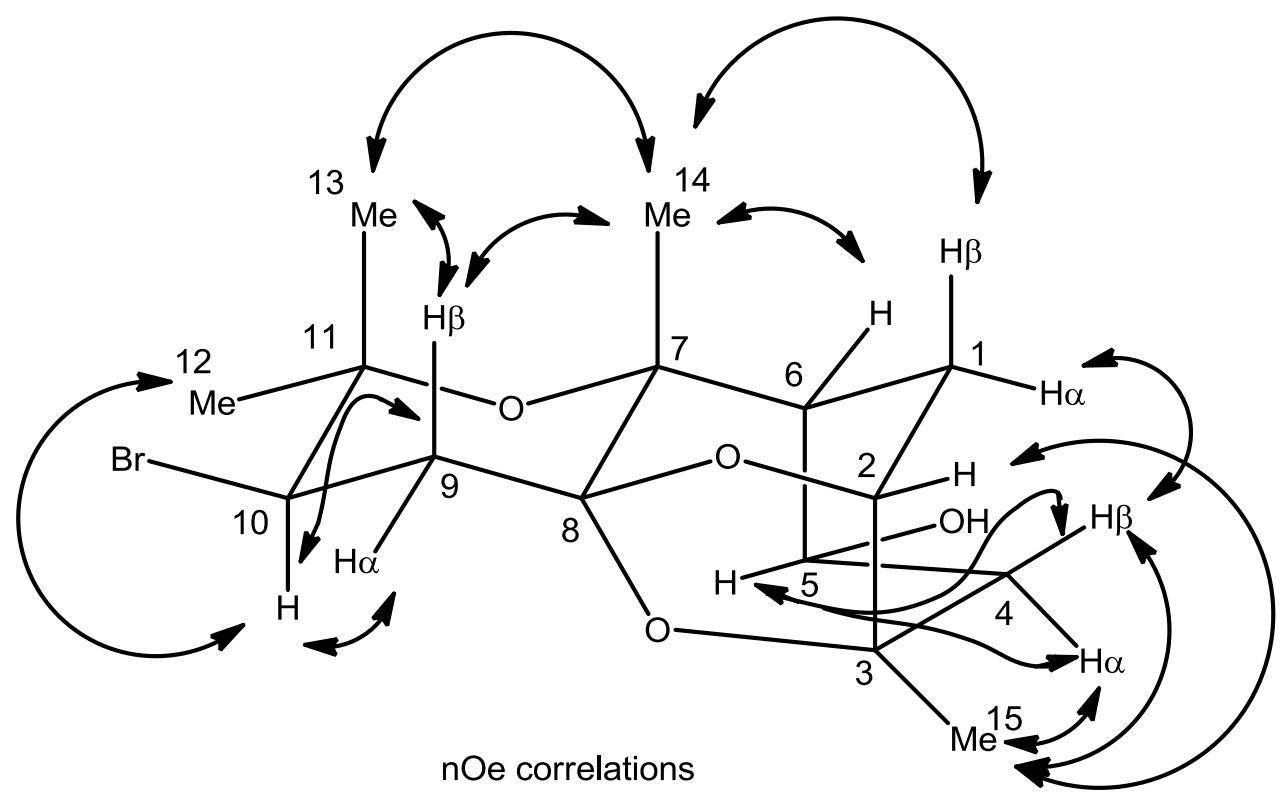

e) HMBC and HMQC spectra

Several discrepancies exist between the supplied HMBC of the natural sample and claimed correlations in the published work (Table 2.5). The authors neither claim, nor does their data support, an H2-C8 HMBC correlation, a key peak observed in the HMBC spectrum of synthetic 2-1, which again strengthens the case that synthetic $\mathbf{2 - 1}$ is the assigned structure of aldingenin $B$, and the assigned structure is not the actual structure of the natural product. 
Table 2.5: HMBC data, authors claim, what the data indicates, and comparison to synthetic sample.

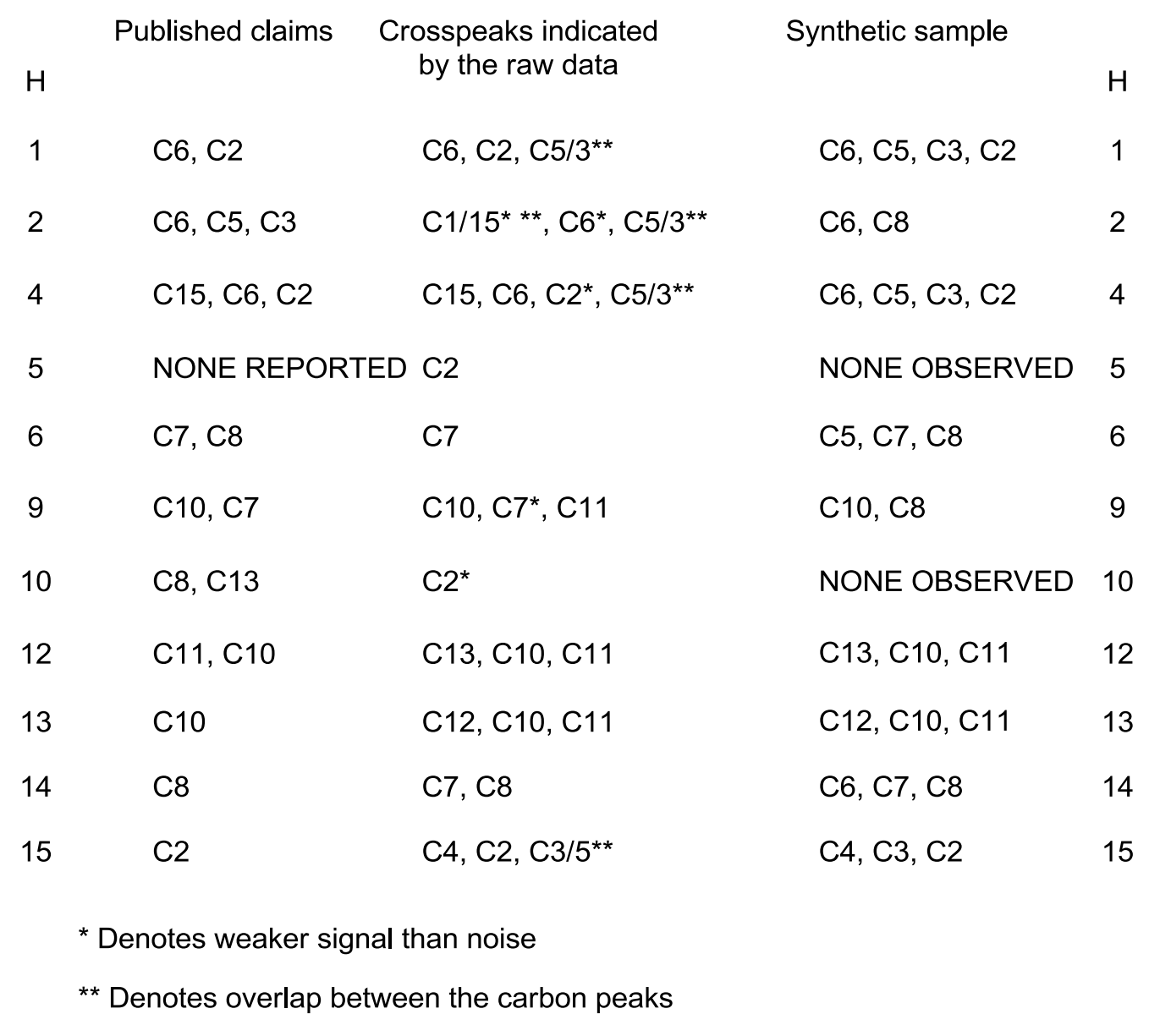

f) Review of identification of selected structures

Given that all the spectral data collected on synthetic 2-1 is consistent with both expectations and the proposed structure, and the provided and published data is not, it is reasonable to assume that structure of synthetic $\mathbf{2 - 1}$ is identical to the proposed structure of aldingenin $\mathrm{B}$, and the proposed structure was misassigned (Figure 2.14). However, before this claim can be formally staked, it is prudent to review structural data on prior compounds in the synthesis of 2-1 (Figure 2.15). 
Figure 2.14: Summary of key evidence against Lago's assignment and for the structure of synthetic 2-1.

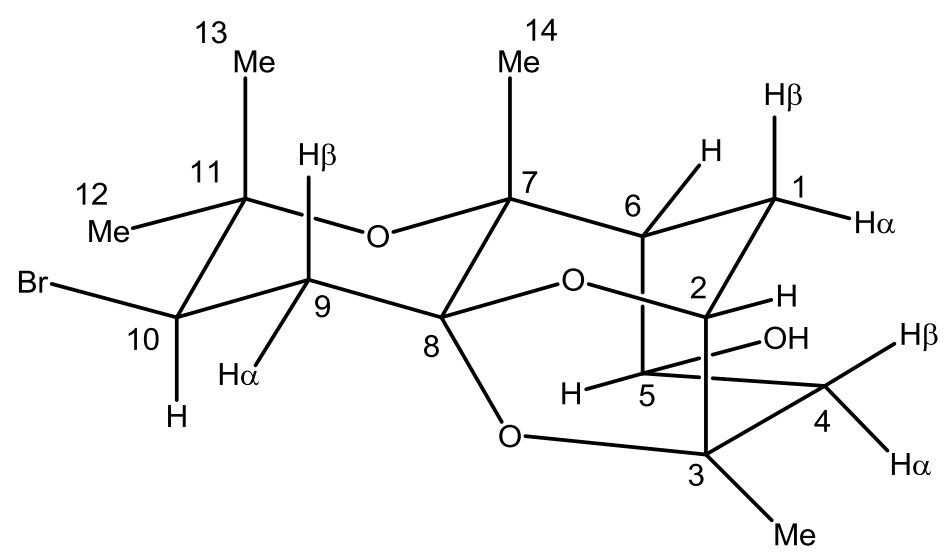

15

\begin{tabular}{|c|c|c|}
\hline $\begin{array}{l}\text { Data raising suspicion against } \\
\text { the assigned structure for the } \\
\text { natural sample: }\end{array}$ & Reasons for suspicion & $\begin{array}{l}\text { Data supportive of the } \\
\text { thesis that the structure of } \\
\text { synthetic } 2-1 \text { is as shown: }\end{array}$ \\
\hline $\begin{array}{l}\text { Large ( } 8.4 \mathrm{~Hz}) \mathrm{H} 6-\mathrm{H} 5 \text { splitting; } \\
\mathrm{H} 5 \text { as a } d d d\end{array}$ & $\begin{array}{l}\text { Large } \mathrm{H} 6-\mathrm{H} 5 \text { splitting impossible; } \\
\text { should be small to non-existant }(<2 \mathrm{~Hz})\end{array}$ & $\begin{array}{r}\text { No } \mathrm{H} 6-\mathrm{H} 5 \text { splitting; } \\
\mathrm{H} 5 \text { is an app. } t\end{array}$ \\
\hline $\begin{array}{l}\text { Large }(9.6-6.3 \mathrm{~Hz}) \mathrm{H} 6 / 2-\mathrm{H} 1 \\
\text { splitting }\end{array}$ & $\begin{array}{l}\text { Large } \mathrm{H} 6 / 2-\mathrm{H} 1 \text { splitting impossible; } \\
\text { should be }<4 \mathrm{~Hz}\end{array}$ & $\begin{array}{r}\text { Small H6/2-H1 splitting } \\
\mathrm{H} 2: 3.6,1.8 \mathrm{~Hz} ; \mathrm{H} 6 \text { : app. } \mathrm{S}\end{array}$ \\
\hline $\begin{array}{l}\text { Lack of HMBC signal } \\
\text { between } \mathrm{H} 2-\mathrm{C} 8\end{array}$ & $\begin{array}{l}\text { Lack of signal may indicate } \\
\text { absence of } \mathrm{H} 2-\mathrm{O}-\mathrm{C} 8 \text { bond linkage }\end{array}$ & $\begin{array}{r}\text { Presence of } \mathrm{HMBC} \mathrm{H}_{2}-\mathrm{C} 8 \\
\text { signal }\end{array}$ \\
\hline
\end{tabular}


Figure 2.15: Sampling of select observed NMR data compared to unobserved data, to weaken arguments against assigned structures.

a) Anti-aldol forming 2-7, then 2-91.



The structure of aldol adduct 2-7 was confirmed by the $J$ values of $\mathrm{H} 5_{\mathrm{ax}}-\mathrm{H} 6_{\mathrm{ax}}$. and $\mathrm{H} 5_{\text {ax. }}-\mathrm{H} 4_{\text {eq./ax. }}$ of $2-91(9.0,3.0,10.8 \mathrm{~Hz}$ respectively), as expected for the structure drawn. If syn-aldol adduct 2-25 were the major product, then all H5 couplings in 2-146 would be $\sim 4 \mathrm{~Hz}$. As this is not the case, and the expected $J$ values of $\mathrm{H} 5$ in 2-91 are observed, the major product of the aldol addition is the antiisomer 2-7. 


\section{b) Syn-dihydroxylation forming 2-30 then 2-91.}

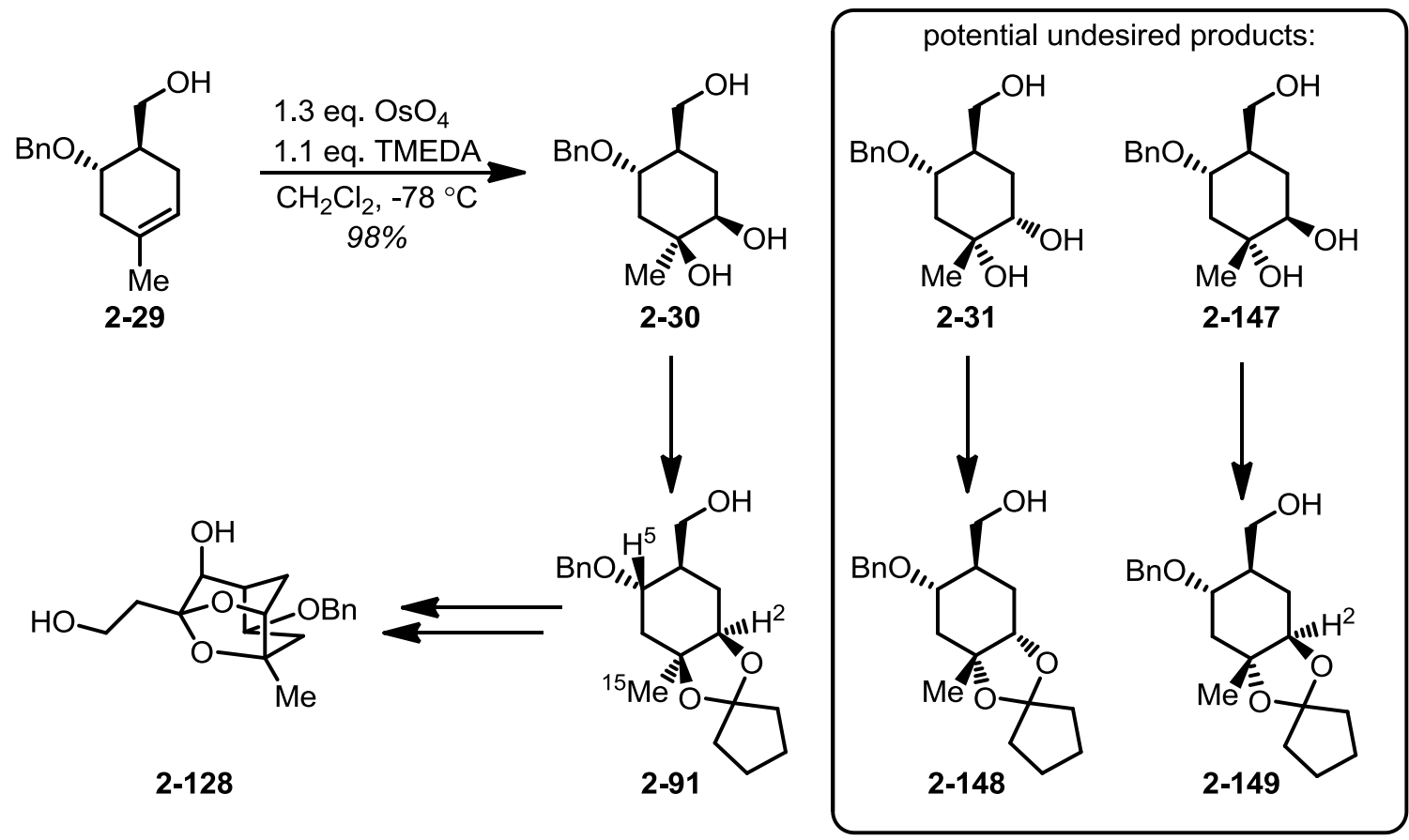

The structure of triol 2-30 was confirmed by a) the $J$ values of H5 in 2-91 b) the lack of nOe signal between Me15-H5 c) presence of Me15-H2 nOe signal d) the cycloketalization to diol 2-128. Two potential undesired products are the antidihydroxylation product 2-147 or the product of oxidation from the undesired face to form 2-31. If the anti-dihydroxylation occurred, then a Me15-H2 nOe would not be observed. If the oxidation occurred from the undesired face of the olefin, then a Me15-H5 nOe would be observed in 2-148, and cycloketalization to 2-128 would not occur. Since a Me15-H2 nOe signal is observed, a Me15-H5 nOe is not observed, and cycloketalization to 2-128 transpires, neither 2-31 nor 2-147 are the major product of the dihydroxylation reaction. 
c) Cycloketalization forming 2-128 then 2-132 then 2-131.
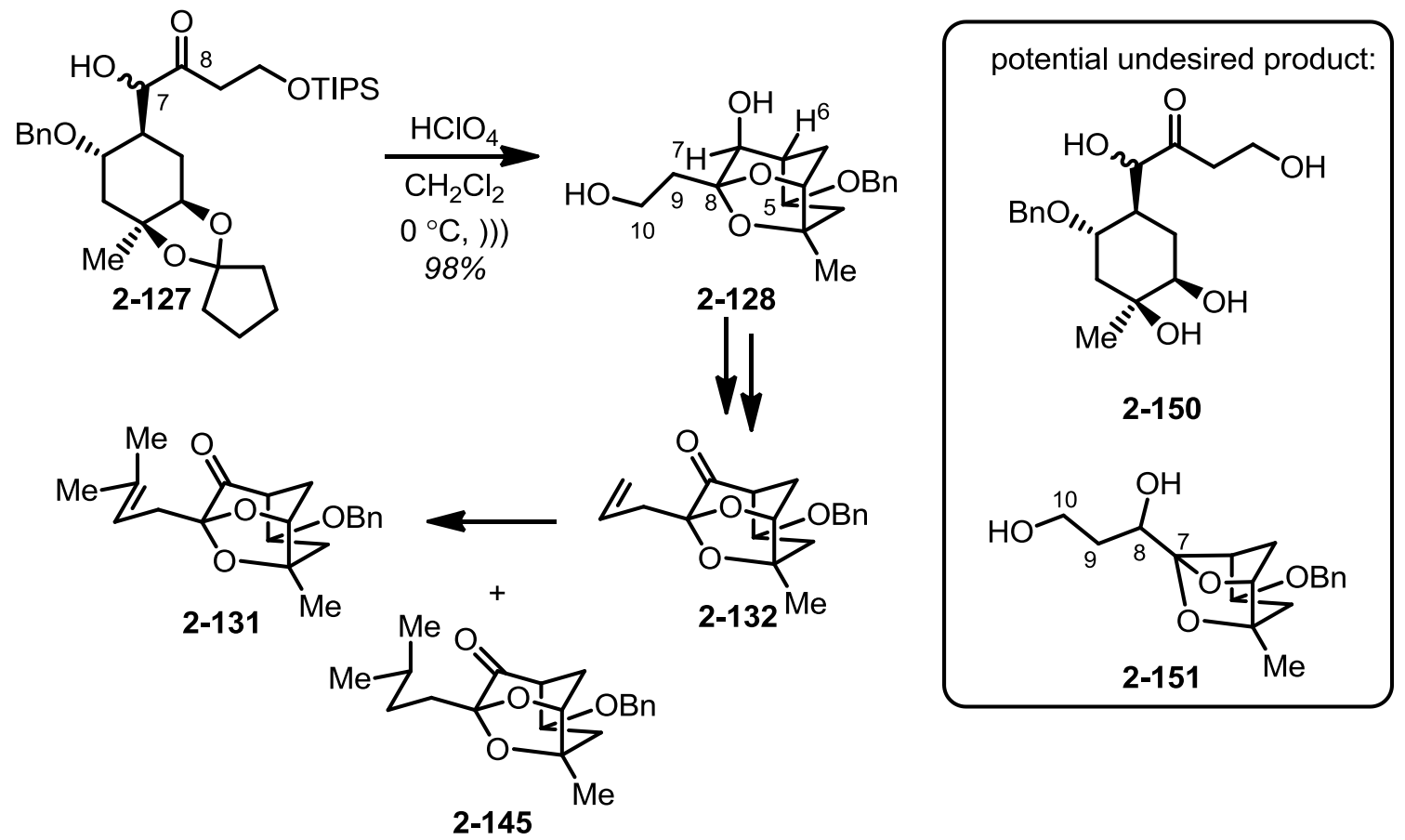

The structure of 2-128 was confirmed by the COSY signal between C7-C6, a NOESY correlation between $\mathrm{H} 7-\mathrm{H} 5$, mass-spec analysis, a new ${ }^{13} \mathrm{C}$ NMR signal characteristic of an acetal, and by analogy of 2-131/2-132/2-145 to known compounds. Two potential undesired products are tetraol 2-150 or tautomerization to the $\mathrm{C} 7$ ketone then cycloketalization to form tricycle 2-151. If tetraol 2-150 were formed, then the ${ }^{13} \mathrm{C}$ NMR would not display a signal in the acetal range, and would have a mass not equal to that of tricycle 2-128. If tricycle 2-151 were formed, then the COSY spectrum would display an H9-H8 crosspeak, and no H6-new carbinol signal would be observed in the COSY spectrum. Additionally, if either of these two compounds were created, the spectra of later-stage compounds would not greatly resemble the spectra of similar compounds made by Professor Dudley. Since the 
${ }^{13} \mathrm{C}$ NMR spectrum of $\mathbf{2 - 1 2 8}$ contains a new signal in the acetal range, a $\mathrm{H} 6-\mathrm{H} 7$ crosspeak is observed in the COSY and $\mathrm{H} 9$ splits only $\mathrm{H} 10$, and the spectra of compounds 2-131/2-132/2-149 greatly resemble the spectra of similar known compounds, the structure of $\mathbf{2 - 1 2 8}$ is confirmed as shown.

d) Formation of 2-2.

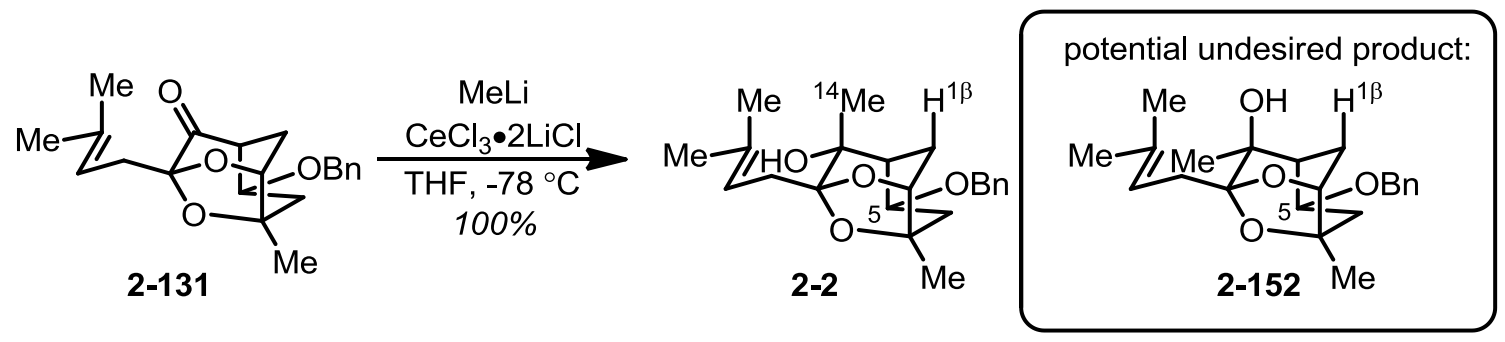

The structure of 2-2 was confirmed by a nOe signal between Me14-H1 $\beta$. A possible undesired reaction is methyl addition from the opposite face of the C7 ketone forming alcohol 2-152. If 2-152 was the product of the reaction, then a H5Me14 nOe signal would be observed. Since a Me14-H1 $\beta$ nOe is observed, and no H5-Me14 nOe signal is observed, the major product of the methyl addition is $\mathbf{2 - 2}$. 


\section{e) Formation of 2-141.}

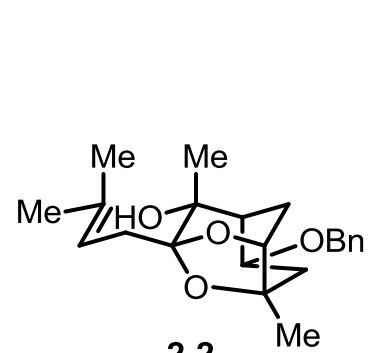

2-2

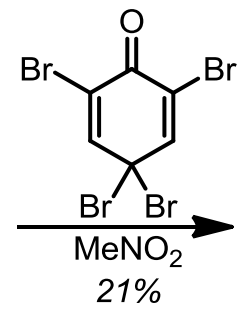

$21 \%$

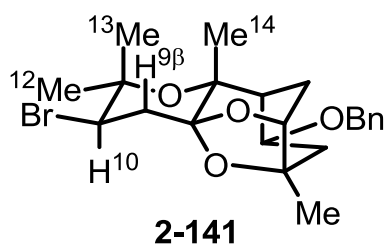

$J_{10-9}=13.2,4.2 \mathrm{~Hz}$ potential undesired product:
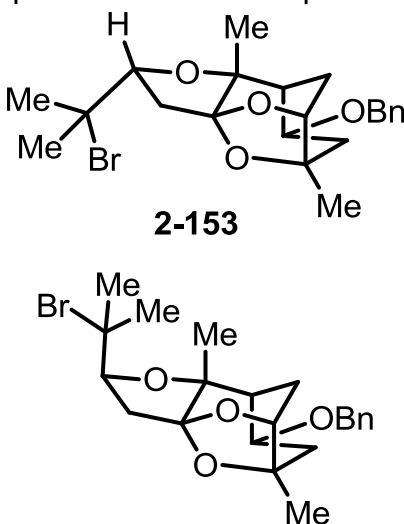

2-154

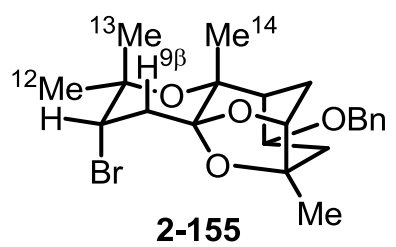

The structure of 2-141 was confirmed by the $J$ values of $\mathrm{H} 10$, nOe correlations between H9ß-Me13/14, Me13-Me14, and H10-Me12. Potential undesired compounds are tetrahyrdofurans 2-153 and 2-154, and axial bromide tetrahydropyran 2-155. If compound 2-141 were mistaken for 2-153, then the $J$ values of $\mathrm{H} 10$ would be $(8 \cdot 0-11.5 \mathrm{~Hz})-(2.0-4.0 \mathrm{~Hz})$, and a strong H9a-Me12/13 crosspeak would exist in the NOESY spectrum if a H9ß-Me12/13 also existed. If compound 2-141 were mistaken for 2-154, then the $J$ values of $\mathrm{H} 10$ would be (9.012.5 Hz) - (6.0-10.0 Hz), and a strong H9a-Me12/13 crosspeak would be observed in the NOESY spectrum if a H9ß-Me12/13 were also observed. If tetrahydropyran 2155 were formed, then both $J$ values of the signal for $\mathrm{H} 10$ would be $\sim 3 \mathrm{~Hz}$. Since the $J$ values of $\mathrm{H} 10$ are 13.2 and $4.2 \mathrm{~Hz}$, and a $\mathrm{H} 9 \beta-M e 13$ crosspeak is observed in the NOESY but no H9a-Me12/13 signal is observed, the structure of 2-141 is as shown. 


\section{f) Formation of 2-1.}

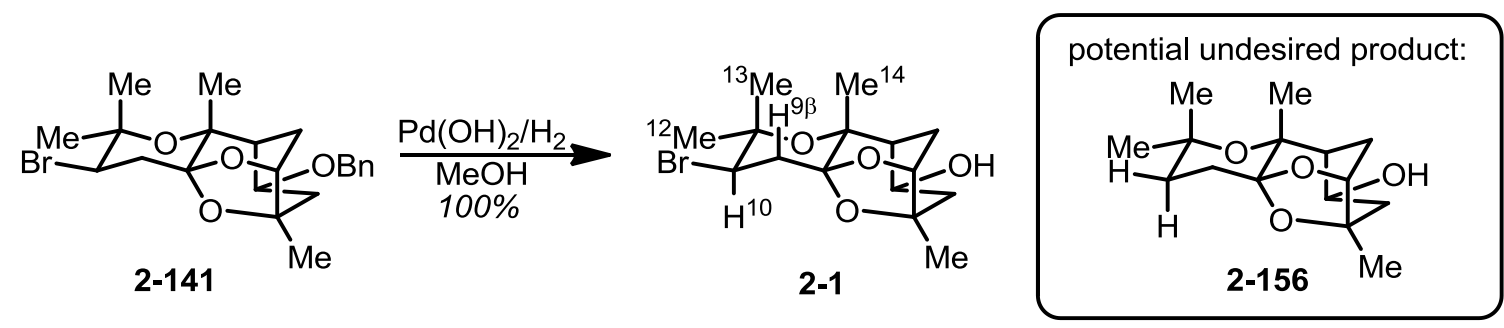

The structure of 2-1 was determined by mass-spectral analysis, the $\mathrm{H} 10 \mathrm{~J}$ values, COSY analysis, NOESY analysis, including observed nOe signals between H9ß-Me13/14, Me13-Me14, H10-Me12, and HMBC, HMQC, and DEPT-135 spectra. A potential undesired product of hydrogenation is the formation of 2-156. If the bromine was replaced with a proton, there would not be three proton signals in the carbinol range, and the mass would be different than that of 2-1. Since the three proton signals from 2-141 are present in 2-1, and the mass is as expected for $\mathbf{2 - 1}$, the $\mathrm{C}-\mathrm{Br}$ bond was not disturbed and the product is as shown.

\section{Attempts to synthesize the actual structure of aldingenin B}

The H5-H6 splitting observed in the spectrum of the natural sample possibly indicates the stereochemistry of the C5 is inverted compared the assigned structure. In order to determine if this hypothesis was correct, 2-1 was oxidized then reduced, producing epi-2-1, 2-158, which did not match the ${ }^{1} \mathrm{H}$ NMR spectrum of the natural sample (Scheme 2.40). 


\section{Scheme 2.40: Synthesis of 2-157.}

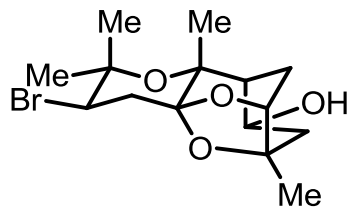

2-1

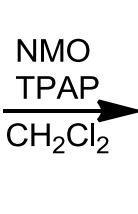

$\underset{\mathrm{H}_{2} \mathrm{Cl}_{2}}{\stackrel{\mathrm{TPAP}}{\mathbf{n}}}$

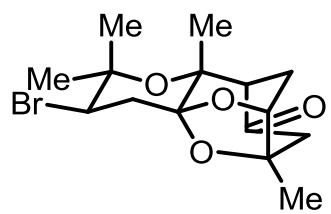

2-157

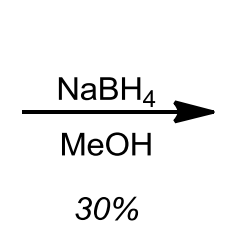

(over two steps)

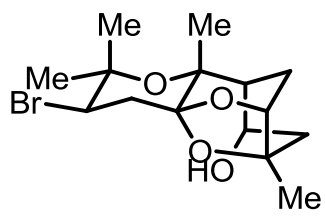

2-158

\section{E. Summary}

In summary, the first total synthesis of the proposed structure of aldingenin B has been accomplished in 16 steps (LLS) and in $2.7 \%$ overall yield. The results of this work dispove the orginally assigned structure of the natural product. Key steps include a substrate-controlled, hydrogen bond-mediated dihydroxylation, a cycloketalization to construct the compact tricycle, and a bromoetherification to complete the carbocycle. The development of a novel way of drying and solubilizing cerium trichloride for the use in non-basic nucleophilic additions was also achieved. 


\section{References}

1) Frater, G.; Gunther, W.; Muller, U. Helvetica Chimica Acta 1989, 72, 1847, Seebach, D.; Naef, R. Helvetica Chimica Acta 1981, 64, 2704.

2) Crimmins, M. T.; Shamszad, M. Org. Lett. 2007, 9, 149.

3) Cosp, A.; Romea, P.; Talavera, P.; Urpi, F.; Vilarrasa, J.; Font-Bardia, M.; Solans, X. Org. Lett. 2001, 3, 615.

4) Crimmins, M. T.; Kirincich, S. J.; Wells, A. J.; Choy, A. L. Synth. Comm. 1998, 28, 3675.

5) Tsunoda, T.; Suzuki, M.; Noyori, R. Tetrahedron Lett. 1980, 21, 1357.

6) Mahrwald, R. Chem. Rev. 1999, 99, 1095.

7) Scholl, M.; Ding, S.; Lee, C. W.; Grubbs, R. H. Org. Lett. 1999, 1, 953.

8) VanReenen, V.; Kelly, R. C.; Cha, D. Y. Tetrahedron Lett. 1976, 17, 1973.

9) Criegee, R., Marchand, B., Wannowius, H. Organic osmium compounds. II. Ann. 1942, 550, 99.

10)Kolb, H. C.; VanNieuwenhze, M. S.; Sharpless, K. B. Chem. Rev. 1994, 94, 2483.

11)Cha, J. K.; Christ W. J.; Kishi, Y. Tetrahedron Lett. 1983, 24, 3943.

12)(a) Donohoe, T. J. Synlett. 2002, 8, 1223. (b) Donohoe, T. J.; Blades, K.; Moore, P. R.; Waring, M. J.; Winter, J. J. G.; Helliwell, M.; Newcombe, N. J.; Stemp, G. J. Org. Chem. 2002, 67, 7946.

13) As an intellectual curiosity, a control experiment was conducted wherein the dihydroxylation was conducted at $-78{ }^{\circ} \mathrm{C}$ in $\mathrm{CH}_{2} \mathrm{Cl}_{2}$, using a catalytic amount of $\mathrm{OsO}_{4}$ and quinuclidine- $\mathrm{N}$-oxide (see ref 12 ). The result was a 2:1 ratio of major/minor products, indicating hydrogen bonding is at play, and not a solvent/temperature effect.

14)(a) Grobel, B. T.; Seebach, D. Synthesis 1977, 6, 357. (b) Smith, A. B.; Condon, S. M.; McCauley, J. A. Acc. Chem. Res. 1998, 31, 35.

15)Flemming, I. Frontier Orbitals and Organic Chemical Reactions; Wiley: Chichester 1976. 
16)De Luca, L.; Giacomelli, G.; Porcheddu, A. Org. Lett. 2001, 3, 3041. (b) Einhorn, J.; Einhorn, C.; Ratajczak, F.; Pierre, J. L. J. Org. Chem. 1996, 61, 7452.

17)Dess, D. B.; Martin, J. C. J. Org. Chem. 1983, 48, 4155.

18)Matsuura, F.; Peters, R.; Anada, M.; Harried, S. S.; Hao, J.; Kishi, Y J. Am. Chem. Soc. 2006, 128, 7463.

19)Mancuso, A. J.; Huang, S.-L.; Swern, D. J. Org. Chem. 1978, 43, 2480.

20)Smith, A. B.; Zhu, W.; Shirakami, S.; Sfouggatakis, C.; Doughty, V. A.; Bennett, C. S.; Sakamoto, Y. Org. Lett. 2003, 5, 761.

21)Imamoto, T. Organocerium Reagents. In Comprehensive Organic Synthesis; Trost, B. M.; Fleming; I.; Schreiber, S. L. Eds.; Pergamon Press: Oxford, 1991; Vol 1; p 231.

22)Imamoto, T.; Kusumoto, T.; Tawarayama, Y.; Mita, T.; Hatanaka, Y.; Yokoyama, M. J. Org. Chem. 1984, 49, 3904.

23)Dimitrov, V.; Kostova, K.; Genov, M. Tetrahedron Lett. 1996, 37, 6787.

24)Paquette, L. A. Cerium(III) Chloride. In Encyclopedia of Reagents for Organic Synthesis; Paquette, L. A. Ed.; Wiley: New York, 1995; Vol 2; p 1031.

25)Evans, W. J.; Feldman, J. D.; Ziller, J. W. J. Am. Chem. Soc. 1996, 118, 4581.

26)(a) Evans, W. J.; Shreeve, J. L.; Ziller, J. W.; Doedens, R. J. Inorg. Chem. 1995, 34, 576. (b) Conlon, D. A.; Kumke, D.; Moeder, C.; Hardiman, M.; Hutson, G.; Sailer, L. Advanced Synthesis \& Catalysis 2004, 346, 1307.

27)Evans, W. J.; Olofson, J. M.; Ziller, J. W. J. Am. Chem. Soc. 1990, 112, 2308.

28)(a)Krasovskiy, A. Kopp, F.; Knochel, P. Angew. Chem. Int. Ed. 2006, 45, 497. (b) Metzger, A.; Gavryushin, A.; Knochel, P. Synlett 2009, 9, 1433.

29)Seebach, D. Angew. Chem. Int. Ed. 1988, 27, 1624.

30)Pray, A. R. Inorganic Syntheses 2007, 28, 321. 
31) (a) Trost, B. M.; Waser, J.; Meyer, A. J. Am. Chem. Soc. 2007, 129, 14556. (b) Trost, B. M.; Waser, J.; Meyer, A. J. Am. Chem. Soc. 2008, 130, 16424.

32)Yanagisawa, A.; Taga, M.; Toshiyuki, A.; Nishimura, K.; Ando, K.; Taguchi, T.; Tsumuki, H.; Chujo, I.; Mohri, S. Org. Process Res. Dev. 2011, 15, 376.

33)Ley, S. V.; Norman, J.; Griffith, W. P.; Marsden, S. P. Synthesis 1994, 639. It was observed larger scale Swern reactions led to epimerization/elimination.

34)Knochel utilized vacuum pumps to evacuate to $0.01 \mathrm{mmHg}$; our best pump could only achieve $0.8 \mathrm{~mm} \mathrm{Hg}$. Thanks to the Wei You group for the use of pumps capable of achieving $0.1 \mathrm{~mm} \mathrm{Hg}$, and the Nicewicz group for use of a pump capable of $0.01 \mathrm{mmHg}$. Unfortunately their pumps did not help this chemistry.

35)Corey, E. J.; Erickson B. W. J. Org. Chem. 1971, 36, 3553; the $\mathrm{AgNO}_{3}$ suppresses $\mathrm{Cl}_{2}$ formation.

36)Kumar, R.; Kumar, D.; Chakraborti, A. K. Synthesis 2007, 299.

37)Smith, A. B.; Kingery-Wood, J.; Leenay, T. L.; Nolen, E. G.; Sunazuka, T. J. Am. Chem. Soc. 1992, 114, 1438.

38)Prasad, K. R.; Anbarasan, P. Tetrahedron 2006, 62, 8303.

39)Burrell, A. J. M.; Coldham, I.; Watson, L.; Oram, N.; Pilgram, C. D.; Martin, N. G. J. Org. Chem. 2009, 74, 2290.

40)Kato, T.; Ichinose, I.; Hosogai, T. Chemistry Letters 1976, 1187.

41)Corey, E. J.; Ha, D.-C. Tetrahedron Lett. 1988, 29, 3171.

42)Gaunt, M. J.; Hook, D. F.; Tanner, H. R.; Ley, S. V. Org. Lett. 2003, 5, 4815.

43)(a) Crimmins, M. T.; Bankaitis-Davis, D. M.; Hollis, W. G. J. Org. Chem. 1998, 53, 652. (b) Crimmins, M. T.; O'Mahony, R. J. Org. Chem. 1990, 55, 5894.

44)Recrystallized according to Aldrich Chimica Acta 1977, 10, 2.

45) (a)Schmidba, H.; Vornberg, W.; Stuhler, H. Chem. Ber. 1972, 105, 1084. (b) Larionov, O. V.; Corey, E. J. J. Am. Chem. Soc. 2008, 130, 2954. (c) Mori, K.; Takikawa, H. Tetrahedron, 1991, 47, 2163. (d) Vedejs, E.; Meier, G. P.; Snoble, K. A. J. J. Am. Chem. Soc. 1981, 103, 2823. (e) Robiette, R.; 
Richardson, J.; Aggarwal, V. K.; Harvey, J. N. J. Am. Chem. Soc. 2006, 128, 2394.

46)Chatterjee, A. K.; Sanders, D. P.; Grubbs, R. H. Org. Lett. 2002, 4, 1939.

47) (a) Takai, K.; Hotta, Y. Oshima, K.; Nozaki, H. Tetrahedron Lett., 1978, 2417. (b) Takai, K.; Hotta, Y. Oshima, K.; Nozaki, H. Bull. Chem. Soc. Jpn. 1980, 53, 1698. (c) Lombardo, L. Tetrahedron Lett., 1982, 23, 4293.

48)L. N. Nysted, US Patent 3865 848, 1975; Chem. Abstr. 1975, 83, 10406q.

49)Matsubara, S.; Sugihara, M.; Utimoto, K. Synlett. 1998, 313.

50)Kato, T.; Ichinose, I.; Hosogai, T. Chemistry Letters 1976, 1187.

51) Becker, D. B., High Resolution NMR, Academic Press, 1969, p. 96.

52) Fort, R. C.; Schleyer, P. v. R. J. Org. Chem. 1965, 30, 789.

53)Yang, J.; Tummatorn, J.; Slegeris, R.; Tlais, S. F.; Dudley, G. B. Org. Lett. 2011, 13, 2065.

54) 2-145 made by oxidation of alcohol 2-120.

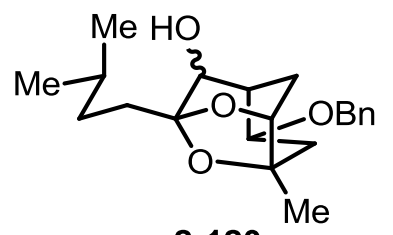

2-120

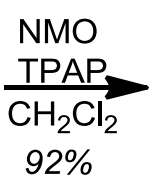

92\%

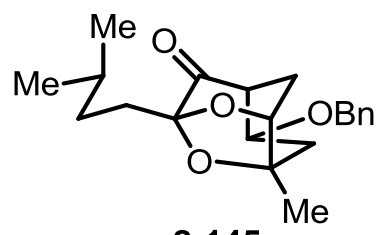

2-145 


\section{CHAPTER 3}

Experimental Information and NMR spectra for Chapter 2

\section{A. Materials and Methods}

Infrared (IR) spectra were obtained using a Jasco 460 Plus Fourier transform infrared spectrometer. Nuclear magnetic resonance $\left({ }^{1} \mathrm{H},{ }^{13} \mathrm{C}, \mathrm{COSY}, \mathrm{NOESY}\right)$ spectra were recorded on Bruker model DRX $400\left({ }^{1} \mathrm{H}\right.$ at $400 \mathrm{MHz} ;{ }^{13} \mathrm{C}$ at $\left.100 \mathrm{MHz}\right)$, Bruker model DRX $500\left({ }^{1} \mathrm{H}\right.$ at $500 \mathrm{MHz} ;{ }^{13} \mathrm{C}$ at $\left.150 \mathrm{MHz}\right)$, and Bruker Ultra Shield $600\left({ }^{1} \mathrm{H}\right.$ at $600 \mathrm{MHz} ;{ }^{13} \mathrm{C}$ at $\left.150 \mathrm{MHz}\right)$ instruments. Chemical shifts are reported relative to chloroform $(\delta 7.26)$, or benzene $(\delta 7.15)$, for ${ }^{1} \mathrm{H}$ NMR spectra and chloroform $(\delta 77.23)$, or benzene $(\delta 128.0)$ for ${ }^{13} \mathrm{C}$ NMR spectra. ${ }^{1} \mathrm{H}$ NMR data are reported as follows: chemical shift, multiplicity $(\mathrm{s}=$ singlet, $\mathrm{d}=$ doublet, $\mathrm{m}=$ multiplet), coupling constant $(\mathrm{Hz})$, and integration. Optical rotations were determined using a Jasco P1010 polarimeter, and concentrations are reported in g/100mL. Mass spectra were obtained using a Bruker BioTOF II mass spectrometer with electrospray ionization (ESI). Thin layer chromatography (TLC) was conducted on silica gel F254 TLC plates purchased from EMD Chemicals Inc. Visualization was accomplished with UV light and/or aqueous ceric ammonium molybdate solution followed by heating unless otherwise noted. Flash column chromatography was carried out using Ultra Pure Silica Gel Silia-P (40 to $63 \mu \mathrm{m}$ ) purchased from SiliCycle 
Inc. Dichloromethane $\left(\mathrm{CH}_{2} \mathrm{Cl}_{2}\right)$, diethyl ether $\left(\mathrm{Et}_{2} \mathrm{O}\right)$, tetrahydrofuran $(\mathrm{THF})$, and toluene $\left(\mathrm{PhCH}_{3}\right)$ were dried by passage through a column of neutral alumina under argon immediately prior to use. All alkylamines, 2,6-lutidine, pyridine, benzene, nitromethane and acetonitrile $\left(\mathrm{CH}_{3} \mathrm{CN}\right)$ were distilled from calcium hydride immediately prior to use. All other reagents and solvents were used as received from the manufacturer. All air and water sensitive reactions were performed in flasks flame dried under positive flow of argon and conducted under an argon atmosphere. Yield refers to yield of analytically pure material unless otherwise noted.

\section{B. Procedures}


<smiles>C=CCCC(=O)O</smiles>

2-17

$\mid \begin{aligned} & \text { oxalyl } \\ & \mathrm{DMF} \\ & \mathrm{CH}_{2} \mathrm{Cl}_{2} \\ & 0{ }^{\circ} \mathrm{C}\end{aligned}$<smiles>C=CCCC(=O)Cl</smiles>

2-18<smiles>CC(C)[C@@H]1CSC(=S)N1</smiles>

2-19<smiles>CC(C)[C@@H]1CSC(=S)N1[NH3+]</smiles>

2-20

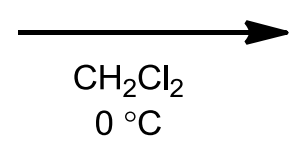

$0^{\circ} \mathrm{C}$<smiles>C=CCCC(=O)N1C(=S)SC[C@H]1C(C)C</smiles>

2-8

Acylated auxiliary 2-8: A 2-necked round-bottomed flask was charged with 4-pentenoic acid (6.4 mL, $63 \mathrm{mmol}), \mathrm{CH}_{2} \mathrm{Cl}_{2}(150 \mathrm{~mL})$, and DMF (3 drops), and fitted with both an outlet to an acid-trap and with an addition funnel containing oxalyl chloride $(34.15 \mathrm{~mL}, 2 \mathrm{M}, 68 \mathrm{mmol})$ and cooled to $0{ }^{\circ} \mathrm{C}$. The oxalyl chloride was added dropwise. Upon completion of addition, the ice-bath was removed and the reaction was allowed to warm to rt. Reaction was deemed complete when gasses were no longer generated.

A separate 2-necked round-bottomed flask was charged with $\mathrm{NaH}(3.22 \mathrm{~g}$, $80.5 \mathrm{mmol}, 60 \%$ in mineral oil) in $\mathrm{CH}_{2} \mathrm{Cl}_{2}(70 \mathrm{~mL})$ and equipped with a magnetic stirring bar, a rubber septum, and flushed with argon. An addition funnel containing auxiliary 2-19 (10 g, $62 \mathrm{mmol})$ and $\mathrm{CH}_{2} \mathrm{Cl}_{2}(70 \mathrm{~mL})$ was fitted into the remaining joint. The auxiliary was then slowly added dropwise into the stirring $\mathrm{NaH}$ solution at $0{ }^{\circ} \mathrm{C}$. After $1 \mathrm{~h}$, pentenoic chloride (see above) was added dropwise via addition funnel to the solution. Upon completion of the addition, the ice-bath was removed and the 
reaction was allowed to stir for $2 \mathrm{~h}$. The reaction was quenched with $\mathrm{MeOH}(3 \mathrm{~mL})$ and allowed to stir for $20 \mathrm{~m}$. The layers were separated and the aqueous layer was extracted $3 \times \mathrm{CH}_{2} \mathrm{Cl}_{2}$. The combined organic extracts were dried over $\mathrm{Na}_{2} \mathrm{SO}_{4}$, filtered, and concentrated. The product was purified by column chromatography (eluting with $10 \%$ EtOAc/hexanes) to yield $13.2 \mathrm{~g}(87 \%)$ of product. ${ }^{1} \mathrm{H}$ NMR (400 $\left.\mathrm{MHz}, \mathrm{CDCl}_{3}\right) \delta$ ppm $0.97(\mathrm{~d}, J=6.82 \mathrm{~Hz}, 3 \mathrm{H}) 1.06(\mathrm{~d}, J=6.82 \mathrm{~Hz}, 3 \mathrm{H}) 2.29-2.52$ $(\mathrm{m}, 3 \mathrm{H}) 3.02(\mathrm{dd}, J=11.6,1.14 \mathrm{~Hz}, 1 \mathrm{H}) 3.19-3.33(\mathrm{~m}, 1 \mathrm{H}) 3.39-3.56(\mathrm{~m}, 2 \mathrm{H})$ 4.99 - $5.13(\mathrm{~m}, 2 \mathrm{H}) 5.1-5.2(\mathrm{~m}, 1 \mathrm{H}) 5.85$ (ddt, $J=17.0,10.30,6.46,6.46 \mathrm{~Hz}, 1 \mathrm{H})$; ${ }^{13} \mathrm{C}$ NMR $\left(150 \mathrm{MHz}, \mathrm{CDCl}_{3}\right) \delta \mathrm{ppm} 202.8,173.3,136.8,115.6,71.6,37.6,30.8$,

30.5, 28.8, 19.1, 17.8; IR (film) $3076 \mathrm{~m}, 2964 \mathrm{~s}, 1698 \mathrm{~s}, 1639 \mathrm{~m} \mathrm{~cm}^{-1} ;[\alpha]^{21}=-297.46$ (c = 2.5); HRMS $(E S I+)$ calcd for $\mathrm{C}_{11} \mathrm{H}_{17} \mathrm{NOS}_{2}[\mathrm{M}+\mathrm{H}]^{+} 244.0830$, found 244.0831

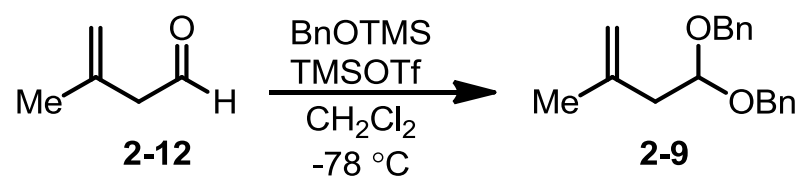

BnOTMS made according to: Azizi, N.; Yousefi, R. Saidi, M. R. J. Organomet. Chem. 2006, 691, 817.

3-methyl-3-butenal 2-12 made according to: Crimmins, M. T.; McDougall, P. J.; Emmitte, K. A. Org. Lett. 2005, 7, 4033.

Dibenzyl acetal 2-9: To a $\mathrm{CH}_{2} \mathrm{Cl}_{2}(0.4 \mathrm{~mL})$ solution containing TMSOTf $(0.007 \mathrm{~mL}$, $0.039 \mathrm{mmol})$ at $-78{ }^{\circ} \mathrm{C}$ were successively added BnOTMS (1.42 g, $\left.7.87 \mathrm{mmol}\right)$ and a 
solution of 3-methyl-3-butenal 2-12 (330 mg, $3.92 \mathrm{mmol})$ in $\mathrm{CH}_{2} \mathrm{Cl}_{2}(2 \mathrm{~mL})$ solution. The mixture was stirred at $-78{ }^{\circ} \mathrm{C}$ for an additional $12 \mathrm{~h}$. After this time, the reaction was quenched by addition of dry pyridine $(0.77 \mathrm{~mL})$, poured into a sat. $\mathrm{NaHCO}_{3 \text { (aq.) }}$ solution $(5 \mathrm{~mL})$, and extracted with $\mathrm{Et}_{2} \mathrm{O}$. The organic layer was dried over a 1:1 mixture of $\mathrm{Na}_{2} \mathrm{CO}_{3}$ and $\mathrm{Na}_{2} \mathrm{SO}_{4}$ and concentrated. Column chromatography eluting with 3\% EtOAc/hexanes afforded dibenzyl acetal $2-9$ (0.797 g, $2.82 \mathrm{mmol}, 72 \%) .{ }^{1} \mathrm{H}$ NMR $\left(600 \mathrm{MHz}, \mathrm{CDCl}_{3}\right) \delta \mathrm{ppm} 1.80(\mathrm{~s}, 3 \mathrm{H}) 2.55(\mathrm{~d}, J=6.0 \mathrm{~Hz}, 2 \mathrm{H}) 4.51(\mathrm{~d}, J=$ 17.4 Hz, 2 H) $4.62(\mathrm{~d}, J=17.4 \mathrm{~Hz}, 2 \mathrm{H}) 4.77(\mathrm{~d}, J=11.4 \mathrm{~Hz}, 2 \mathrm{H}) 4.84(\mathrm{t}, J=5.4 \mathrm{~Hz}$, $1 \mathrm{H}) 7.29-7.35(\mathrm{~m}, 2 \mathrm{H}) 7.35-7.44(\mathrm{~m}, 8 \mathrm{H}) ;{ }^{13} \mathrm{C} \mathrm{NMR}\left(150 \mathrm{MHz}, \mathrm{CDCl}_{3}\right) \delta \mathrm{ppm}$ 141.1, 138.2, 128.4, 127.8, 127.6, 113.3, 100.9, 67.2, 41.7, 23.1; IR (film) 3053 m, $1719 \mathrm{~m}, 1454 \mathrm{~s} \mathrm{~cm}^{-1}$; HRMS (ESI+) calcd for $\mathrm{C}_{19} \mathrm{H}_{22} \mathrm{O}_{2}[\mathrm{M}+\mathrm{Na}]^{+}$305.1512, found 305.1512.

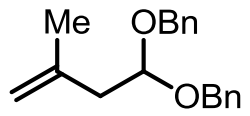

2-9

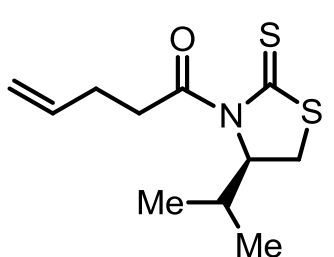

2-8

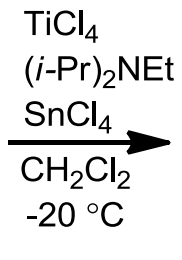
$1.88 \mathrm{mmol}$ ) was added dropwise to a solution of acylated auxiliary $2-8(415 \mathrm{mg}, 1.71 \mathrm{mmol})$ in $\mathrm{CH}_{2} \mathrm{Cl}_{2}(14 \mathrm{~mL})$, at $0{ }^{\circ} \mathrm{C}$ under Ar. The mixture was stirred for $5 \mathrm{~min}$. at $0{ }^{\circ} \mathrm{C}$, cooled to $-78{ }^{\circ} \mathrm{C}$, and a solution of $(i-\operatorname{Pr})_{2} \mathrm{NEt}(0.327 \mathrm{~mL}, 1.88 \mathrm{mmol})$ in $\mathrm{CH}_{2} \mathrm{Cl}_{2}(1.7 \mathrm{~mL})$ was added. The dark red solution was stirred for $2 \mathrm{~h}$ at $-40{ }^{\circ} \mathrm{C}$, and a solution of $\mathrm{SnCl}_{4}(0.22 \mathrm{~mL}, 1.88 \mathrm{mmol}$, in $\left.1.9 \mathrm{~mL} \mathrm{CH}_{2} \mathrm{Cl}_{2}\right)$ followed by a solution of acetal $2-9(530 \mathrm{mg}, 1.88 \mathrm{mmol}$, in $1.7 \mathrm{~mL}$ 
$\mathrm{CH}_{2} \mathrm{Cl}_{2}$ ) were added dropwise at $-78{ }^{\circ} \mathrm{C}$. The resulting mixture was stirred at $-78{ }^{\circ} \mathrm{C}$ for 15 min. and kept at $-20^{\circ} \mathrm{C}$ for $2 \mathrm{~h}$. The reaction was quenched with $\mathrm{NH}_{4} \mathrm{Cl}_{\text {(aq.) }}$, the layers were separated and the aqueous layer was extracted with $\mathrm{CH}_{2} \mathrm{Cl}_{2}$. The combined organic extracts were dried over $\mathrm{Na}_{2} \mathrm{SO}_{4}$, filtered, and concentrated. The product was purified by column chromatography (eluting with a gradient of $5 \%$ $\mathrm{CH}_{2} \mathrm{Cl}_{2} /$ hexanes to $50 \% \mathrm{CH}_{2} \mathrm{Cl}_{2} /$ hexanes by increments of $5 \% \mathrm{CH}_{2} \mathrm{Cl}_{2} /$ hexanes) to yield $476 \mathrm{mg}(67 \%, 1.14 \mathrm{mmol}, 94: 6$ d.r. $)$ of aldol adduct 2-7. ${ }^{1} \mathrm{H} \mathrm{NMR}(600 \mathrm{MHz}$, $\left.\mathrm{CDCl}_{3}\right) \delta \mathrm{ppm} 0.92(\mathrm{~d}, J=6.6 \mathrm{~Hz}, 3 \mathrm{H}) 0.97(\mathrm{~d}, J=6.6 \mathrm{~Hz}, 3 \mathrm{H}) 1.80(\mathrm{~s}, 3 \mathrm{H}) 2.23-$ $2.28(\mathrm{~m}, 1 \mathrm{H}) 2.30-2.37(\mathrm{~m}, 1 \mathrm{H}) 2.42-2.48(\mathrm{~m}, 2 \mathrm{H}) 2.48-2.54(\mathrm{~m}, 1 \mathrm{H}) 2.98(\mathrm{~d}, J$ $=11.4 \mathrm{~Hz}, 1 \mathrm{H}) 3.43(\mathrm{dd}, J=11.4,9 \mathrm{~Hz}, 1 \mathrm{H}) 4.14(\mathrm{ddd}, J=8.4,7.2,3 \mathrm{~Hz}, 1 \mathrm{H}) 4.58$ - 4.67 (m, 2 H) 4.85 (br. s., 2 H) $5.00-5.10(\mathrm{~m}, 2$ H) 5.15 (t, J = 6.6 Hz, 1 H) 5.26 (ddd, $J=10.2,7.2,4.2 \mathrm{~Hz}, 1 \mathrm{H}) 5.74-5.86(\mathrm{~m}, 1 \mathrm{H}) 7.22-7.39(\mathrm{~m}, 5 \mathrm{H}) ;{ }^{13} \mathrm{C}$ NMR $\left(150 \mathrm{MHz} \mathrm{CDCl}_{3}\right) \delta \mathrm{ppm} 203,174.6,142.7,138.8,135.3,128.1,127.6,127.3,116.9$ 113.2, 78.0, 72.0, 71.9, 47.1, 39.1, 33.0, 30.9, 30.2, 23.2, 19.1, 17.5; IR (film) 3065 m, $2967 \mathrm{~s}, 1691 \mathrm{~s}, 1641 \mathrm{~m}, 1454 \mathrm{~m}, 1364 \mathrm{~s} \mathrm{~cm}^{-1} ;[\alpha]^{22}=-88.14\left(\mathrm{c}=2.6, \mathrm{CH}_{2} \mathrm{Cl}_{2}\right)$; HRMS (ESI+) calcd for $\mathrm{C}_{23} \mathrm{H}_{31} \mathrm{NO}_{2} \mathrm{~S}_{2}[\mathrm{M}+\mathrm{Cs}]^{+} 550.0845$, found 550.0868 .

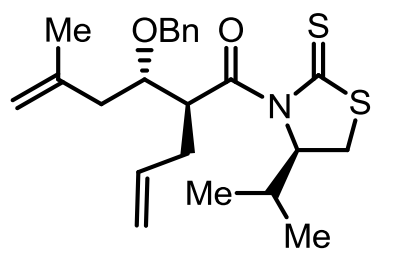

2-7
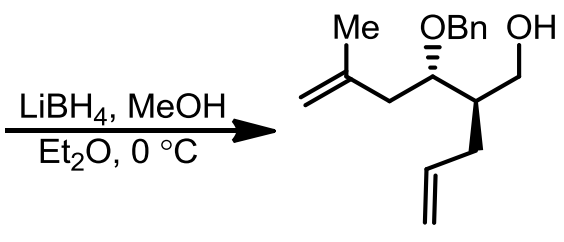

2-28 
Alcohol 2-28: A flame-dried round bottomed flask was loaded with aldol adduct 2-7 (840 mg, $2.01 \mathrm{mmol})$, a stir bar, $\mathrm{Et}_{2} \mathrm{O}(20 \mathrm{~mL})$ and $\mathrm{MeOH}(0.1 \mathrm{~mL})$, and cooled to 0 ${ }^{\circ} \mathrm{C}$. Once cold, $\mathrm{LiBH}_{4}(1.3 \mathrm{~mL}, 2 \mathrm{M}, 2.6 \mathrm{mmol})$ was added, and the reaction was allowed to stir. After $5 \mathrm{~m}$, the ice-bath was removed and the reaction was allowed to warm to rt. After $1 \mathrm{~h}, \mathrm{NaOH}_{\text {(aq.) }}(20 \mathrm{~mL})$ was added and the mixture was stirred for 2 h. The ether was removed under vacuum, and the aqueous layer and EtOAc were added to a separation funnel. The layers were separated and the aqueous layer was extracted with EtOAc (the aqueous wash was later treated with acid to reacquire the cleaved chiral auxiliary). The combined organic extracts were dried over $\mathrm{Na}_{2} \mathrm{SO}_{4}$, filtered, and concentrated. The product was purified by column chromatography (eluting with $5 \%$ to $10 \%$ EtOAc/hexanes) to yield $445 \mathrm{mg}(85 \%, 1.71 \mathrm{mmol})$ of alcohol 2-28. ${ }^{1} \mathrm{H}$ NMR $\left(400 \mathrm{MHz}, \mathrm{CDCl}_{3}\right) \delta \mathrm{ppm} 1.61-1.71(\mathrm{~m}, 1 \mathrm{H}) 1.76(\mathrm{~s}, 3 \mathrm{H})$ $2.29(\mathrm{t}, J=7.2 \mathrm{~Hz}, 2 \mathrm{H}) 2.35-2.45(\mathrm{~m}, 1 \mathrm{H}) 2.45-2.60(\mathrm{~m}, 1 \mathrm{H}) 2.79(\mathrm{dd}, J=8.0$, $3.6 \mathrm{~Hz}, 1 \mathrm{H}) 3.52-3.72(\mathrm{~m}, 1 \mathrm{H}) 3.72-3.88(\mathrm{~m}, 1 \mathrm{H}) 3.97(\mathrm{dt}, J=11.2,3.0 \mathrm{~Hz}, 1 \mathrm{H})$ $4.45(\mathrm{~d}, J=11.2 \mathrm{~Hz}, 1 \mathrm{H}) 4.68(\mathrm{~d}, J=11.2 \mathrm{~Hz}, 1 \mathrm{H}) 4.82(\mathrm{~d}, J=16.4 \mathrm{~Hz}, 2 \mathrm{H}) 4.92$ $5.14(\mathrm{~m}, 2 \mathrm{H}) 5.65-5.92(\mathrm{~m}, 1 \mathrm{H}) 7.13-7.42(\mathrm{~m}, 5 \mathrm{H}) ;{ }^{13} \mathrm{C} \mathrm{NMR}\left(150 \mathrm{MHz}, \mathrm{CDCl}_{3}\right) \delta$ ppm 142.3, 138.1, 136.9, 128.5, 127.9, 127.87, 116.7, 113.6, 80.3, 72.4, 62.6, 42.2, 40.3, 33.6, 22.8; IR (film) 3442 br, 2930 s, $1641 \mathrm{~m}, 1454 \mathrm{~m} \mathrm{~cm}^{-1}$; [a $]^{21}=+25.03$ (c = 3.0, $\mathrm{CH}_{2} \mathrm{Cl}_{2}$ ); HRMS (ESI+) calcd for $\mathrm{C}_{17} \mathrm{H}_{24} \mathrm{O}_{2}[\mathrm{M}+\mathrm{Na}]^{+}$283.1668, found 283.1669. 


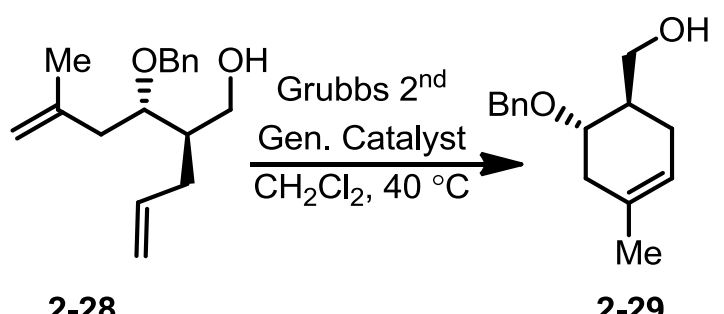

Alcohol 2-29: A 2-necked flame-dried round bottomed flask equipped with a reflux condenser and an outlet needle, was charged with alcohol 2-28 $(1.6 \mathrm{~g}, 6.15 \mathrm{mmol})$ and dissolved in $\mathrm{CH}_{2} \mathrm{Cl}_{2}(60 \mathrm{~mL})$. The inlet needle was placed into the solution, and argon was vigorously bubbled through the solvent heated at reflux for $1 \mathrm{~h}$. After the degassing, Grubbs second generation catalyst $(200 \mathrm{mg}, 0.24 \mathrm{mmol})$ was added. After $2 \mathrm{~h}$, the reaction was removed from heat and the solution was allowed to sit open to air. The solution was concentrated and purified by flash column chromatography (eluting with 10\% EtOAc/hexanes) to yield alcohol 2-29 (1.28 g, 90\%, $5.51 \mathrm{mmol}) .{ }^{1} \mathrm{H}$ NMR (400 MHz, $\left.\mathrm{CDCl}_{3}\right) \delta$ ppm 1.69 (s, $\left.3 \mathrm{H}\right) 1.74$ (br. s., $1 \mathrm{H}$ ) $1.88-2.00(\mathrm{~m}, 1 \mathrm{H}) 2.08(\mathrm{dd}, J=14.8,5.2 \mathrm{~Hz}, 2 \mathrm{H}) 2.45(\mathrm{dd}, J=24.0,7.6 \mathrm{~Hz}, 1 \mathrm{H})$ $3.12(\mathrm{dd}, J=9.6,2.4 \mathrm{~Hz}, 1 \mathrm{H}) 3.56-3.70(\mathrm{~m}, 3 \mathrm{H}) 4.50(\mathrm{~d}, J=11.2 \mathrm{~Hz}, 1 \mathrm{H}) 4.75(\mathrm{~d}$, $J=11.2 \mathrm{~Hz}, 1 \mathrm{H}) 5.32$ (br. s., $1 \mathrm{H}) 7.29-7.43(\mathrm{~m}, 5 \mathrm{H}) ;{ }^{13} \mathrm{C}$ NMR $\left(150 \mathrm{MHz}, \mathrm{CDCl}_{3}\right)$ $\delta$ ppm 138.1, 131.3, 128.6, 127.9, 127.8, 119.9, 80.3, 70.4, 67.2, 41.0, 36.0, 27.7, 23.3; IR (film) $3509 \mathrm{br}, 3054 \mathrm{~s}, 2915 \mathrm{~m}, 1421 \mathrm{~m} \mathrm{~cm}^{-1}$; [a] ${ }^{21}=+121.87$ (c = 4.0, $\mathrm{CH}_{2} \mathrm{Cl}_{2}$ ); HRMS (ESI+) calcd for $\mathrm{C}_{15} \mathrm{H}_{20} \mathrm{O}_{2}[\mathrm{M}+\mathrm{Na}]^{+} 255.1355$, found 255.1366. 


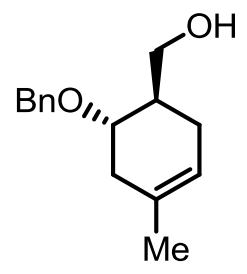

2-29

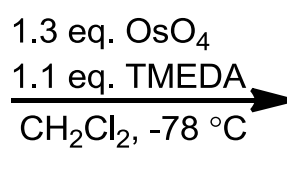

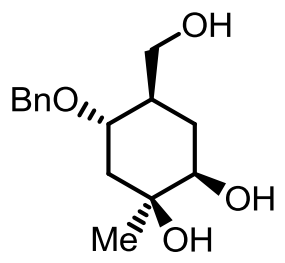

2-30

Triol 2-30: A $500 \mathrm{~mL}$ round bottomed flask was charged with alcohol 2-29 (1.27 g, $5.45 \mathrm{mmol})$, TMEDA $(0.98 \mathrm{~mL}, 6.54 \mathrm{mmol})$ and $\mathrm{CH}_{2} \mathrm{Cl}_{2}(300 \mathrm{~mL})$ and cooled to -78 ${ }^{\circ} \mathrm{C}$. To this flask was added $\mathrm{OsO}_{4}(1.8 \mathrm{~g}, 7.08 \mathrm{mmol})$. The reaction was kept at this temperature for $14 \mathrm{~h}$, then the reaction was quenched with ethylenediamine $(4 \mathrm{~mL})$, and allowed to stir for $48 \mathrm{~h}$ at rt. Silica gel was then added to this mixture, and then it was concentrated. Once concentrated, $\mathrm{MeOH}(40 \mathrm{~mL})$ was added to the flask, and concentrated again. The dry black silica gel was loaded on top of a silica plug, and purified (eluting with $100 \%$ EtOAc to $5 \% \mathrm{MeOH} / \mathrm{EtOAc}$ to $100 \% \mathrm{MeOH}$ ) to yield of triol 2-30 (1.42 g, 98\%, $5.33 \mathrm{mmol})$.

Note: fractions containing product and $\mathrm{MeOH}$ do not register by TLC. It was necessary to remove the methanol and replace with a solvent such as ethyl acetate to determine if product was included in these fractions. This was accomplished by concentrating methanol containing fractions followed by addition of ethyl acetate to the residue, followed by spotting on a TLC plate. After the resultant triol 2-30 was concentrated, it was dissolved in EtOAc and filtered through cotton to remove trace impurities of silica embedded during the $\mathrm{MeOH}$ elution of the column. ${ }^{1} \mathrm{H}$ NMR $(600$ $\mathrm{MHz}_{\mathrm{CDCl}}$ ) $\delta$ ppm 1.26 (br. s., $\left.1 \mathrm{H}\right) 1.31$ (s, $\left.3 \mathrm{H}\right) 1.34-1.53(\mathrm{~m}, 3 \mathrm{H}) 1.67$ - 1.84 $(\mathrm{m}, 3 \mathrm{H}) 2.37(\mathrm{dd}, J=13.2,4.2 \mathrm{~Hz}, 1 \mathrm{H}) 3.50-3.62(\mathrm{~m}, 2 \mathrm{H}) 3.65-3.76(\mathrm{~m}, 2 \mathrm{H})$ $4.45(\mathrm{~d}, J=11.4 \mathrm{~Hz}, 1 \mathrm{H}) 4.68(\mathrm{~d}, J=11.4 \mathrm{~Hz}, 1 \mathrm{H}) 7.29-7.41(\mathrm{~m}, 5 \mathrm{H}) ;{ }^{13} \mathrm{C}$ NMR 
$\left(150 \mathrm{MHz}, \mathrm{CDCl}_{3}\right) \delta \mathrm{ppm} 138.0,128.6,128.0,127.9,78.8,74.0,72.1,70.9,67.1$ 43.5, 41.2, 31.6, 27.4; IR (film) 3409 br, $3054 \mathrm{~s}, 2931 \mathrm{w}, 1637 \mathrm{w} \mathrm{cm}^{-1} ;[\alpha]^{21}=+49.29$ (c = 2.0, $\left.\mathrm{CH}_{2} \mathrm{Cl}_{2}\right)$; HRMS $\left(\mathrm{ESI}+\right.$ ) calcd for $\mathrm{C}_{15} \mathrm{H}_{22} \mathrm{O}_{4}[\mathrm{M}+\mathrm{Na}]^{+}$289.1410, found 289.1424 .

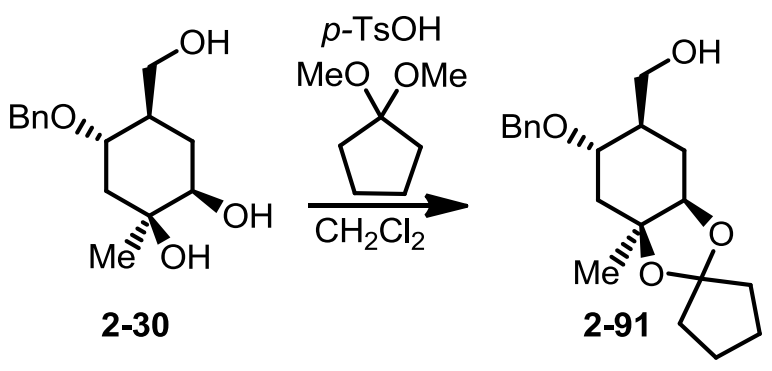

1,1-dimethoxy cyclopentane made according to: Yanagisawa, A.; Taga, M.; Toshiyuki, A.; Nishimura, K.; Ando, K.; Taguchi, T.; Tsumuki, H.; Chujo, I.; Mohri, S. Org. Process Res. Dev. 2011, 15, 376

Ketal 2-91: A $25 \mathrm{~mL}$ round bottomed flask was charged with triol 2-30 (705 mg, 2.65 mmol). To this was added an excess of 1,1-dimethoxy cyclopentane and $p-\mathrm{TsOH}$. The mixture was allowed to stir for $12 \mathrm{~h}$. The reaction was then stirred in $\mathrm{NaOH}_{\text {(aq.) }}$ (20 mL) for $30 \mathrm{~m}$, and extracted with $\mathrm{CH}_{2} \mathrm{Cl}_{2}$. The combined organics were then added in a separation funnel with $10 \% \mathrm{HCl}(40 \mathrm{~mL})$ and shaken for $2 \mathrm{~m}$ (to remove the methoxy cyclopentane from the primary alcohol). The combined organic extracts were dried over $\mathrm{Na}_{2} \mathrm{SO}_{4}$, filtered, and concentrated. The product was purified by column chromatography (eluting with 30\% EtOAc/hexanes) to yield ketal 2-91 (877 $\mathrm{mg}, 100 \%, 2.64 \mathrm{mmol}) .{ }^{1} \mathrm{H}$ NMR $\left(600 \mathrm{MHz}, \mathrm{CDCl}_{3}\right) \delta \mathrm{ppm} 1.35(\mathrm{~s}, 3 \mathrm{H}) 1.44(\mathrm{dd}, J=$ 13.8, 10.8 Hz, 1 H) $1.61(\mathrm{~s}, 2 \mathrm{H}) 1.62-1.67(\mathrm{~m}, 3 \mathrm{H}) 1.68$ - $1.75(\mathrm{~m}, 1 \mathrm{H}) 1.75-1.82$ 
$(\mathrm{m}, 2 \mathrm{H}) 1.83-1.87(\mathrm{~m}, 1 \mathrm{H}) 1.89-1.93(\mathrm{~m}, 1 \mathrm{H}) 1.93-1.99(\mathrm{~m}, 1 \mathrm{H}) 2.23(\mathrm{dd}, J=$ 13.8, 3.0 Hz, $1 \mathrm{H}) 2.91(\mathrm{~d}, J=6.6 \mathrm{~Hz}, 1 \mathrm{H}) 3.66(\mathrm{dd}, J=10.8,4.2 \mathrm{~Hz}, 1 \mathrm{H}) 3.72$ (dd, $J=10.8,4.2 \mathrm{~Hz}, 1 \mathrm{H}$ ) 3.77 (ddd, $J=10.8,9.0,3.0 \mathrm{~Hz}, 1 \mathrm{H}$ ) 3.86 (app. t, $J=4.8 \mathrm{~Hz}, 1$ H) $4.45(\mathrm{~d}, J=11.4 \mathrm{~Hz}, 1 \mathrm{H}) 4.63(\mathrm{~d}, J=11.4 \mathrm{~Hz}, 1 \mathrm{H}) 7.26-7.38(\mathrm{~m}, 5 \mathrm{H}) ;{ }^{13} \mathrm{C}$ NMR $\left(150 \mathrm{MHz}, \mathrm{CDCl}_{3}\right) \delta \mathrm{ppm} 138.3,128.5,127.9,127.7,117.4,80.0,78.2,74.7$, 70.9, 65.7, 40.2, 38.5, 38.0, 37.5, 27.3, 26.7, 24.1, 23.2; IR (film) 3448 br, 3054 s, $2305 \mathrm{w}, 1421 \mathrm{~m} \mathrm{~cm}^{-1} ;[\alpha]^{21}=+5.62\left(\mathrm{c}=2.4, \mathrm{CH}_{2} \mathrm{Cl}_{2}\right)$; HRMS (ESI+) calcd for $\mathrm{C}_{20} \mathrm{H}_{28} \mathrm{O}_{4}[\mathrm{M}+\mathrm{Na}]^{+} 355.1880$, found 355.1870.

\section{$\mathrm{CeCl}_{3} \cdot 2 \mathrm{LiCl}$ preparation}

Cerium trichloride heptahydrate $(50 \mathrm{~g})$ was heated while stirring at $80{ }^{\circ} \mathrm{C}$ at 0.8 $\mathrm{mmHg}$ for 24 hours. Upon cooling to room temperature, the $\mathrm{CeCl}_{3} \cdot \mathrm{H}_{2} \mathrm{O}$ was stored in a desiccator. A portion of this $\mathrm{CeCl}_{3} \cdot \mathrm{H}_{2} \mathrm{O}(2.36 \mathrm{~g}, 8.93 \mathrm{mmol})$ was removed from the desiccator and combined with $0.756 \mathrm{~g} \mathrm{LiCl}(17.83 \mathrm{mmol})$ and $50 \mathrm{~mL}$ freshly distilled $\mathrm{SOCl}_{2}$ in a $100 \mathrm{~mL}$ round bottomed flask topped with a reflux condenser. This was heated at $90{ }^{\circ} \mathrm{C}$ for $12 \mathrm{~h}$ with an acid trap. Once sufficiently cooled, the reflux condenser was removed and replaced with a distillation head. A majority $(40 \mathrm{~mL})$ of $\mathrm{SOCl}_{2}$ was then distilled out of the flask. After cooling to room temperature, the remaining $\mathrm{SOCl}_{2}$ was removed under reduced pressure, with an oil bath to maintain room temperature. After four hours of under vacuum, the material was placed into a $100 \mathrm{~mL}$ Schlenk flask containing a stir bar (note: it is important to change the pump oil at this point to avoid corrosion). This flask was then fitted with a Vigreux 
condenser with a glass stopper sealed on the female end of the condenser. The apparatus was heated at $140{ }^{\circ} \mathrm{C}$ for two days while under vacuum (pressures ranging from $0.8-9.5 \mathrm{mmHg}$ proved effective). After returning to room temperature under pressure, the flask was back-filled with argon and $20 \mathrm{~mL}$ anhydrous degassed THF was injected into the flask, which was then heated at reflux overnight to dissolve the $\mathrm{CeCl}_{3} \cdot 2 \mathrm{LiCl}$ into solution. The resultant solution usually proved successful if clear, milky white, or slightly grey. It was found that reactions employing a solution with any hint of yellow resulted in failed reaction.
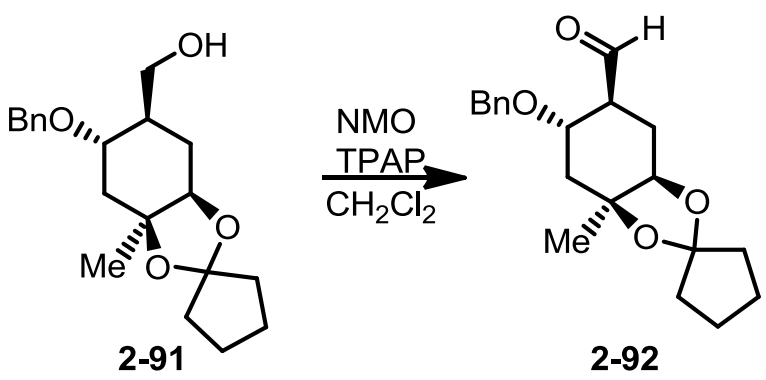

Aldehyde 2-92: Alcohol 2-91 (957 mg, $2.88 \mathrm{mmol})$, activated $4 \AA$ molecular sieves $(1 \mathrm{~g}), \mathrm{CH}_{2} \mathrm{Cl}_{2}(30 \mathrm{~mL})$ and $\mathrm{N}$-methylmorpholine- $\mathrm{N}$-oxide (NMO, $\left.510 \mathrm{mg}, 4.35 \mathrm{mmol}\right)$ were stirred in a $50 \mathrm{~mL}$ round-bottomed flask under argon. After $10 \mathrm{~m}$, tetrapropylammonium perruthenate (TPAP, $51 \mathrm{mg}, 0.145 \mathrm{mmol}$ ) was added and the reaction was stirred until TLC analysis indicated the reaction was done (ca. $3 \mathrm{~h}$ ). When done, the solution was filtered through a plug of silica gel, eluting with $1 \%$ EtOAc/ $/ \mathrm{CH}_{2} \mathrm{Cl}_{2}$. After fractions were combined and concentrated in an oven-dried heart-shaped flask, aldehyde 2-92 (830 $\mathrm{mg}, 2.51 \mathrm{mmol}, 87 \%)$ was combined with a $\mathrm{CeCl}_{3} \cdot 2 \mathrm{LiCl}$ solution $(6.45 \mathrm{~mL}, 2.88 \mathrm{mmol}, 0.45 \mathrm{M})$ under $\mathrm{Ar}$ and allowed to mix for 1 $\mathrm{h}$ prior to addition to dithiane anion mixture. 


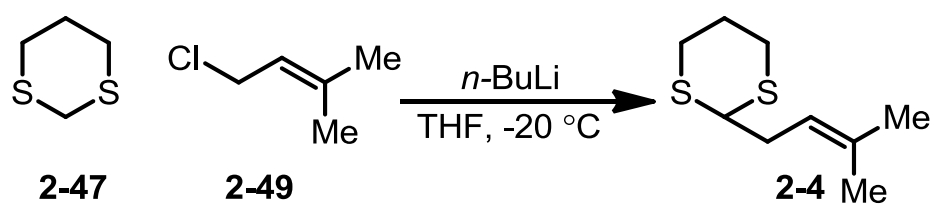

Prenyl dithiane 2-4: A $250 \mathrm{~mL}$ round bottomed flask was charged with 1,3 dithiane 2-47 (3.0 g, $25 \mathrm{mmol})$, THF (40 mL), and a stir bar. A solution of $n$-BuLi $(18.7 \mathrm{~mL}$, 1.6 $\mathrm{M}, 30 \mathrm{mmol}$ ) was added at $-20{ }^{\circ} \mathrm{C}$ and allowed to stir for one hour. The reaction mixture was cooled to $-78{ }^{\circ} \mathrm{C}$ and prenyl chloride $2-49(8.4 \mathrm{~mL}, 75 \mathrm{mmol})$ in THF (10 $\mathrm{mL}$ ) was added to the dithiane anion. The solution was slowly warmed to room temperature. The reaction was quenched with $\mathrm{NH}_{4} \mathrm{Cl}_{(\mathrm{aq} \text {.) }}$, extracted with EtOAc, and purified with column chromatography, eluting with $2 \%$ EtOAc/hexanes, to provide prenyl dithiane $2-4$ (3.9 g, 83\%, $20.74 \mathrm{mmol}) .{ }^{1} \mathrm{H}$ NMR $\left(600 \mathrm{MHz}, \mathrm{CDCl}_{3}\right) \delta \mathrm{ppm} 1.67$ (s, $3 \mathrm{H}) 1.76(\mathrm{~s}, 3 \mathrm{H}) 1.83-1.92(\mathrm{~m}, 1 \mathrm{H}) 2.11-2.17(\mathrm{~m}, 1 \mathrm{H}) 2.47(\mathrm{t}, \mathrm{J}=7.2 \mathrm{~Hz}, 2$ H) $2.81-2.94(\mathrm{~m}, 4 \mathrm{H}) 4.09(\mathrm{t}, J=7.2 \mathrm{~Hz}, 1 \mathrm{H}) 5.24(\mathrm{t}, J=7.2 \mathrm{~Hz}, 1 \mathrm{H}) ;{ }^{13} \mathrm{C}$ NMR (150 MHz, $\left.\mathrm{CDCl}_{3}\right) \delta \mathrm{ppm} 135.0,119.6,48.2,34.2,30.6,25.9,25.8,18.1$; IR (film) $1664 \mathrm{~m} \mathrm{~cm}^{-1}$; HRMS (ESI+) calcd for $\mathrm{C}_{9} \mathrm{H}_{16} \mathrm{~S}_{2}[\mathrm{M}+\mathrm{Na}]^{+} 211.0585$, found 211.0592.<smiles>C[C@]12C[C@H](OCc3ccccc3)[C@@H](C=O)C[C@H]1OC1(CCCC1)O2</smiles>

2-92
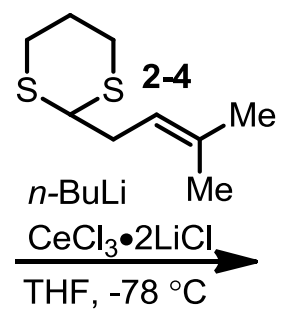

$\mathrm{BnO}$

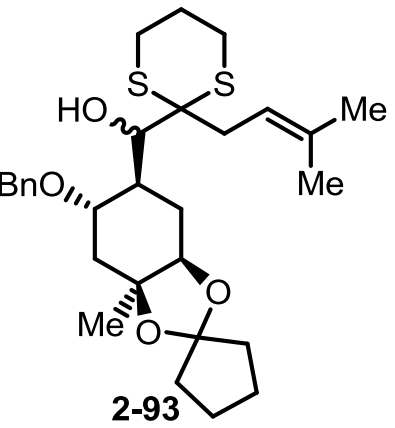

Dithiane 2-93: Dithiane 2-4, (1.2 g, $6.37 \mathrm{mmol})$ was purified immediately prior to use by column chromatography eluting with toluene. This dry dithiane was then 
combined with THF $(30 \mathrm{~mL})$ and HMPA $(1.7 \mathrm{~mL})$ in a $50 \mathrm{~mL}$ round-bottomed flask charged with a magnetic stir bar under argon and cooled to $-78{ }^{\circ} \mathrm{C}$. A solution of $n$ BuLi (2.3 mL, $2.5 \mathrm{M}, 5.75 \mathrm{mmol}$ ) was then added slowly, and the resulting red solution was stirred for $40 \mathrm{~m}$. A portion of the $\mathrm{CeCl}_{3} \cdot 2 \mathrm{LiCl}$ solution $(6.45 \mathrm{~mL}, 0.45 \mathrm{M}$, $2.88 \mathrm{mmol}$ ) was removed from the Schlenk flask, and injected into a $50 \mathrm{~mL}$ heartshaped flask containing aldehyde 2-92. The remaining $\mathrm{CeCl}_{3} \cdot 2 \mathrm{LiCl}$ solution (13.55 $\mathrm{mL}, 6.05 \mathrm{mmol}$ ) was brought to $-78{ }^{\circ} \mathrm{C}$, and the dithiane anion solution was slowly added via cannula, keeping the solution cold by clamping dry ice to the cannula. The solution was then stirred for $2.5 \mathrm{~h}$. Premade aldehyde- $\mathrm{CeCl}_{3} \cdot 2 \mathrm{LiCl}$ solution was added dropwise via syringe, and the reaction mixture was stirred overnight. The reaction was then quenched with $\mathrm{NH}_{4} \mathrm{Cl}_{\text {(aq.) }}$, filtered through a plug of Celite (to minimize emulsions), and extracted with $\mathrm{Et}_{2} \mathrm{O}(8 \times 125 \mathrm{~mL})$, and concentrated under reduced pressure. This crude oil was then combined with EtOH $(30 \mathrm{~mL})$ and was allowed to react with excess $\mathrm{NaBH}_{4}$ for $20 \mathrm{~m}$ (to reduce any unreacted aldehyde, which co-spots with product). At this time, the reaction was quenched with $\mathrm{NH}_{4} \mathrm{Cl}_{(\text {aq.) }}$ at $0{ }^{\circ} \mathrm{C}$ and the ethanol was removed under reduced pressure. The residue was diluted with brine, and the aqueous solution was washed with $\mathrm{Et}_{2} \mathrm{O}$, dried over $\mathrm{MgSO}_{4}$, and concentrated under reduced pressure. The product was separated with column chromatography eluting with $5 \%$ to $10 \%$ EtOAc/hexanes to yield dithiane 293 (935 mg, $1.8 \mathrm{mmol}, 72 \%) .{ }^{1} \mathrm{H}$ NMR $\left(600 \mathrm{MHz}, \mathrm{CDCl}_{3}\right) \delta \mathrm{ppm} 1.42(\mathrm{~s}, 3 \mathrm{H}) 1.61(\mathrm{~s}$, $3 \mathrm{H}) 1.69(\mathrm{~d}, J=3.2 \mathrm{~Hz}, 4 \mathrm{H}) 1.76(\mathrm{~s}, 3 \mathrm{H}) 1.78-1.88(\mathrm{~m}, 3 \mathrm{H}) 1.93(\mathrm{~m}, 3 \mathrm{H}) 2.00$ (br. s., 1 H) $2.10-2.17(\mathrm{~m}, 2 \mathrm{H}) 2.22(\mathrm{dd}, J=13.8,3.2 \mathrm{~Hz}, 1 \mathrm{H}) 2.34-2.41(\mathrm{~m}, 1 \mathrm{H})$ $2.57(\mathrm{dd}, J=15.6,6.0 \mathrm{~Hz}, 1 \mathrm{H}) 2.65-2.77(\mathrm{~m}, 3 \mathrm{H}) 2.89-2.97(\mathrm{~m}, 1 \mathrm{H}) 3.06-3.16$ 
$(\mathrm{m}, 1 \mathrm{H}) 3.47(\mathrm{~d}, J=3.6 \mathrm{~Hz}, 1 \mathrm{H}) 3.83-3.90(\mathrm{~m}, 1 \mathrm{H}) 4.15-4.25(\mathrm{~m}, 2 \mathrm{H}) 4.48(\mathrm{~d}, J$ $=11.4 \mathrm{~Hz}, 1 \mathrm{H}) 4.62(\mathrm{~d}, J=11.4 \mathrm{~Hz}, 1 \mathrm{H}) 5.38(\mathrm{t}, J=4.2 \mathrm{~Hz}, 1 \mathrm{H}) 7.29-7.41(\mathrm{~m}, 5$ $\mathrm{H}) ;{ }^{13} \mathrm{CNMR}\left(150 \mathrm{MHz}, \mathrm{CDCl}_{3}\right) \delta 138.7,134.5,128.3,127.5,127.4,119.1,117.2$, $78.9,75.1,74.9,70.2,59.9,38.3,38.1,37.3,36.7,33.3,29.7,29.7,26.5,26.3,26.0$ 25.8, 24.6, 23.8, 23.4, 18.3; IR (film) 3054 m, 2986 m, 2305 w, 1421 m, $1265 \mathrm{~s} \mathrm{~cm}^{-}$ ${ }^{1} ;[\alpha]^{21}=+5.52\left(\mathrm{c}=0.445, \mathrm{CH}_{2} \mathrm{Cl}_{2}\right) ; \operatorname{HRMS}(\mathrm{ESI}+)$ calcd for $\mathrm{C}_{29} \mathrm{H}_{42} \mathrm{O}_{4} \mathrm{~S}_{2}[\mathrm{M}+\mathrm{Cs}]^{+}$ 651.1574 , found 651.1524 .
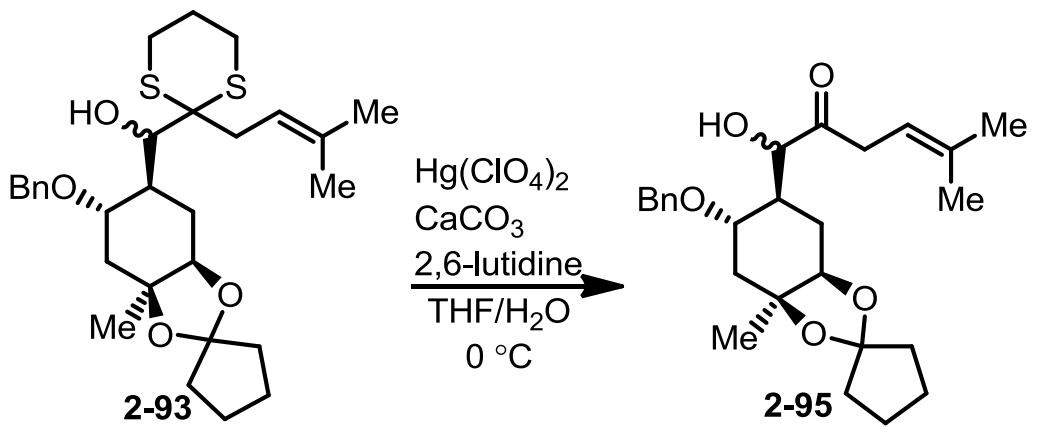

Hydroxy ketone 2-95: Dithiane 2-93 (28 $\mathrm{mg}, 0.054 \mathrm{mmol})$ was combined with $\mathrm{CaCO}_{3}(60 \mathrm{mg}, 0.6 \mathrm{mmol})$ and 2,6-lutidine $(0.063 \mathrm{~mL}, 0.54 \mathrm{mmol})$ in THF $(5.6 \mathrm{~mL})$ and $\mathrm{H}_{2} \mathrm{O}(0.56 \mathrm{~mL})$ at $0{ }^{\circ} \mathrm{C}$. To this was added $\mathrm{Hg}\left(\mathrm{ClO}_{4}\right)_{2} \bullet 4 \mathrm{H}_{2} \mathrm{O}(54 \mathrm{mg}, 0.11 \mathrm{mmol})$, and the mixture was stirred for $20 \mathrm{~s}$, poured into $\mathrm{NaHCO}_{3 \text { (aq.), }}$ then filtered through a pad of Celite. The layers were separated and the aqueous layer was extracted with EtOAc. The organic layer was dried with $\mathrm{Na}_{2} \mathrm{SO}_{4}$ and concentrated, then hydroxy ketone 2-95 used directly in the next reaction. ${ }^{1} \mathrm{H} \mathrm{NMR}\left(600 \mathrm{MHz}, \mathrm{CDCl}_{3}\right) \delta \mathrm{ppm}$ $1.35(\mathrm{~s}, 3 \mathrm{H}) 1.47(\mathrm{~s}, 3 \mathrm{H}) 1.49-1.53(\mathrm{~m}, 1 \mathrm{H}) 1.64(\mathrm{~s}, 3 \mathrm{H}) 1.65-1.70(\mathrm{~m}, 4 \mathrm{H}) 1.80$ - $1.86(\mathrm{~m}, 2 \mathrm{H}) 1.90-1.99(\mathrm{~m}, 3 \mathrm{H}) 1.99-2.06(\mathrm{~m}, 1 \mathrm{H}) 2.20-2.27(\mathrm{~m}, 1 \mathrm{H}) 2.33$ (dd, $J=14.4,4.2 \mathrm{~Hz}, 1 \mathrm{H}) 3.13(\mathrm{dd}, J=17.4,7.2 \mathrm{~Hz}, 1 \mathrm{H}) 3.23(\mathrm{dd}, J=17.4,7.2 \mathrm{~Hz}$ 
$1 \mathrm{H}) 3.71(\mathrm{td}, J=9.6,4.2 \mathrm{~Hz}, 1 \mathrm{H}) 3.94(\mathrm{dd}, J=7.8,5.4 \mathrm{~Hz}, 1 \mathrm{H}) 3.98-4.00(\mathrm{~m}, 1 \mathrm{H})$ $4.02(\mathrm{~d}, J=3.0 \mathrm{~Hz}, 1 \mathrm{H}) 4.17(\mathrm{~d}, J=10.8 \mathrm{~Hz}, 1 \mathrm{H}) 4.36(\mathrm{~d}, J=10.8 \mathrm{~Hz}, 1 \mathrm{H}) 5.10(\mathrm{t}$, $J=7.2 \mathrm{~Hz}, 1 \mathrm{H}) 7.22-7.31(\mathrm{~m}, 5 \mathrm{H}) ;{ }^{13} \mathrm{CNMR}\left(150 \mathrm{MHz}, \mathrm{CDCl}_{3}\right) \delta$ 209.2, 138.0, $135.6,128.4,128.3,127.7,118.1,115.8,80.6,78.8,77.9,72.0,71.0,43.1,39.1$, $39.0,38.9,38.0,30.4,27.2,25.7,24.1,23.6,18.1$

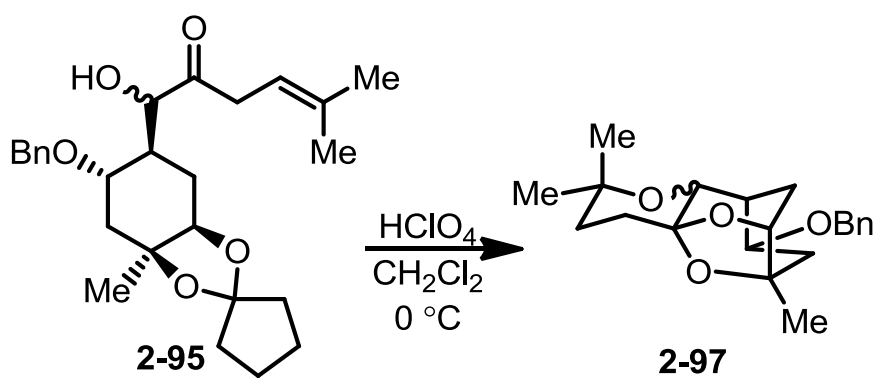

Tetracycle 2-89: Hydroxy ketone 2-97 from the previous reaction was combined with $\mathrm{CH}_{2} \mathrm{Cl}_{2}(10 \mathrm{~mL})$ at $0{ }^{\circ} \mathrm{C}$. To this was added $\mathrm{HClO}_{4}(70 \%, 5.7 \mu \mathrm{L}, 0.066 \mathrm{mmol})$. After TLC indicated the disappearance of starting material (ca. $10 \mathrm{~m}$ ), sat. $\mathrm{NaHCO}_{3 \text { (aq.) }}(2 \mathrm{~mL})$ was added to the reaction flask. The layers were separated, the aqueous layer extracted $\left(\mathrm{CH}_{2} \mathrm{Cl}_{2}\right)$ and concentrated under reduced pressure. The product was separated with column chromatography eluting with $70 \%-100 \%$ EtOAc/hexanes, providing tetracycle 2-97 (18.6 mg, 100\%, $0.054 \mathrm{mmol}) .{ }^{1} \mathrm{H}$ NMR $\left(600 \mathrm{MHz}, \mathrm{CDCl}_{3} / \mathrm{D}_{2} \mathrm{O}\right) \delta \mathrm{ppm} 1.21-1.28(\mathrm{~m}, 7 \mathrm{H}) 1.47$ - $1.56(\mathrm{~m}, 4 \mathrm{H})$ 1.63-1.75 (m, 2 H) $1.82-1.86(\mathrm{~m}, 2$ H) $2.07-2.10(\mathrm{~m}, 1 \mathrm{H}) 2.15$ (br. s., 1 H) 2.44 (dd, $J=13.8,7.8$ Hz, 1 H) $3.20(\mathrm{~s}, 1 \mathrm{H}) 3.88(\mathrm{t}, J=7.8 \mathrm{~Hz}, 1 \mathrm{H}) 4.05(\mathrm{~s}, 1 \mathrm{H}) 4.45(\mathrm{~d}, J=11.4 \mathrm{~Hz}, 1 \mathrm{H})$ $4.57(\mathrm{~d}, J=11.4 \mathrm{~Hz}, 1 \mathrm{H}) 7.20-7.38(\mathrm{~m}, 5 \mathrm{H}) ;{ }^{13} \mathrm{C} \mathrm{NMR}\left(150 \mathrm{MHz}, \mathrm{CDCl}_{3}\right) \delta$ 138.5, $128.4,127.6,127.5,103.8,79.5,78.5,76.3,72.0,71.9,70.4,37.5,37.4,34.3,30.9$, 28.5, 27.0, 22.8, 21.7; $\mathrm{MS}(\mathrm{ESI}+)$ calcd for $\mathrm{C}_{21} \mathrm{H}_{28} \mathrm{O}_{4}[\mathrm{M}+\mathrm{Na}]^{+} 367.19$, found 367.21. 


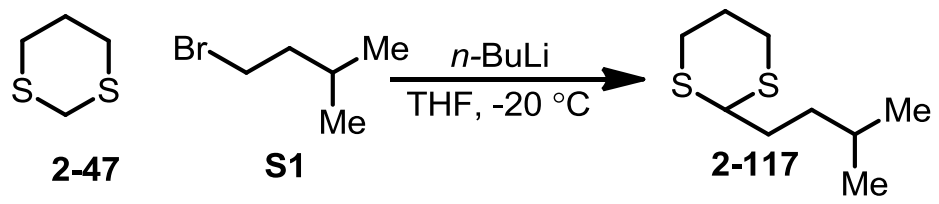

Dithiane 2-117: A $50 \mathrm{~mL}$ round bottomed flask was charged with 1,3 dithiane 247(800 mg, $6.6 \mathrm{mmol})$, THF (16 mL), and a stir bar. A solution of $n$-BuLi (3.46 mL, 1.6 $\mathrm{M}, 5.5 \mathrm{mmol}$ ) was added at $-20{ }^{\circ} \mathrm{C}$ and the solution was allowed to stir for one hour. The reaction mixture was cooled to $-78{ }^{\circ} \mathrm{C}$ and 1-bromo-3-methylbutane S1 (3.35 mL, $26 \mathrm{mmol})$ in THF $(5 \mathrm{~mL})$ was added to the dithiane anion. The solution was slowly warmed to room temperature. The reaction was quenched with $\mathrm{NH}_{4} \mathrm{Cl}_{\text {(aq.), }}$, extracted with EtOAc, and purified with column chromatography, eluting with $2 \%$ EtOAc/hexanes, to provide prenyl dithiane 2-117 (940 mg, 75\%, 4.94 mmol). ${ }^{1} \mathrm{H}$ NMR $\left(400 \mathrm{MHz}, \mathrm{CDCl}_{3}\right) \delta \mathrm{ppm} 0.9(\mathrm{~m}, 6 \mathrm{H}) 1.35$ - $1.45(\mathrm{~m}, 2 \mathrm{H})$ 1.51-1.63 $(\mathrm{m}, 1 \mathrm{H}) 1.70-1.80(\mathrm{~m}, 2 \mathrm{H}) 1.80-1.90(\mathrm{~m}, 1 \mathrm{H}) 2.10-2.20(\mathrm{~m}, 1 \mathrm{H})$ 2.8-3.0 (m, $4 \mathrm{H})$ 4.05 (t, J = 7.2 Hz, $1 \mathrm{H}) ;{ }^{13} \mathrm{C}$ NMR $\left(150 \mathrm{MHz}, \mathrm{CDCl}_{3}\right) \delta 48.0,35.7,33.4,30.6,27.8$, 26.1, 22.5; IR (film) $2958 \mathrm{~s}, 2253.4 \mathrm{w}, 908 \mathrm{~s} \mathrm{~cm}^{-1}$.

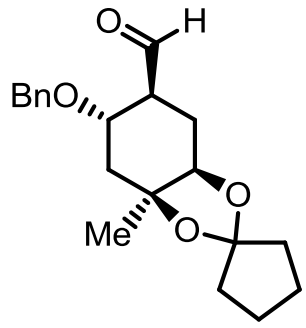

2-92
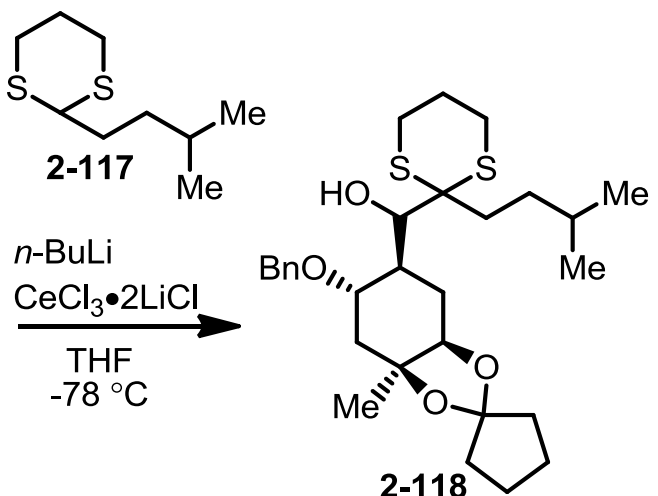

Dithiane 2-118: Saturated dithiane 2-117, (127 $\mathrm{mg}, 0.67 \mathrm{mmol}$ ) was purified immediately prior to use by column chromatography eluting with toluene. This dry 
dithiane was then combined with THF $(3.6 \mathrm{~mL})$ and HMPA $(0.2 \mathrm{~mL})$ in a $15 \mathrm{~mL}$ round-bottomed flask charged with a magnetic stir bar under argon and cooled to $78{ }^{\circ} \mathrm{C}$. A solution of $n$-BuLi $(0.24 \mathrm{~mL}, 2.5 \mathrm{M}, 0.6 \mathrm{mmol})$ was then added slowly, and the resulting red solution was stirred for $40 \mathrm{~m}$. A portion of a $\mathrm{CeCl}_{3} \cdot 2 \mathrm{LiCl}$ solution ( 3 $\mathrm{mL}, 0.22 \mathrm{M}, 0.67 \mathrm{mmol}$ ) was removed from the Schlenk flask, and injected into a 10 $\mathrm{mL}$ heart-shaped flask, to be combined with aldehyde 2-92. The remaining solution ( $3 \mathrm{~mL}, 0.22 \mathrm{M}, 0.67 \mathrm{mmol}$ ) was brought to $-78{ }^{\circ} \mathrm{C}$, and the dithiane anion solution was slowly added via cannula, keeping the solution cold by clamping dry ice to the cannula. The solution was then stirred for $3 \mathrm{~h}$. Premade aldehyde- $\mathrm{CeCl}_{3} \cdot 2 \mathrm{LiCl}$ solution (26.4 mg aldehyde; $0.079 \mathrm{mmol}$ ) was added dropwise via syringe, and the reaction mixture was stirred overnight. The reaction was then quenched with $\mathrm{NH}_{4} \mathrm{Cl}_{\text {(aq.) }}$, filtered through a plug of Celite (to minimize emulsions), and extracted with $\mathrm{Et}_{2} \mathrm{O}$, and concentrated under reduced pressure. This crude oil was then combined with $10 \mathrm{~mL} \mathrm{EtOH}$ and was allowed to react with excess $\mathrm{NaBH}_{4}$ for $20 \mathrm{~m}$ (to reduce any unreacted aldehyde, which co-spots with product). At this time, the reaction was quenched with $\mathrm{NH}_{4} \mathrm{Cl}_{(\text {aq. }}$ at $0{ }^{\circ} \mathrm{C}$ and the ethanol was removed under reduced pressure. The residue was diluted with brine, and the aqueous solution was washed with $\mathrm{Et}_{2} \mathrm{O}$, dried over $\mathrm{MgSO}_{4}$, and concentrated under reduced pressure. The product was separated with column chromatography eluting with $5 \%$ to $10 \%$ EtOAc/hexanes to yield dithiane 2-118 (34 mg, $0.065 \mathrm{mmol}, 81 \%) .{ }^{1} \mathrm{H}$ NMR (600 $\left.\mathrm{MHz}, \mathrm{CDCl}_{3}\right) \delta \mathrm{ppm} 0.89(\mathrm{~m}, 6 \mathrm{H}) 1.38-1.51(\mathrm{~m}, 3 \mathrm{H})$ 1.55-1.61 (m, $\left.3 \mathrm{H}\right)$ 1.62-1.75 $(\mathrm{m}, 3 \mathrm{H}) 1.76-1.90(\mathrm{~m}, 3 \mathrm{H}) 1.91-2.0(\mathrm{~m}, 2 \mathrm{H})$ 2.0-210 (m, 2 H) 2.1-2.2 (m, 2 H) 2.2-2.3 (m, $1 \mathrm{H})$ 2.32-2.4 (m, $2 \mathrm{H})$ 2.5-2.6 (m, $1 \mathrm{H})$ 2.65-2.75 (m, $2 \mathrm{H})$ 2.90-3.0 (m, 2 
H) $3.05-3.18(\mathrm{~m}, 1 \mathrm{H}) 3.43(\mathrm{~d}, J=3.6 \mathrm{~Hz}, 1 \mathrm{H}) 3.87(\mathrm{t}, J=3.6,1 \mathrm{H}) 4.10-4.19(\mathrm{~m}, 1$

H) $4.19-4.23(\mathrm{t}, J=4.2 \mathrm{~Hz}, 1 \mathrm{H}) 4.46(\mathrm{~d}, J=11.4 \mathrm{~Hz}, 1 \mathrm{H}) 4.62(\mathrm{~d}, J=11.4 \mathrm{~Hz}, 1 \mathrm{H})$ $7.36(\mathrm{~m}, 5 \mathrm{H})$.

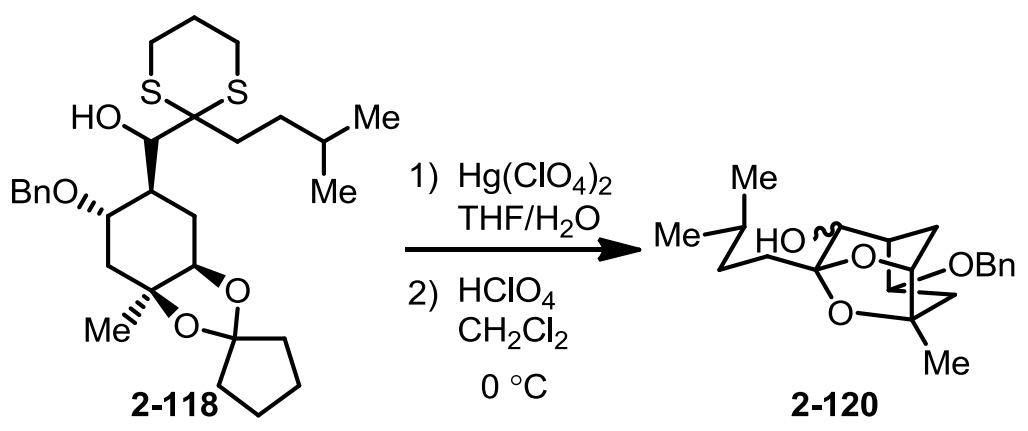

Tricycle 2-120: Dithiane 2-118 (16 mg, $0.03 \mathrm{mmol}$ ) was combined with $\mathrm{CaCO}_{3}$ (30 $\mathrm{mg}, 0.3 \mathrm{mmol})$ in THF $(2 \mathrm{~mL})$ and $\mathrm{H}_{2} \mathrm{O}(0.4 \mathrm{~mL})$ at $0{ }^{\circ} \mathrm{C}$. To this solution was added $\mathrm{Hg}\left(\mathrm{ClO}_{4}\right)_{2} \bullet 4 \mathrm{H}_{2} \mathrm{O}(30 \mathrm{mg}, 0.064 \mathrm{mmol})$, and the mixture was stirred for $40 \mathrm{~s}$, poured

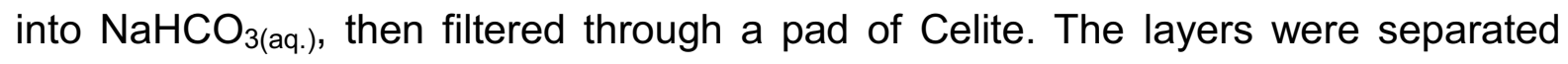
and the aqueous layer was extracted with EtOAc. The organic layer was dried with $\mathrm{Na}_{2} \mathrm{SO}_{4}$ and concentrated, then combined with $\mathrm{CH}_{2} \mathrm{Cl}_{2}(10 \mathrm{~mL})$ at $0{ }^{\circ} \mathrm{C}$. To this hydroxy ketone 2-119 was added $\mathrm{HClO}_{4}(70 \%, 1.6 \mu \mathrm{L}, 0.018 \mathrm{mmol})$. After TLC indicated the disappearance of starting material (ca. $10 \mathrm{~min}$ ), sat. $\mathrm{NaHCO}_{3 \text { (aq.) }}(2 \mathrm{~mL}$ ) was added to the reaction flask. The layers were separated, the aqueous layer extracted $\left(\mathrm{CH}_{2} \mathrm{Cl}_{2}\right)$ and concentrated under reduced pressure. The product was separated with column chromatography eluting with $30 \%$ EtOAc/hexanes. The fractions containing product were concentrated, providing tricycle 2-120 (10.6 mg, 100\%, $0.03 \mathrm{mmol})$. Major isomer: ${ }^{1} \mathrm{H}$ NMR $\left(600 \mathrm{MHz}, \mathrm{CDCl}_{3}\right) \delta \mathrm{ppm}$ 0.89-0.92 (m, 6 H) $1.28-1.31(\mathrm{~m}, 6 \mathrm{H})$ 1.50-1.70 (m, 2 H) $1.80-1.85(\mathrm{~m}, 2 \mathrm{H})$ 2.00-2.10 (m, 2 H) 2.30 
$(\mathrm{t}, J=1.8 \mathrm{~Hz}, 1 \mathrm{H}) 2.47(\mathrm{dd}, J=14.4,7.8 \mathrm{~Hz}, 1 \mathrm{H}) 3.33(\mathrm{~d}, J=2.4 \mathrm{~Hz}, 1 \mathrm{H}) 3.89(\mathrm{t}, J$ $=7.8 \mathrm{~Hz}, 1 \mathrm{H}) 4.08(\mathrm{~d}, J=1.8 \mathrm{~Hz}, 1 \mathrm{H}) 4.49(\mathrm{~d}, J=12.0 \mathrm{~Hz}, 1 \mathrm{H}) 4.56(\mathrm{~d}, J=12.0$ $\mathrm{Hz}, 1 \mathrm{H}) 7.34(\mathrm{~m}, 5 \mathrm{H}) ;{ }^{13} \mathrm{C} \mathrm{NMR}\left(150 \mathrm{MHz}, \mathrm{CDCl}_{3}\right) \delta \mathrm{ppm} 138.4,128.5,127.7$, $127.6,109.1,80.0,78.6,75.0,72.6,70.5,40.1,37.3,30.7,30.6,28.2,26.5,22.7$, 22.6, 22.5; IR (film) 3408 br., 3051 m, 1421 m, $1265 \mathrm{~s} \mathrm{~cm}^{-1}$; HRMS (ESI+) calcd for $\mathrm{C}_{21} \mathrm{H}_{30} \mathrm{O}_{4}[\mathrm{M}+\mathrm{Na}]^{+} 369.2036$, found 369.2048.

To compare to a compound prepared by Professor Greg Dudley
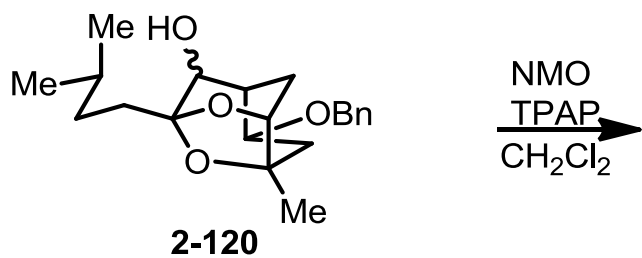

2-120

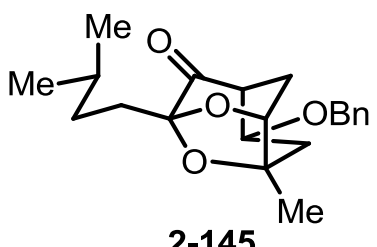

Ketone 2-144: Alcohol 2-120 (2.3 mg, $0.0066 \mathrm{mmol}), 200 \mathrm{mg}$ activated $4 \AA$ molecular sieves, $\mathrm{CH}_{2} \mathrm{Cl}_{2}(1 \mathrm{~mL})$ and $\mathrm{N}$-methylmorpholine- $\mathrm{N}$-oxide (NMO, $1.16 \mathrm{mg}$, $0.0099 \mathrm{mmol}$ ) were stirred in a $10 \mathrm{~mL}$ round-bottomed flask under argon. After 10 $\mathrm{m}$, tetrapropylammonium perruthenate (TPAP, $0.116 \mathrm{mg}, 0.00033 \mathrm{mmol}$ ) was added and the reaction was stirred until TLC analysis indicated the reaction was done. When done, the solution was filtered through a plug of silica gel, eluting with EtOAc, providing carbonyl 2-145 $(2.1 \mathrm{mg}, 92 \%, 0.0061 \mathrm{mmol})$. The spectrum of this compound is nearly identical to a compound prepared by Professor Greg Dudley (protecting group is PMB). ${ }^{1} \mathrm{H}$ NMR $\left(600 \mathrm{MHz}, \mathrm{CDCl}_{3}\right) \delta \mathrm{ppm} 0.91-0.93(\mathrm{~m}, 6 \mathrm{H})$ 1.26 - $1.36(\mathrm{~m}, 2 \mathrm{H}) 1.39(\mathrm{~s}, 3 \mathrm{H}) 1.51-1.61(\mathrm{~m}, 1 \mathrm{H}) 1.69-1.84(\mathrm{~m}, 3 \mathrm{H}) 2.20(\mathrm{~d}, J$ $=13.8 \mathrm{~Hz}, 1 \mathrm{H}) 2.31(\mathrm{~d}, J=13.8 \mathrm{~Hz}, 1 \mathrm{H}) 2.53(\mathrm{dd}, J=14.4,7.8 \mathrm{~Hz}, 1 \mathrm{H}) 2.92(\mathrm{br}$. s., 1 H) 3.81 (t, J = $7.8 \mathrm{~Hz}, 1 \mathrm{H}) 4.24(\mathrm{~d}, J=1.8 \mathrm{~Hz}, 1 \mathrm{H}) 4.45(\mathrm{~d}, J=12.0 \mathrm{~Hz}, 1 \mathrm{H})$ 
$4.59(\mathrm{~d}, J=12.0 \mathrm{~Hz}, 1 \mathrm{H}) 7.30-7.40(\mathrm{~m}, 5 \mathrm{H}) ;{ }^{13} \mathrm{C} \mathrm{NMR}\left(150 \mathrm{MHz}, \mathrm{CDCl}_{3}\right) \delta \mathrm{ppm}$ $200.4,137.8,128.4,127.8,127.6,108.4,79.73,79.6,74.4,70.9,48.1,37.1,30.5$, 29.2, 28.1, 26.8, 26.6, 22.5, 22.4; IR (film) $3054 \mathrm{~m}, 2985 \mathrm{~m}, 1729 \mathrm{~s}, 1421 \mathrm{~m} \mathrm{~cm}^{-1}$; $[\alpha]^{27}=+43.73\left(\mathrm{c}=1.3, \mathrm{CH}_{2} \mathrm{Cl}_{2}\right)$; HRMS $(\mathrm{ESI}+)$ calcd for $\mathrm{C}_{21} \mathrm{H}_{28} \mathrm{O}_{4}[\mathrm{M}+\mathrm{Na}]^{+}$367.1880, found 367.1888 .

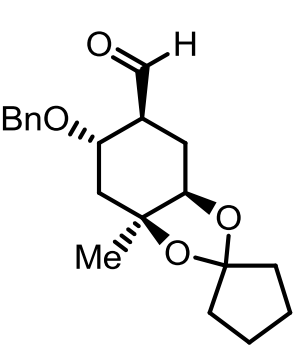

2-92
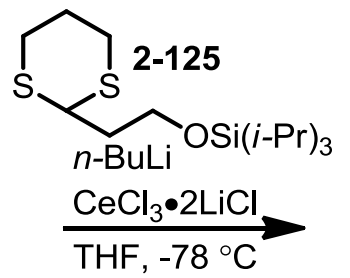

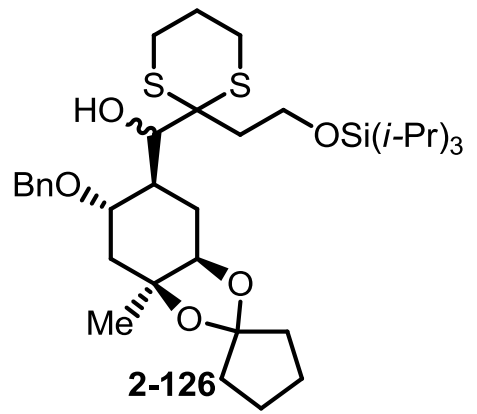

Dithiane 2-126: Dithiane 2-125 (2.24 g, $6.98 \mathrm{mmol})$ was combined with THF (25 $\mathrm{mL}$ ) and HMPA (1.25 mL) in a $50 \mathrm{~mL}$ round-bottomed flask charged with a magnetic stir bar under argon and cooled to $-78{ }^{\circ} \mathrm{C}$. A solution of $n$-BuLi $(2.54 \mathrm{~mL}, 2.5 \mathrm{M}, 6.35$ mmol) was then added slowly, and the resulting pale brown solution was stirred for $40 \mathrm{~m}$. After $40 \mathrm{~m}$, the dithiane anion solution was added via cannula to a solution of $\mathrm{CeCl}_{3} \cdot 2 \mathrm{LiCl}$ in THF $(13.5 \mathrm{~mL}, 0.47 \mathrm{M}, 6.35 \mathrm{mmol})$, as before, the cannula was maintained at a low temperature. The solution was then stirred for $2.5 \mathrm{~h}$. A premixed aldehyde- $\mathrm{CeCl}_{3} \cdot 2 \mathrm{LiCl}$ solution $(575 \mathrm{mg}$ aldehyde $2-92$ [1.74 mmol] in a 5.5 $\mathrm{mL}$ solution $0.47 \mathrm{M}$ of $\mathrm{CeCl}_{3} \cdot 2 \mathrm{LiCl}$ in THF) was added dropwise via syringe, and the green reaction mixture was stirred overnight at $-78{ }^{\circ} \mathrm{C}$. The reaction was then quenched with $\mathrm{NH}_{4} \mathrm{Cl}_{(\text {aq.) }}$, filtered through Celite (to minimize emulsions), and 
extracted with $\mathrm{Et}_{2} \mathrm{O}(8 \times 125 \mathrm{~mL})$, and concentrated under reduced pressure. This crude oil was then combined with $\mathrm{EtOH}(30 \mathrm{~mL})$ and was allowed to react with excess $\mathrm{NaBH}_{4}$ for $20 \mathrm{~m}$ (to reduce any unreacted aldehyde). At this time, the reaction was quenched with $\mathrm{NH}_{4} \mathrm{Cl}_{(\text {aq.) }}$ at $0{ }^{\circ} \mathrm{C}$ and the ethanol was removed under reduced pressure. The residue was diluted with brine, and the aqueous solution was washed with $\mathrm{Et}_{2} \mathrm{O}$, dried over $\mathrm{MgSO}_{4}$, and concentrated under reduced pressure. The product was separated with column chromatography using $5 \%$ to $10 \%$ EtOAc/hexanes, affording dithiane 2-126 (905 mg, 80\%, 2.7:1 d.r., $1.39 \mathrm{mmol})$. Major isomer: ${ }^{1} \mathrm{H}$ NMR $\left(600 \mathrm{MHz}, \mathrm{CDCl}_{3}\right) \delta \mathrm{ppm} 1.00-1.14(\mathrm{~m}, 21 \mathrm{H}) 1.39(\mathrm{~s}, 3 \mathrm{H})$ $1.60-1.70(\mathrm{~m}, 4 \mathrm{H})$ 1.7-1.8 (m, $2 \mathrm{H}) 1.84-1.91(\mathrm{~m}, 3 \mathrm{H})$ 1.91-2.0 (m, $2 \mathrm{H})$ 2.05-2.1 $(\mathrm{m}, 1 \mathrm{H}) 2.13$ - $2.21(\mathrm{~m}, 3 \mathrm{H})$ 2.3-2.37 (m, $1 \mathrm{H})$ 2.4-2.45 (m, $1 \mathrm{H}) 2.67$ - $2.75(\mathrm{~m}, 2 \mathrm{H})$ 2.82-2.9 (m, 1 H) 3.0-3.07 (m, 1 H) $3.69(\mathrm{~d}, J=3.8 \mathrm{~Hz}, 1 \mathrm{H}) 3.84(\mathrm{dd}, J=5.0,4.0$ $\mathrm{Hz}, 1 \mathrm{H}) 3.93-4.00(\mathrm{~m}, 2 \mathrm{H}) 4.11-4.18(\mathrm{~m}, 2 \mathrm{H}) 4.48(\mathrm{~d}, J=12.0 \mathrm{~Hz}, 1 \mathrm{H}) 4.57(\mathrm{~d}, J$ $=12.0 \mathrm{~Hz}, 1 \mathrm{H}) 7.29-7.36(\mathrm{~m}, 5 \mathrm{H}) ;{ }^{13} \mathrm{C}$ NMR $\left(150 \mathrm{MHz}, \mathrm{CDCl}_{3}\right) \delta \mathrm{ppm} 138.8$, 128.3, 127.4, 127.3, 117.1, 78.9, 78.8, 75.2, 70.3, 60.4, 58.1, 38.4, 38.3, 37.8, 37.4, 36.6, 29.5, 26.3, 26.2, 25.8, 24.8, 23.8, 23.4, 18.1, 12.0; IR (film) 3420 br, $3053 \mathrm{~s}$, $2960 \mathrm{~m}, 1265 \mathrm{~m} \mathrm{~cm}^{-1} ;[\alpha]^{21}=+9.06\left(\mathrm{c}=2.9, \mathrm{CH}_{2} \mathrm{Cl}_{2}\right)$; HRMS $(\mathrm{ESI}+)$ calcd for $\mathrm{C}_{35} \mathrm{H}_{58} \mathrm{O}_{5} \mathrm{~S}{ }_{2} \mathrm{Si}[\mathrm{M}+\mathrm{Na}]^{+}$673.3387, found 673.3381 . 

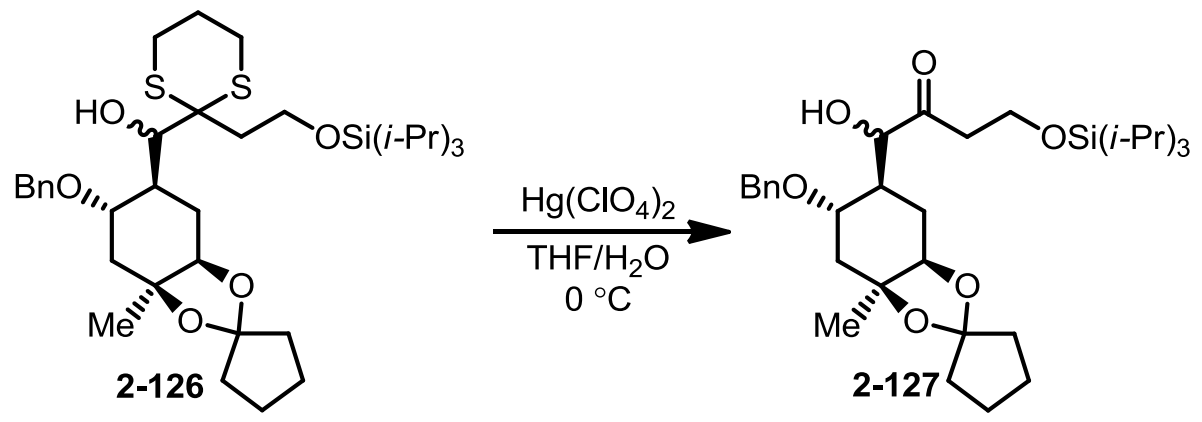

Hydroxy-ketone 2-127: Dithiane 2-126 (195 mg, $0.299 \mathrm{mmol}$ ) was combined with $\mathrm{CaCO}_{3}(350 \mathrm{mg}, 3.5 \mathrm{mmol})$ in THF $(28 \mathrm{~mL})$ and $\mathrm{H}_{2} \mathrm{O}(5.5 \mathrm{~mL})$ at $0{ }^{\circ} \mathrm{C}$. To this solution was added $\mathrm{Hg}\left(\mathrm{ClO}_{4}\right)_{2} \bullet 4 \mathrm{H}_{2} \mathrm{O}(296 \mathrm{mg}, 0.627 \mathrm{mmol})$, and the mixture was

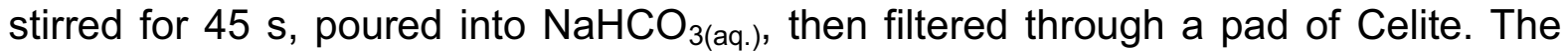
layers were separated and the aqueous layer was extracted with EtOAc. The organic layer was dried with $\mathrm{Na}_{2} \mathrm{SO}_{4}$ and concentrated to provide hydroxy ketone 2127 (168 mg, $0.299 \mathrm{mmol}$ ), which was then used directly in the next reaction. ${ }^{1} \mathrm{H}$ NMR (600 MHz, $\left.\mathrm{CDCl}_{3}\right) \delta$ ppm 1.02 (br. s., $\left.21 \mathrm{H}\right) 1.34$ (s, $\left.3 \mathrm{H}\right) 1.51$ (dd, $J=$ 14.4, $10.8 \mathrm{~Hz}, 1 \mathrm{H}) 1.68$ (br. s., 4 H) $1.86(\mathrm{~d}, J=5.4 \mathrm{~Hz}, 2 \mathrm{H}) 1.94-2.06(\mathrm{~m}, 4 \mathrm{H}) 2.25$ (br. s., 1 H) 2.41 (dd, $J=14.4,4.2 \mathrm{~Hz}, 1 \mathrm{H}) 2.60-2.85(\mathrm{~m}, 2 \mathrm{H}) 3.72(\mathrm{dd}, J=7.8,4.2 \mathrm{~Hz}$, 2 H) 3.81-3.91 (m, 1 H) 3.97 (t, J = 7.8 Hz, 1 H) 4.01 (br. s., 1 H) 4.06 (d, J = 2.4 Hz, $1 \mathrm{H}) 4.18(\mathrm{~d}, J=10.2 \mathrm{~Hz}, 1 \mathrm{H}) 4.39(\mathrm{~d}, J=10.2 \mathrm{~Hz}, 1 \mathrm{H}) 7.21-7.39(\mathrm{~m}, 5 \mathrm{H}) ;{ }^{13} \mathrm{C}$ NMR $\left(150 \mathrm{MHz}, \mathrm{CDCl}_{3}\right) \delta$ ppm 209.6, 137.9, 128.3, 127.6, 118.1, 80.6, 78.9, 78.7, $76.8,72.0,71.0,59.5,43.0,41.7,39.2,39.2,38.9,30.6,27.2,24.0,23.6,17.9,11.8$ 

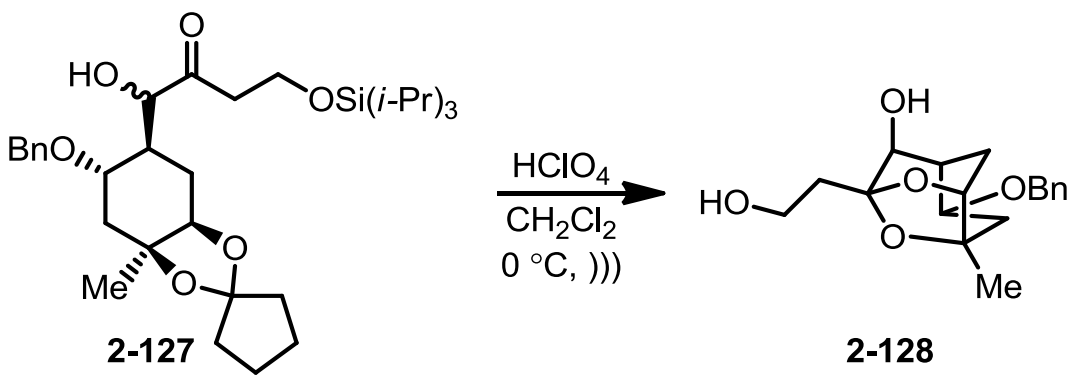

Diol 2-128: Hydroxy ketone 2-127 (168 $\mathrm{mg}, 0.299 \mathrm{mmol})$ of was combined with $\mathrm{CH}_{2} \mathrm{Cl}_{2}(26 \mathrm{~mL})$ at $0{ }^{\circ} \mathrm{C}$ while subjected to ultrasonic irradiation. To this was added $\mathrm{HClO}_{4}(70 \%, 26 \mu \mathrm{L}, 0.30 \mathrm{mmol})$. After TLC indicated the disappearance of starting material (ca. $10 \mathrm{~min}$ ), sat. $\mathrm{NaHCO}_{3 \text { (aq.) }}(20 \mathrm{~mL})$ was added to the reaction flask. The layers were separated, the aqueous layer extracted $\left(\mathrm{CH}_{2} \mathrm{Cl}_{2}\right)$ and concentrated under reduced pressure. The product was separated with column chromatography eluting with 70\%-100\% EtOAc/hexanes. The fractions containing product were concentrated, providing diol 2-128 (94 mg, 98\%, 0.293). Major isomer: ${ }^{1} \mathrm{H}$ NMR (600 $\left.\mathrm{MHz}, \mathrm{CDCl}_{3}\right) \delta \mathrm{ppm} 1.35(\mathrm{~s}, 3 \mathrm{H}) 1.60(\mathrm{dd}, J=14.4,7.8 \mathrm{~Hz}, 1 \mathrm{H}) 1.81-1.92(\mathrm{~m}, 2 \mathrm{H})$ $2.06(\mathrm{dt}, J=14.4,2.4 \mathrm{~Hz}, 1 \mathrm{H}) 2.20(\mathrm{ddd}, J=15.6,7.2,3.8 \mathrm{~Hz}, 1 \mathrm{H}) 2.32(\mathrm{dd}, J=$ 4.2, $1.8 \mathrm{~Hz}, 1 \mathrm{H}) 2.49(\mathrm{dd}, J=13.8,7.8 \mathrm{~Hz}, 1 \mathrm{H}) 3.34$ - $3.38(\mathrm{~m}, 1 \mathrm{H}) 3.79$ - $3.87(\mathrm{~m}$, 2 H) $3.87-3.93(\mathrm{~m}, 1 \mathrm{H}) 4.15(\mathrm{~d}, J=2.4 \mathrm{~Hz}, 1 \mathrm{H}) 4.50(\mathrm{~d}, J=12.0 \mathrm{~Hz}, 1 \mathrm{H}) 4.57(\mathrm{~d}$, $J=12.0 \mathrm{~Hz}, 1 \mathrm{H}) 7.30-7.41(\mathrm{~m}, 5 \mathrm{H}) ;{ }^{13} \mathrm{C}$ NMR $\left(150 \mathrm{MHz}, \mathrm{CDCl}_{3}\right) \delta \mathrm{ppm} 138.2$, 128.5, 127.7, 127.6, 109.4, 79.9, 79.1, 74.8, 72.7, 70.5, 57.9, 39.8, 37.2, 35.0, 26.6, 22.4; IR (film) 3565 br., $3056 \mathrm{~s}, 1421 \mathrm{w} \mathrm{cm}^{-1}$; $[\alpha]^{22}=+30.28$ (c=3.3, $\mathrm{CH}_{2} \mathrm{Cl}_{2}$ ); HRMS (ESI+) calcd for $\mathrm{C}_{18} \mathrm{H}_{24} \mathrm{O}_{5}[\mathrm{M}+\mathrm{Na}]^{+} 343.1516$, found 343.1520. 


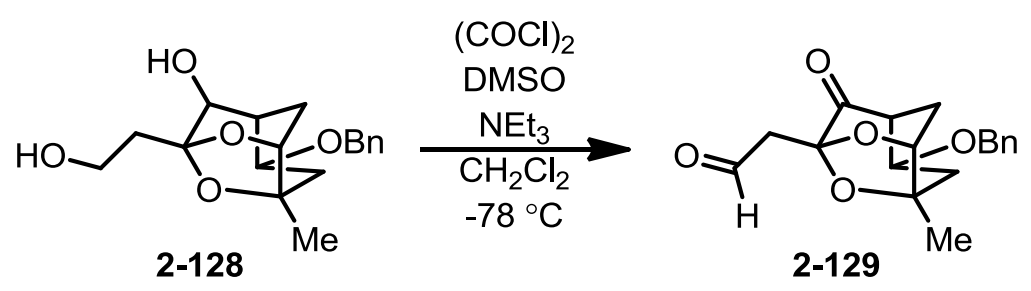

Keto-aldehyde 2-129: A stirring solution of oxalyl chloride (83 $\mu \mathrm{L}, 0.97 \mathrm{mmol})$ in $\mathrm{CH}_{2} \mathrm{Cl}_{2}(8 \mathrm{~mL})$ was cooled to $-78{ }^{\circ} \mathrm{C}$. DMSO $(138 \mu \mathrm{L}, 1.94 \mathrm{mmol})$ was added dropwise by syringe. After stirring for $10 \mathrm{~min}$, a solution of diol 2-128 (100 mg, 0.31 mmol) in $\mathrm{CH}_{2} \mathrm{Cl}_{2}(3 \mathrm{~mL})$ was added dropwise by syringe and stirred for $15 \mathrm{~min}$. Triethylamine $(500 \mu \mathrm{L}, 3.59 \mathrm{mmol})$ was added and the mixture was allowed to stir for 15 min before being allowed to warm to rt. The reaction mixture was pipetted directly onto a silica column (20\% EtOAc/hexanes), providing ketoaldehyde 2-129 which was immediately used in the next reaction. ${ }^{1} \mathrm{H}$ NMR $\left(600 \mathrm{MHz}, \mathrm{CDCl}_{3}\right) \delta \mathrm{ppm} 1.42$ (s, $3 \mathrm{H}) 1.77$ (dd, $J=14.4,7.8 \mathrm{~Hz}, 1 \mathrm{H}) 2.26$ (ddd, $J=13.8,4.2,1.8 \mathrm{~Hz}, 1 \mathrm{H}) 2.36$ (ddd, $J=13.8,4.2,1.8 \mathrm{~Hz}, 1 \mathrm{H}) 2.59(\mathrm{dd}, J=14.4,7.8 \mathrm{~Hz}, 1 \mathrm{H}) 2.80(\mathrm{dd}, J=2.4,1.8$ $\mathrm{Hz}, 2 \mathrm{H}) 2.98(\mathrm{~d}, J=1.8 \mathrm{~Hz}, 1 \mathrm{H}) 3.84(\mathrm{t}, J=7.8 \mathrm{~Hz}, 1 \mathrm{H}) 4.34(\mathrm{dd}, J=4.2,1.8 \mathrm{~Hz}$, $1 \mathrm{H}) 4.46(\mathrm{~d}, J=12.0 \mathrm{~Hz}, 1 \mathrm{H}) 4.59(\mathrm{~d}, J=12.0 \mathrm{~Hz}, 1 \mathrm{H}) 7.28-7.39(\mathrm{~m}, 5 \mathrm{H}) 9.71(\mathrm{t}$, $J=2.4 \mathrm{~Hz}, 1 \mathrm{H}$ ) 


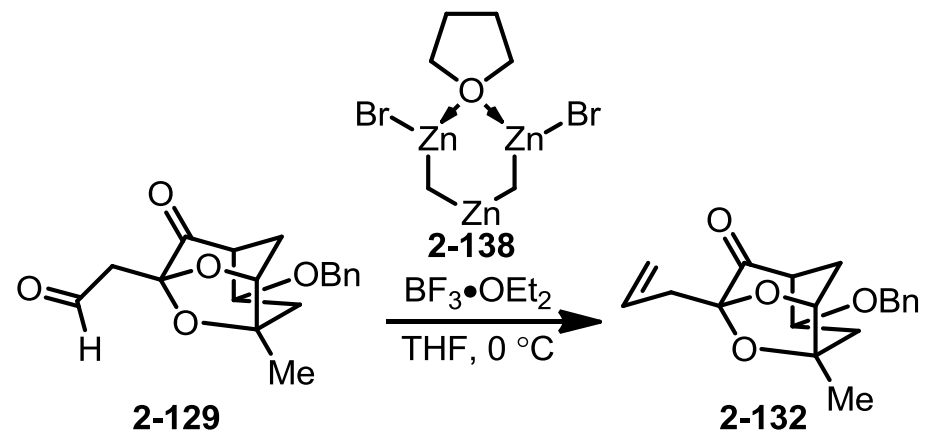

Terminal olefin 2-132: Nysted reagent 2-138 (20 wt.\% suspension in THF-shaken well before use, $0.84 \mathrm{~mL}, 0.437 \mathrm{mmol})$ was added to THF $(1.5 \mathrm{~mL})$ in a flask at $0{ }^{\circ} \mathrm{C}$. $\mathrm{BF}_{3} \cdot \mathrm{OEt}_{2}(54 \mu \mathrm{L}, 0.437 \mathrm{mmol})$ was added and the resulting mixture was stirred at 0 ${ }^{\circ} \mathrm{C}$ for $5 \mathrm{~min}$. A solution of keto-aldehyde $2-129(92 \mathrm{mg}, 0.291 \mathrm{mmol})$ in THF (1.5 $\mathrm{mL}$ ) was added, and the mixture was allowed to slowly warm to rt and stirred for 12

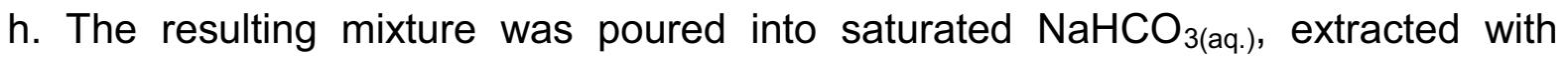
EtOAc, dried over $\mathrm{Na}_{2} \mathrm{SO}_{4}$, and concentrated. The crude product was purified by flash chromatography (7\% EtOAc/hexanes) to yield terminal olefin 2-132 (53 mg, $0.17 \mathrm{mmol}, 54 \%$ over two steps). ${ }^{1} \mathrm{H}$ NMR $\left(600 \mathrm{MHz}, \mathrm{CDCl}_{3}\right) \delta \mathrm{ppm} 1.42(\mathrm{~s}, 3 \mathrm{H})$ $1.78(\mathrm{dd}, J=14.4,7.8 \mathrm{~Hz}, 1 \mathrm{H}) 2.19-2.29(\mathrm{~m}, 1 \mathrm{H}) 2.35(\mathrm{dt}, J=14.4,1.8 \mathrm{~Hz}, 1 \mathrm{H})$ $2.51-2.61(\mathrm{~m}, 2 \mathrm{H}) 2.61-2.69(\mathrm{~m}, 1 \mathrm{H}) 2.92-3.01(\mathrm{~m}, 1 \mathrm{H}) 3.85(\mathrm{t}, J=7.2 \mathrm{~Hz}, 1 \mathrm{H})$ $4.30(\mathrm{~d}, J=1.8 \mathrm{~Hz}, 1 \mathrm{H}) 4.48(\mathrm{~d}, J=12.0 \mathrm{~Hz}, 1 \mathrm{H}) 4.62(\mathrm{~d}, J=12.0 \mathrm{~Hz}, 1 \mathrm{H}) 5.13-$ $5.23(\mathrm{~m}, 2 \mathrm{H}) 5.86(\mathrm{~m}, 1 \mathrm{H}) 7.29-7.40(\mathrm{~m}, 5 \mathrm{H}) ;{ }^{13} \mathrm{C} \mathrm{NMR}\left(150 \mathrm{MHz}, \mathrm{CDCl}_{3}\right) \delta \mathrm{ppm}$ $199.9,137.7,130.9,128.5,127.8,127.7,118.6,107.3,80.0,79.8,74.2,70.9,48.1$ 37.1, 33.8, 29.1, 26.6; IR (film) $3054 \mathrm{~m}, 2978 \mathrm{~m}, 1730 \mathrm{~s}, 1266 \mathrm{~s} \mathrm{w} \mathrm{cm}^{-1}$; [a] $]^{26}=$ $+100.46\left(\mathrm{c}=4.0, \mathrm{CH}_{2} \mathrm{Cl}_{2}\right)$; HRMS $(\mathrm{ESI}+)$ calcd for $\mathrm{C}_{19} \mathrm{H}_{22} \mathrm{O}_{4}[\mathrm{M}+\mathrm{Na}]^{+}$337.1410, found 337.1414 . 


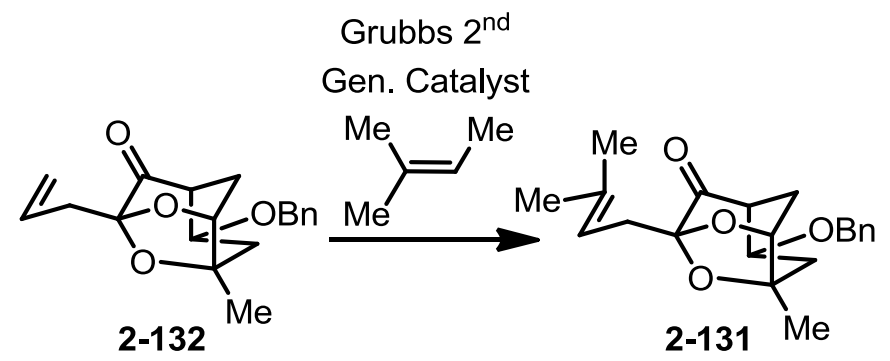

Prenyl-ketone 2-131: A solution of terminal olefin 2-132 $(25 \mathrm{mg}, 0.079 \mathrm{mmol})$ in 2methyl-2-butene $(10 \mathrm{~mL})$ was added by syringe to flask containing Grubbs $2^{\text {nd }}$ Generation Catalyst $(3.4 \mathrm{mg}, 0.004 \mathrm{mmol})$, and the mixture was allowed to stir at rt for $12 \mathrm{~h}$. The solution was then pipetted onto a silica gel column (eluting with $10 \%$ EtOAc/hexanes) to provide prenyl-ketone 2-131 (27.2 $\mathrm{mg}, 0.079 \mathrm{mmol}, 100 \%) .{ }^{1} \mathrm{H}$ NMR $\left(600 \mathrm{MHz}, \mathrm{CDCl}_{3}\right) \delta$ ppm $1.43(\mathrm{~s}, 3 \mathrm{H}) 1.67(\mathrm{~s}, 3 \mathrm{H}) 1.75(\mathrm{~s}, 3 \mathrm{H}) 1.8(\mathrm{dd}, J=$ 7.2, $14.4 \mathrm{~Hz}, 1 \mathrm{H}) 2.19-2.28(\mathrm{~m}, 1 \mathrm{H}) 2.30-2.37(\mathrm{~m}, 1 \mathrm{H}) 2.45-2.53(\mathrm{~m}, 1 \mathrm{H}) 2.53$ - $2.63(\mathrm{~m}, 2 \mathrm{H}) 2.96$ (app. s, $1 \mathrm{H}) 3.86(\mathrm{t}, J=7.8 \mathrm{~Hz}, 1 \mathrm{H}) 4.29$ (d, J = 2.4 Hz, $1 \mathrm{H})$ $4.48(\mathrm{~d}, J=12.0 \mathrm{~Hz}, 1 \mathrm{H}) 4.62(\mathrm{~d}, J=12.0 \mathrm{~Hz}, 1 \mathrm{H}) 5.19(\mathrm{t}, J=1.2 \mathrm{~Hz}, 1 \mathrm{H}) 7.30-$ $7.43(\mathrm{~m}, 5 \mathrm{H}) ;{ }^{13} \mathrm{C}$ NMR $\left(150 \mathrm{MHz}, \mathrm{CDCl}_{3}\right) \delta \mathrm{ppm} 200.1,137.8,134.9,128.5,127.8$, $127.6,116.0,108.0,79.9,79.7,74.4,70.9,48.1,37.1,29.1,28.1,26.6,26.0,18.2$; IR (film) $2926 \mathrm{~s}, 1731 \mathrm{~s}, 1496 \mathrm{~s} \mathrm{w} \mathrm{cm}^{-1} ;[\alpha]^{26}=+101.15\left(\mathrm{c}=0.9, \mathrm{CH}_{2} \mathrm{Cl}_{2}\right.$ ); HRMS (ESI+) calcd for $\mathrm{C}_{21} \mathrm{H}_{26} \mathrm{O}_{4}[\mathrm{M}+\mathrm{Na}]^{+} 365.1723$, found 365.1712 . 


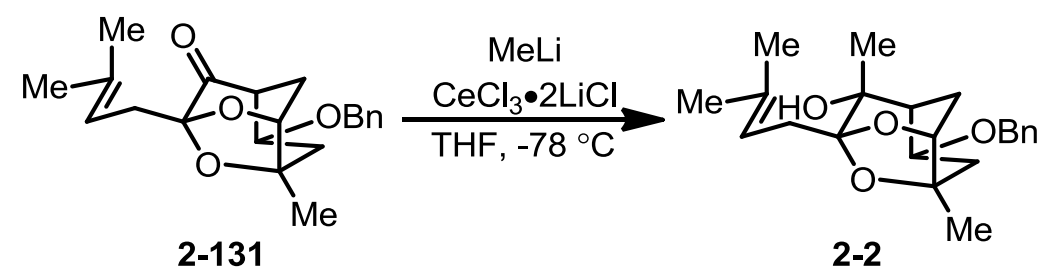

Alcohol 2-2: A solution of MeLi $(1.25 \mathrm{~mL}, 1.6 \mathrm{M}, 2.0 \mathrm{mmol})$ was added by syringe to a solution of $\mathrm{CeCl}_{3} \cdot 2 \mathrm{LiCl}$ in THF $(7 \mathrm{~mL}, 0.32 \mathrm{M}$, prepared in the method described earlier), at $-78{ }^{\circ} \mathrm{C}$ and stirred for $2.5 \mathrm{~h}$. A portion of this solution $(2 \mathrm{~mL}, 0.48 \mathrm{mmol})$ was added to a solution of carbonyl $2-131(27.2 \mathrm{mg}, 0.079 \mathrm{mmol})$ in $\mathrm{CeCl}_{3} \cdot 2 \mathrm{LiCl}$ in THF ( $3 \mathrm{~mL}, 0.32 \mathrm{M}$, premixed with $2-131$ for $1 \mathrm{~h}$ ) at $-78{ }^{\circ} \mathrm{C}$ and stirred for $5 \mathrm{~min}$. The

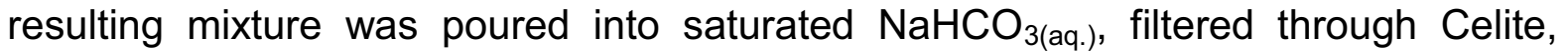
extracted with EtOAc, dried over $\mathrm{Na}_{2} \mathrm{SO}_{4}$, and concentrated. The crude product was purified by flash chromatography (10\% EtOAc/hexanes) to yield tertiary alcohol $\mathbf{2 - 2}$ (28.6 mg, $0.079 \mathrm{mmol}, 100 \%) .{ }^{1} \mathrm{H}$ NMR $\left(600 \mathrm{MHz}, \mathrm{CDCl}_{3}\right) \delta \mathrm{ppm} 1.30(\mathrm{~s}, 3 \mathrm{H}) 1.4$ (s, 3 H) $1.54(\mathrm{dd}, J=13.8,7.2 \mathrm{~Hz}, 1 \mathrm{H}) 1.65(\mathrm{~s}, 3 \mathrm{H}) 1.75(\mathrm{~s}, 3 \mathrm{H}) 1.96(\mathrm{~s}, 1 \mathrm{H}) 1.98(\mathrm{~s}$, 2 H) 2.06 (br. s., 1 H) 2.40 (dd, $J=16.2,6.6 \mathrm{~Hz}, 1 \mathrm{H}) 2.47$ (dd, $J=13.8,7.8 \mathrm{~Hz}, 1 \mathrm{H}$ ) $2.60(\mathrm{dd}, J=16.2,6.6 \mathrm{~Hz}, 1 \mathrm{H}) 4.10(\mathrm{~d}, J=1.8 \mathrm{~Hz}, 1 \mathrm{H}) 4.20$ (t, $J=7.8 \mathrm{~Hz}, 1 \mathrm{H}) 4.50$ $(\mathrm{d}, J=12.0 \mathrm{~Hz}, 1 \mathrm{H}) 4.57(\mathrm{~d}, J=12.0 \mathrm{~Hz}, 1 \mathrm{H}) 5.25(\mathrm{t}, J=6.6 \mathrm{~Hz}, 1 \mathrm{H}) 7.33-7.40$ $(\mathrm{m}, 5 \mathrm{H}) ;{ }^{13} \mathrm{C}$ NMR $\left(150 \mathrm{MHz}, \mathrm{CDCl}_{3}\right) \delta \mathrm{ppm} 138.6,134.0,128.4,127.6,127.6$, $117.4,111.7,79.9,79.6,74.5,72.5,70.5,45.9,37.3,28.0,26.1,25.9,25.9,23.7$, 18.2; IR (film) $3481 \mathrm{br}, 2963 \mathrm{~s}, 1556 \mathrm{w} \mathrm{cm}^{-1} ;[\mathrm{\alpha}]^{26}=+27.44\left(\mathrm{c}=3.7, \mathrm{CH}_{2} \mathrm{Cl}_{2}\right)$, HRMS (ESI+) calcd for $\mathrm{C}_{22} \mathrm{H}_{30} \mathrm{O}_{4}[\mathrm{M}+\mathrm{Na}]^{+}$381.2036, found 381.2029. 


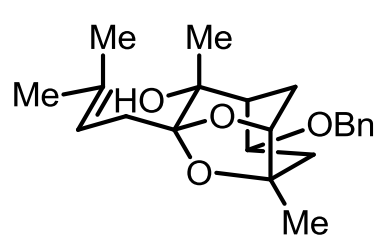

2-2

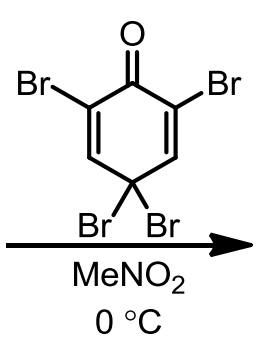

$0{ }^{\circ} \mathrm{C}$

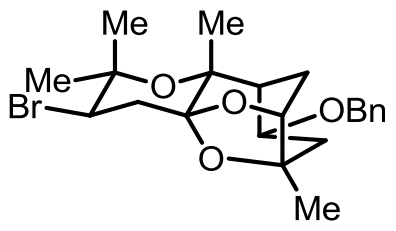

2-141

Bromo-tetrahydropyran 2-141: To a stirred $0{ }^{\circ} \mathrm{C}$ solution of $2-2(24 \mathrm{mg}, 0.067$ $\mathrm{mmol})$ in $\mathrm{CH}_{3} \mathrm{NO}_{2}(11 \mathrm{~mL})$ was added TBCO $(33.6 \mathrm{mg}, 0.082 \mathrm{mmol})$ in the dark. After $4 \mathrm{~h}$ the reaction was poured into a $1 \mathrm{M} \mathrm{NaOH}$ solution $(20 \mathrm{~mL})$, diluted with ether $(10 \mathrm{~mL})$, and stirred for $10 \mathrm{~min}$. The aqueous phases were extracted with ether, the combined organic phases were washed with sat. $\mathrm{NaCl}_{(\text {aq.) }}$, dried over $\mathrm{Na}_{2} \mathrm{SO}_{4}$, filtered and concentrated. Purification with HPLC provided the desired isomer 2-141 (6.13 mg, $0.014 \mathrm{mmol}, 21 \%) .{ }^{1} \mathrm{H}$ NMR (600 MHz, $\left.\mathrm{CDCl}_{3}\right) \mathrm{d}$ ppm 1.25 (s, 3 H) $1.32(\mathrm{~s}, 3 \mathrm{H}) 1.45-1.55(\mathrm{~m}, 7 \mathrm{H}) 1.90-2.00(\mathrm{~m}, 2 \mathrm{H}) 2.03-2.11(\mathrm{~m}, 2 \mathrm{H})$ $2.36(\mathrm{dd}, J=13.8,7.8 \mathrm{~Hz}, 1 \mathrm{H}) 2.53(\mathrm{t}, J=13.2 \mathrm{~Hz}, 1 \mathrm{H}) 4.12(\mathrm{~d}, J=1.8 \mathrm{~Hz}, 1 \mathrm{H})$ $4.29(\mathrm{dd}, J=13.2,4.2 \mathrm{~Hz}, 1 \mathrm{H}) 4.36(\mathrm{t}, J=7.8 \mathrm{~Hz}, 1 \mathrm{H}) 4.44(\mathrm{~d}, J=12.0 \mathrm{~Hz}, 1 \mathrm{H})$ $4.54(\mathrm{~d}, J=12.0 \mathrm{~Hz}, 1 \mathrm{H}) 7.25-7.4(\mathrm{~m}, 5 \mathrm{H}) ;{ }^{13} \mathrm{C} \mathrm{NMR}\left(150 \mathrm{MHz}, \mathrm{CDCl}_{3}\right) \delta \mathrm{ppm}$ $138.8,128.3,127.9,127.4,107.5,81.1,77.6,76.4,75.9,71.4,70.3,54.4,44.3$, 37.5, 36.6, 30.2, 26.4, 25.6, 25.4, 24.6; IR (film) $2962 \mathrm{~m}, 2884 \mathrm{w}, 1311 \mathrm{w} \mathrm{cm}^{-1}$; [a] $]^{23}$ $=+73.58\left(\mathrm{c}=1.1, \mathrm{CH}_{2} \mathrm{Cl}_{2}\right)$; $\mathrm{HRMS}(\mathrm{ESI}+)$ calcd for $\mathrm{C}_{22} \mathrm{H}_{29} \mathrm{BrO}_{4}[\mathrm{M}+\mathrm{Na}]^{+}$459.1141, found 459.1147 . 


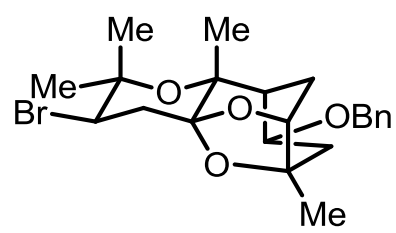

2-141

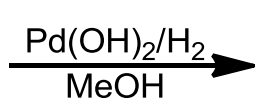

2-1

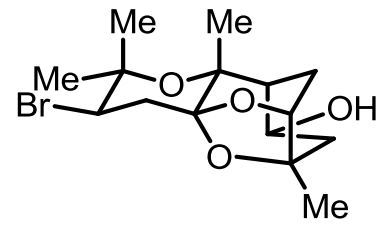

$-1$

The proposed structure of aldingenin B 2-1: THP 2-141 $(2.4 \mathrm{mg}, 0.0055 \mathrm{mmol})$ was combined with Pearlmans's catalyst $\left(\mathrm{Pd}(\mathrm{OH})_{2}\right.$ on carbon, $\left.0.1 \mathrm{mg}\right)$ in $4 \mathrm{~mL}$ $\mathrm{MeOH}$, then an atmosphere of $\mathrm{H}_{2}$ was injected via balloon, and the reaction was stirred for $1 \mathrm{~h}$. The mixture was then filtered through Celite and concentrated to afford the proposed structure of aldingenin B 2-1 (1.9 mg, $0.0055 \mathrm{mmol}, 100 \%) .{ }^{1} \mathrm{H}$ NMR $\left(600 \mathrm{MHz}, \mathrm{C}_{6} \mathrm{D}_{6}\right) \delta$ ppm $1.00(\mathrm{~s}, 3 \mathrm{H}) 1.10(\mathrm{dd}, J=13.8,7.8 \mathrm{~Hz}, 1 \mathrm{H}) 1.24(\mathrm{~s}, 3$ H) 1.39 (s, 3 H) 1.40 (s, 3 H) 1.53 (app. s, 1 H), 1.55 (ddd, J = 15.0, 3.6, 1.8 Hz, 1 H) 1.65 (ddd, $J=15.0,3.6,1.8 \mathrm{~Hz}, 1 \mathrm{H}) 2.21(\mathrm{dd}, J=13.8,7.8,1 \mathrm{H}) 2.25(\mathrm{dd}, J=13.2$, 4.2 Hz, $1 \mathrm{H}) 2.50(\mathrm{t}, J=13.2 \mathrm{~Hz}, 1 \mathrm{H}) 3.62(\mathrm{dd}, J=3.6,1.8 \mathrm{~Hz}, 1 \mathrm{H}) 4.55(\mathrm{dd}, J=$ 13.2, $4.2 \mathrm{~Hz}, 1 \mathrm{H}) 4.65(\mathrm{t}, J=7.8 \mathrm{~Hz}, 1 \mathrm{H}) ;{ }^{13} \mathrm{C}$ NMR $\left(150 \mathrm{MHz}, \mathrm{C}_{6} \mathrm{D}_{6}\right) \delta \mathrm{ppm} 107.4$, $80.7,77.4,76.6,75.7,64.2,54.5,48.6,39.3,37.0,29.9,26.0,25.5,24.7,24.5$; IR (film) 3477 br, $2962 \mathrm{~s}, 1555 \mathrm{w} \mathrm{cm}^{-1}$; $[\alpha]^{24}=+85.58\left(\mathrm{c}=1.0, \mathrm{CH}_{2} \mathrm{Cl}_{2}\right)$; HRMS (ESI+) calcd for $\mathrm{C}_{15} \mathrm{H}_{23} \mathrm{BrO}_{4}[\mathrm{M}+\mathrm{H}]^{+} 347.0852$, found 347.0858 . 


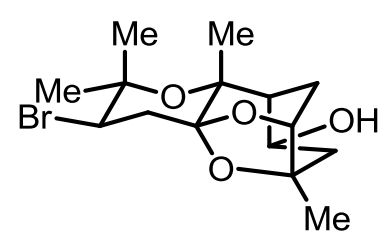

2-1

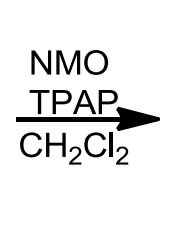

$\underset{\mathrm{H}_{2} \mathrm{Cl}_{2}}{-}$

$2-157$

Ketone 2-157: The proposed structure of aldingenin B $1(7 \mathrm{mg}, 0.020 \mathrm{mmol}), 6.8 \mathrm{mg}$ activated $4 \AA$ molecular sieves, $1 \mathrm{~mL} \mathrm{CH}_{2} \mathrm{Cl}_{2}$ and $3.55 \mathrm{mg} \mathrm{N}$-methylmorpholine- $N$ oxide (NMO, $0.030 \mathrm{mmol}$ ) were stirred in a $10 \mathrm{~mL}$ round-bottomed flask under argon. After $10 \mathrm{~m}, 0.35 \mathrm{mg}$ tetrapropylammonium perruthenate (TPAP, 0.000997 mmol) was added and the reaction was stirred until TLC analysis indicated the reaction was done. When done, the solution was filtered through a plug of silica gel, eluting with EtOAc, providing carbonyl 2-157.

${ }^{1} \mathrm{H}$ NMR $\left(600 \mathrm{MHz}, \mathrm{CDCl}_{3}\right)$ d ppm 1.35 (s, $\left.3 \mathrm{H}\right) 1.40(\mathrm{~s}, 3 \mathrm{H}) 1.49(\mathrm{~s}, 3 \mathrm{H}) 1.52$ (s, 3 H) $1.93(\mathrm{dt}, J=15.0,2.4 \mathrm{~Hz}, 1 \mathrm{~Hz}) 2.18(\mathrm{dd}, J=12.0,4.8 \mathrm{~Hz}, 1 \mathrm{H}) 2.40(\mathrm{dt}, J=15.0$, $2.4 \mathrm{~Hz}, 1 \mathrm{~Hz}) 2.55(\mathrm{~m}, 3 \mathrm{H}) 2.73(\mathrm{~d}, J=13.2 \mathrm{~Hz}, 1 \mathrm{H}) 4.31(\mathrm{dd}, J=13.2,4.8 \mathrm{~Hz}, 1 \mathrm{H})$ $4.37(\mathrm{~d}, J=1.8 \mathrm{~Hz}, 1 \mathrm{H})$.

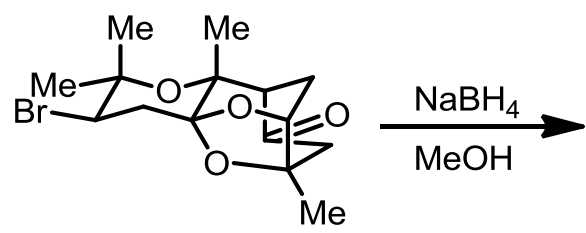

2-157

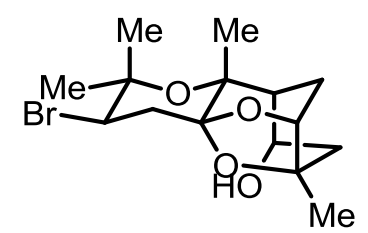

2-158

Epi-aldingenin B 2-158: Carbonyl 2-157 was dissolved in $5 \mathrm{~mL} \mathrm{MeOH}$, and an excess of $\mathrm{NaBH}_{4}$ was added. When TLC analysis indicated complete conversion, the reaction was quenched with $\mathrm{NH}_{4} \mathrm{Cl}_{(\text {aq.) }}$, the methanol was removed under reduced pressure, and the remaining aqueous layer was extracted with EtOAc to 
provide epi-1, 2-158 (2.1 mg, $0.006 \mathrm{mmol}, 30 \%$ over two steps). The spectra of this compound did not match that of the natural sample, eliminating it as a possibilty of the actual structure of aldingenin $\mathrm{B} .{ }^{1} \mathrm{H} N M R\left(600 \mathrm{MHz}, \mathrm{CDCl}_{3}\right) \mathrm{d} \mathrm{ppm} \mathrm{1.07-1.56} \mathrm{(m,}$ $14 \mathrm{H}) 2.10(\mathrm{~m}, 2 \mathrm{H}) 2.22(\mathrm{~d}, J=15.0 \mathrm{~Hz}, 1 \mathrm{H}) 2.30(\mathrm{dd}, J=12.6,4.2 \mathrm{~Hz}, 1 \mathrm{H}) 2.43(\mathrm{t}$, $J=7.2 \mathrm{~Hz}, 1 \mathrm{H}$ ) 3.48 (app. s, $1 \mathrm{H}) 4.00$ (dd, $J=15.0,7.8 \mathrm{~Hz}, 1 \mathrm{H}) 4.57$ (dd, $J=12.6$, $4.2 \mathrm{~Hz}, 1 \mathrm{H}) 5.75(\mathrm{~d}, J=8.4,1 \mathrm{H})$.

\section{Selected Spectra}




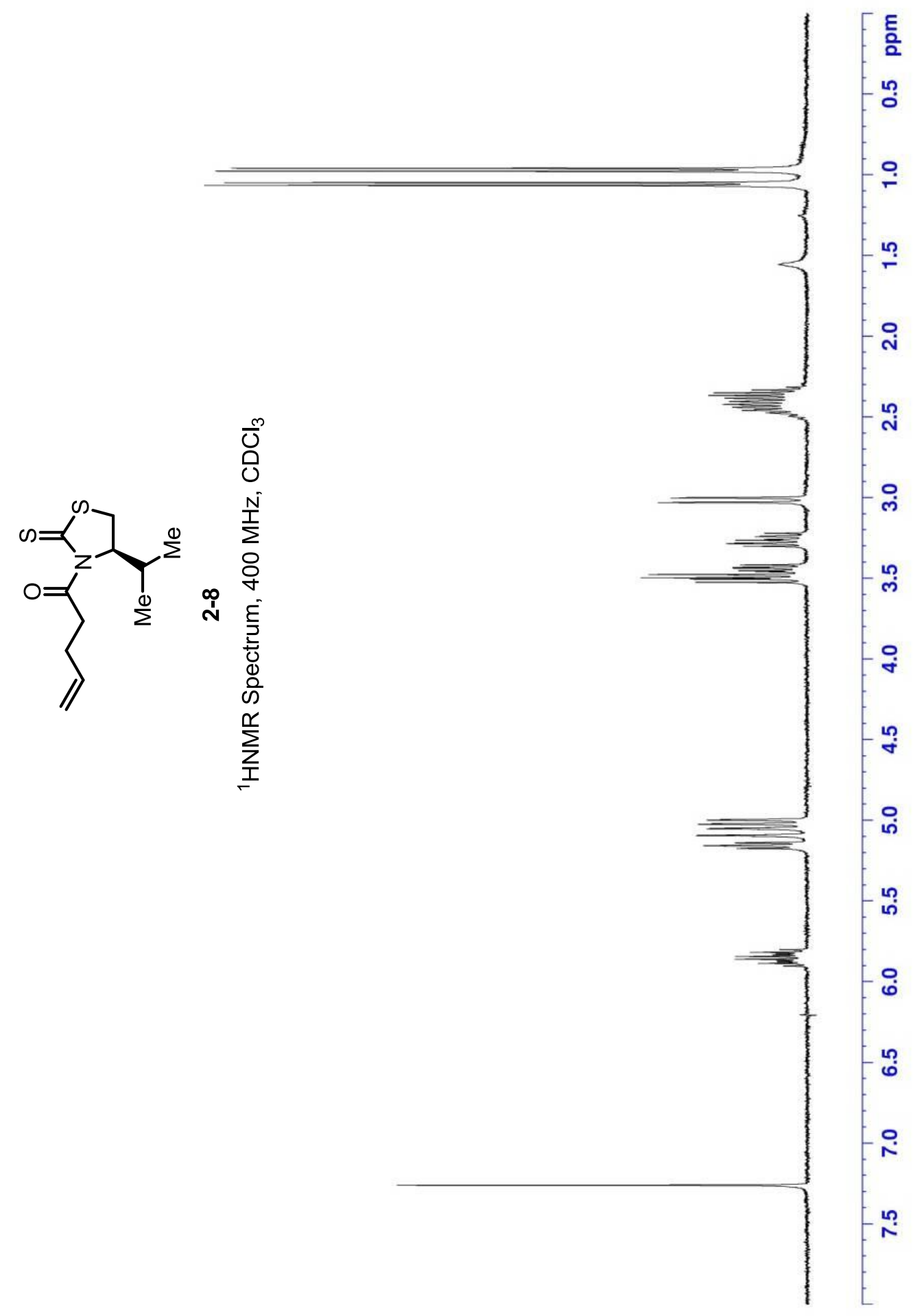




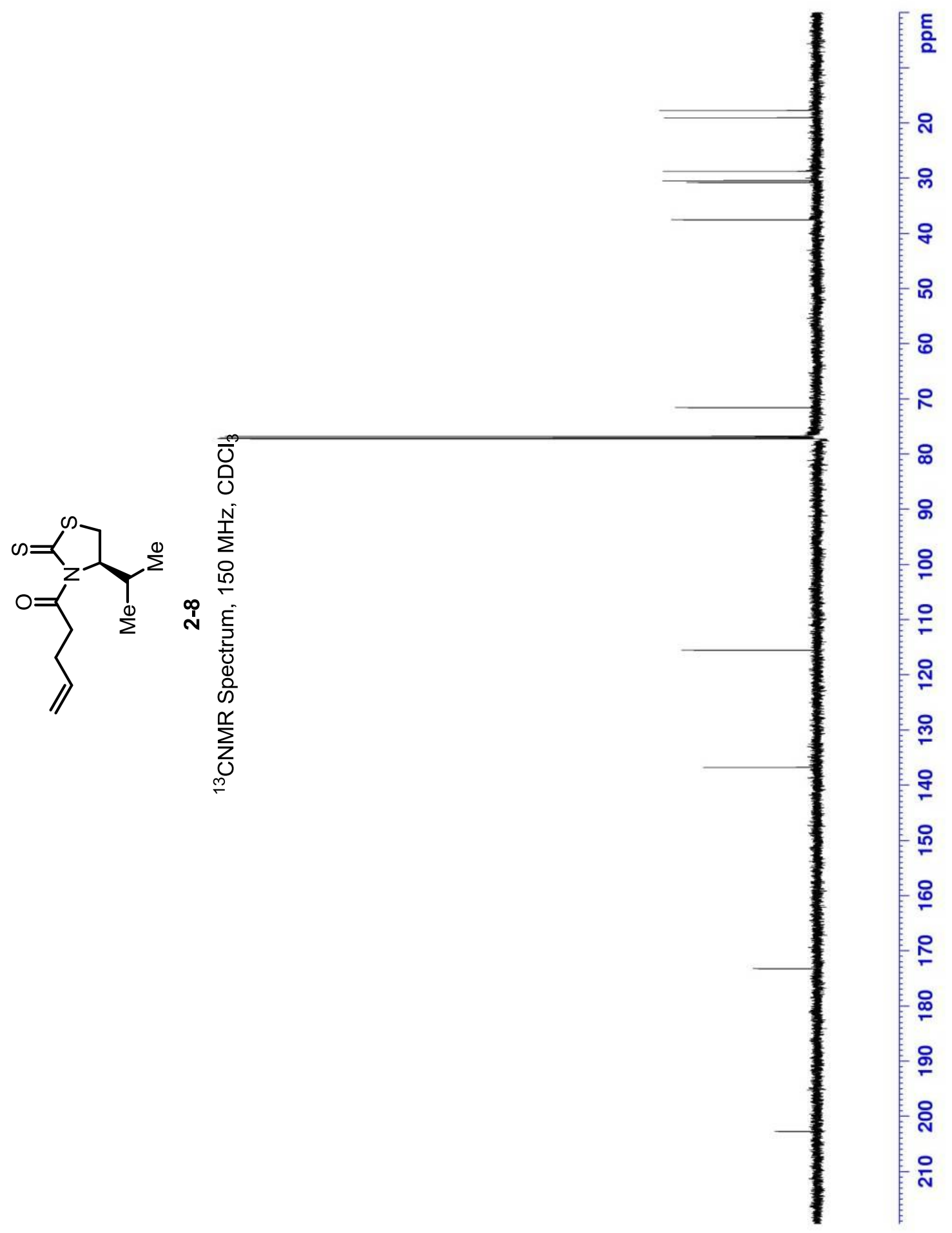




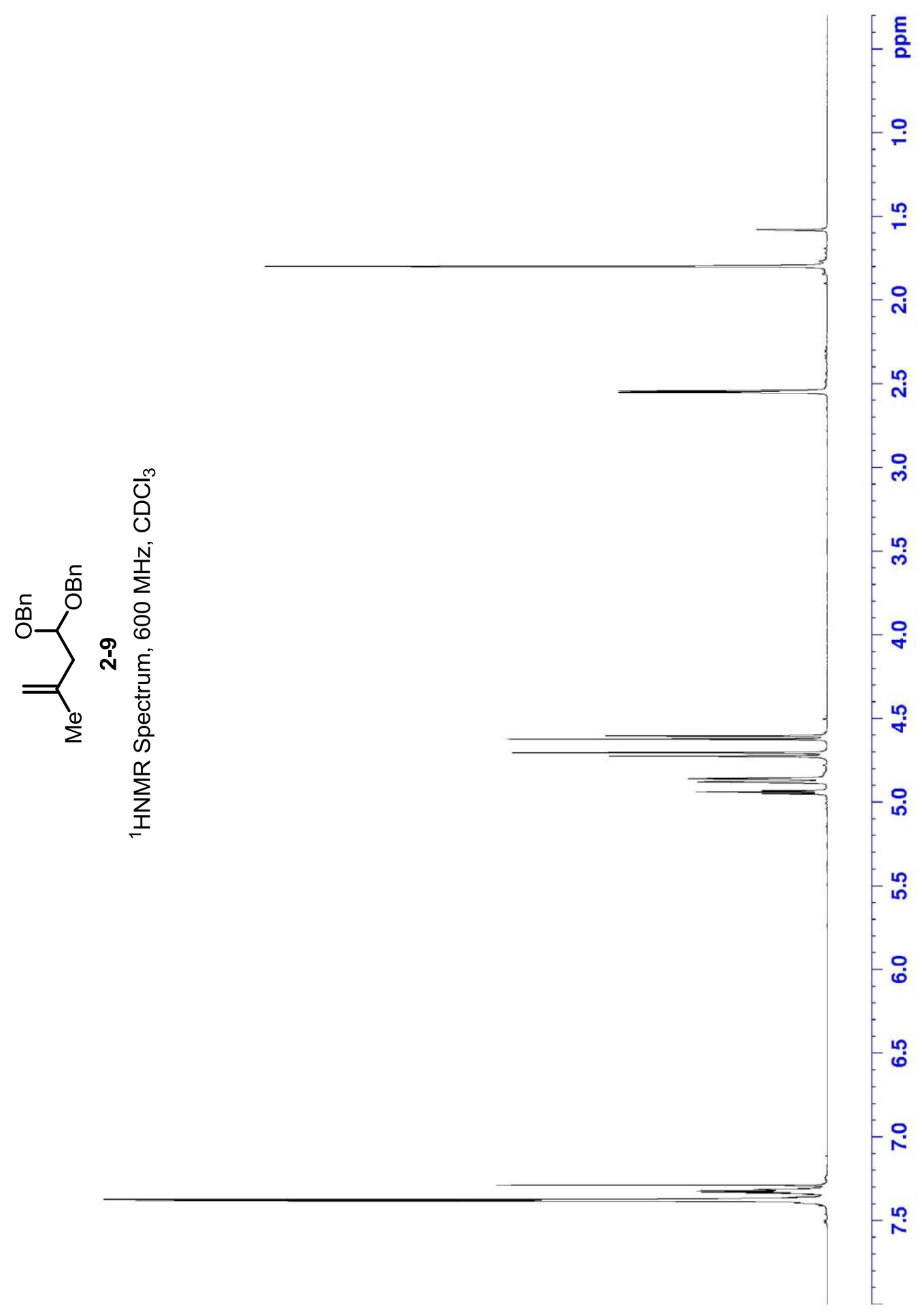




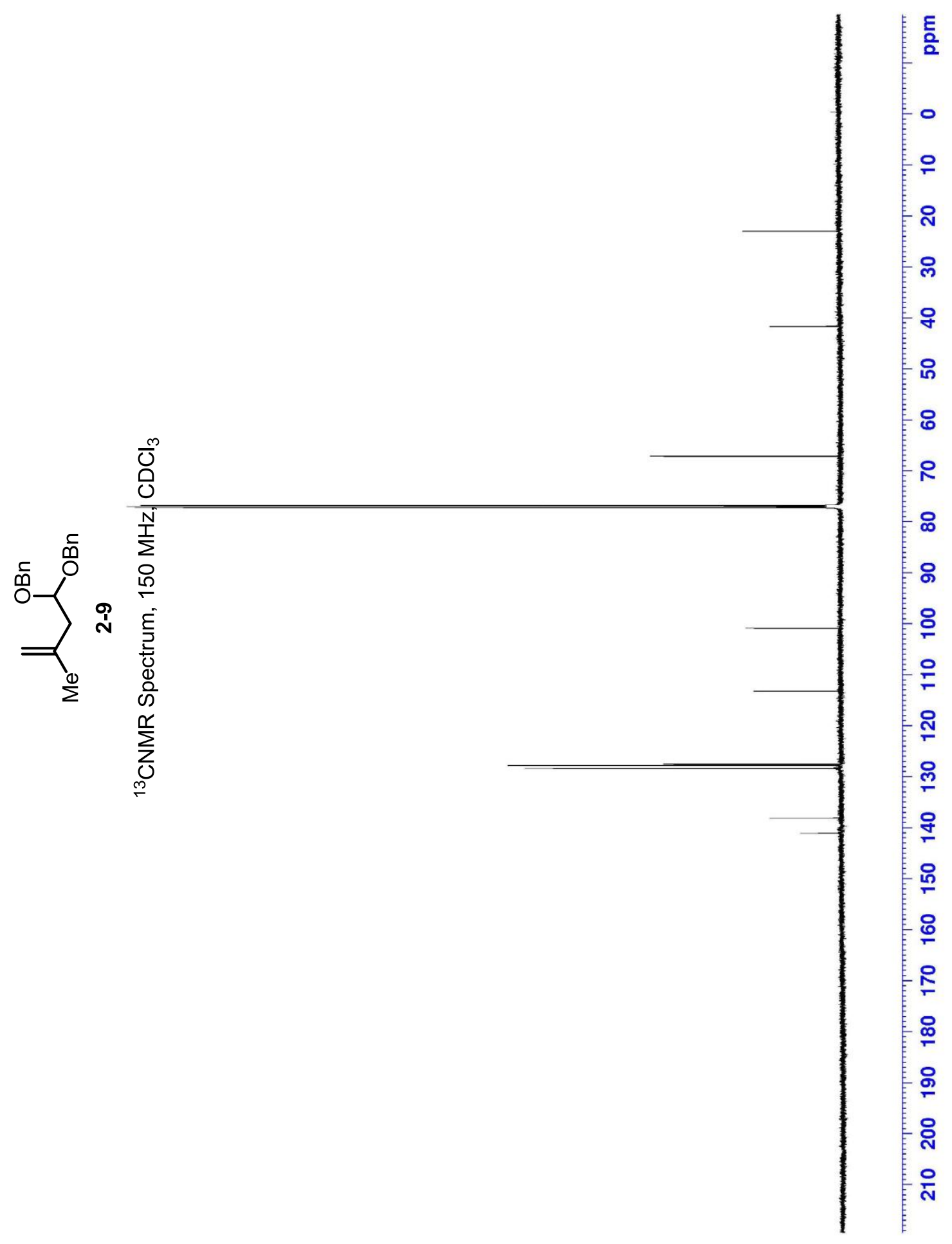




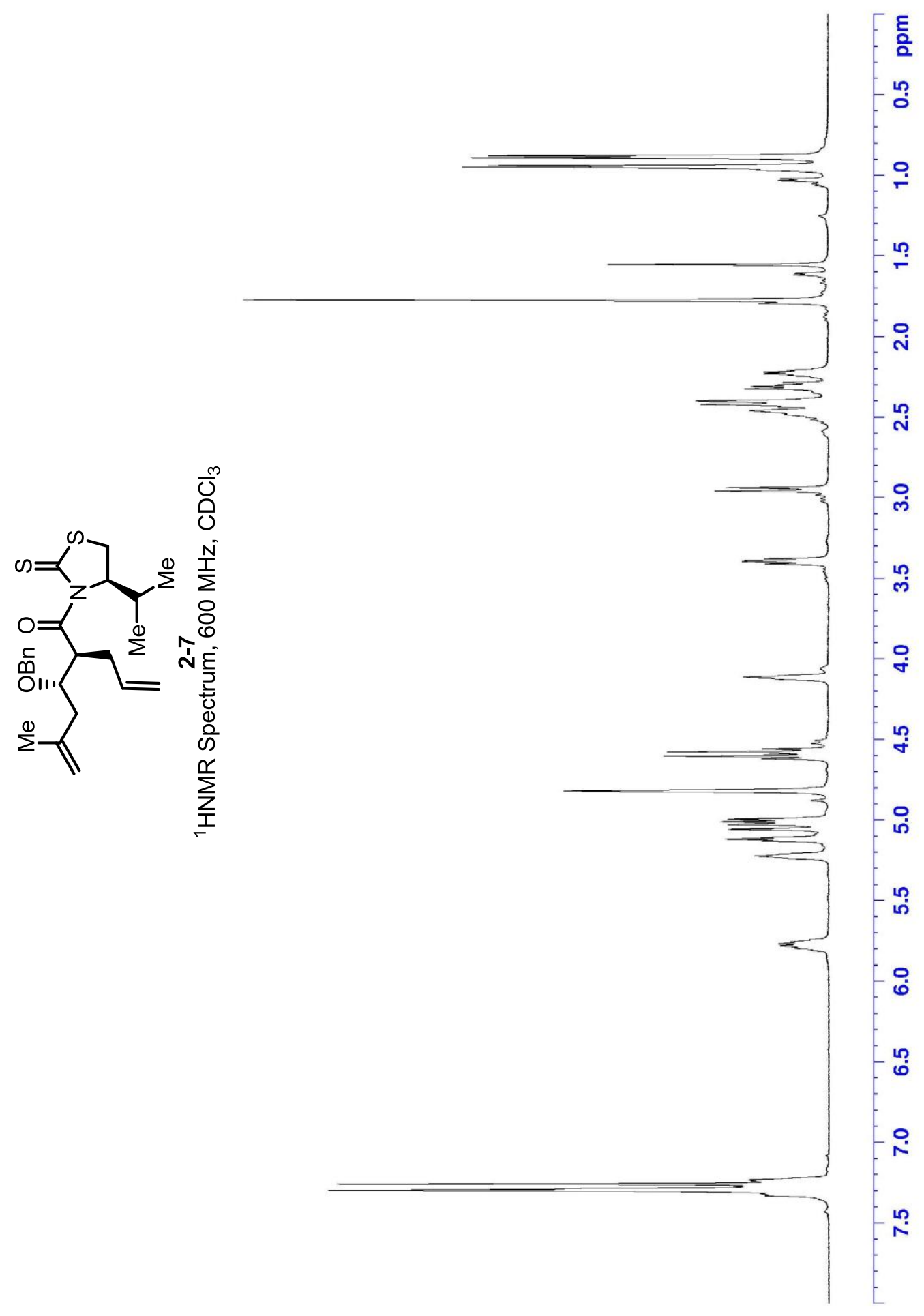


Aldol COSY

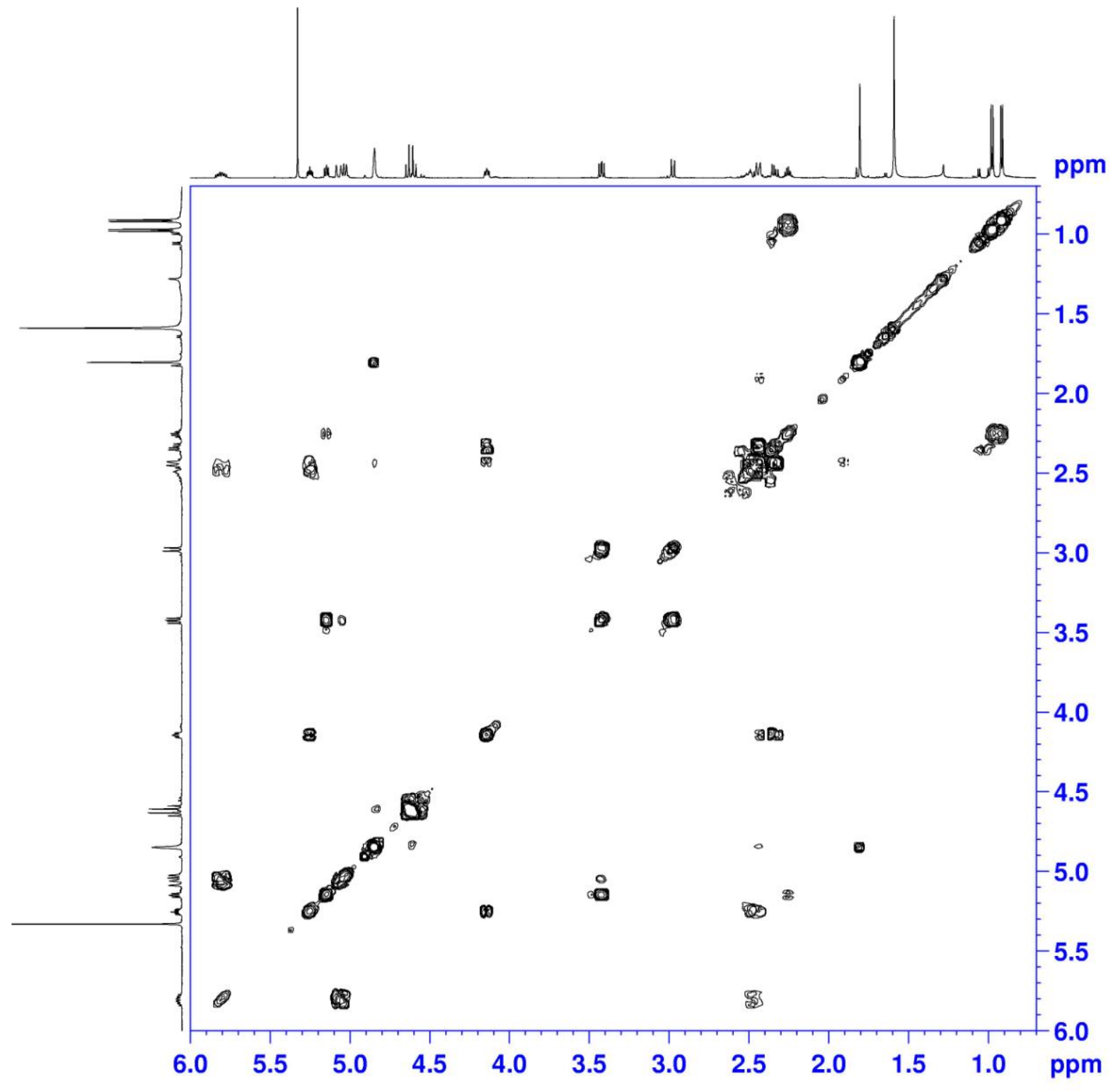




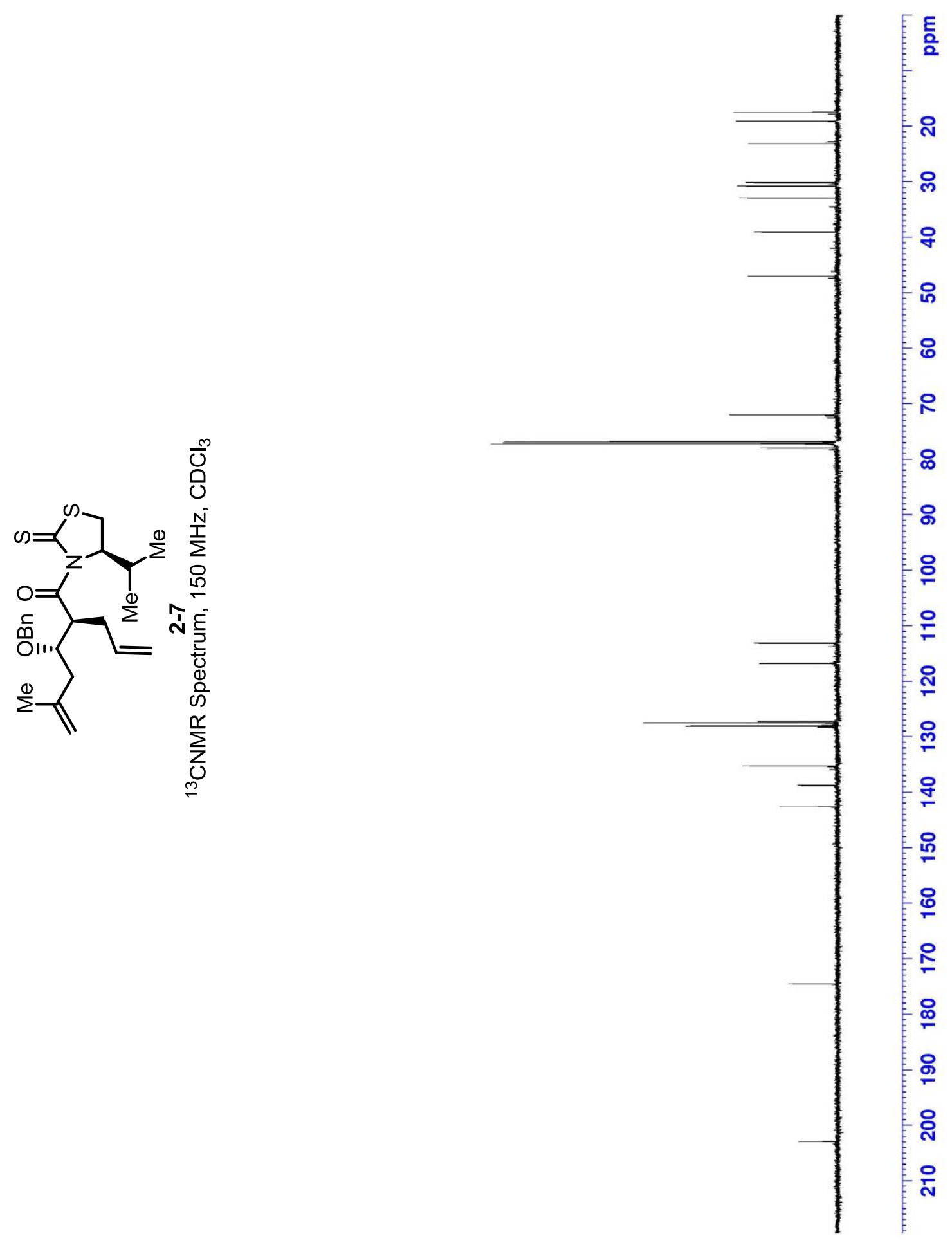




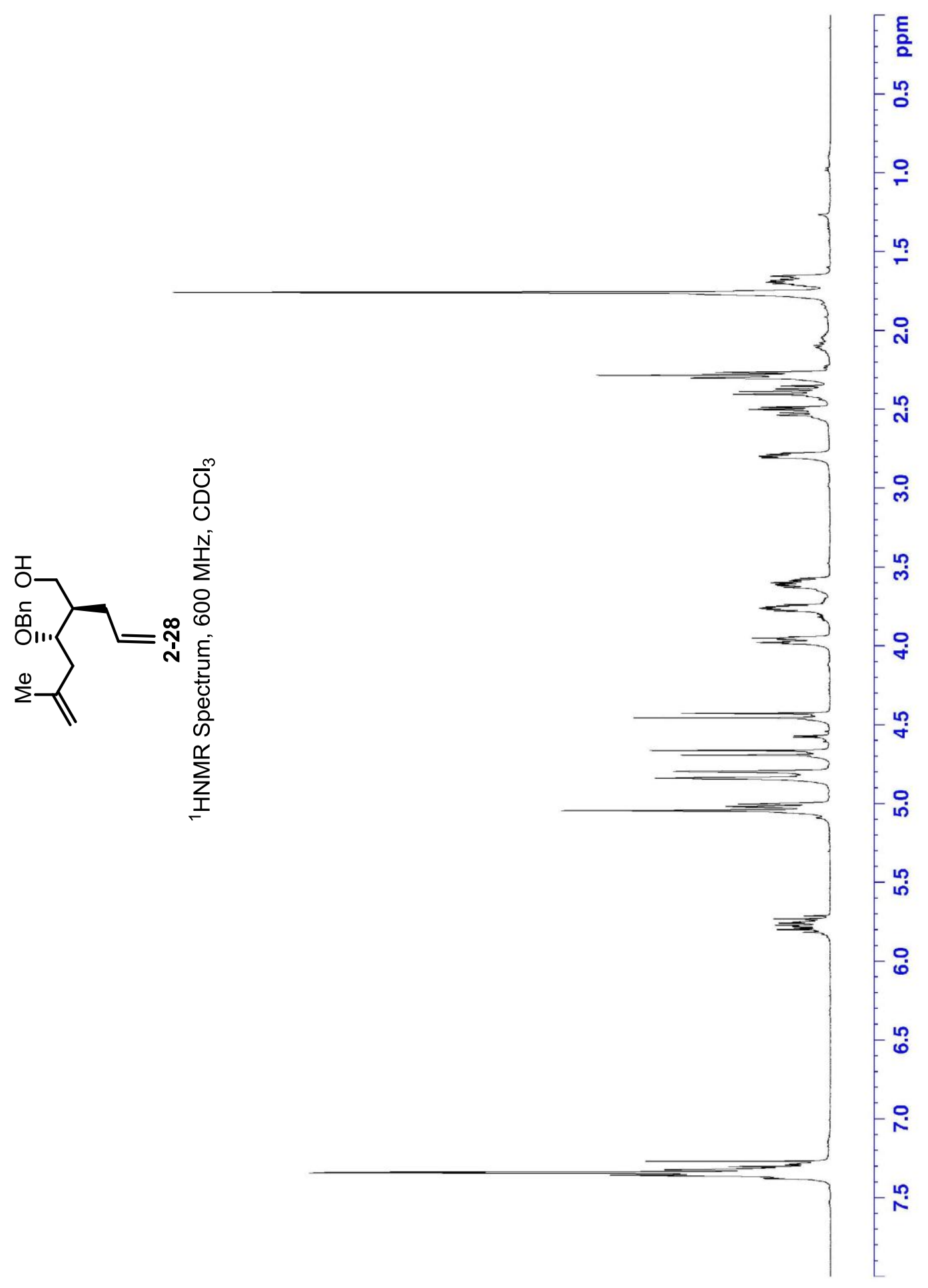




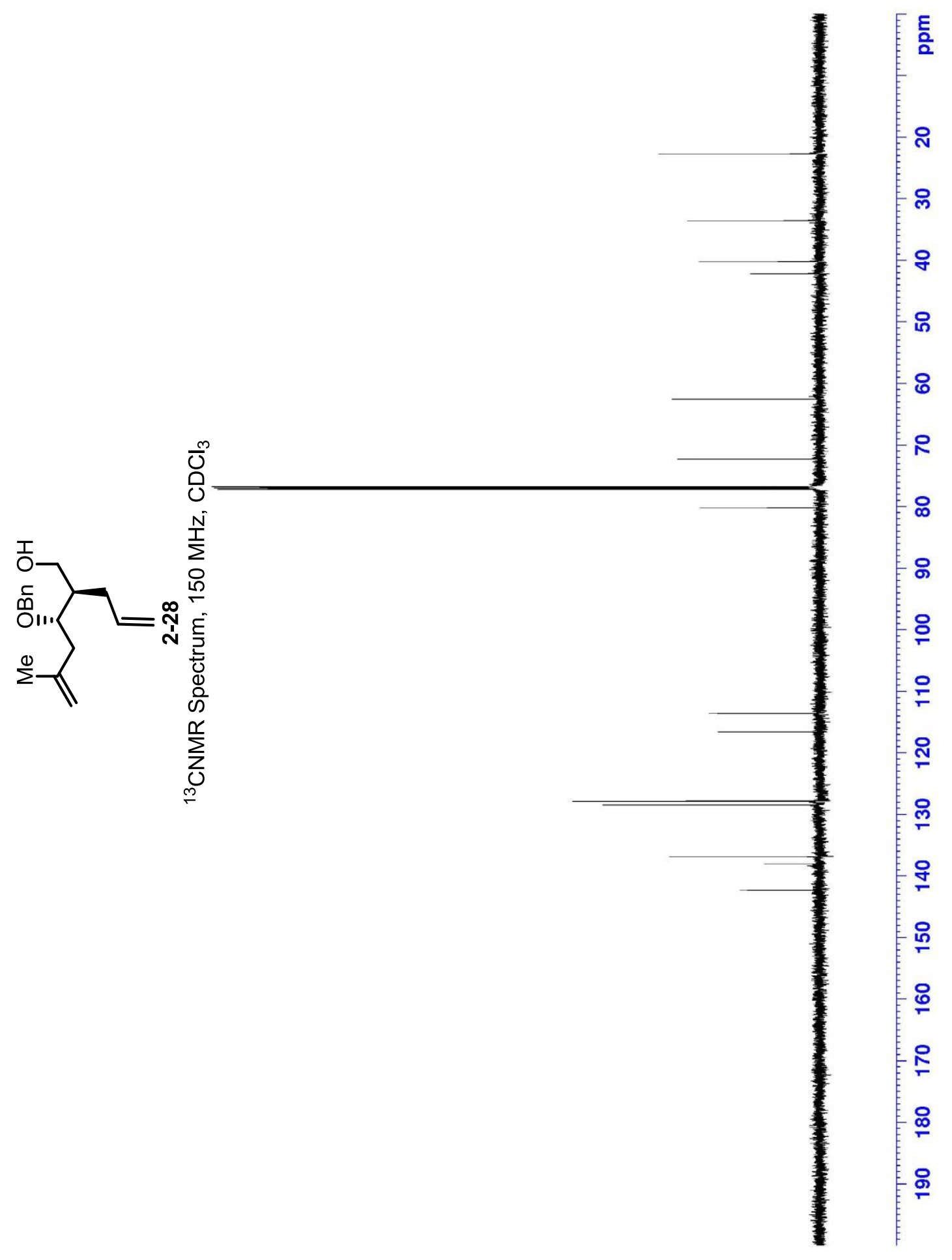




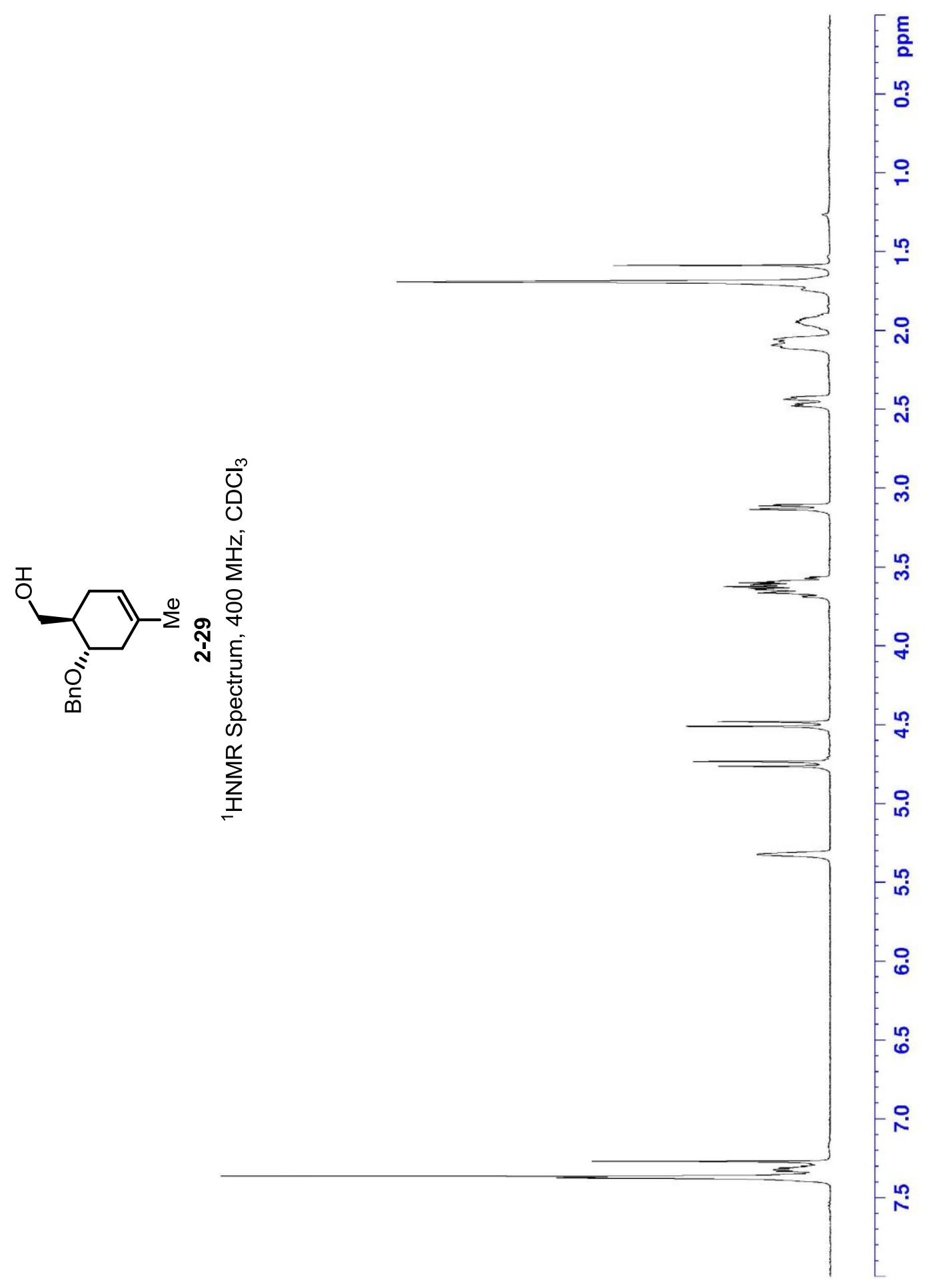




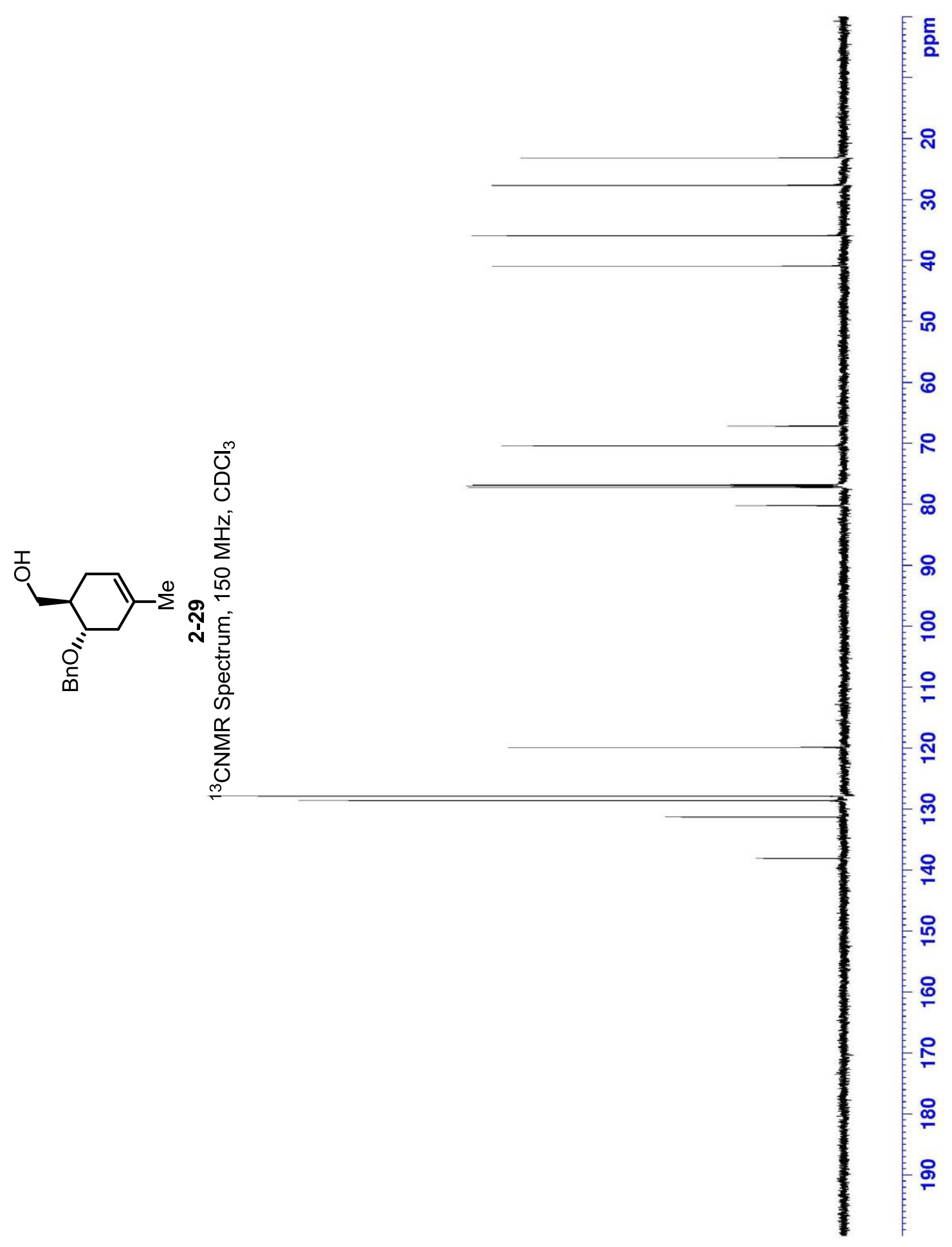




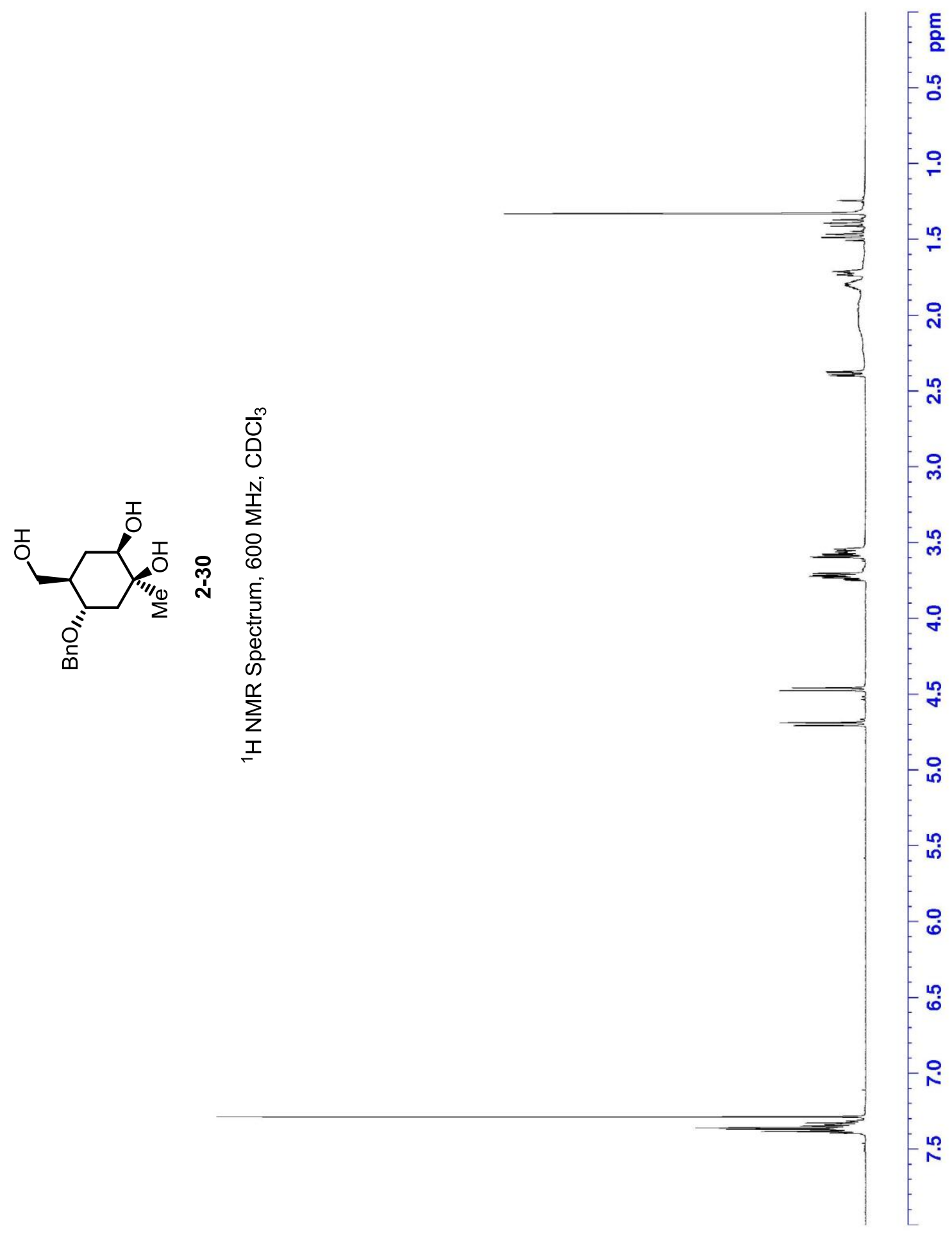




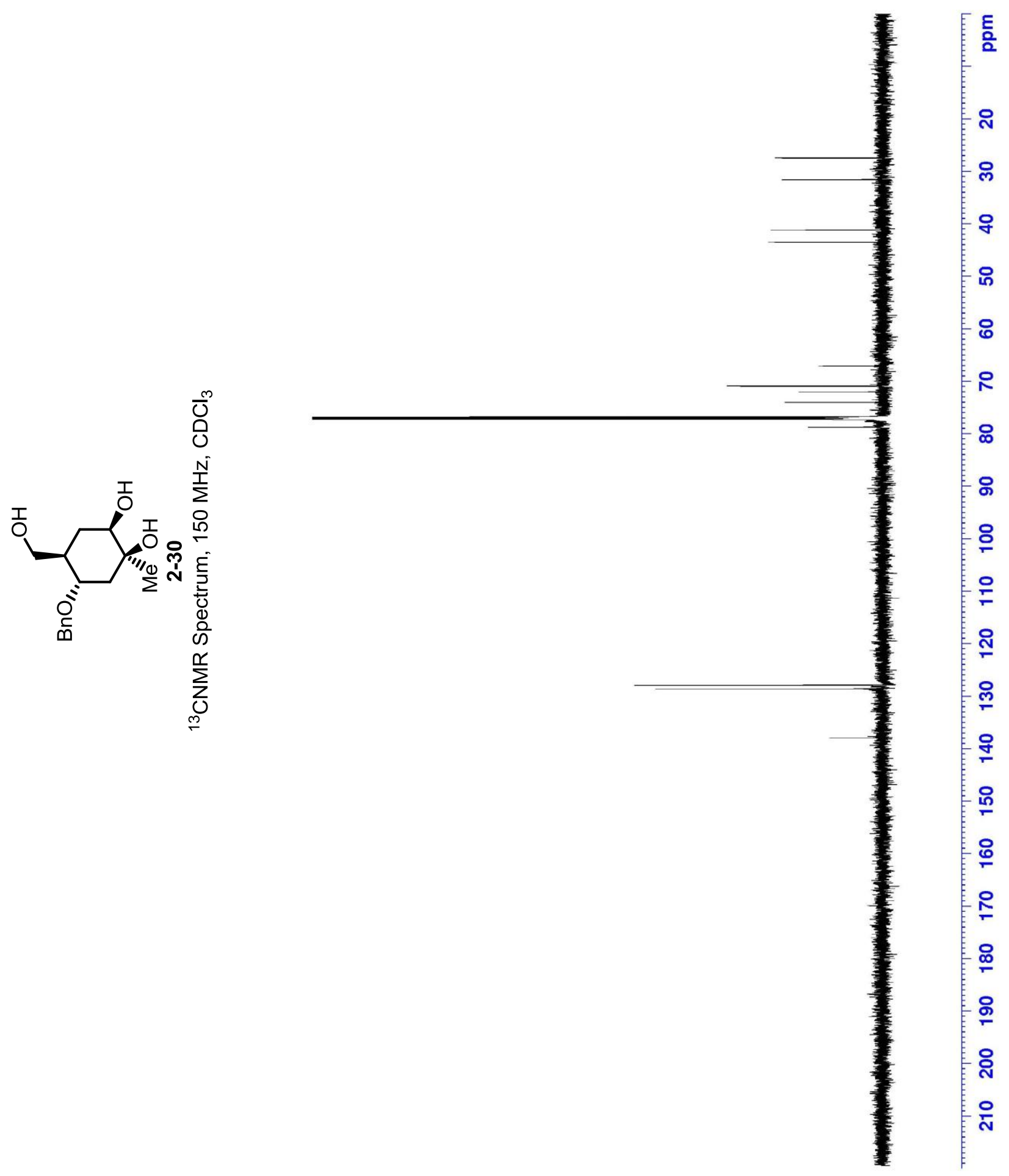




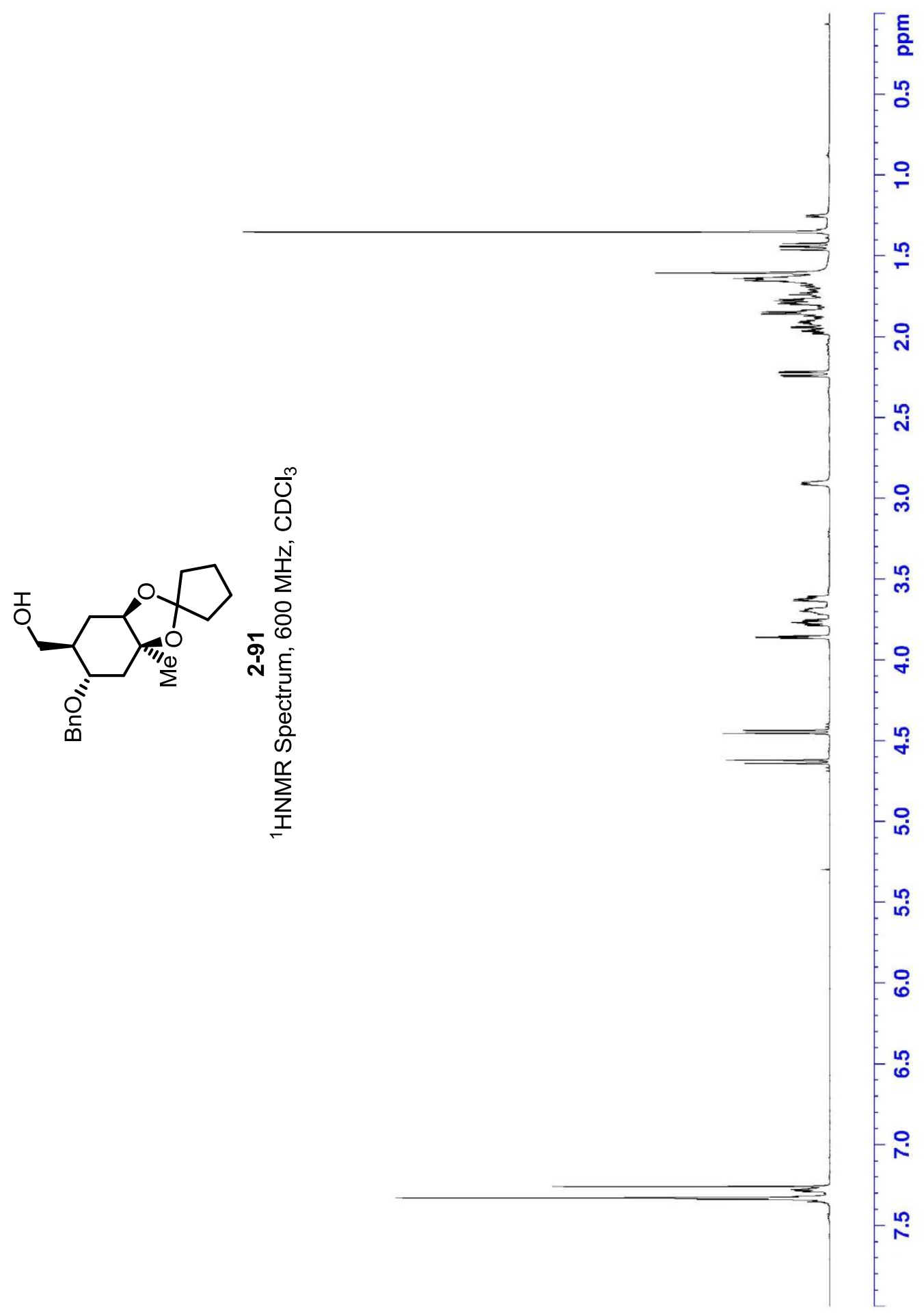




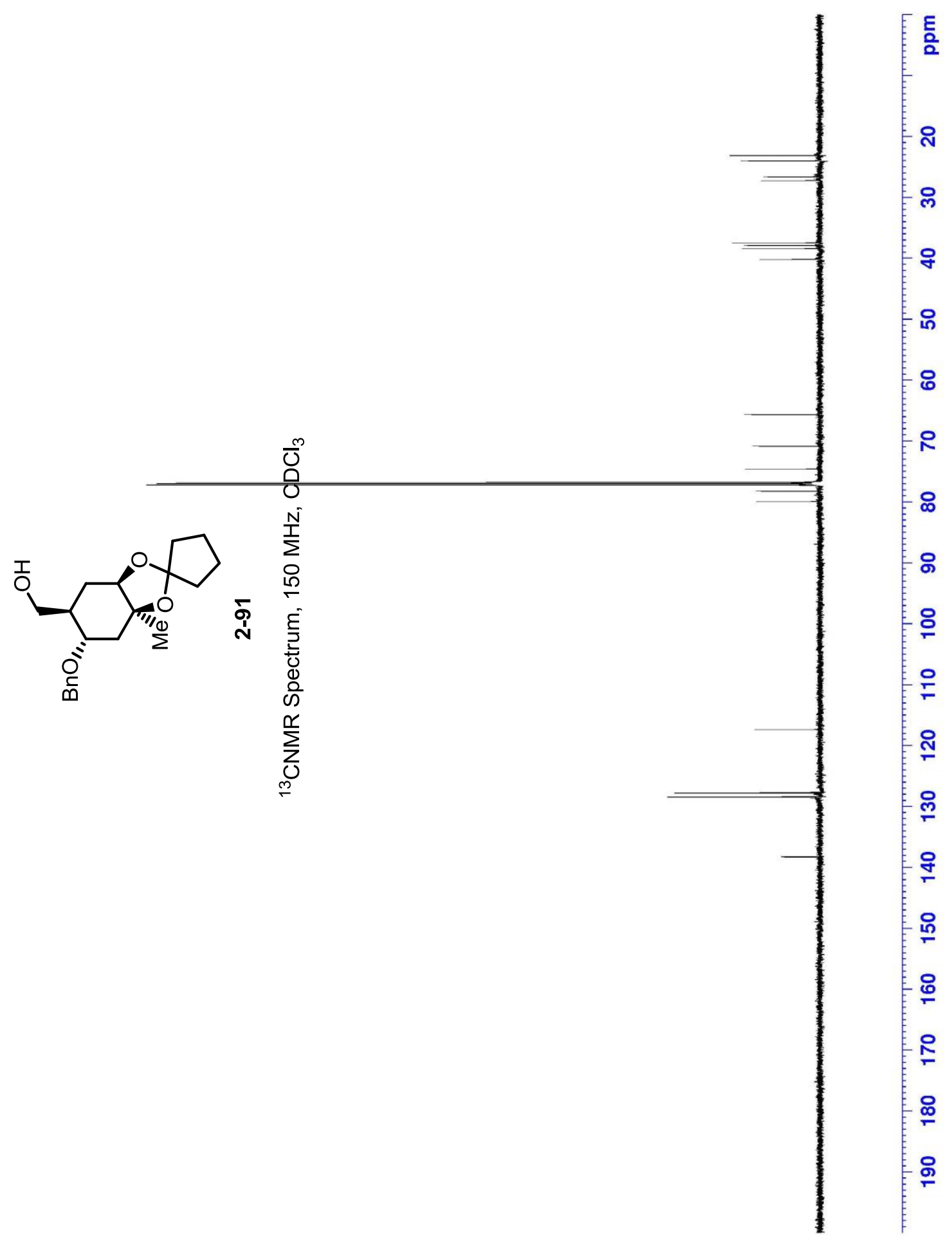




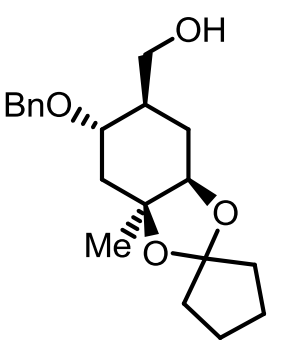

2-91

COSY Spectrum, $600 \mathrm{MHz}, \mathrm{CDCl}_{3}$

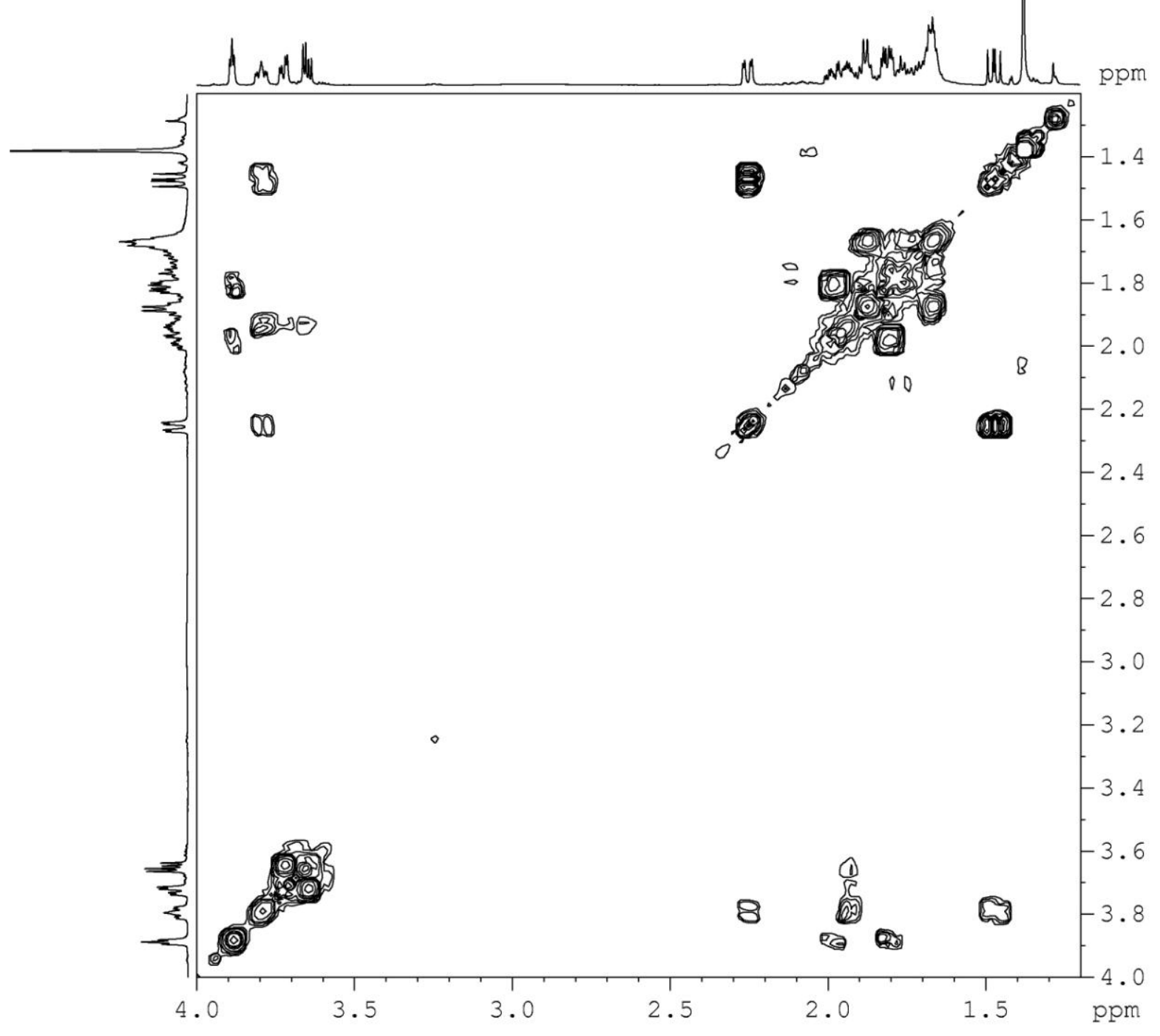




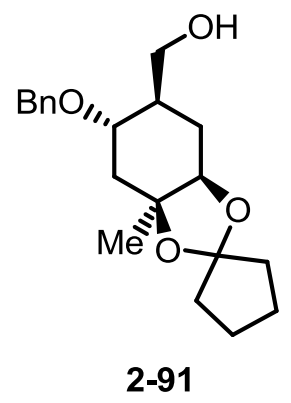

NOESY Spectrum, $600 \mathrm{MHz}, \mathrm{CDCl}_{3}$

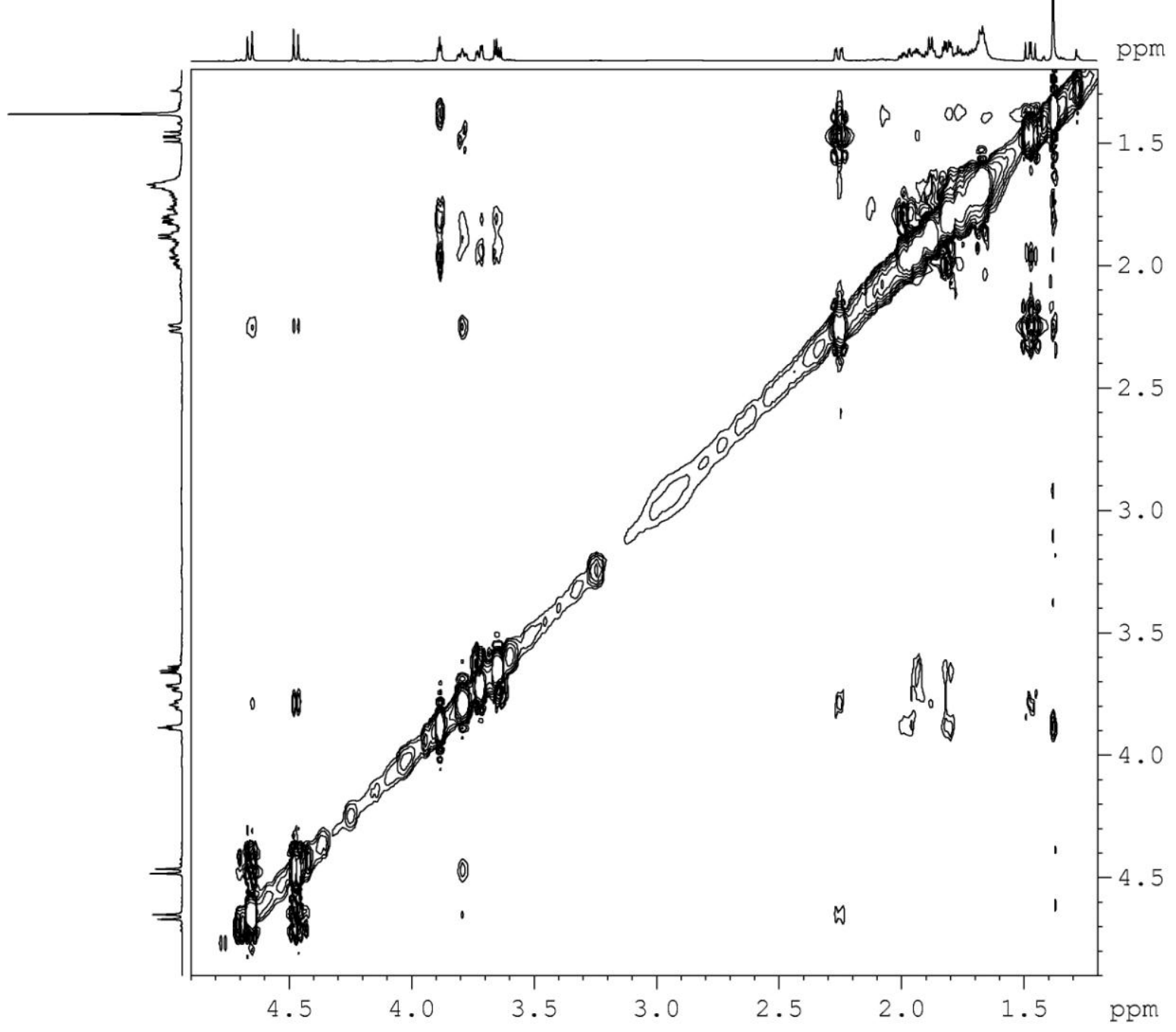




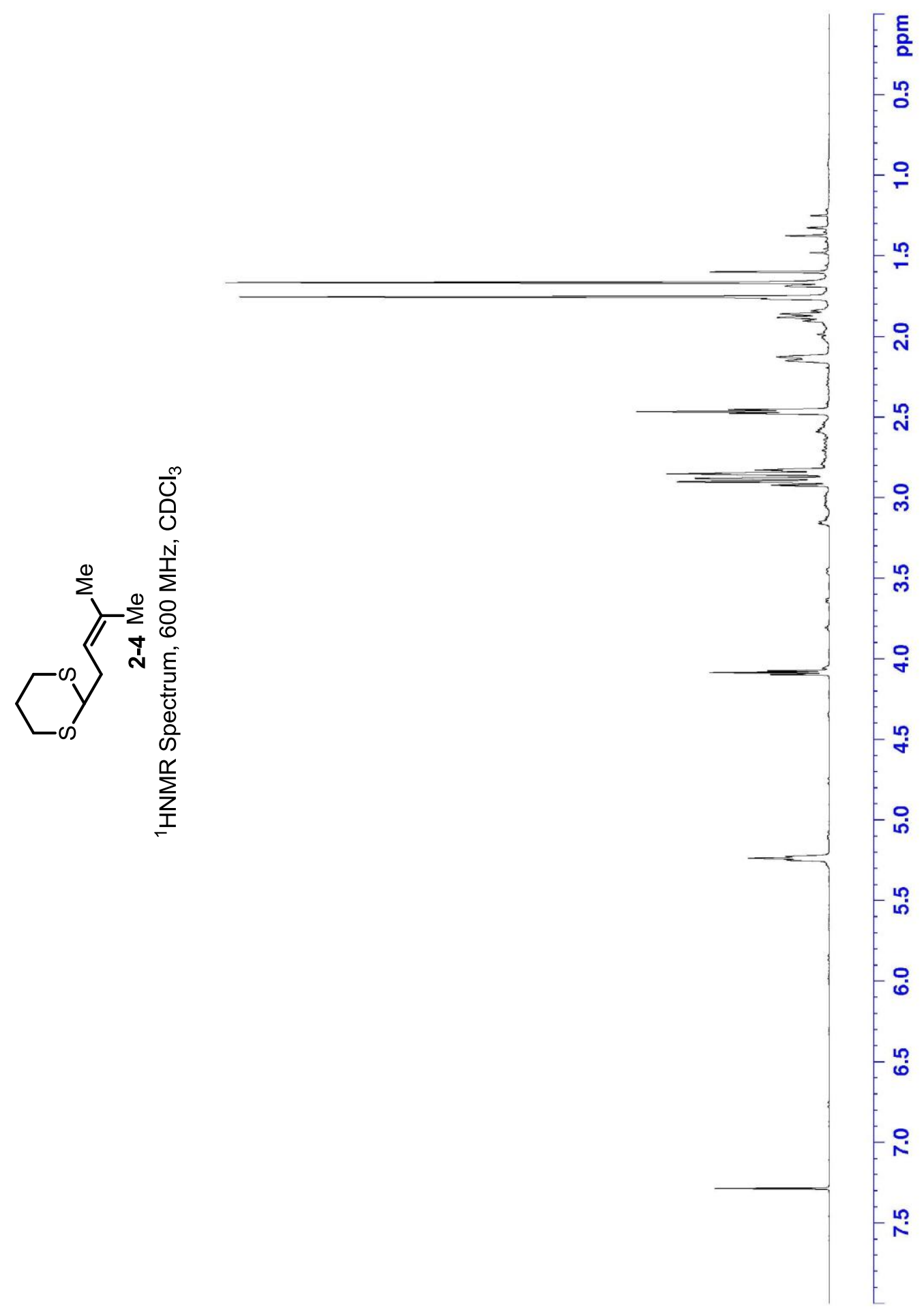




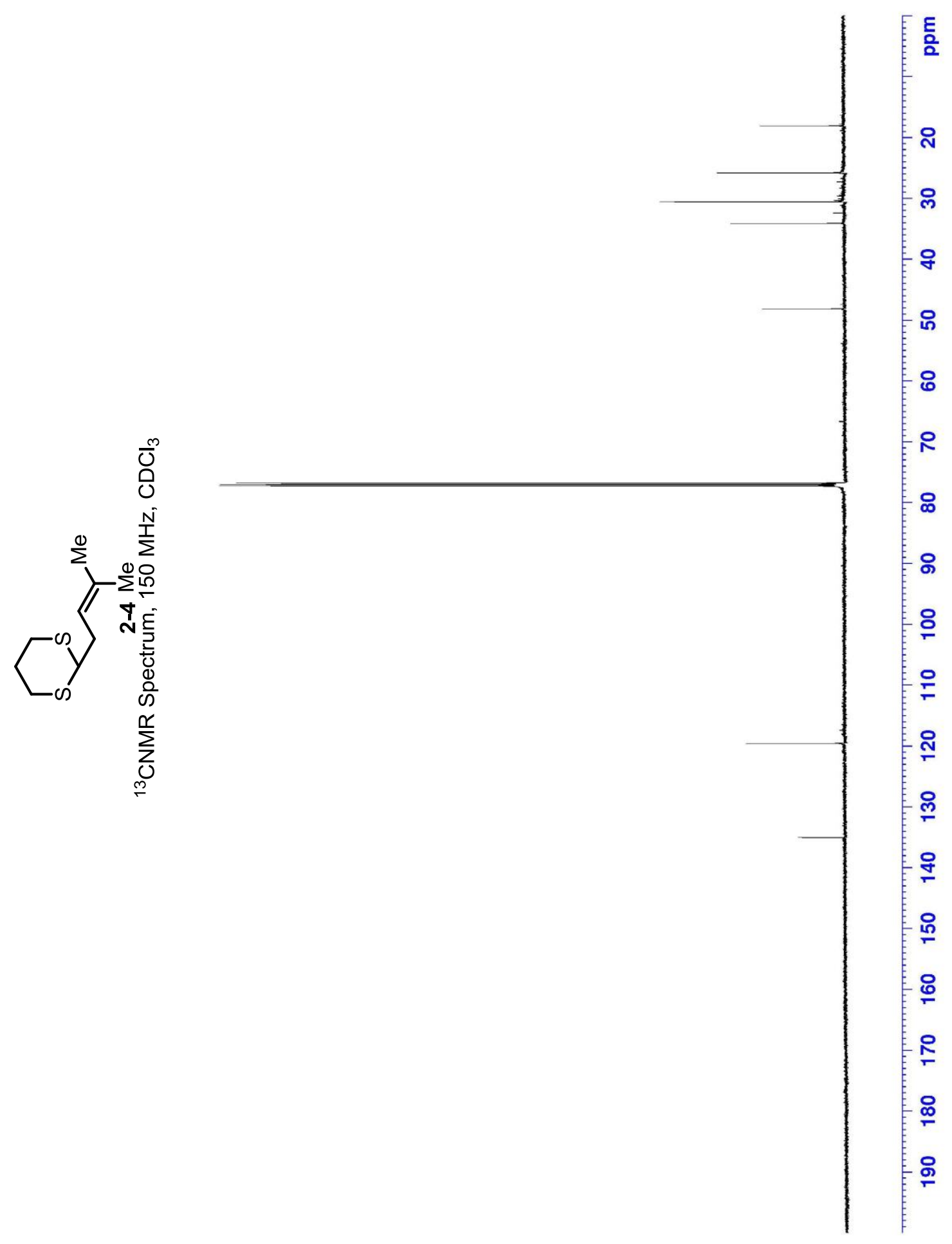




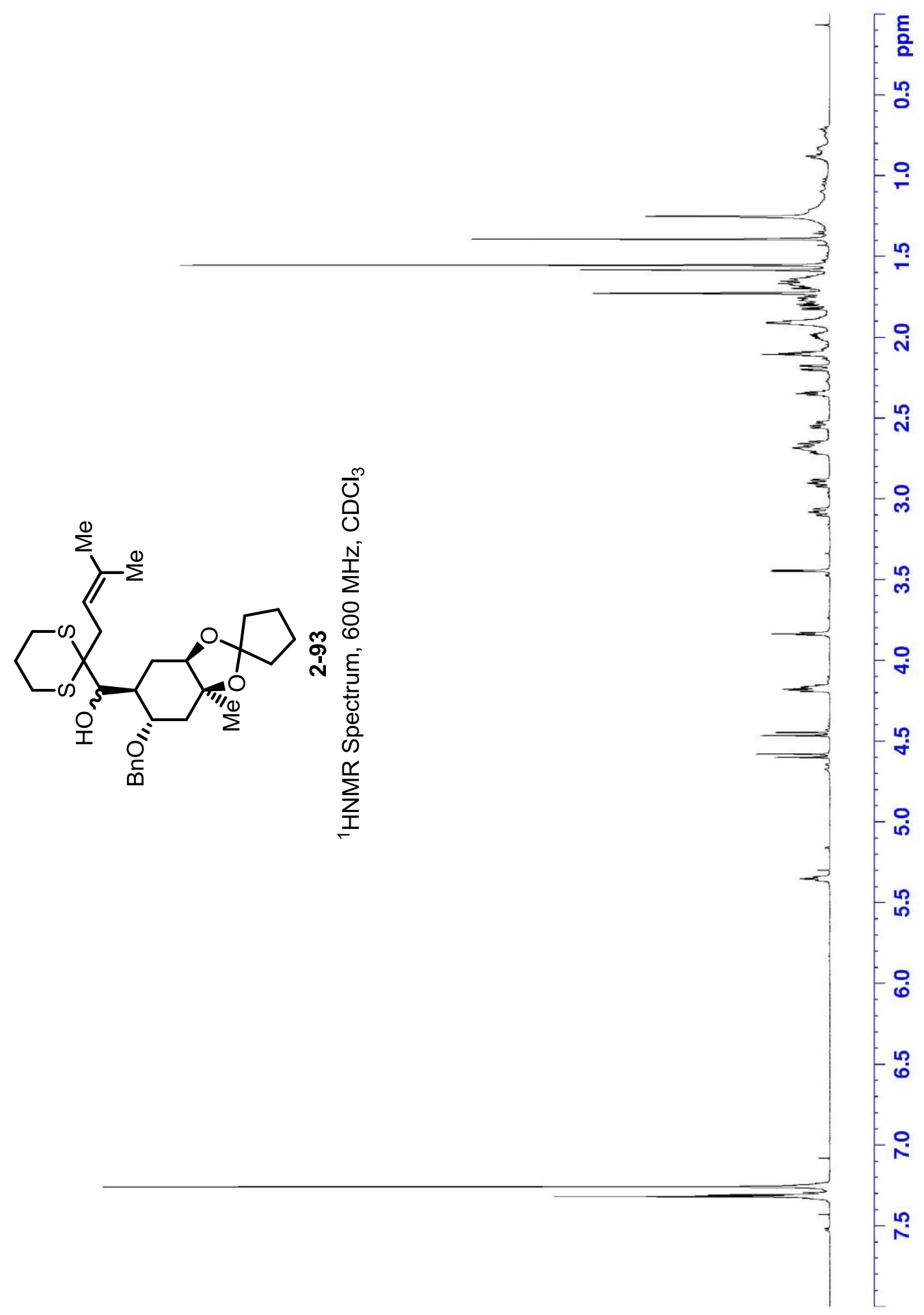




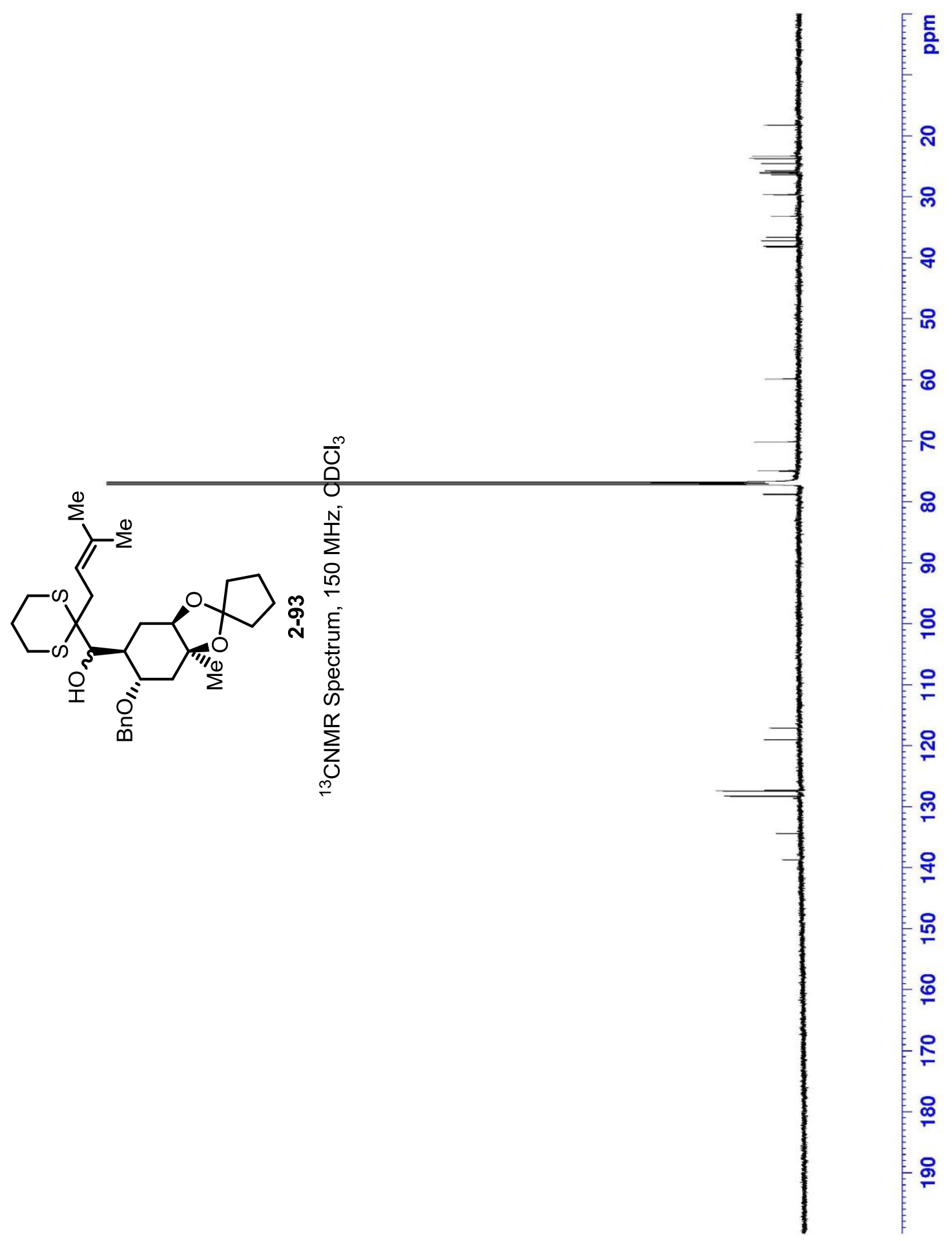




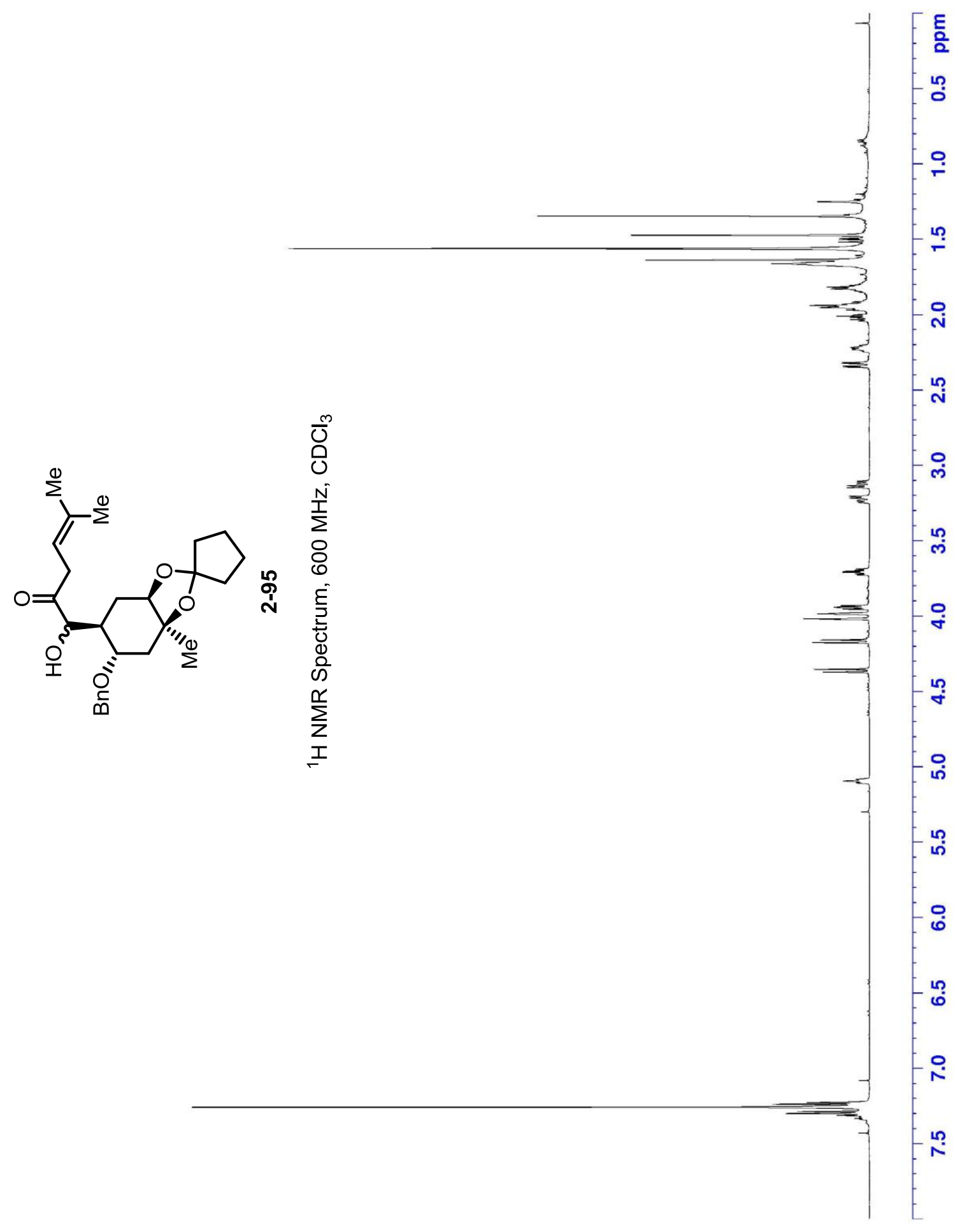




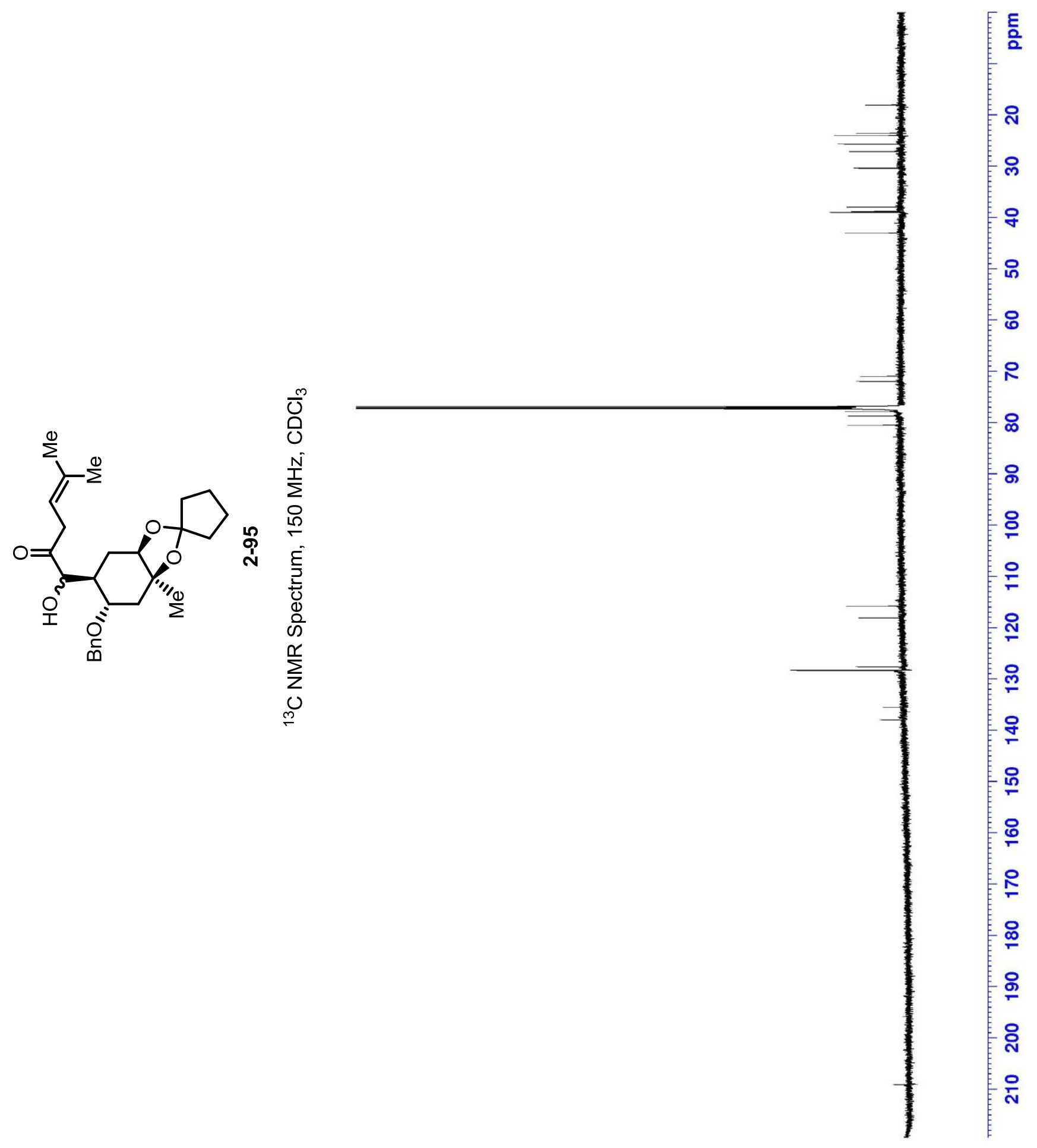




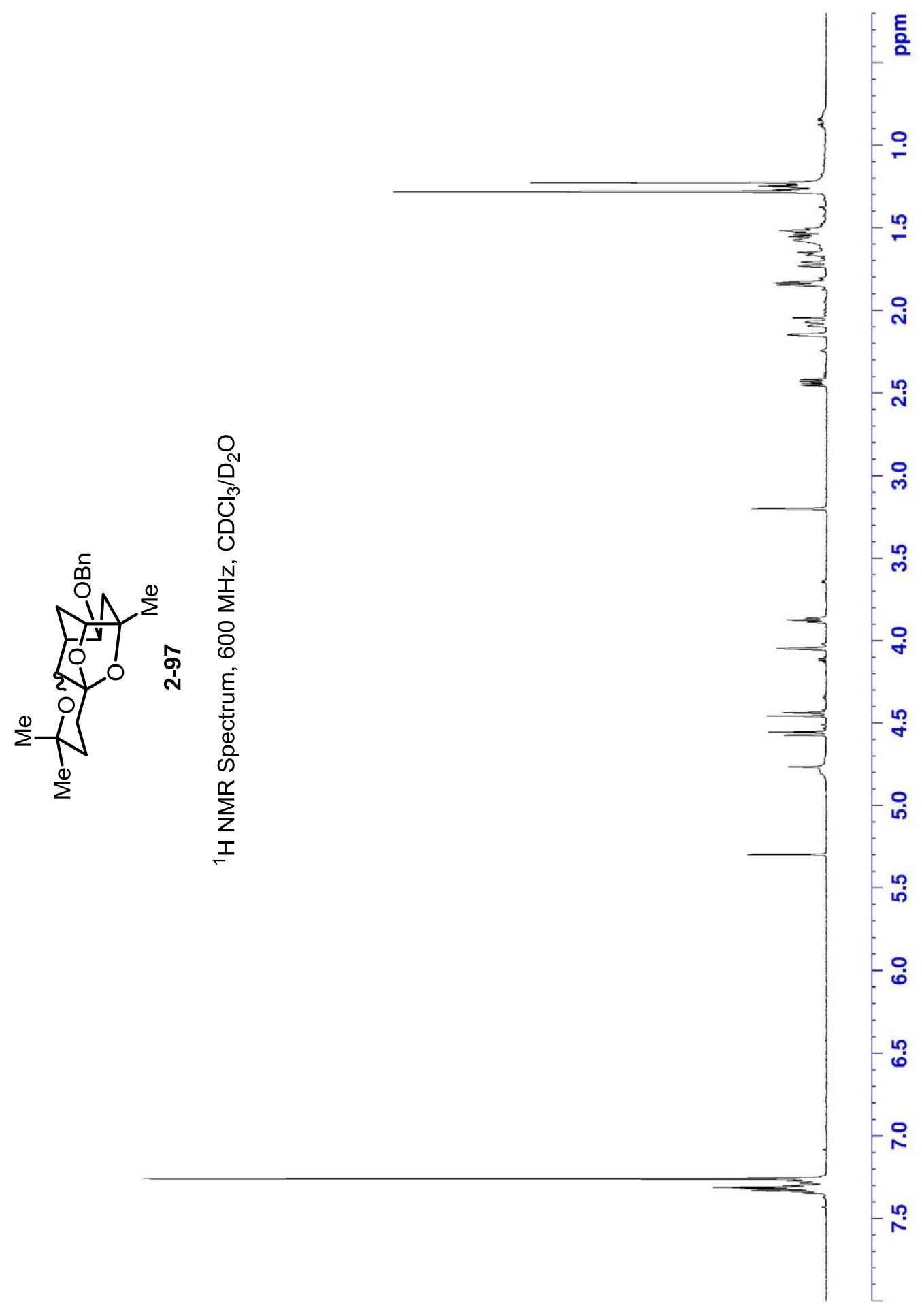




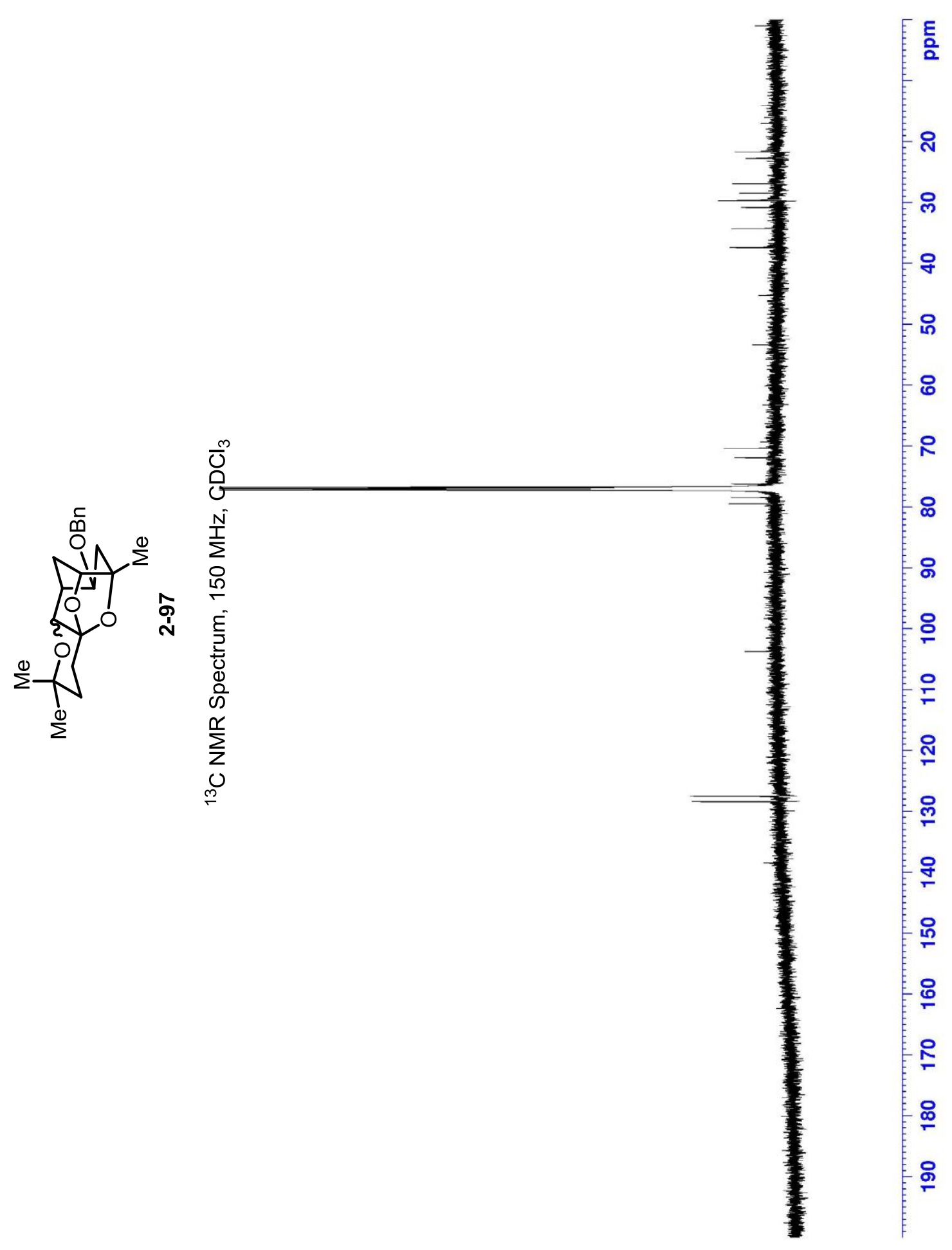




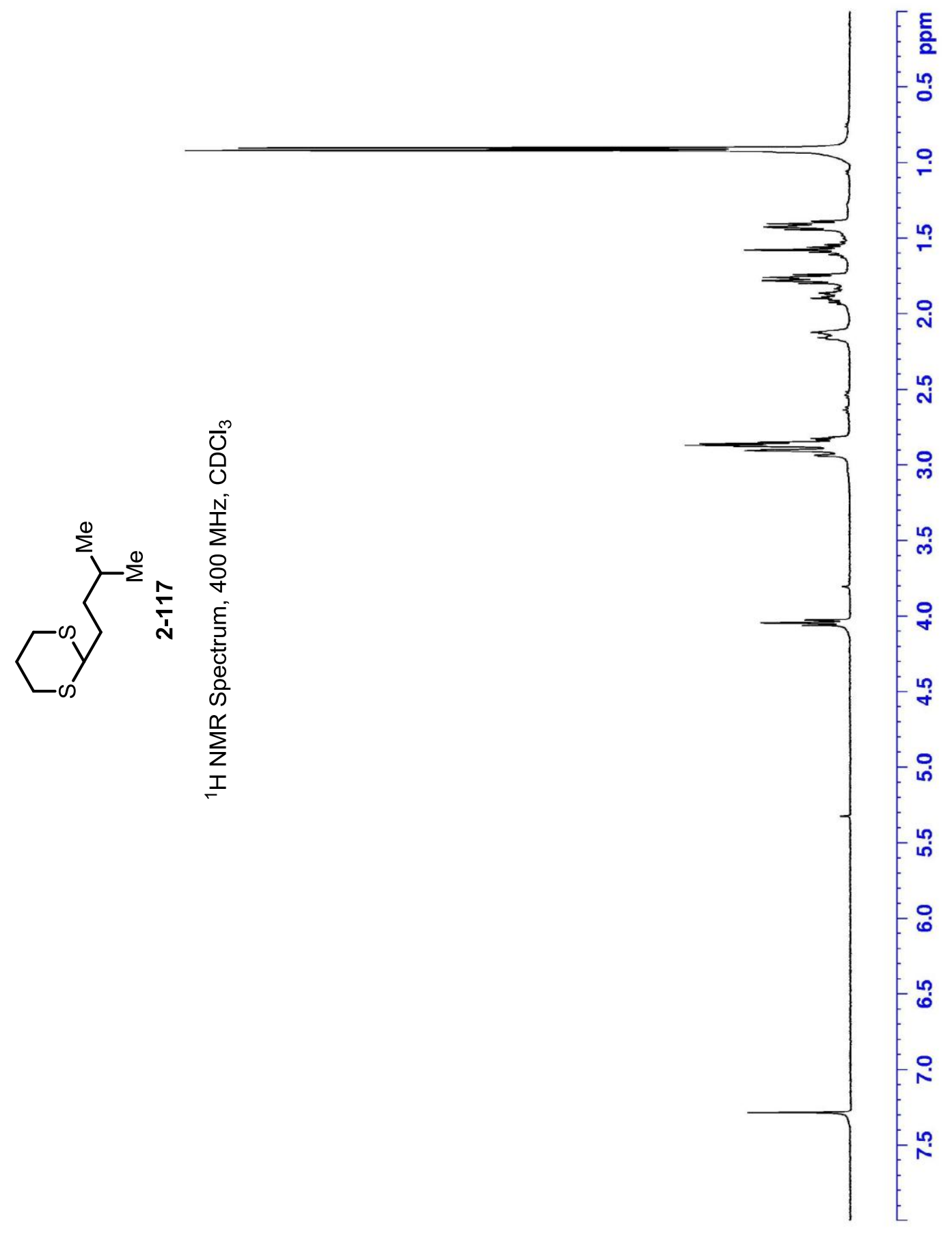




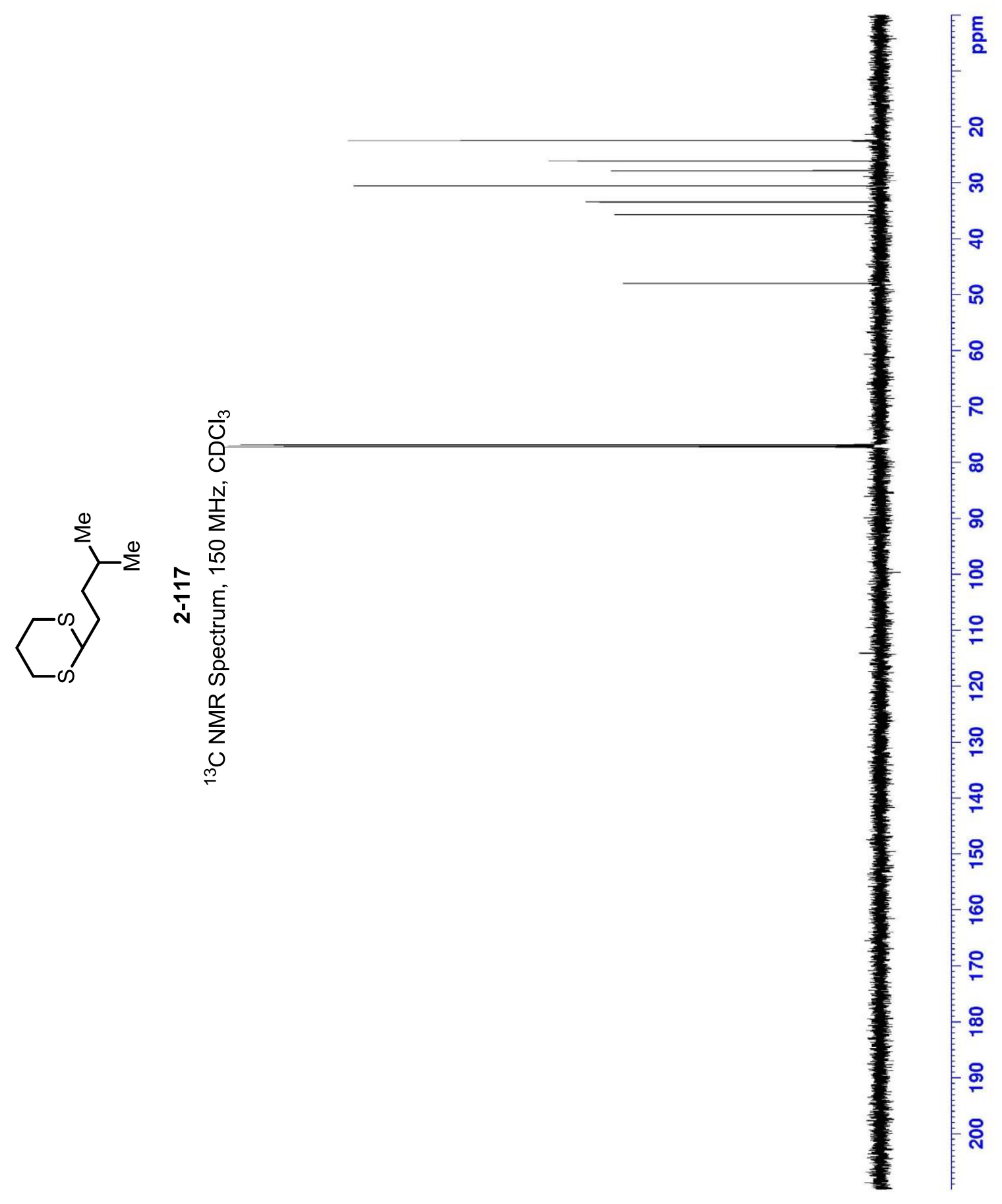




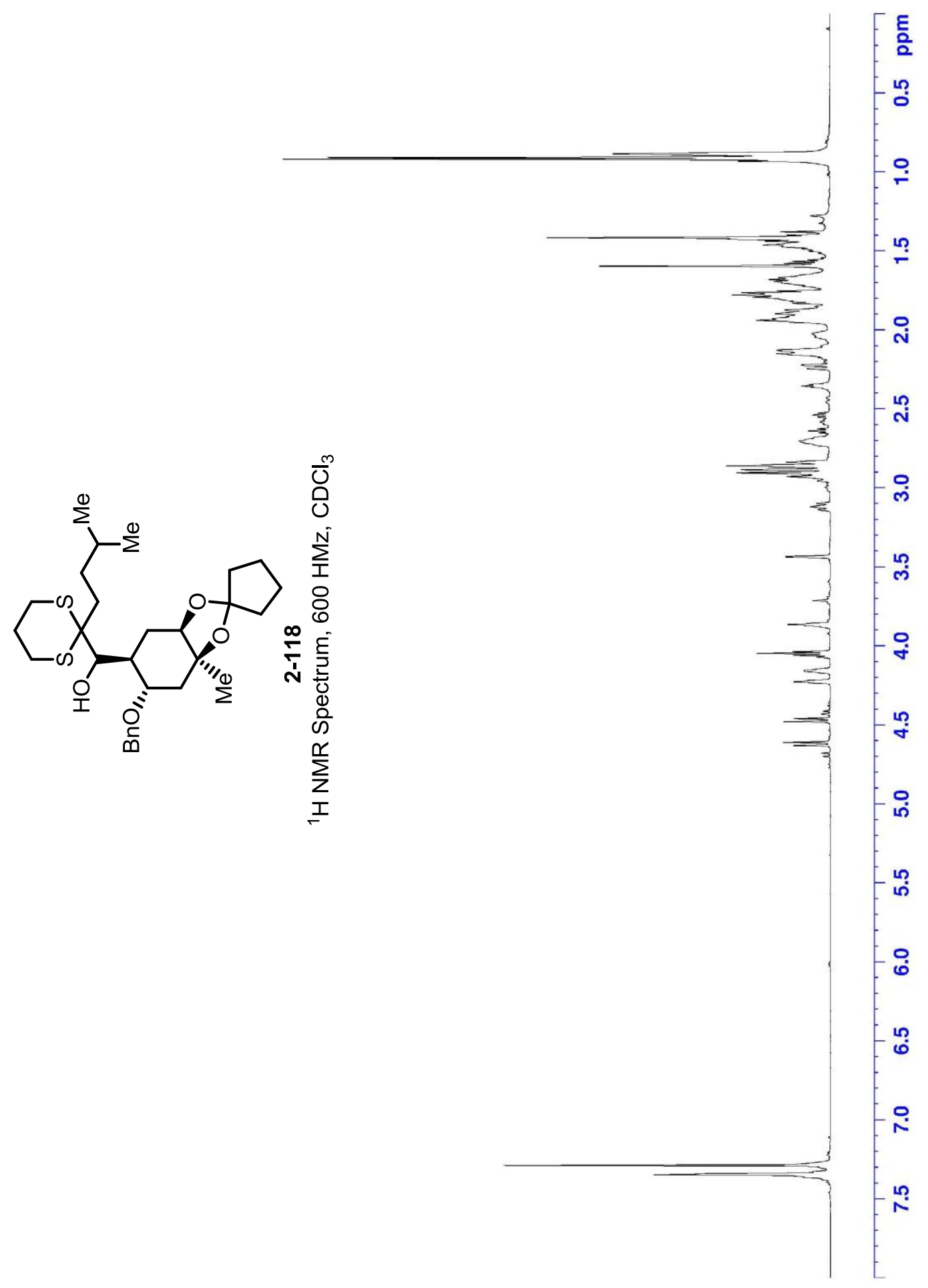




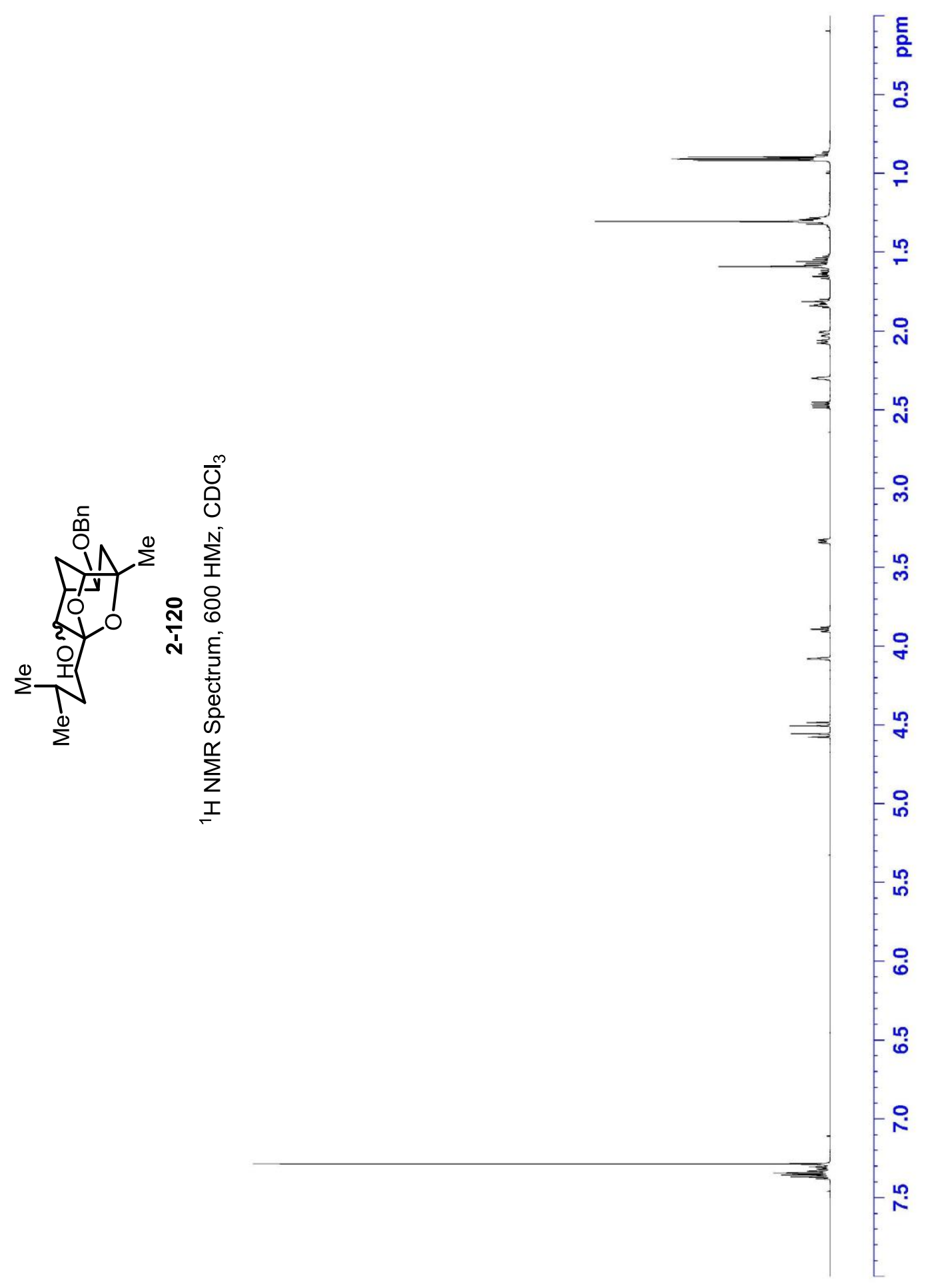




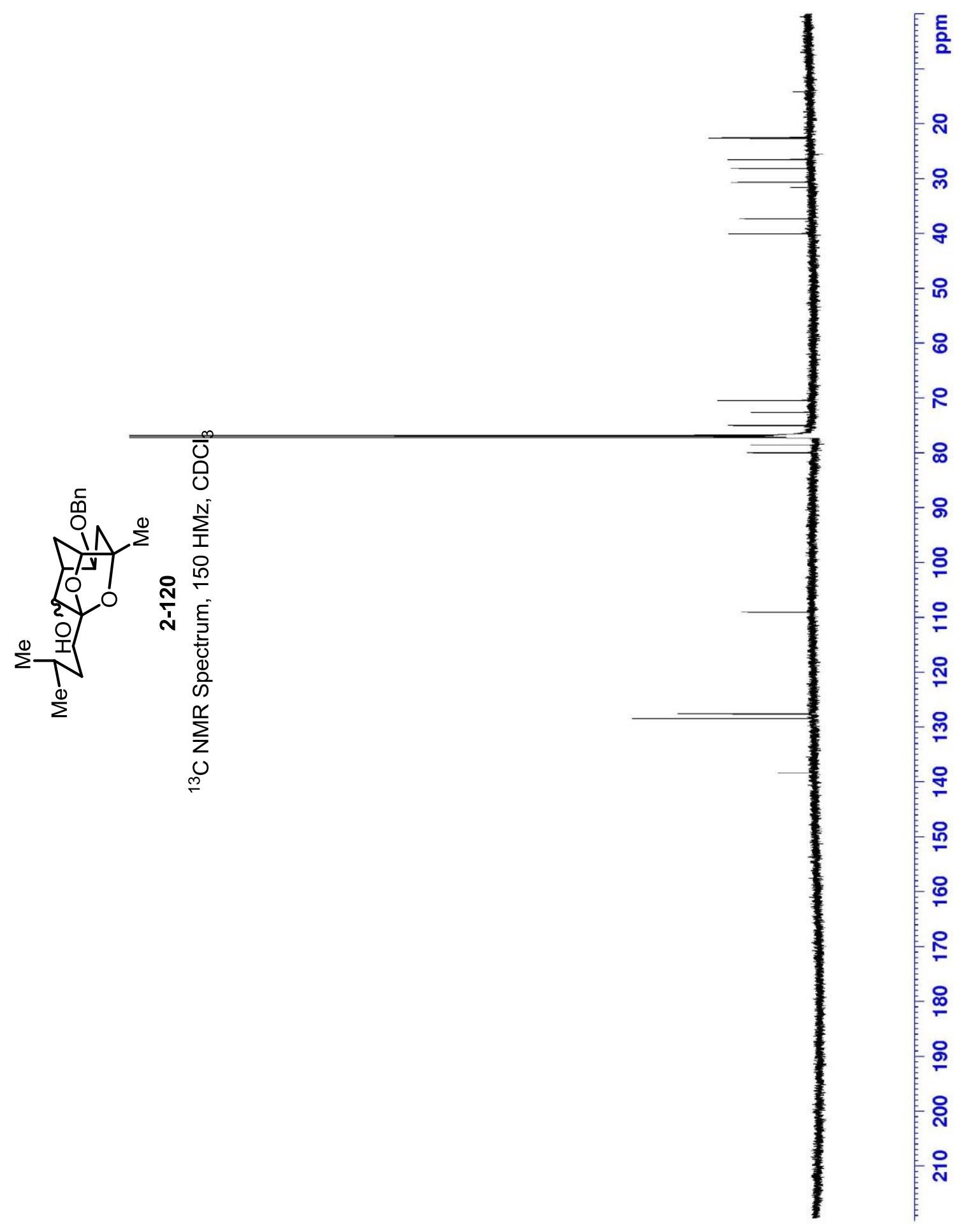



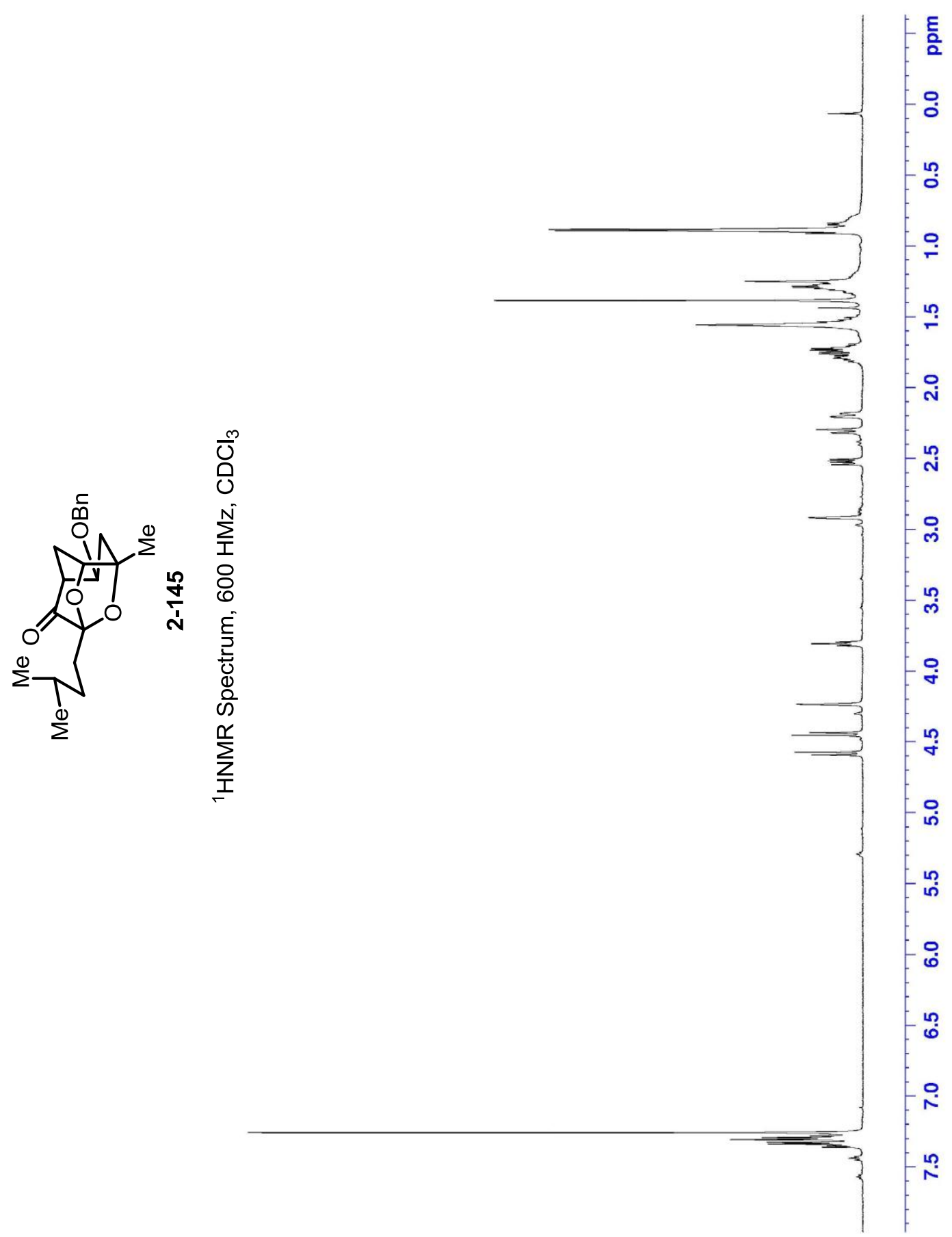


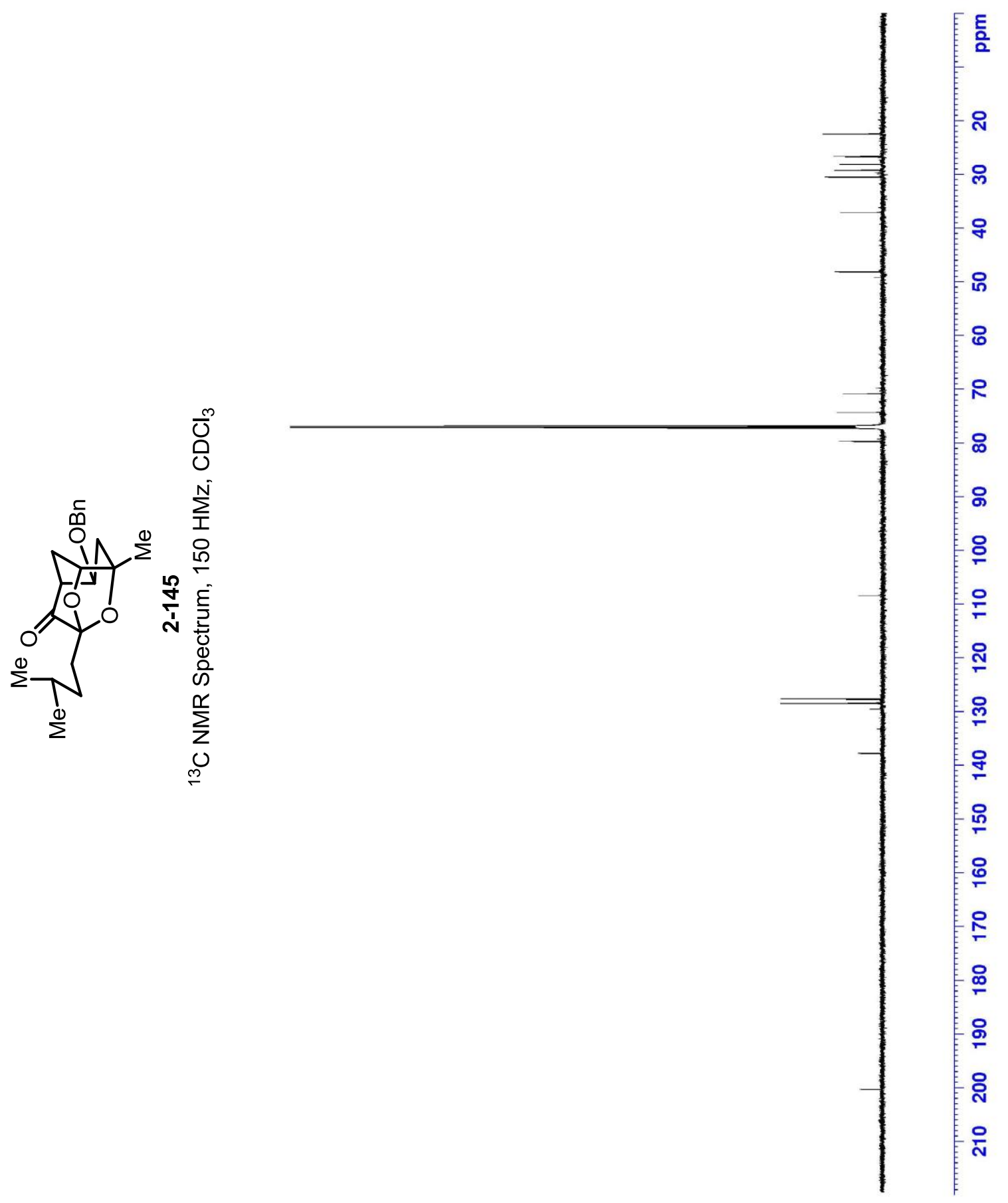




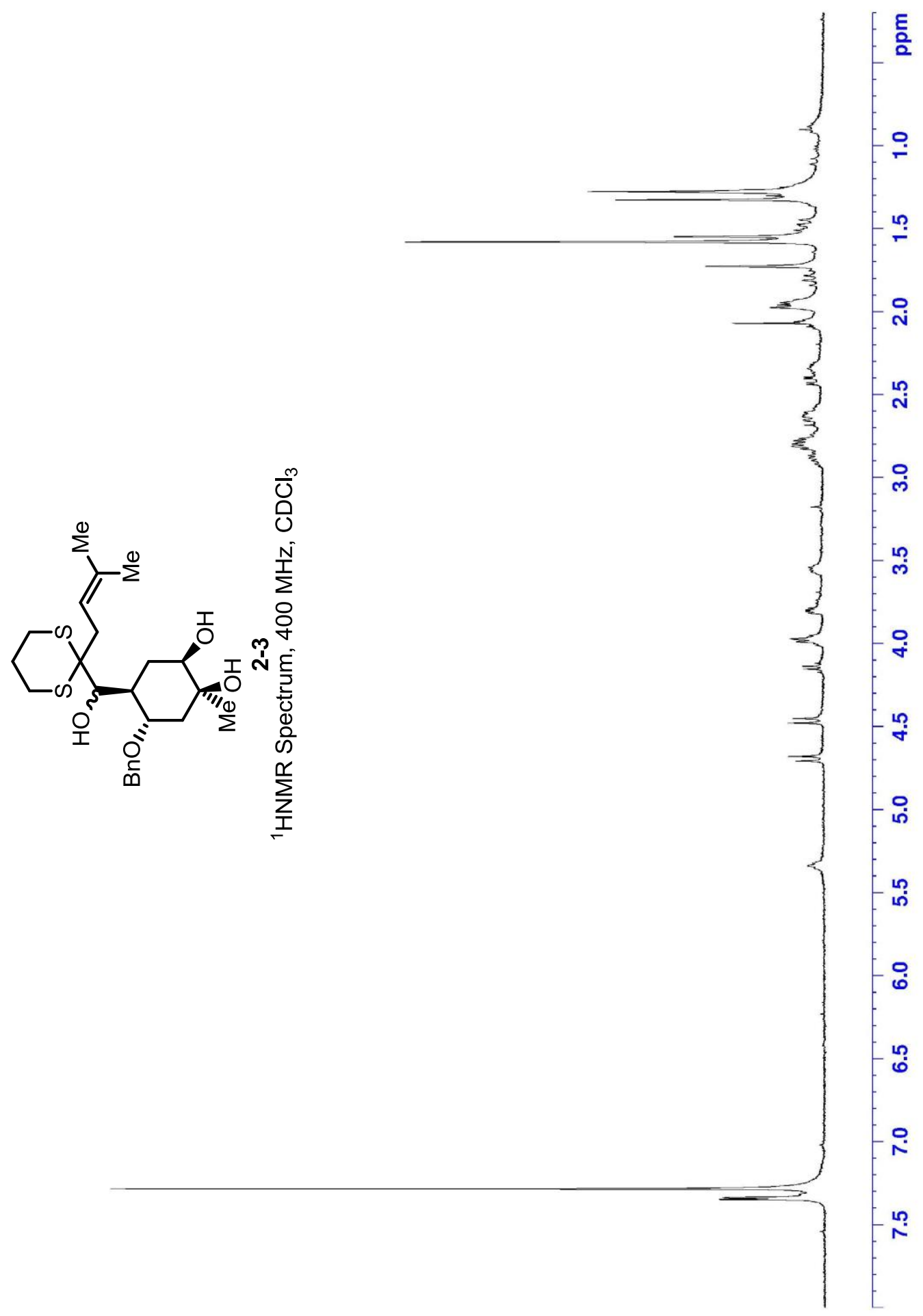




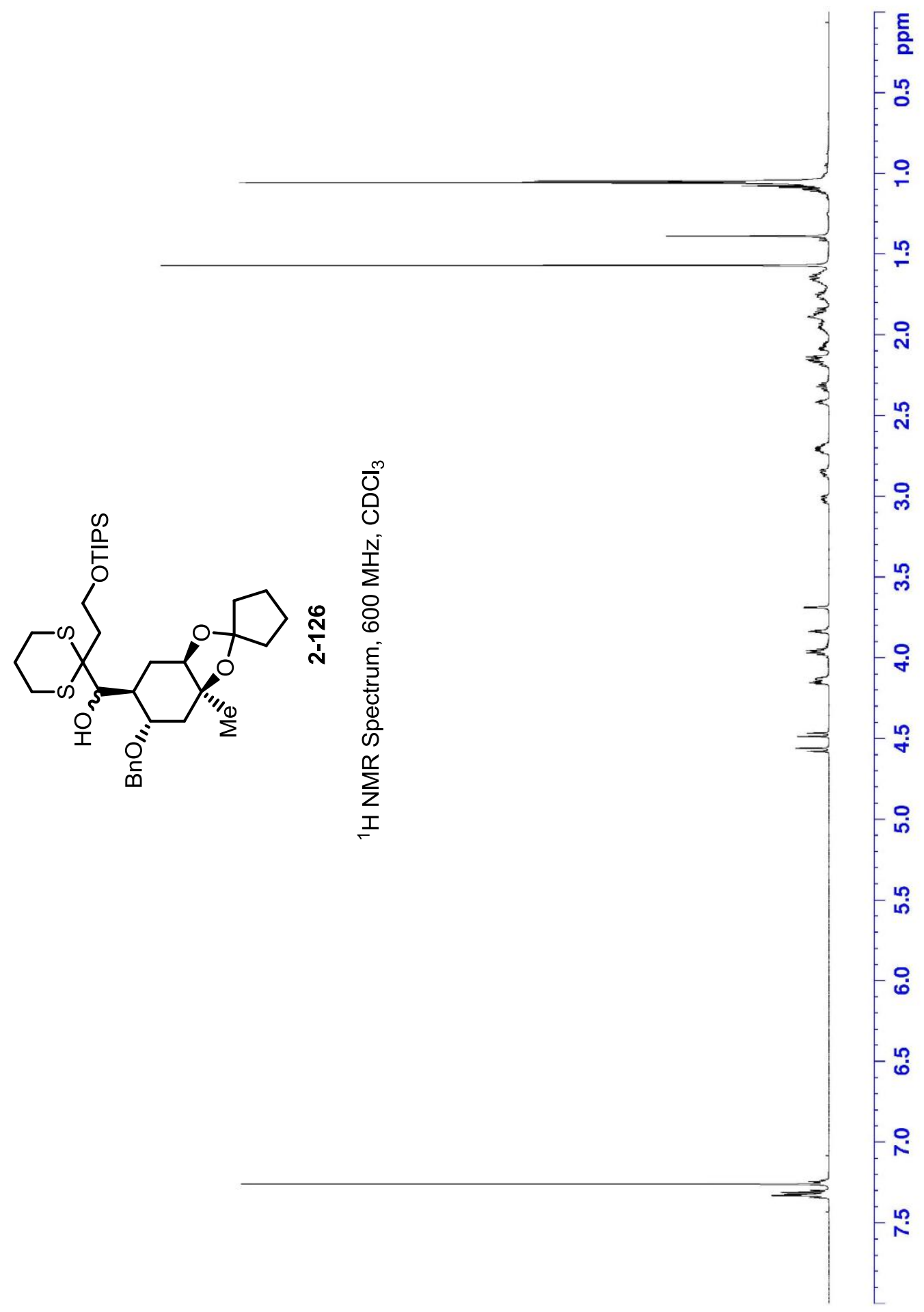




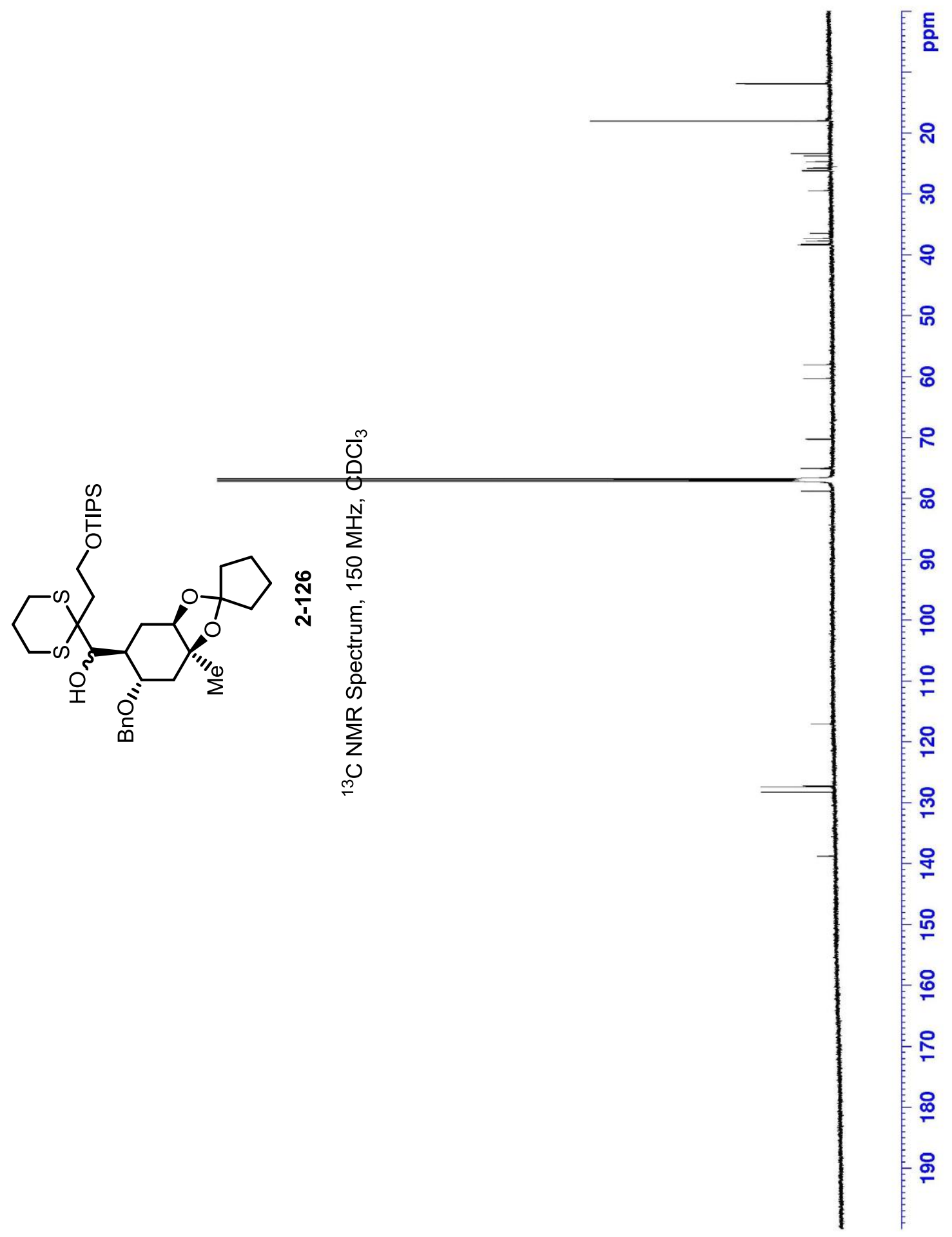




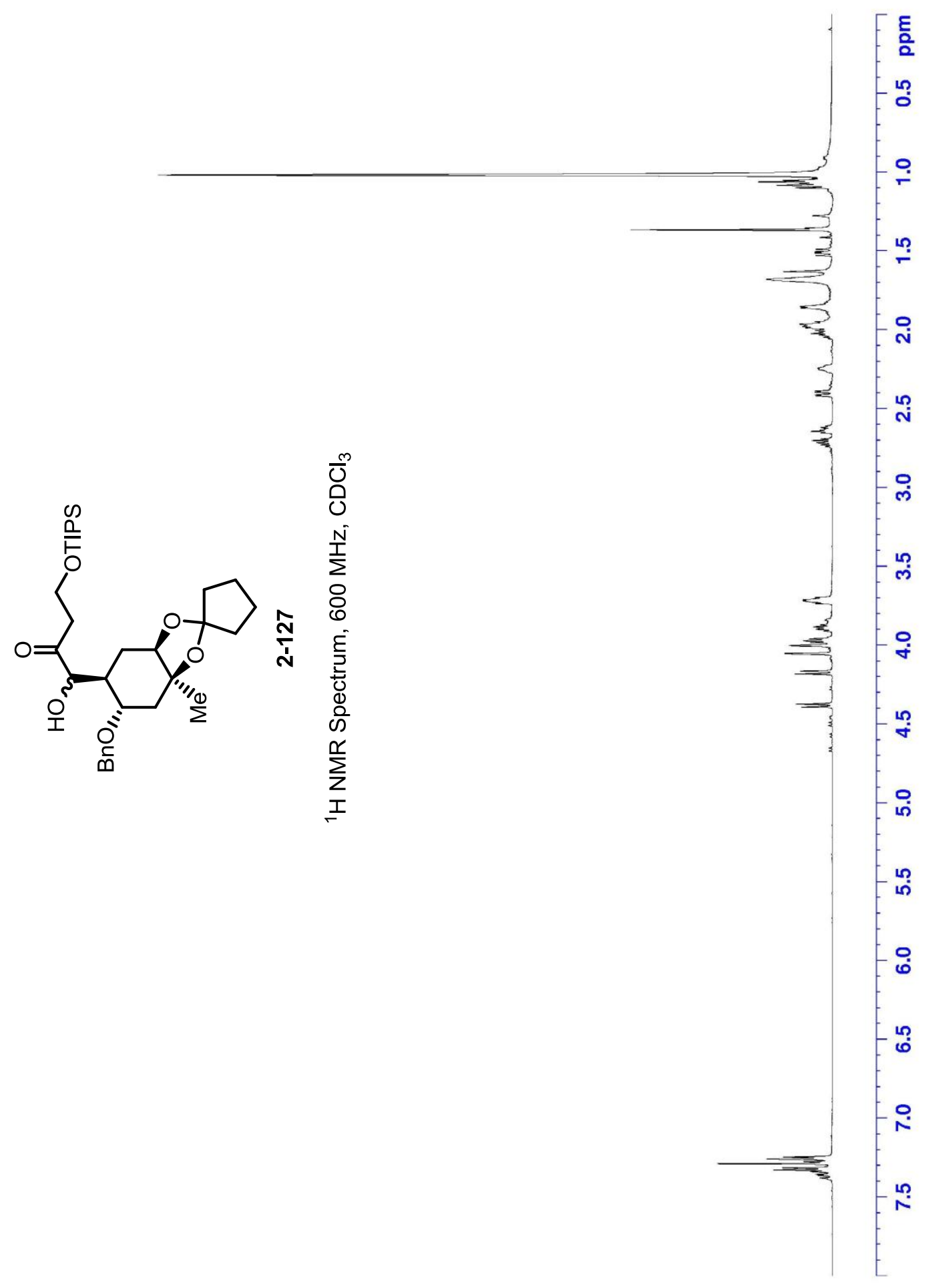




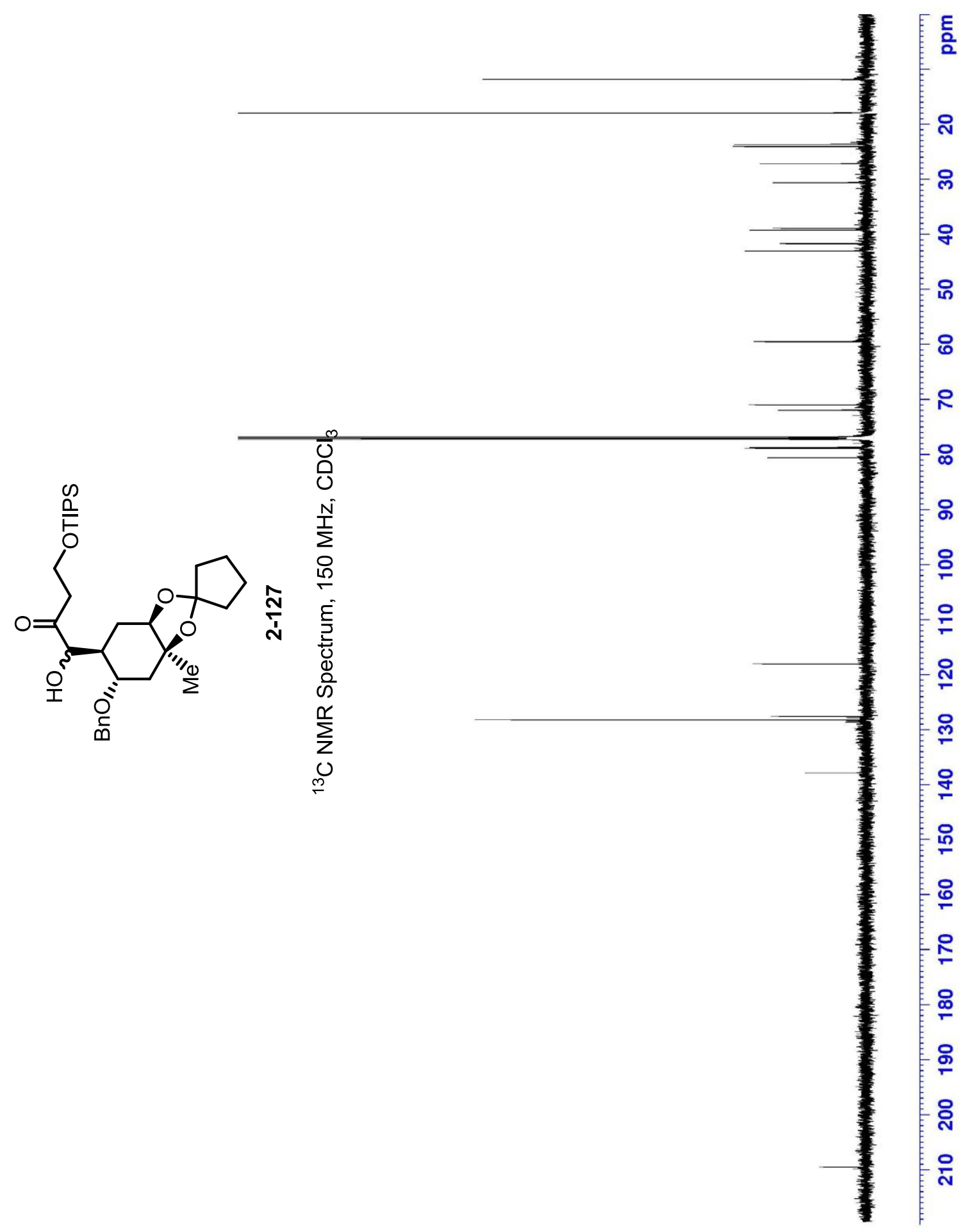




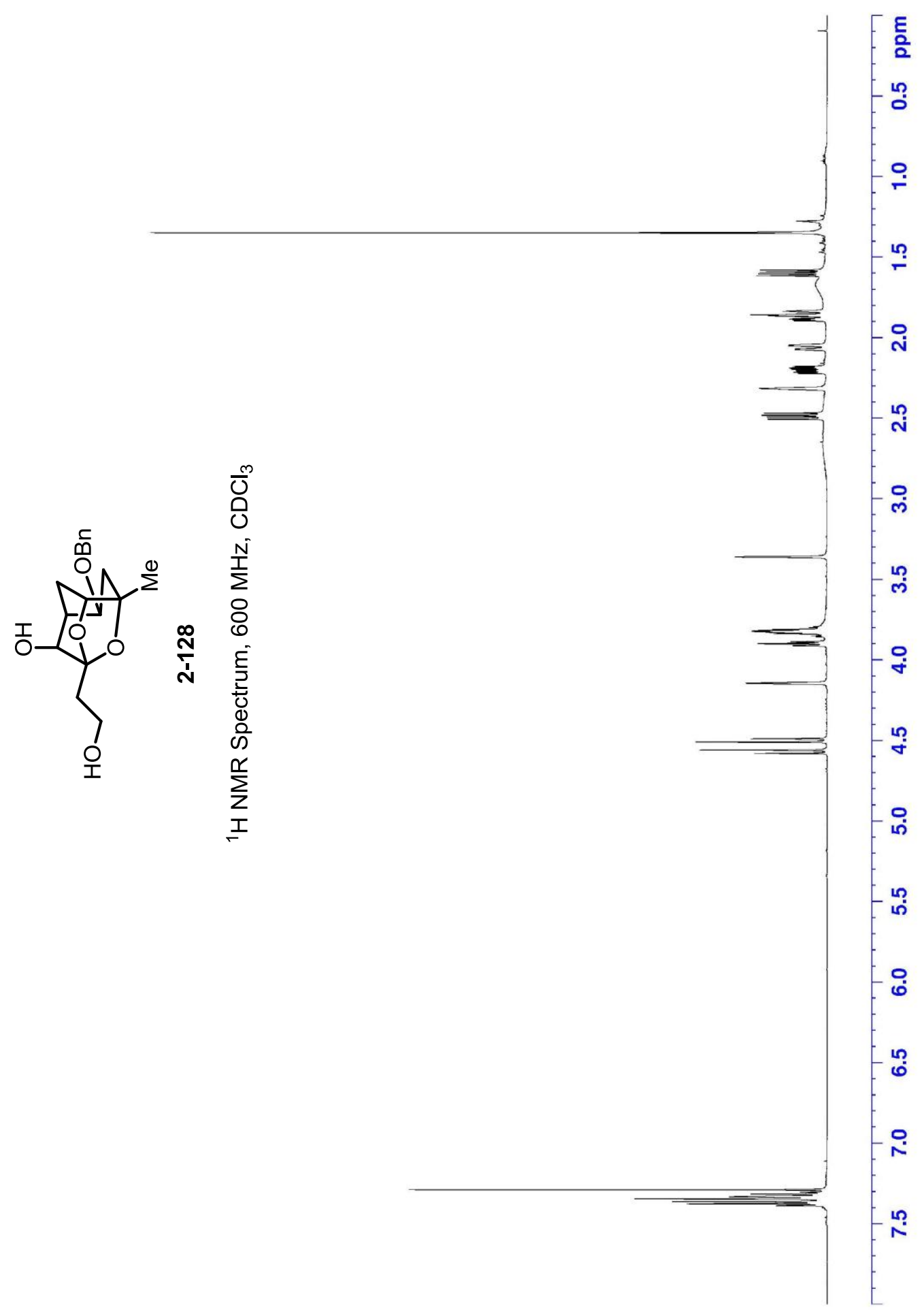




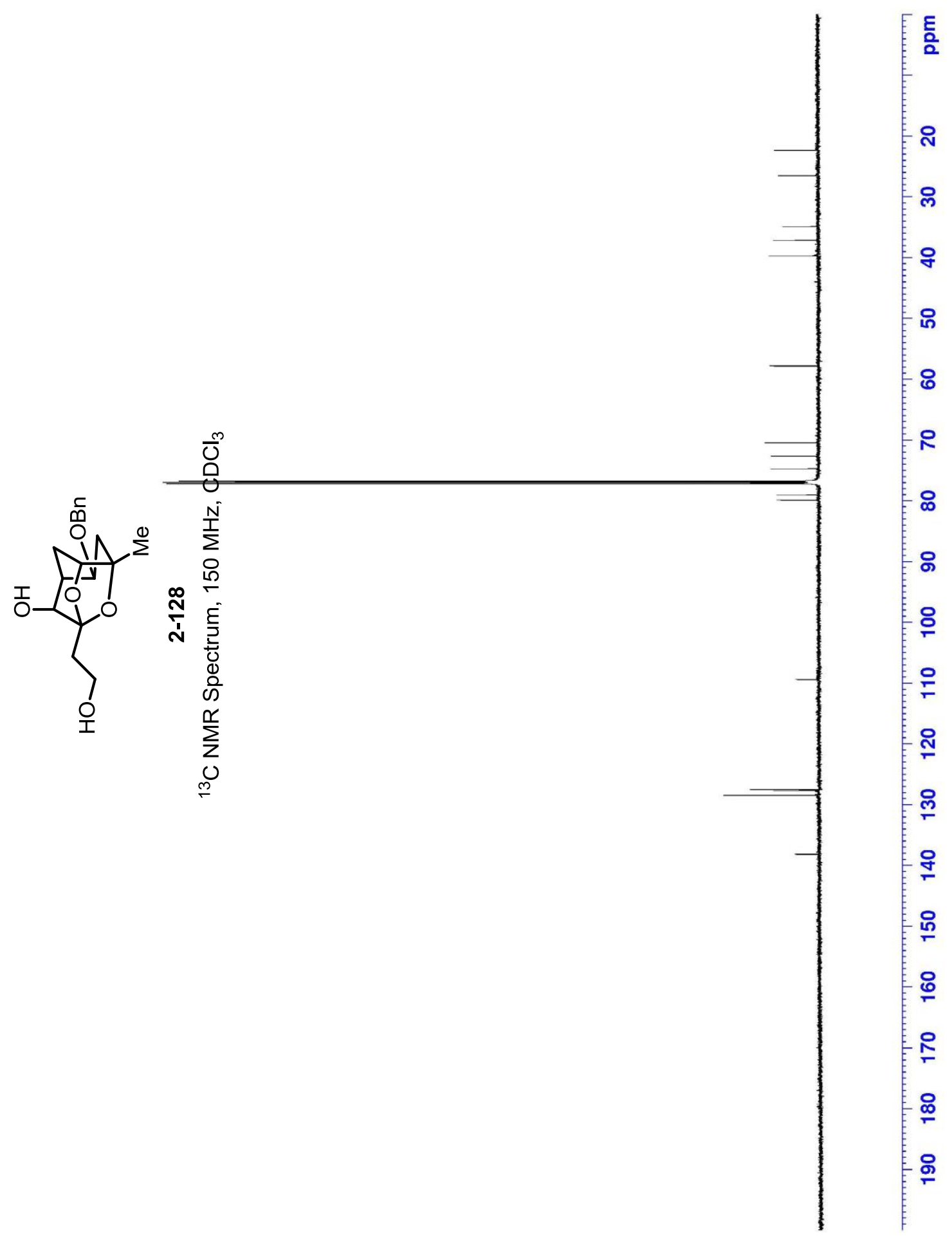




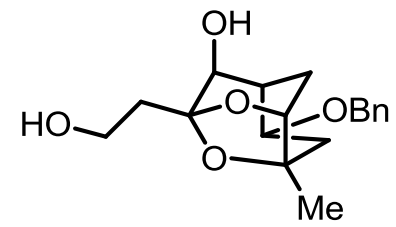

2-128

COSY Spectrum, $600 \mathrm{MHz}, \mathrm{CDCl}_{3}$

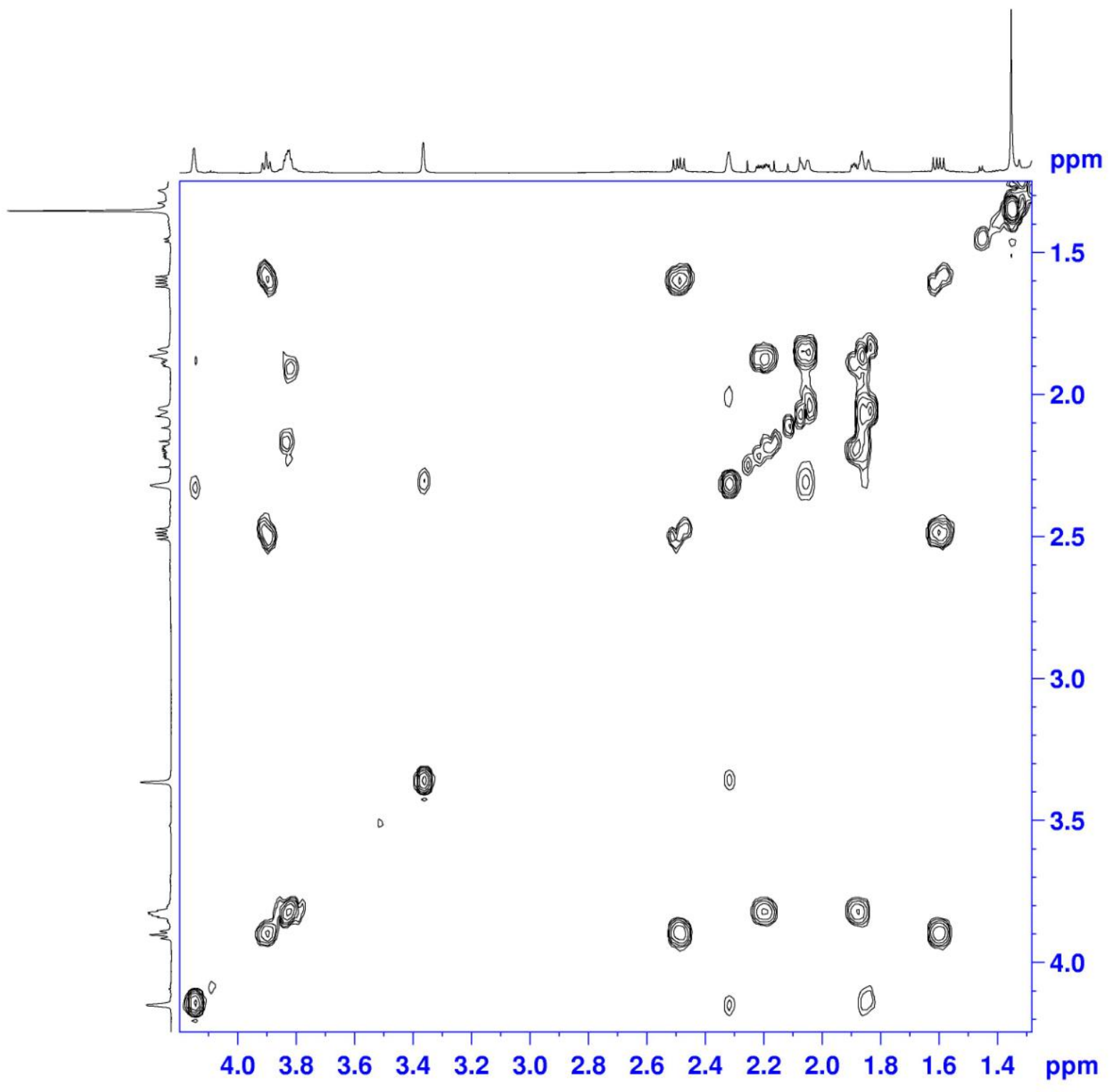




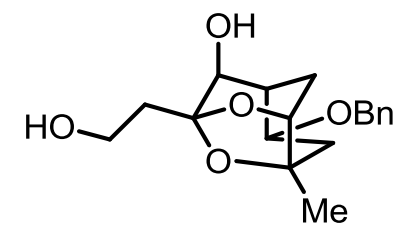

2-128

NOESY Spectrum, $600 \mathrm{MHz}, \mathrm{CDCl}_{3}$

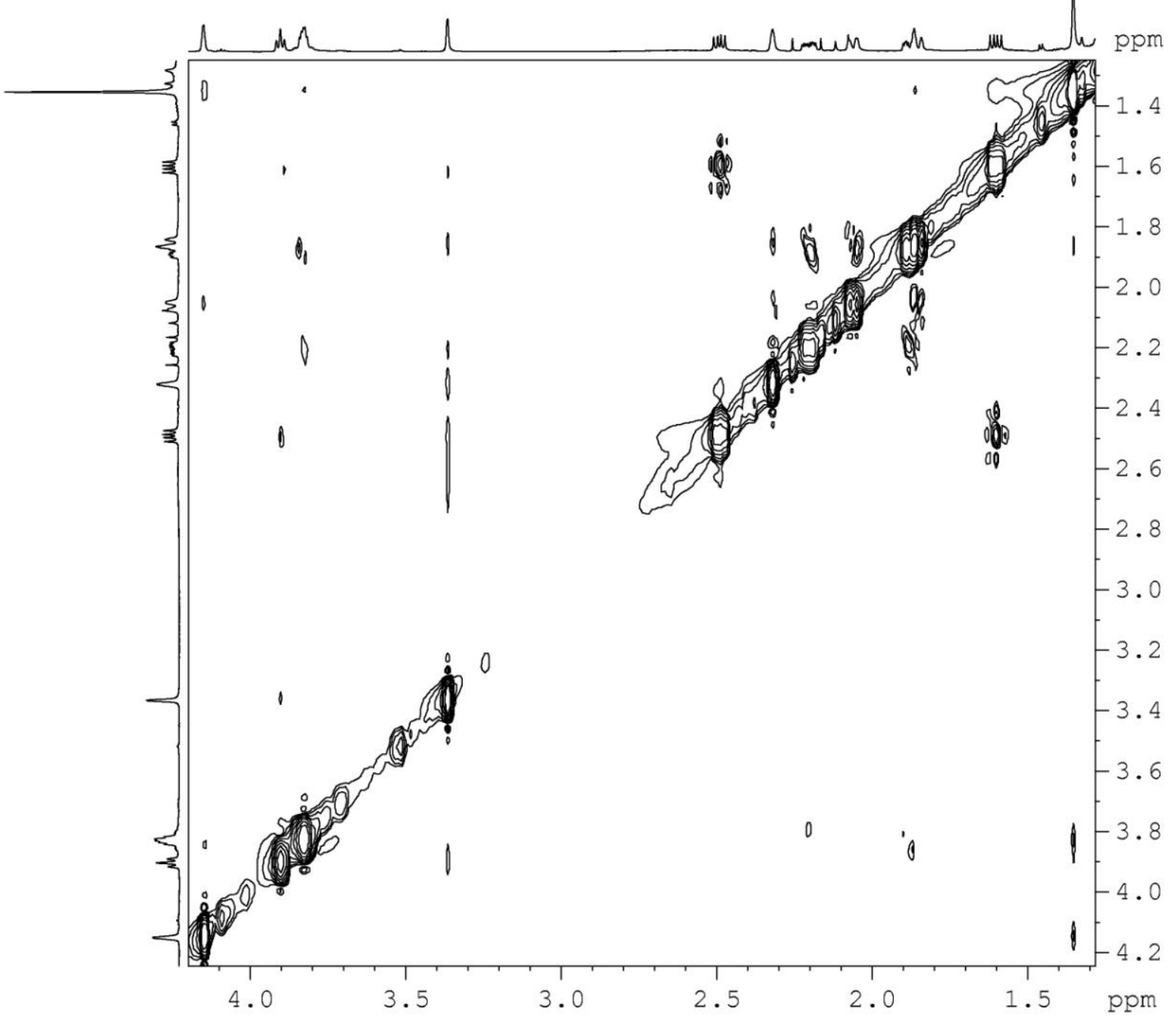




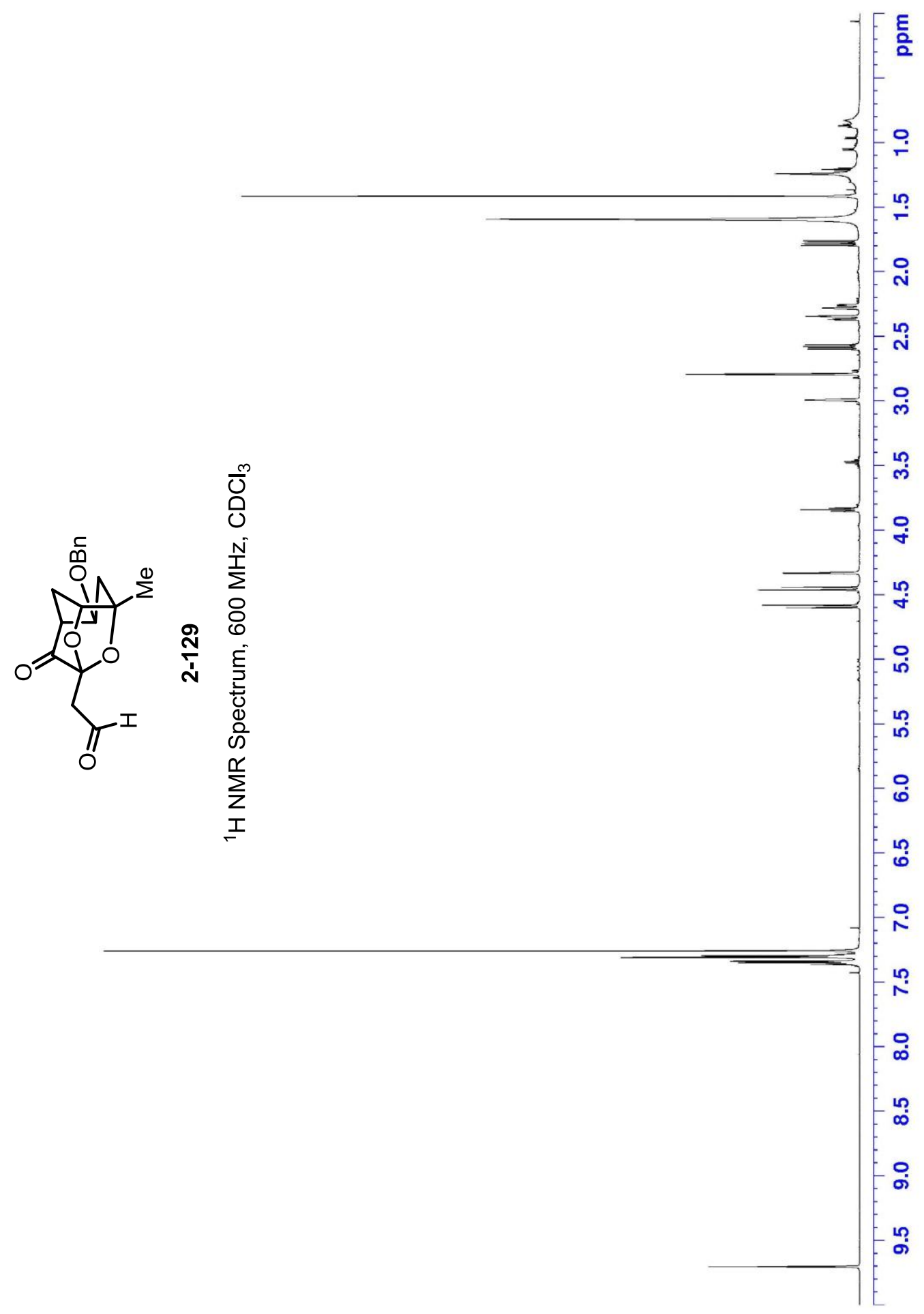




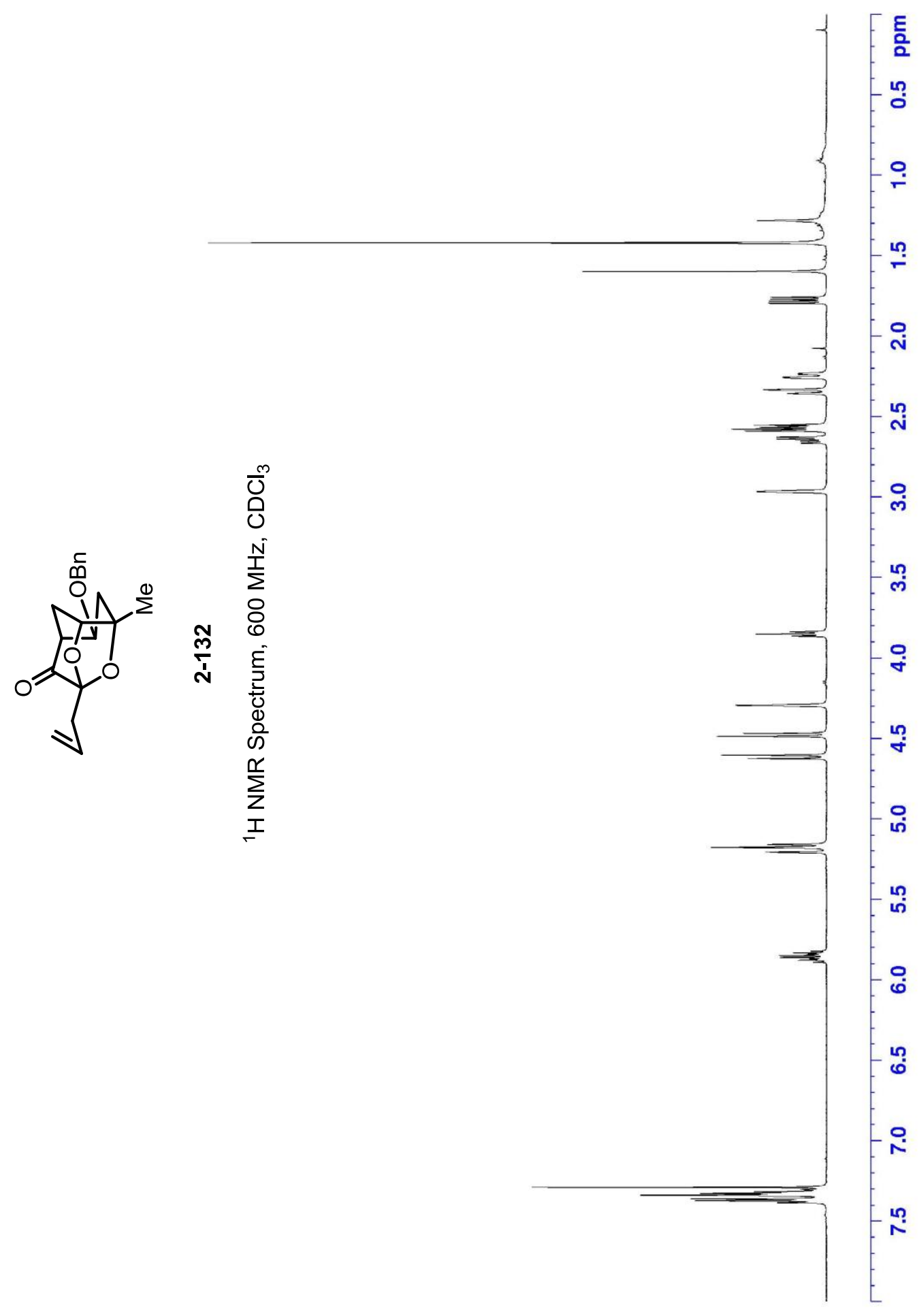




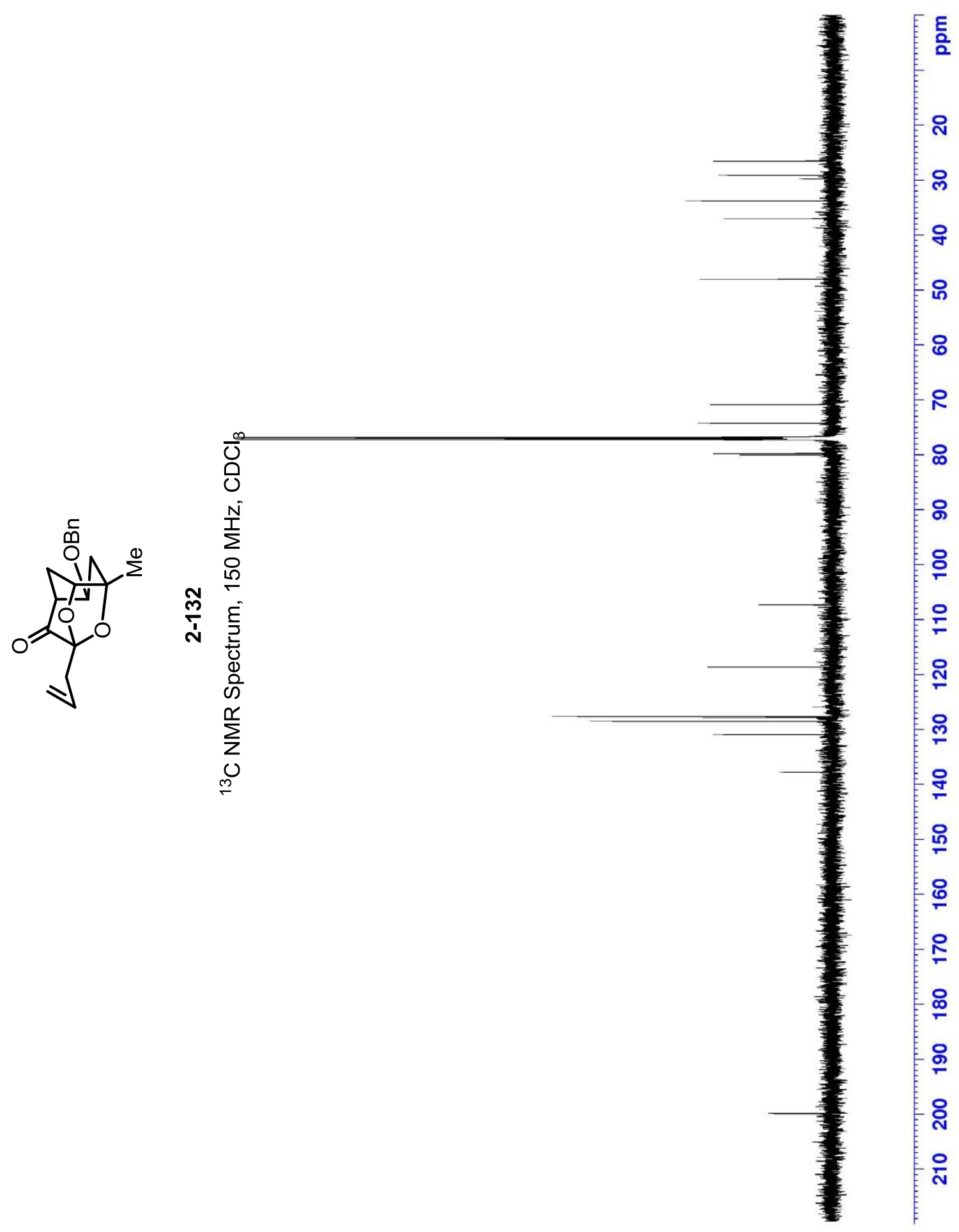




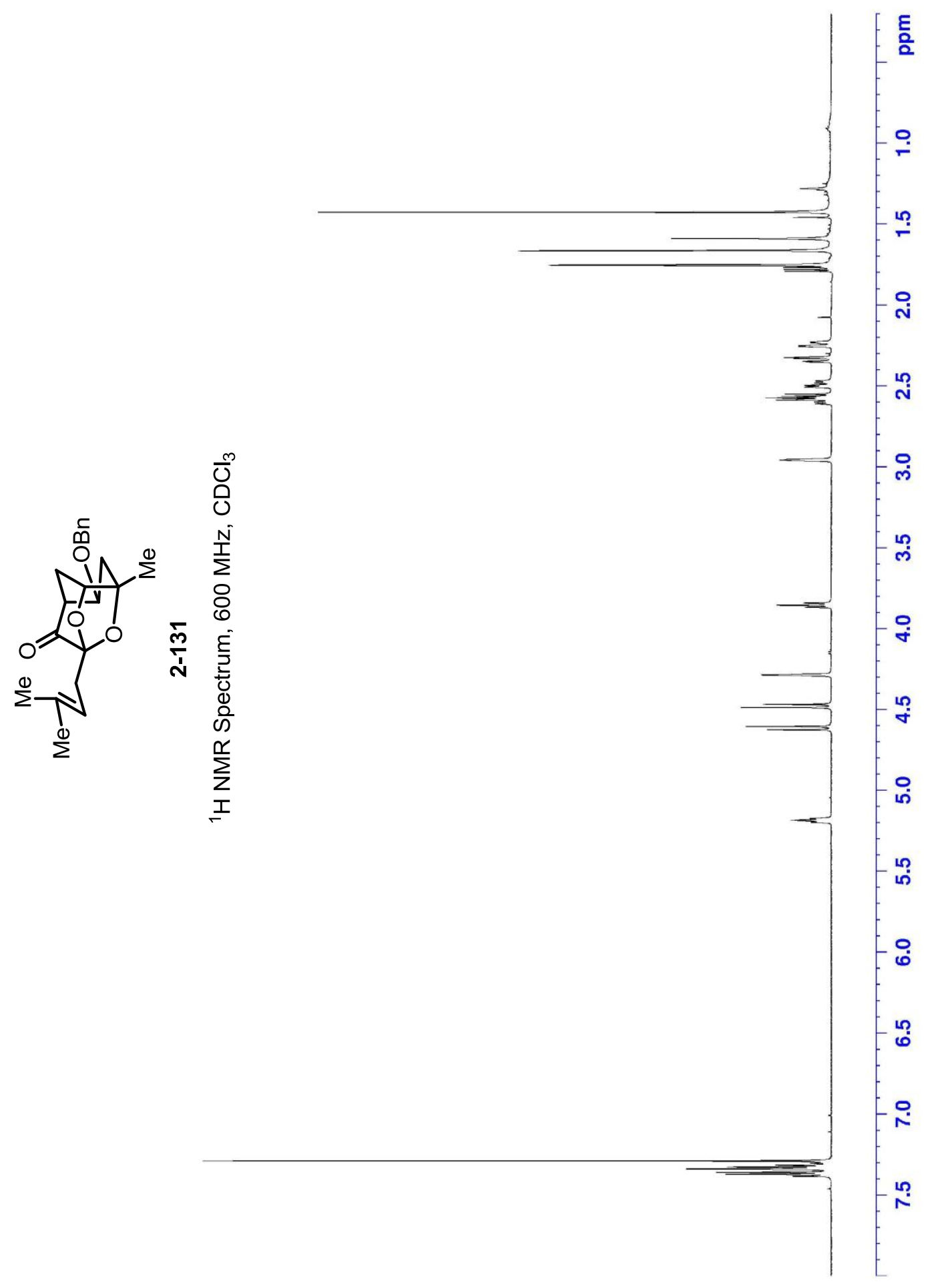




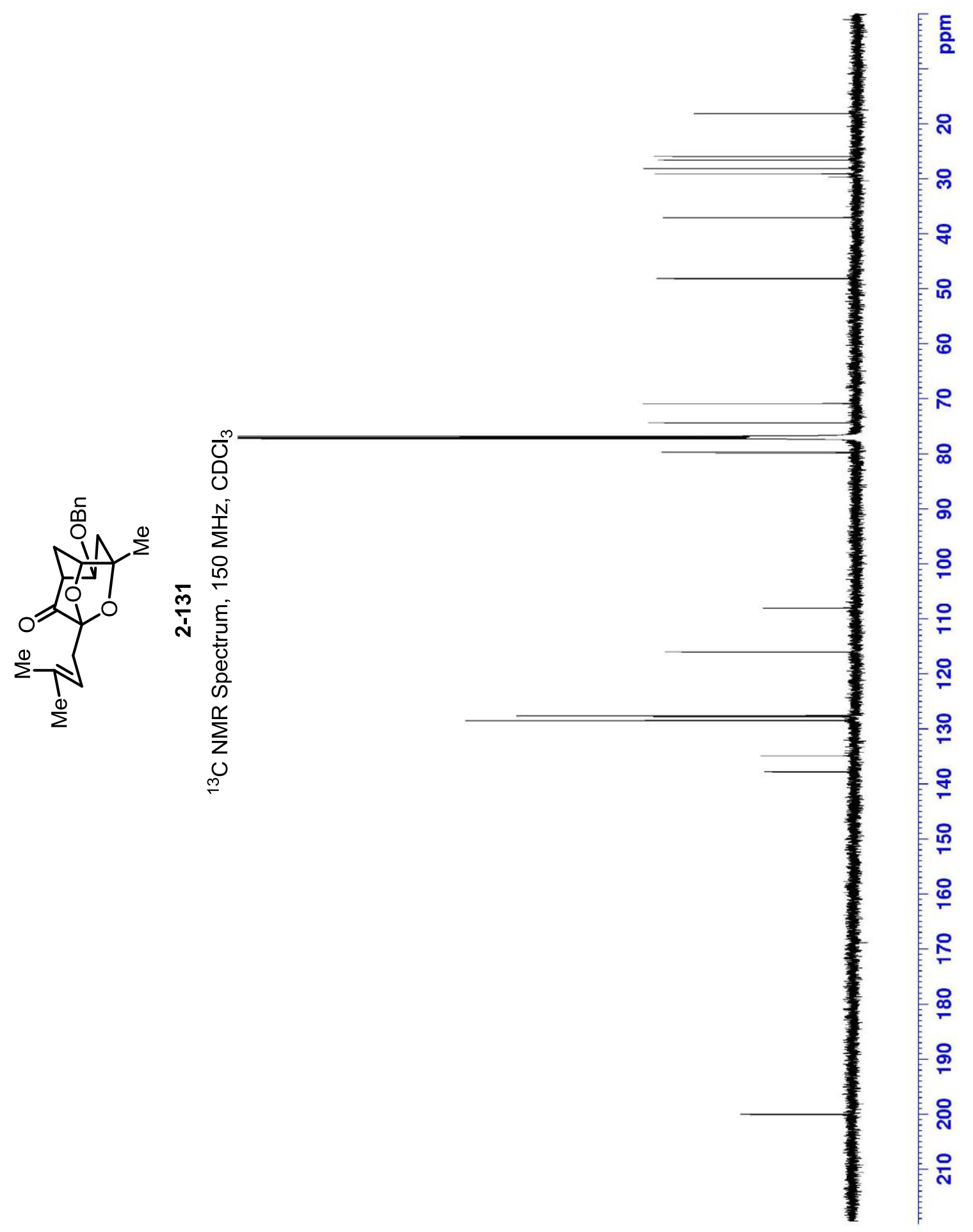




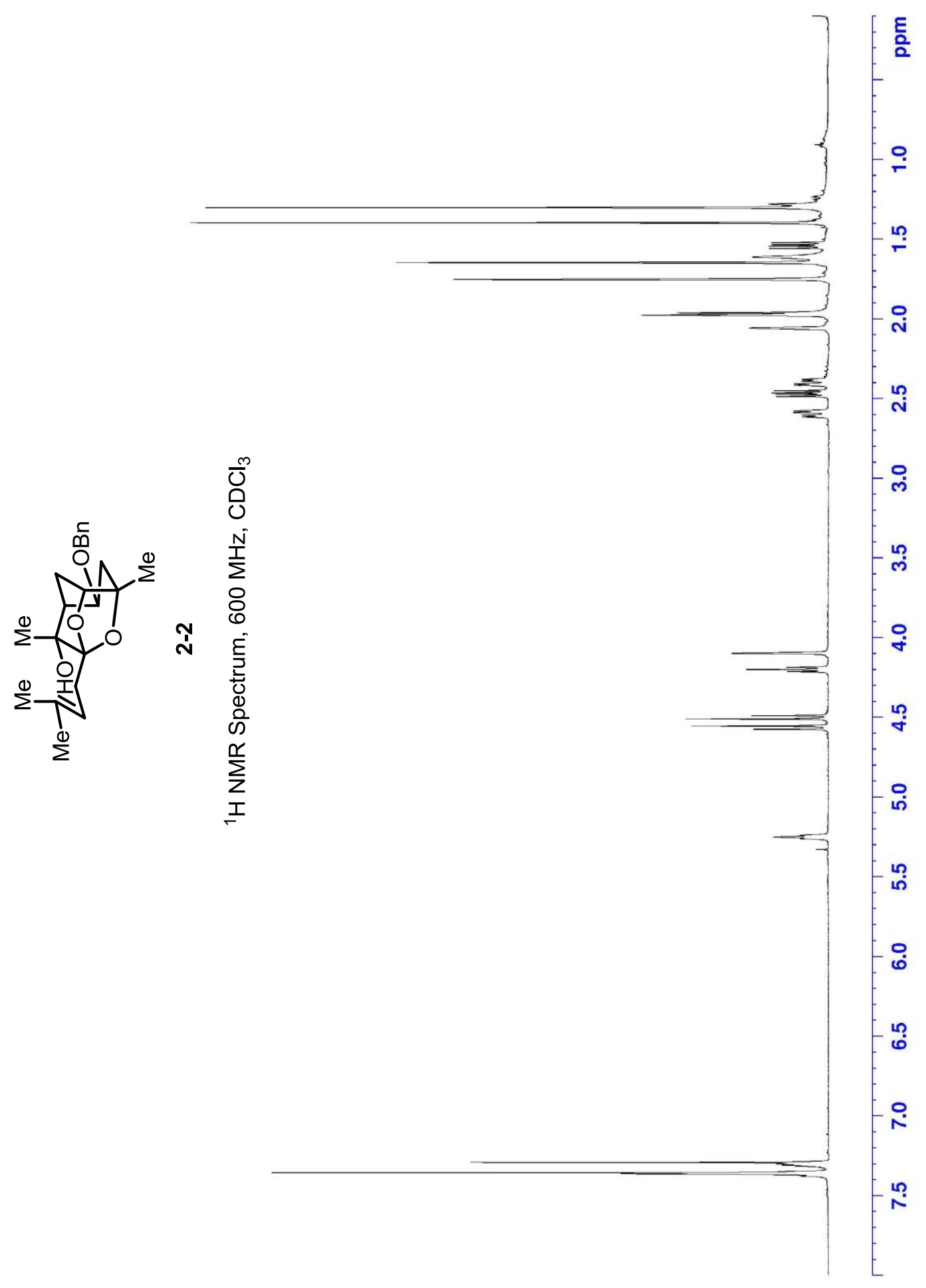




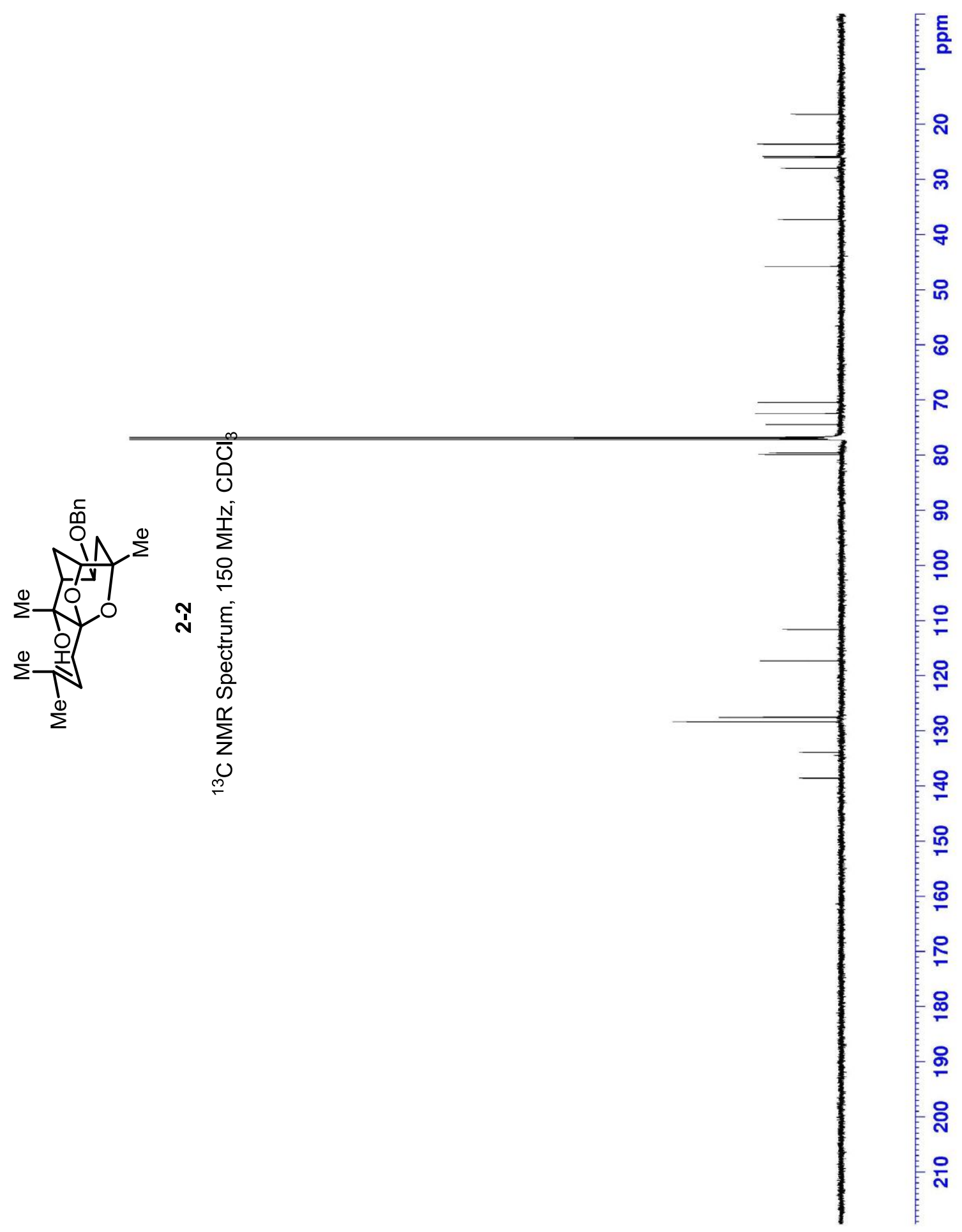




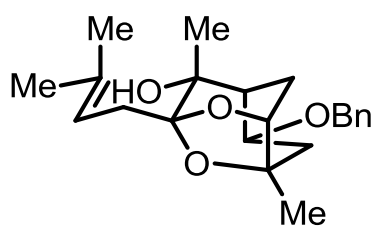

2-2

COSY Spectrum, $600 \mathrm{MHz}, \mathrm{CDCl}_{3}$

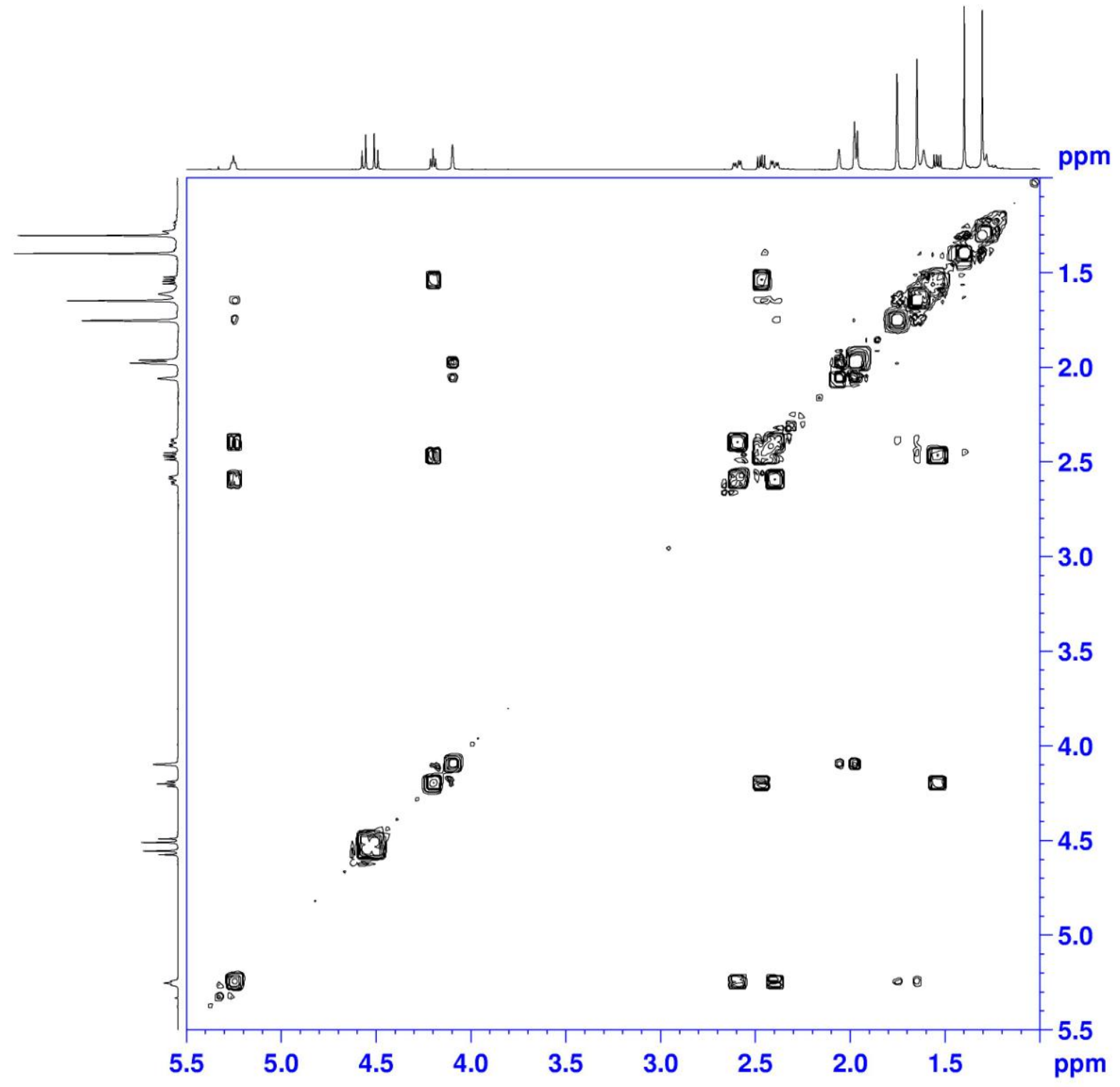




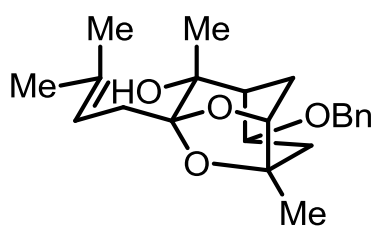

2-2

NOESY Spectrum, $600 \mathrm{MHz}, \mathrm{CDCl}_{3}$

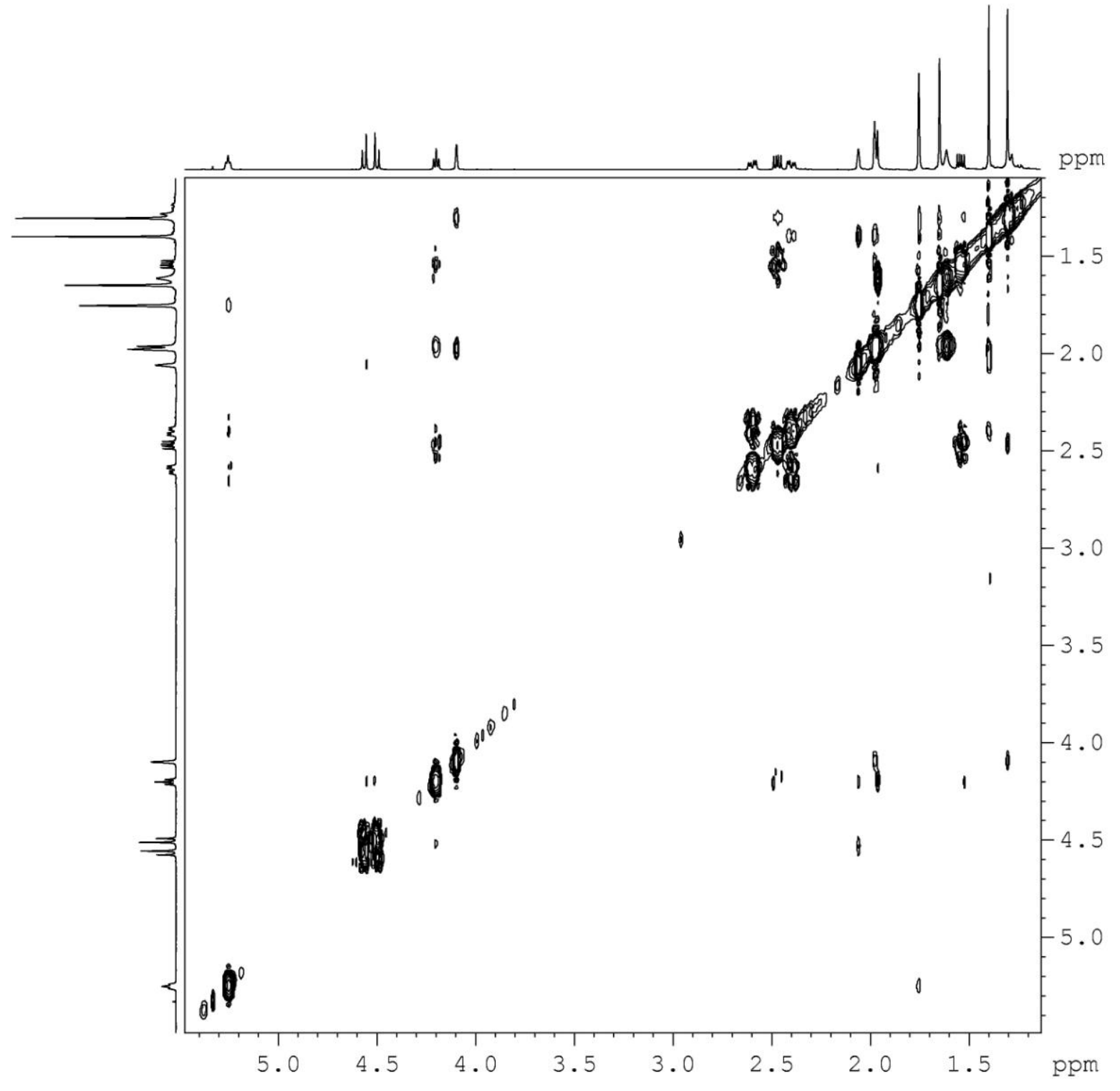




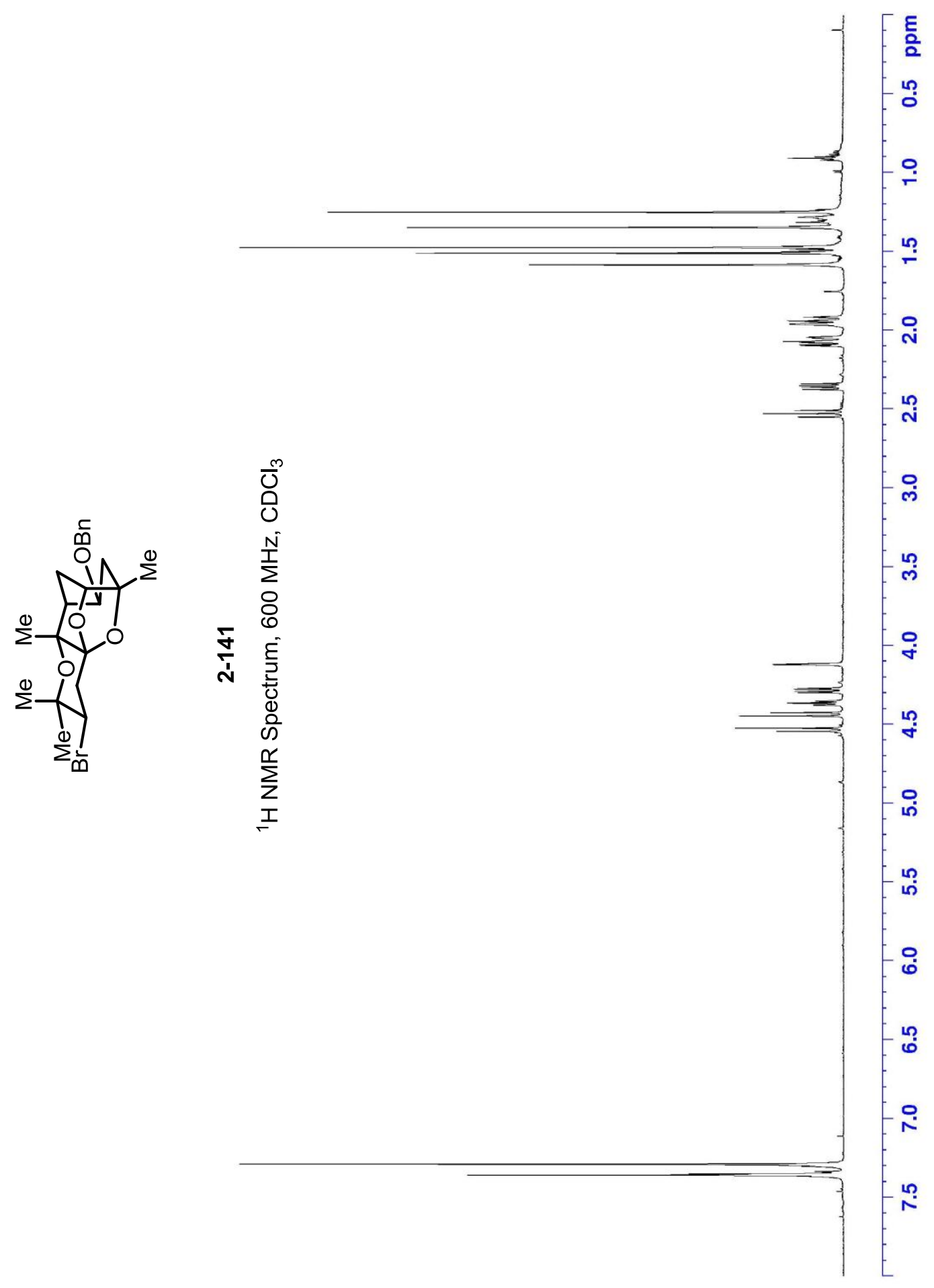




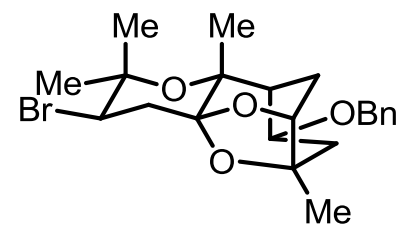

2-141

COSY Spectrum, $600 \mathrm{MHz}, \mathrm{CDCl}_{3}$

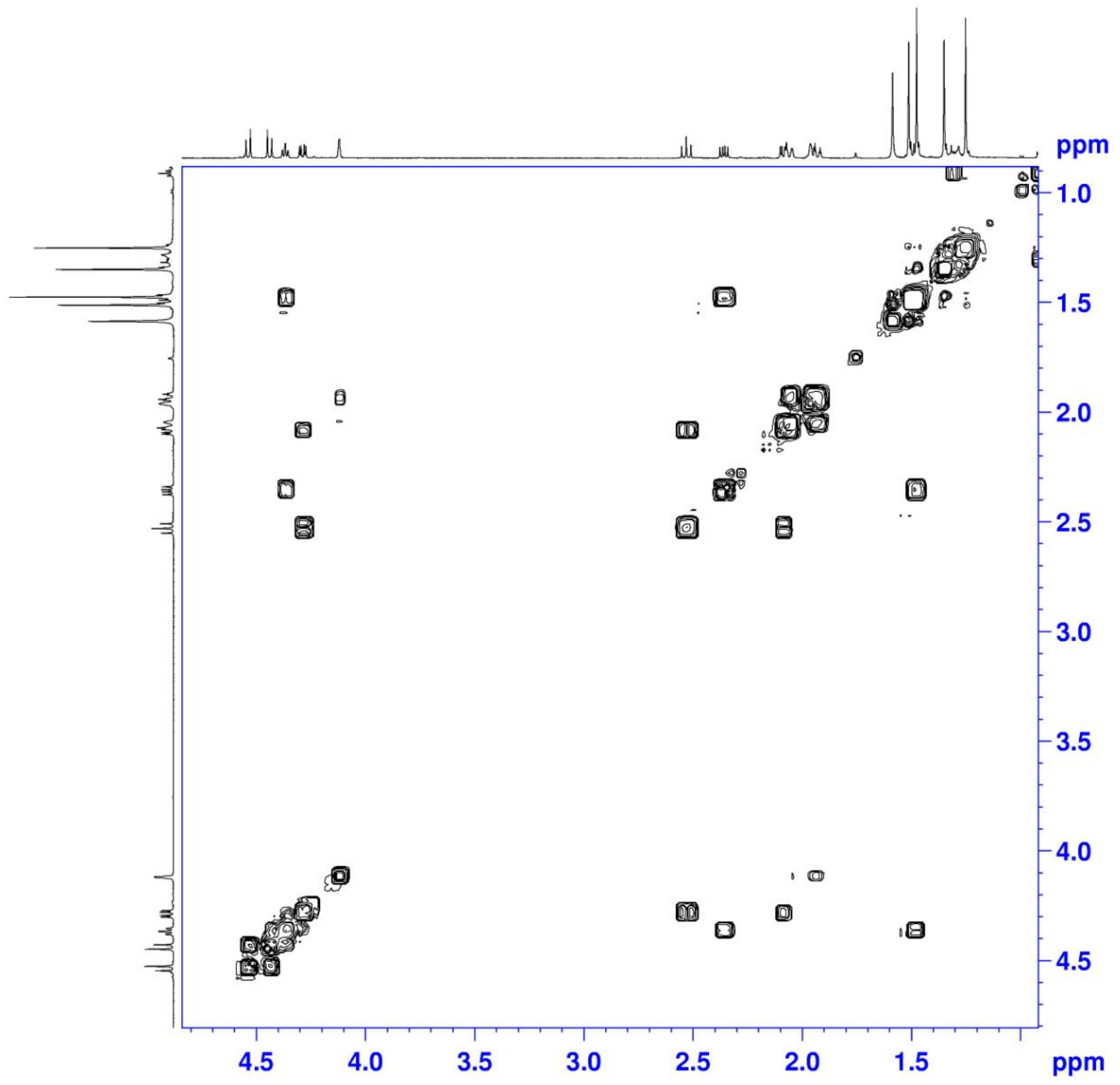




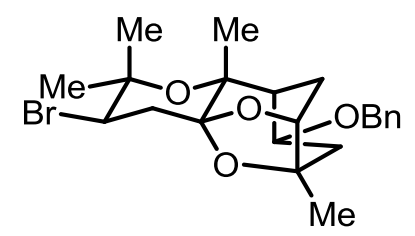

2-141

NOESY Spectrum, $600 \mathrm{MHz}, \mathrm{CDCl}_{3}$

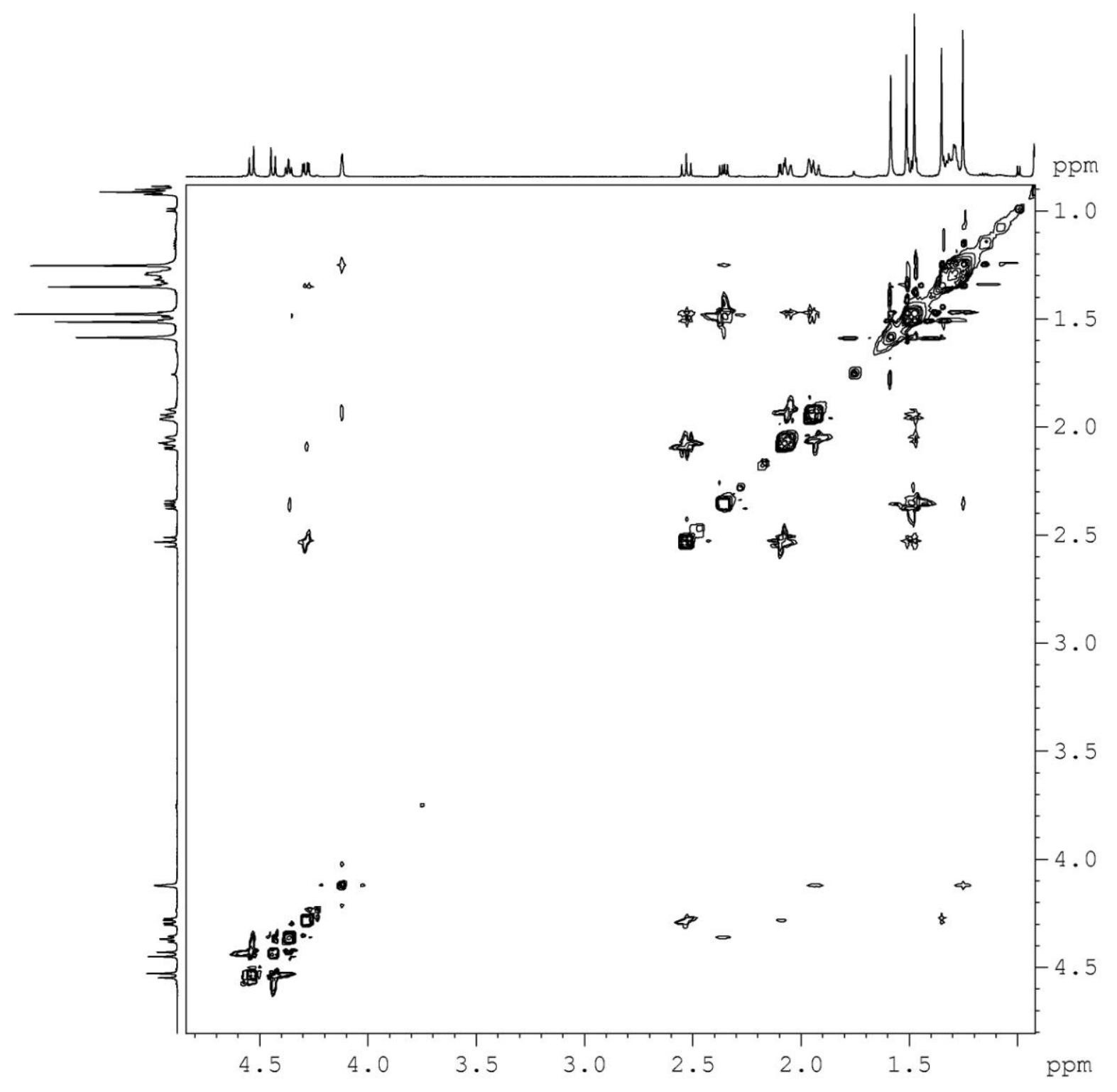




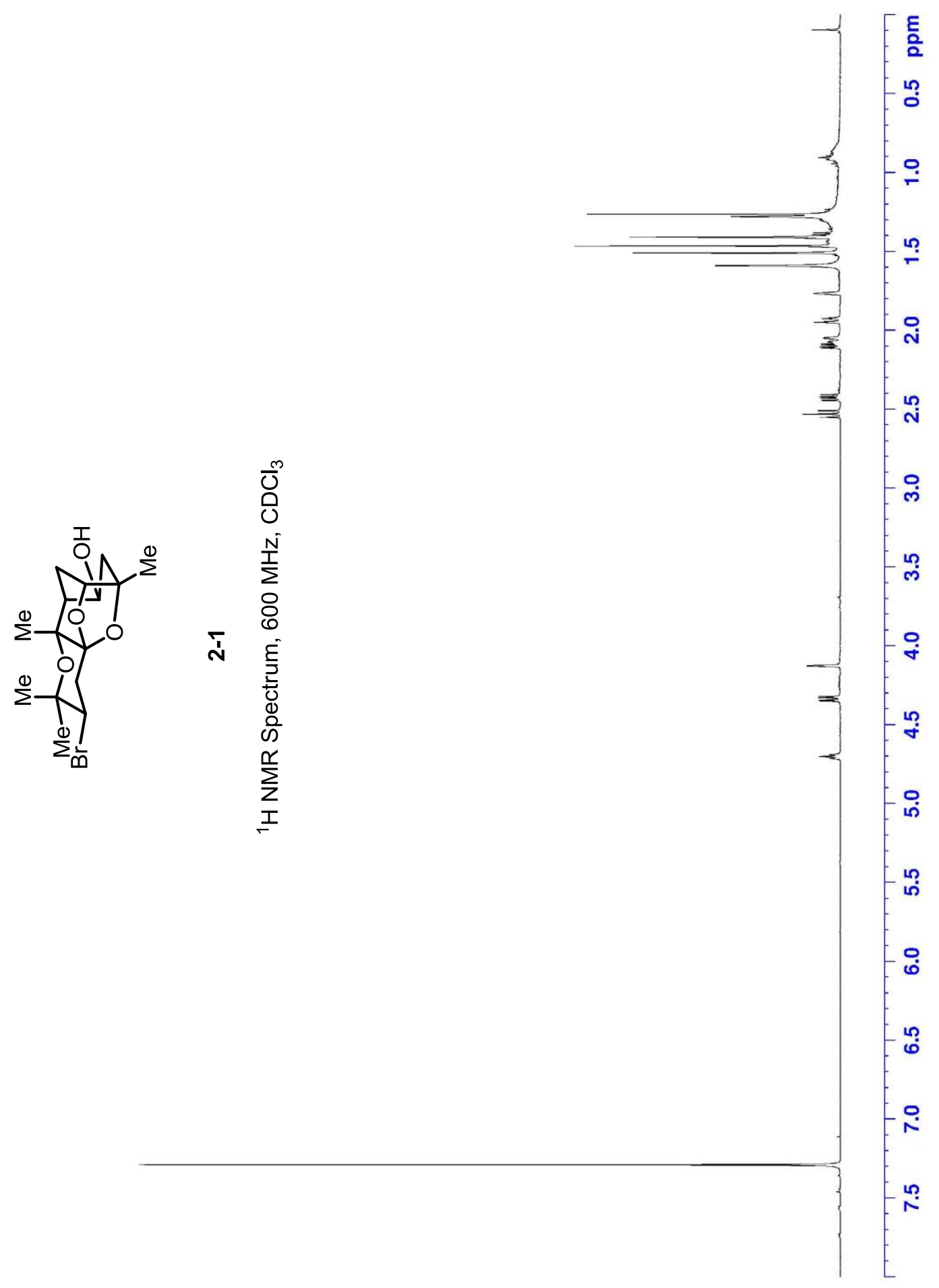




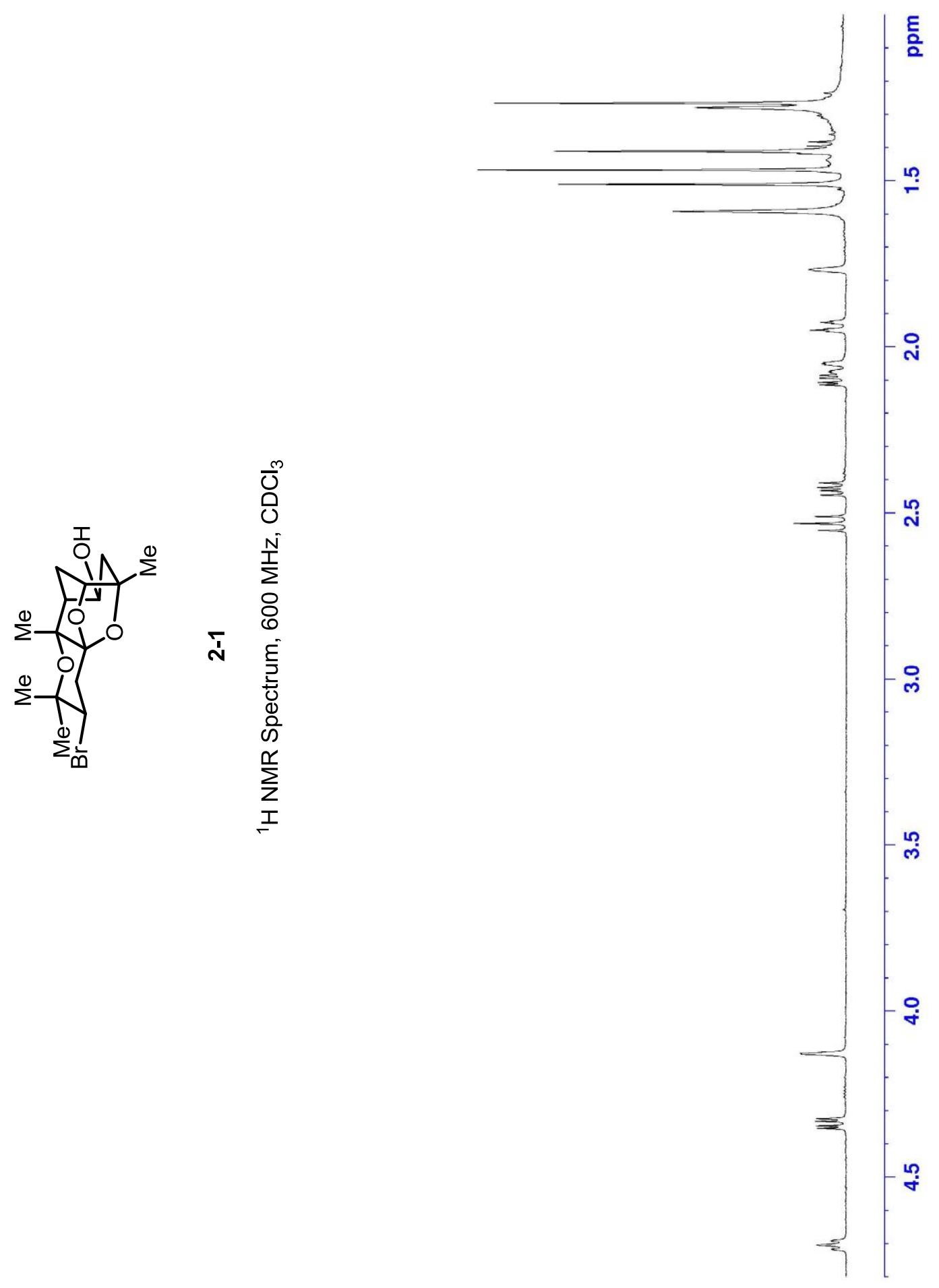




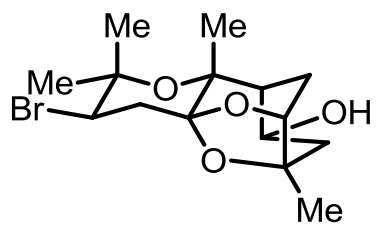

2-1

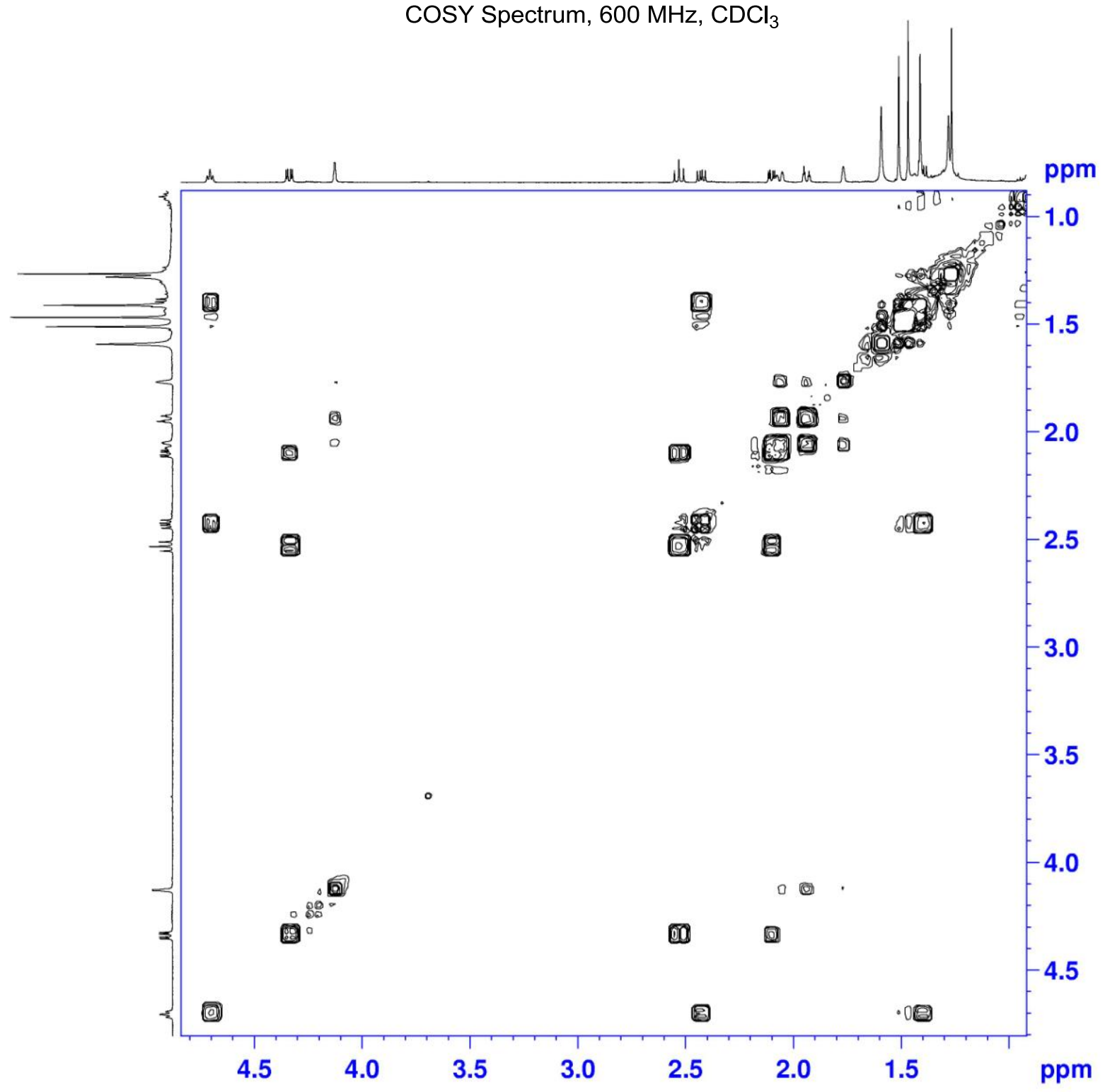




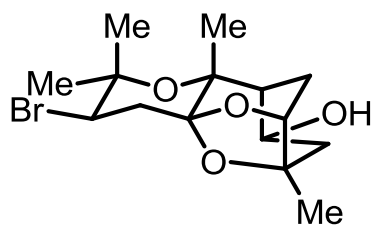

2-1

NOESY Spectrum, $600 \mathrm{MHz}, \mathrm{CDCl}_{3}$

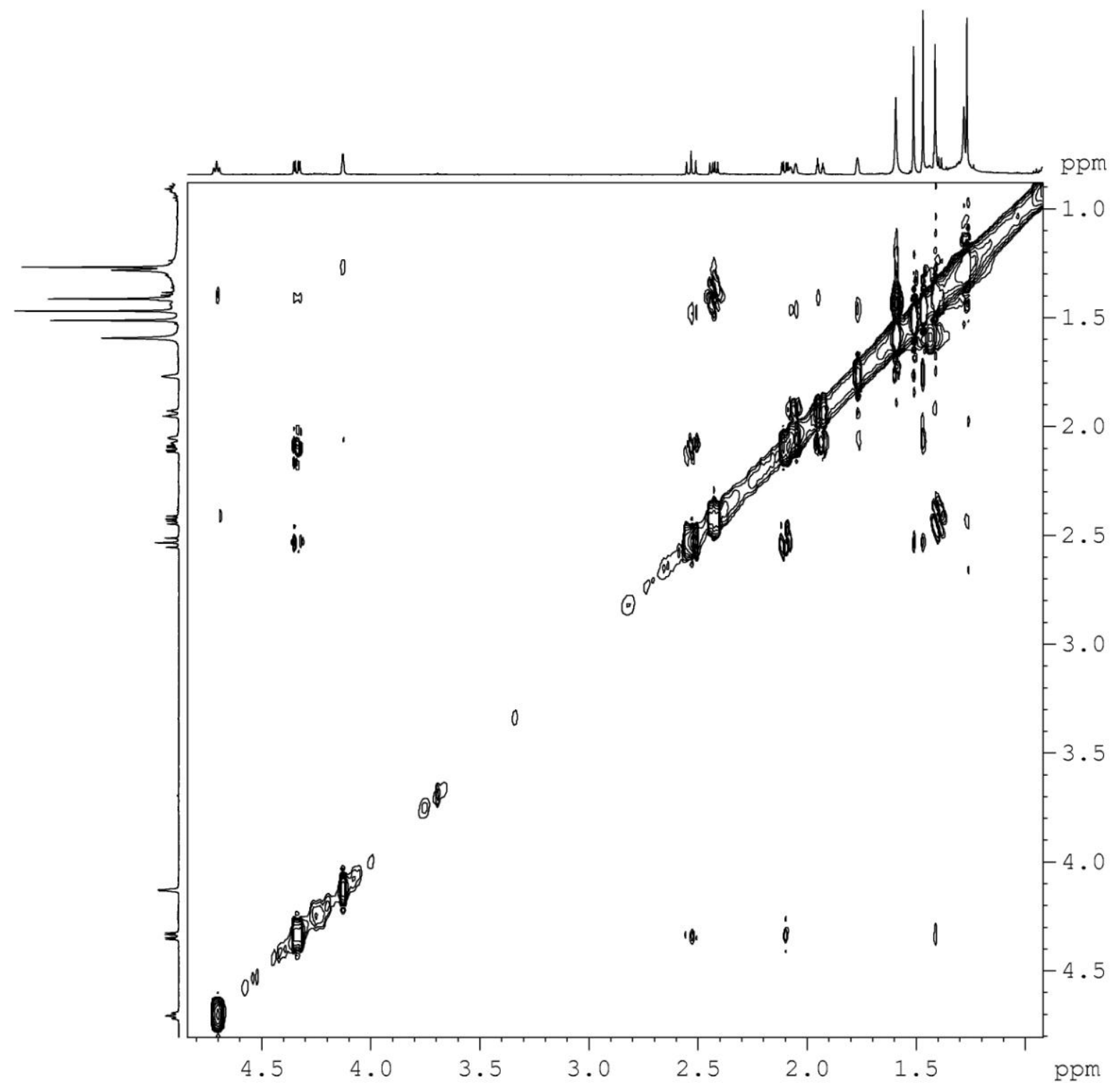




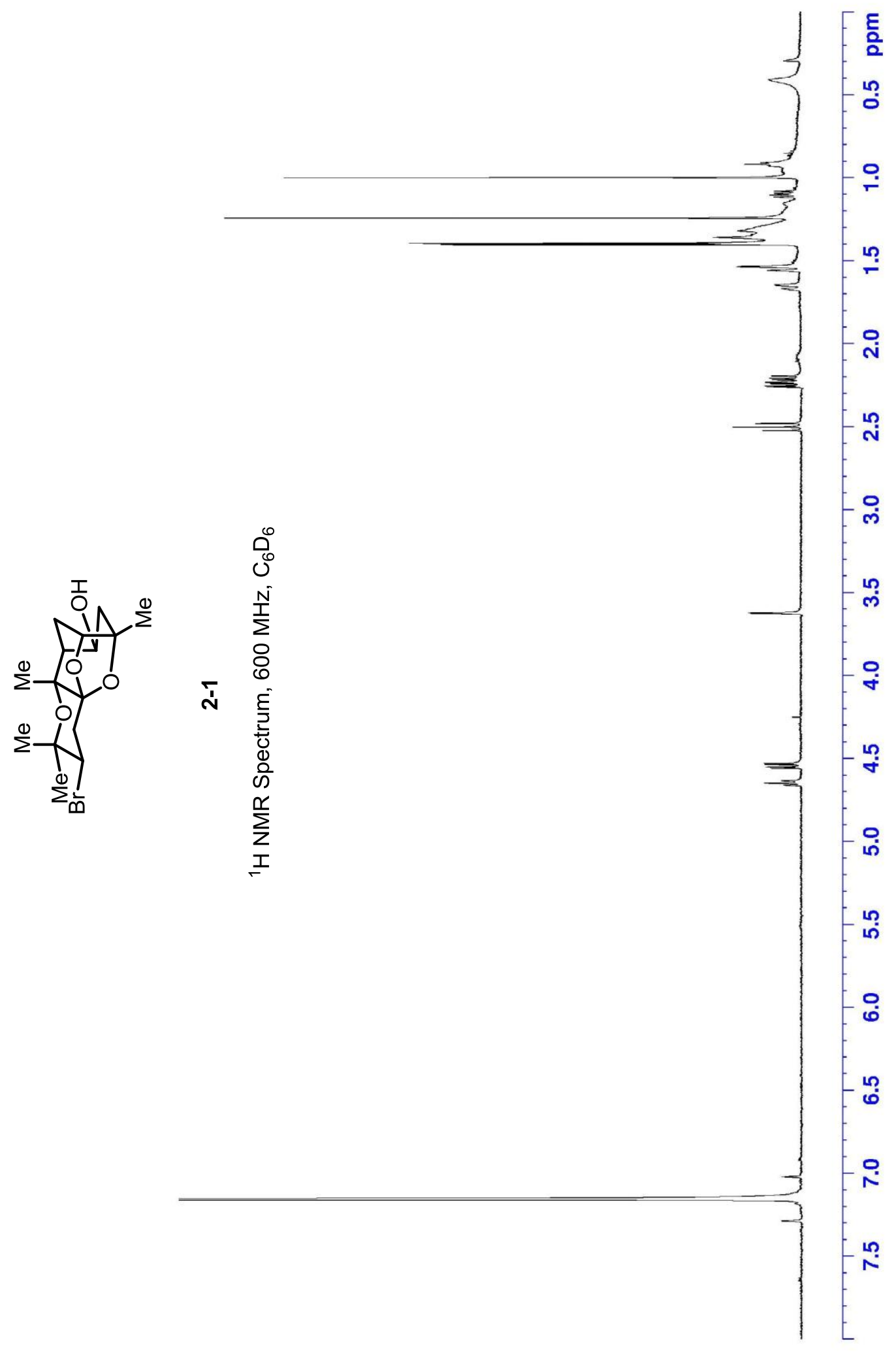




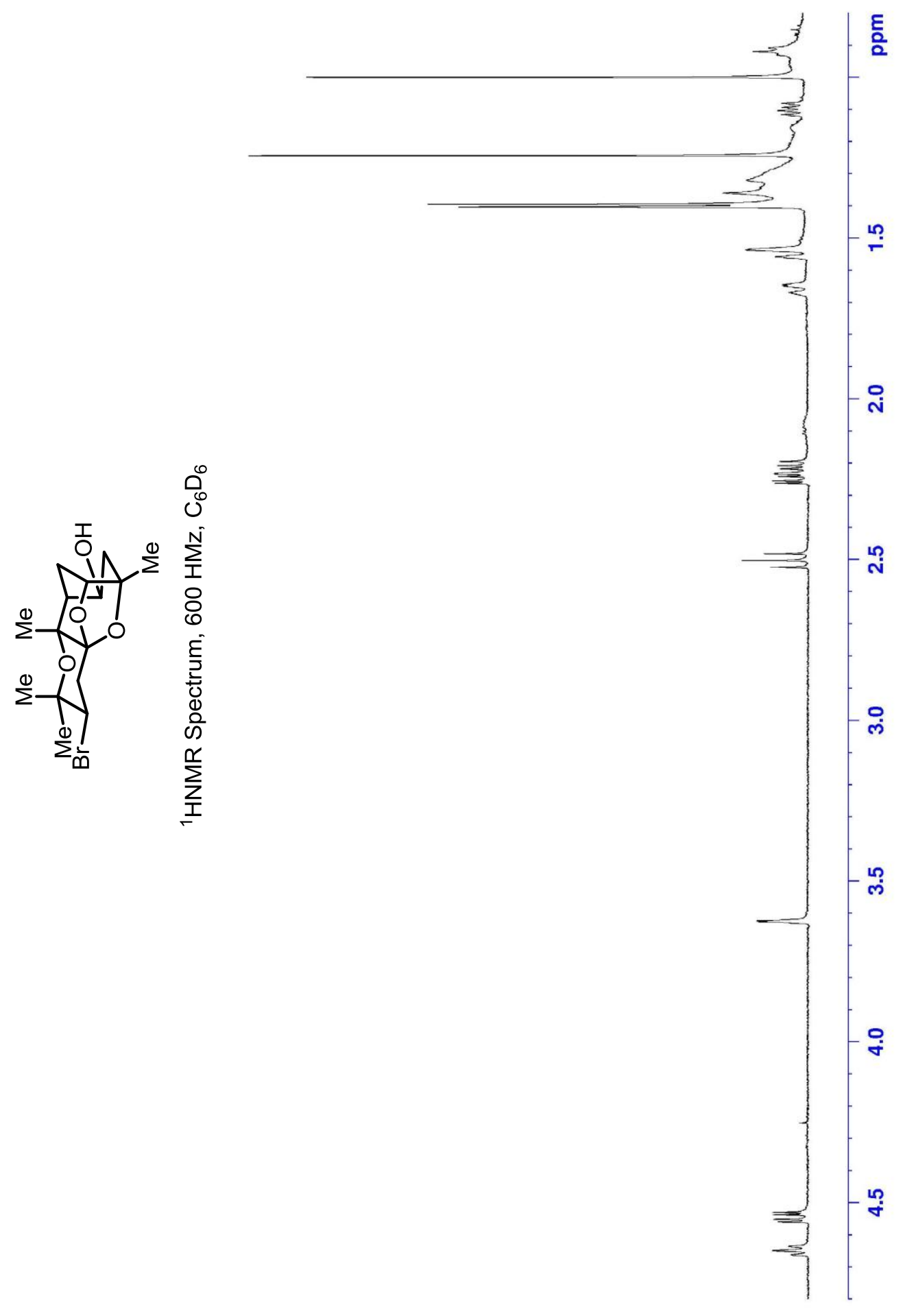




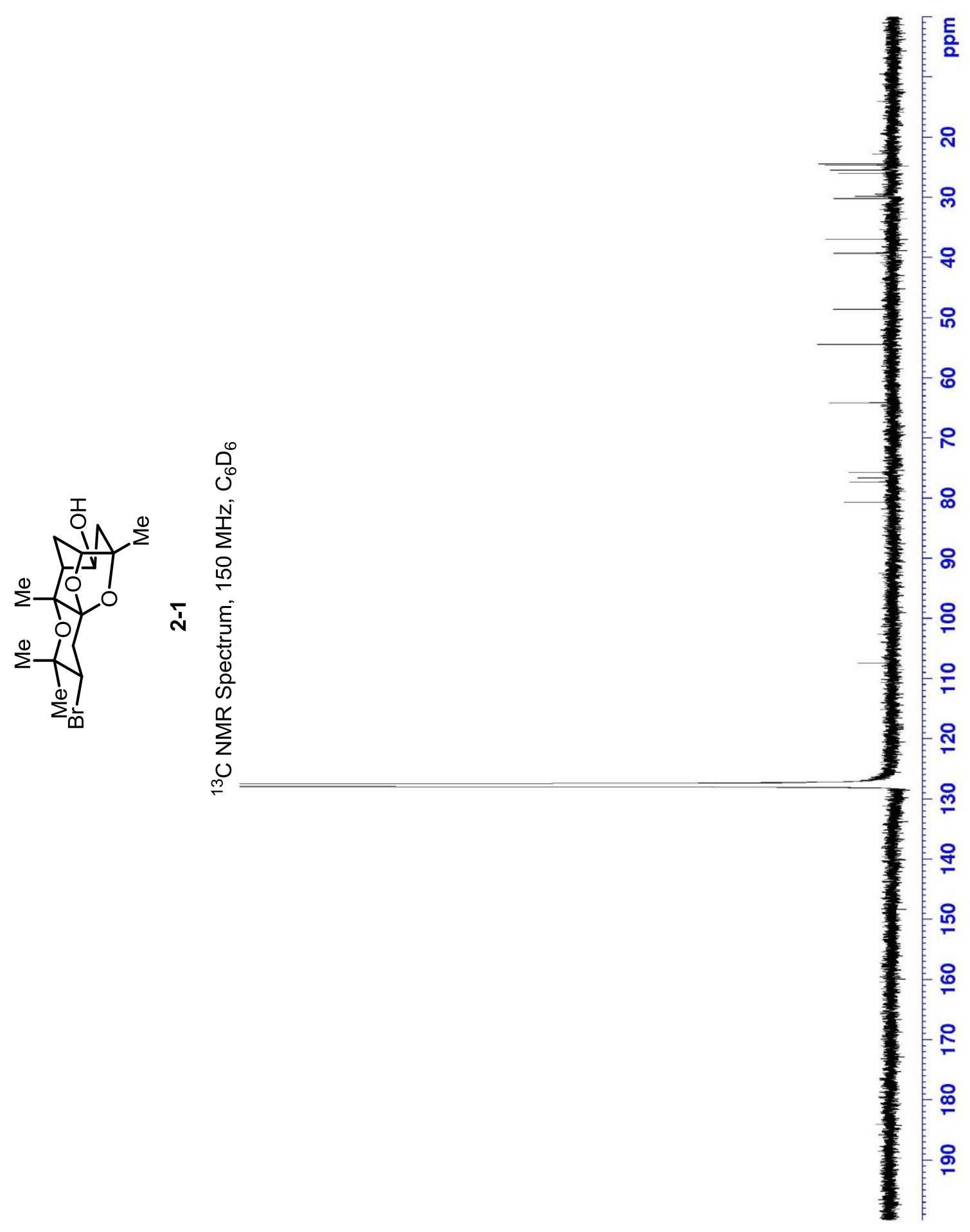



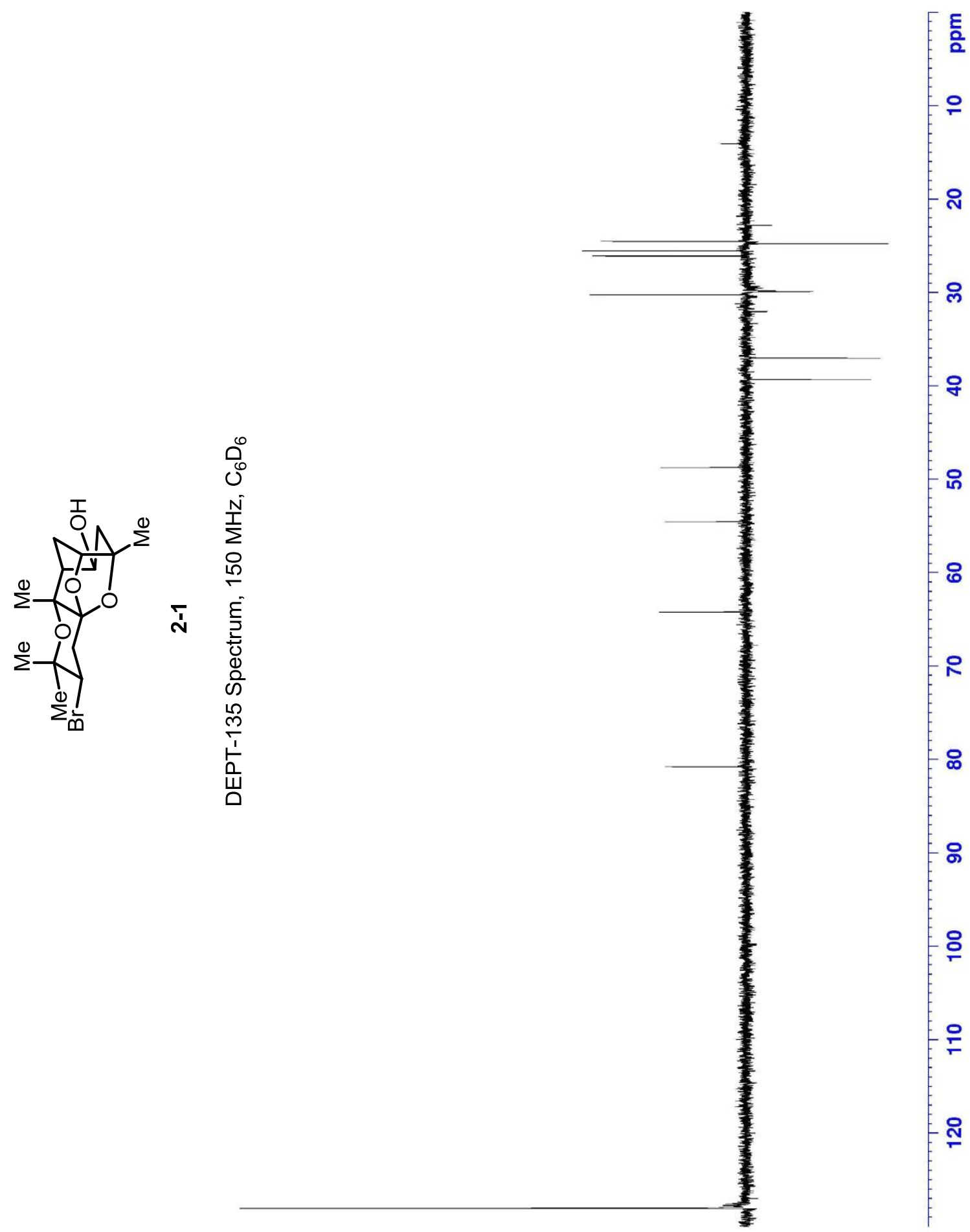


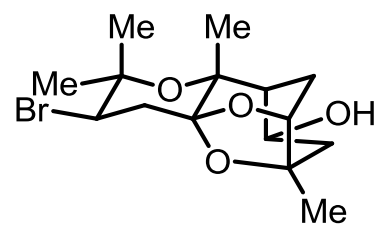

2-1

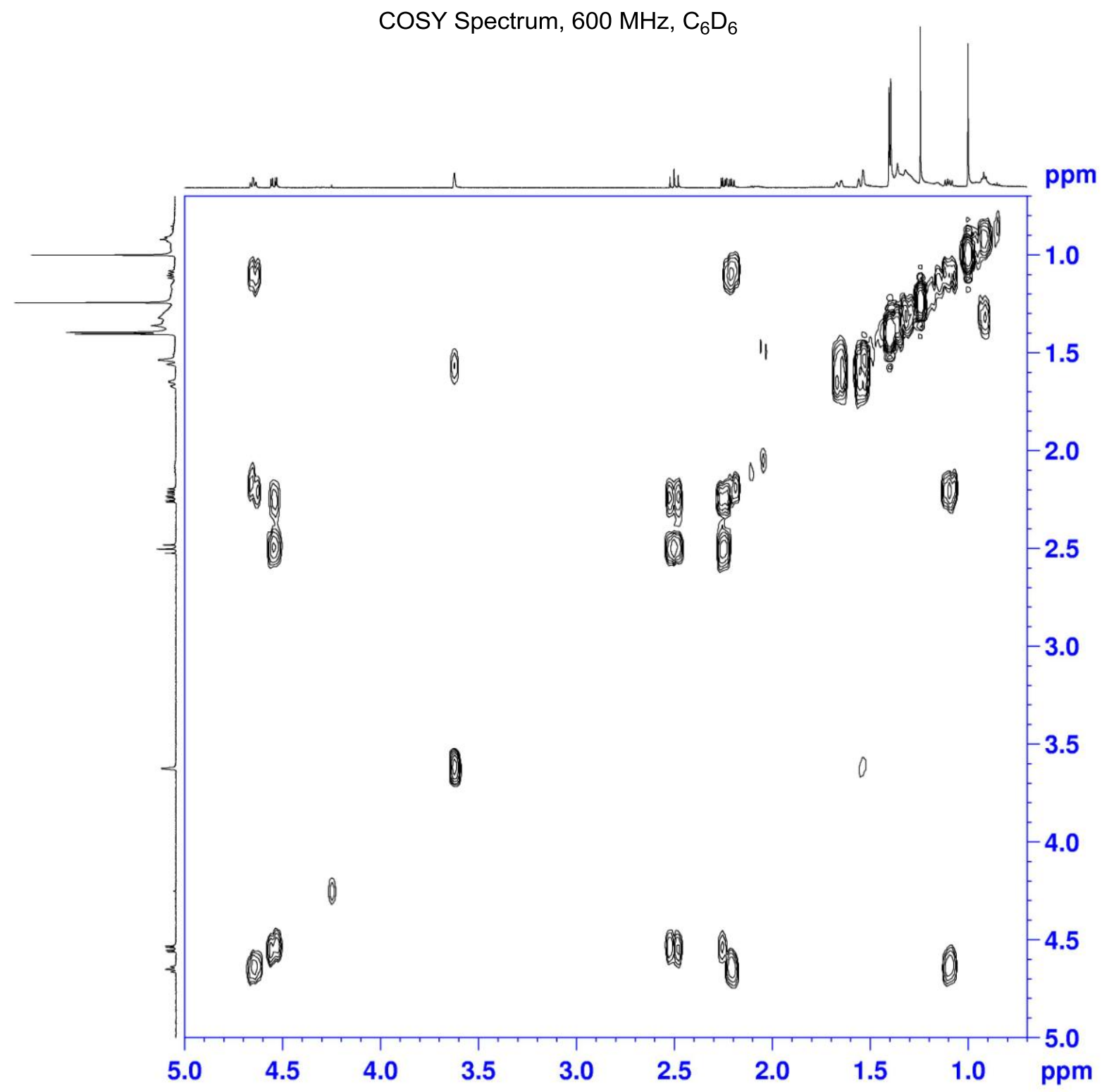




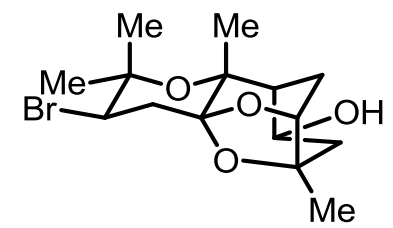

$2-1$

NOESY Spectrum, $600 \mathrm{MHz}, \mathrm{C}_{6} \mathrm{D}_{6}$

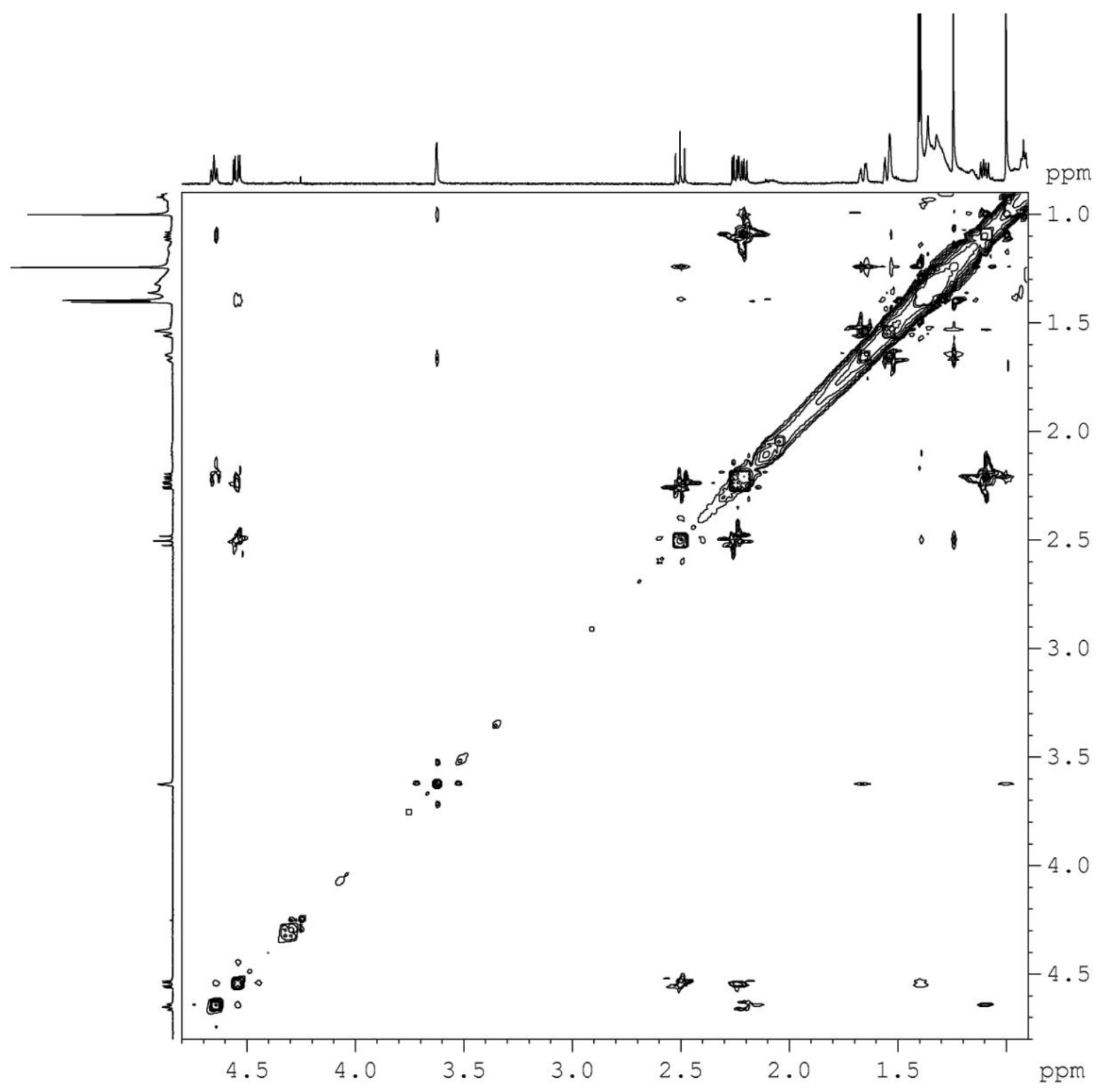




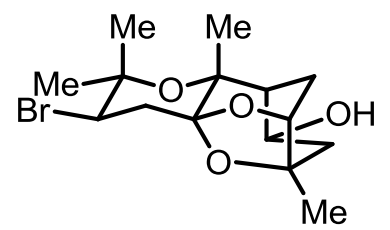

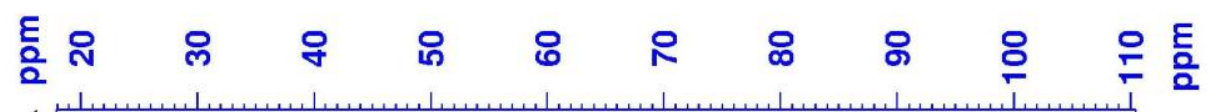

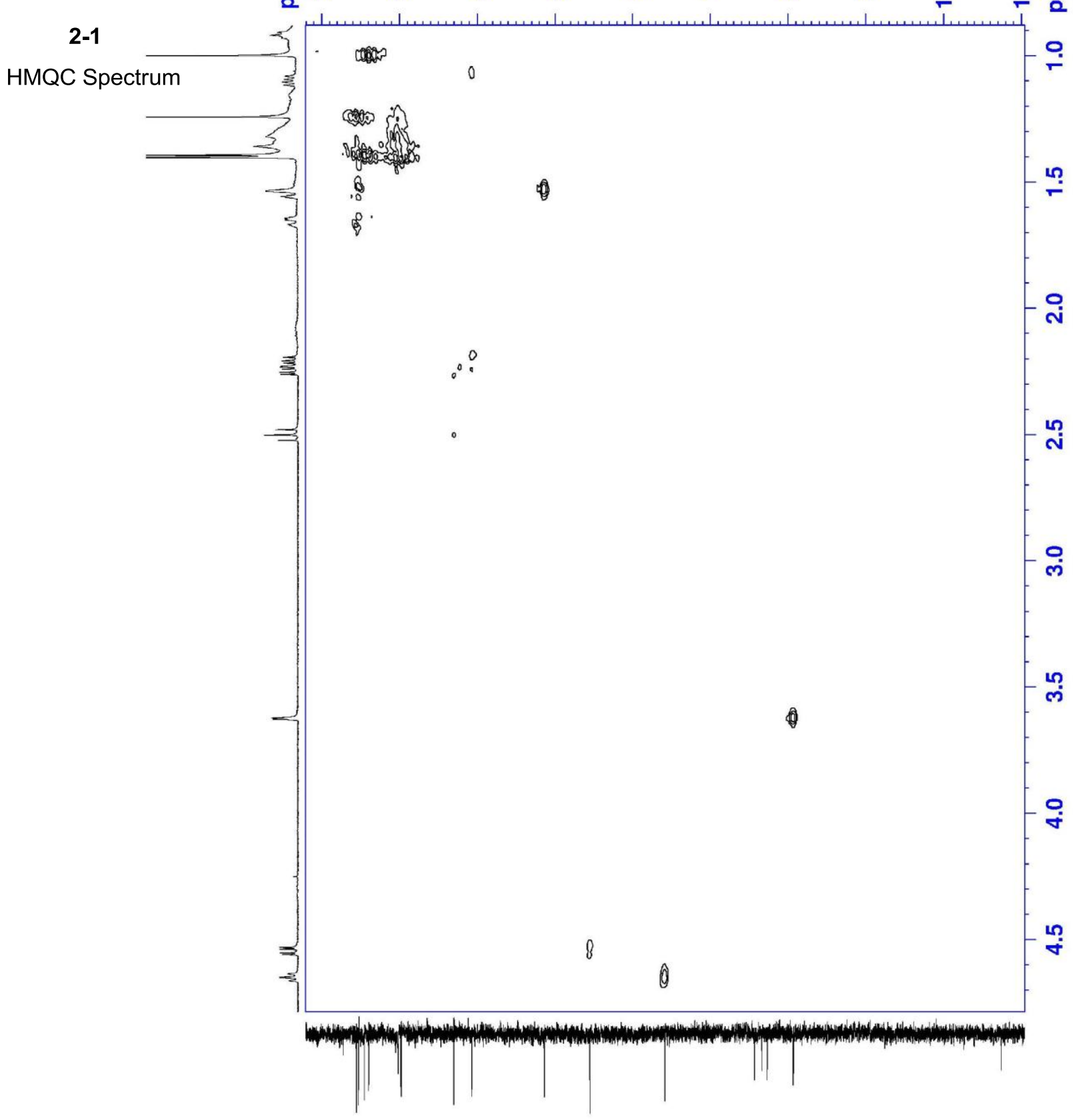



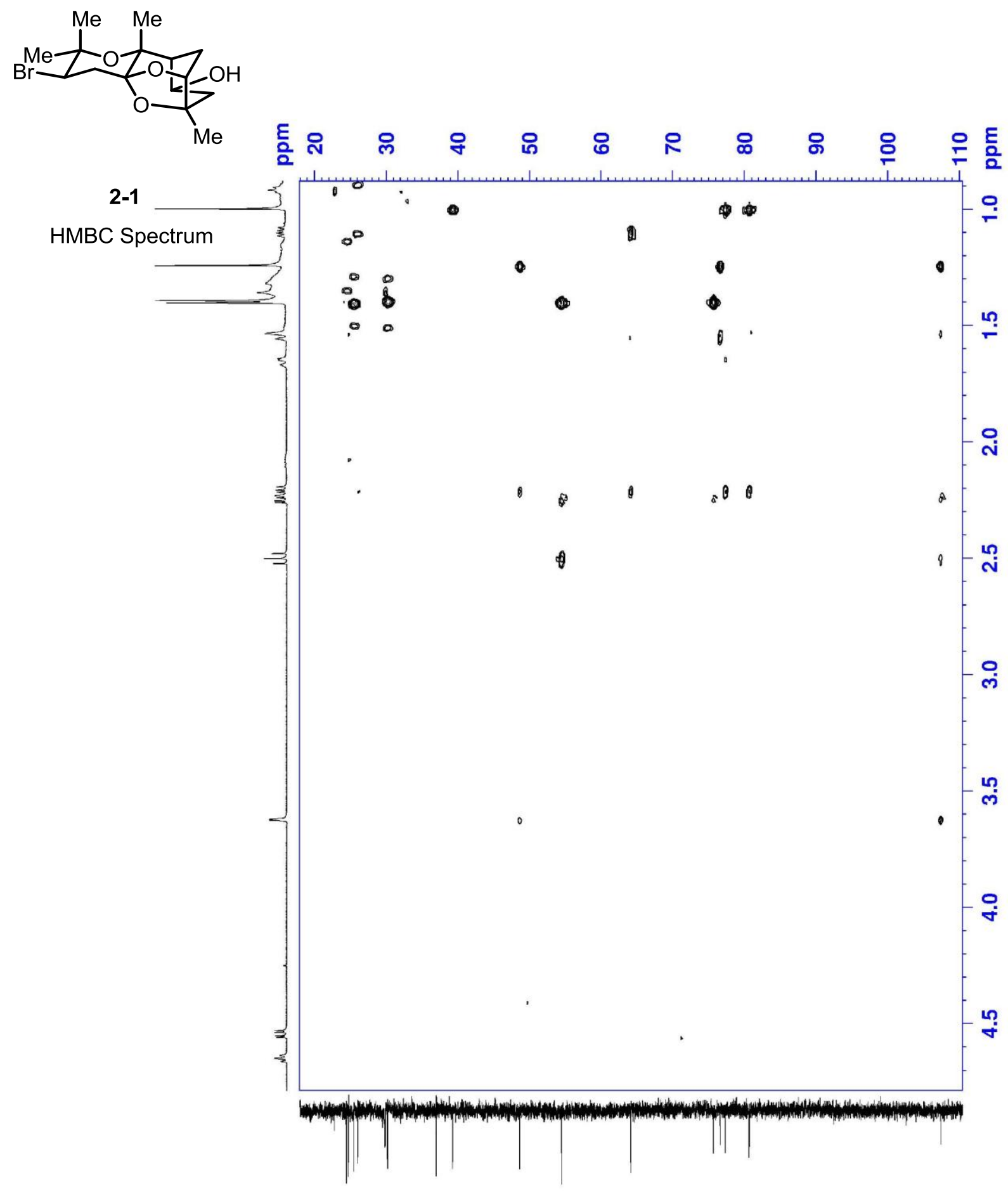


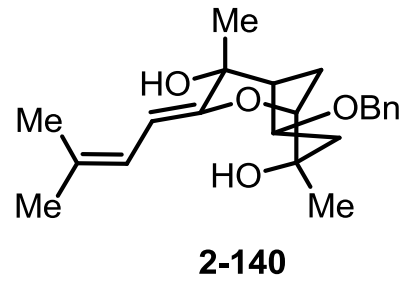

${ }^{1} \mathrm{H}$ NMR Spectrum, $600 \mathrm{MHz}, \mathrm{CDCl}_{3}$

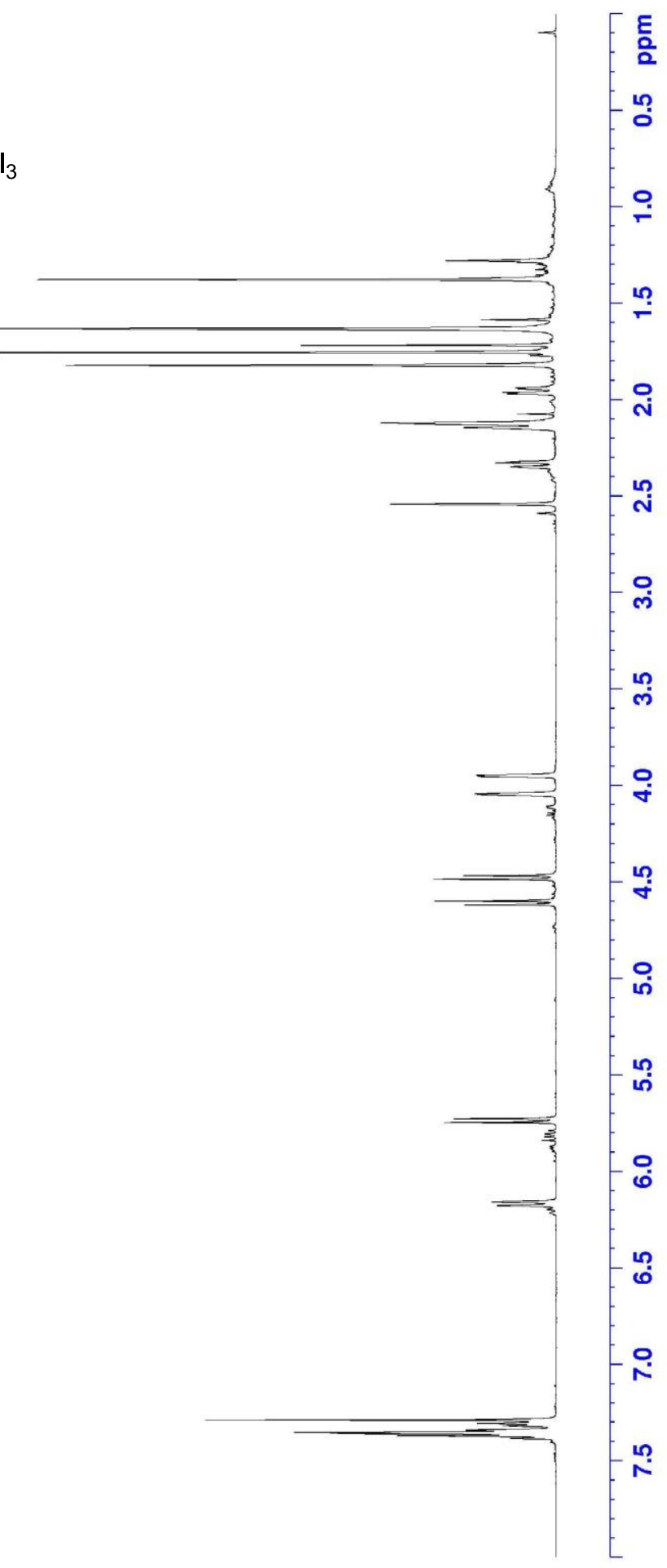




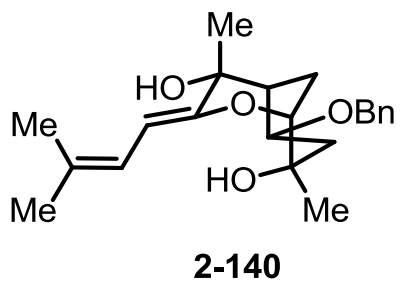

COSY Spectrum, $600 \mathrm{MHz}, \mathrm{CDCl}_{3}$

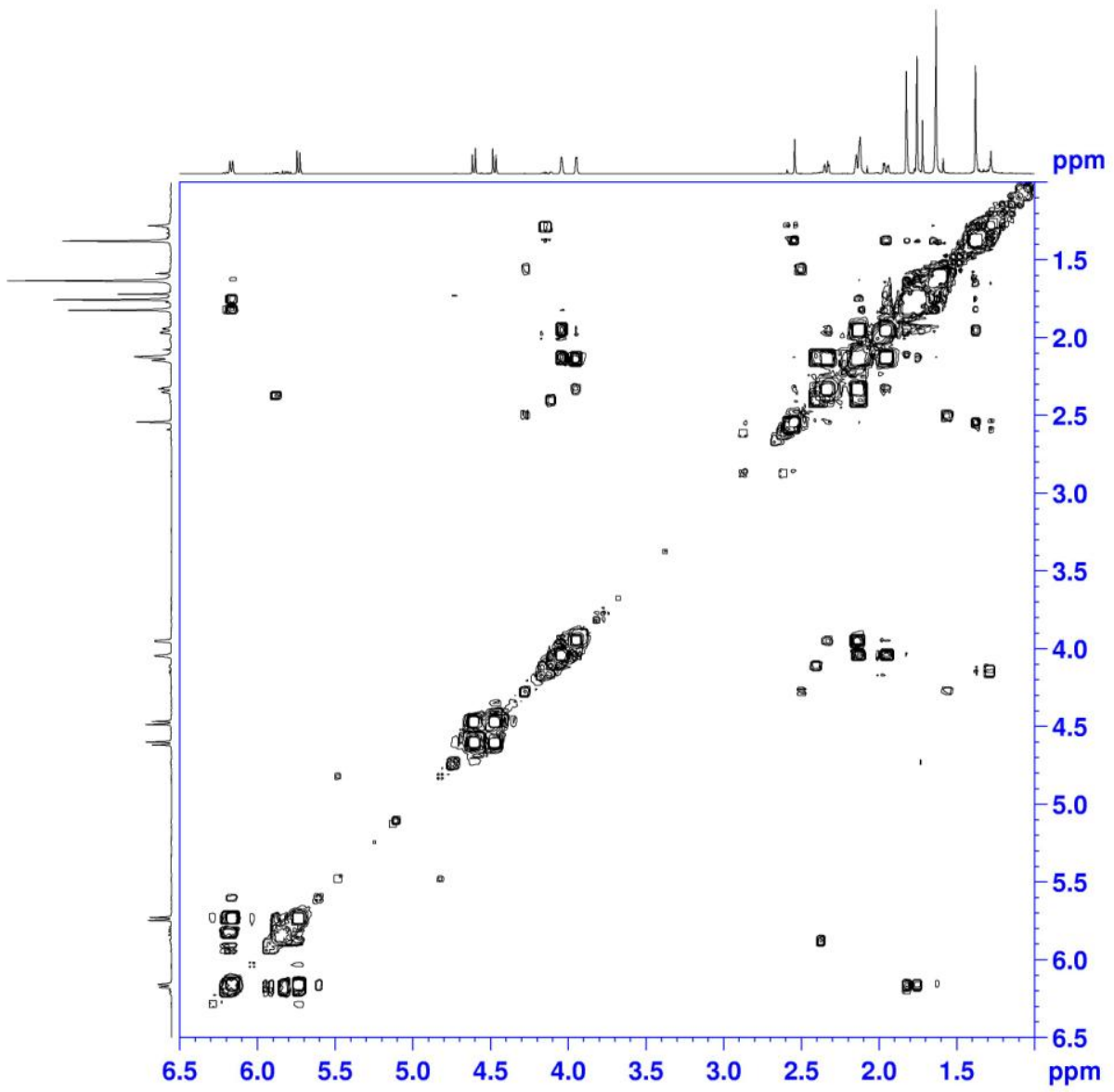




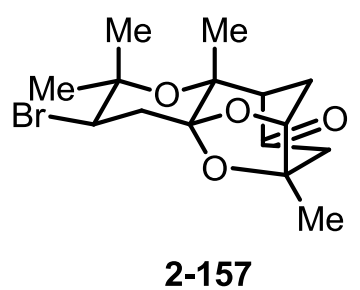

${ }^{1} \mathrm{HNMR}$ Spectrum, $600 \mathrm{HMz}, \mathrm{CDCl}_{3}$

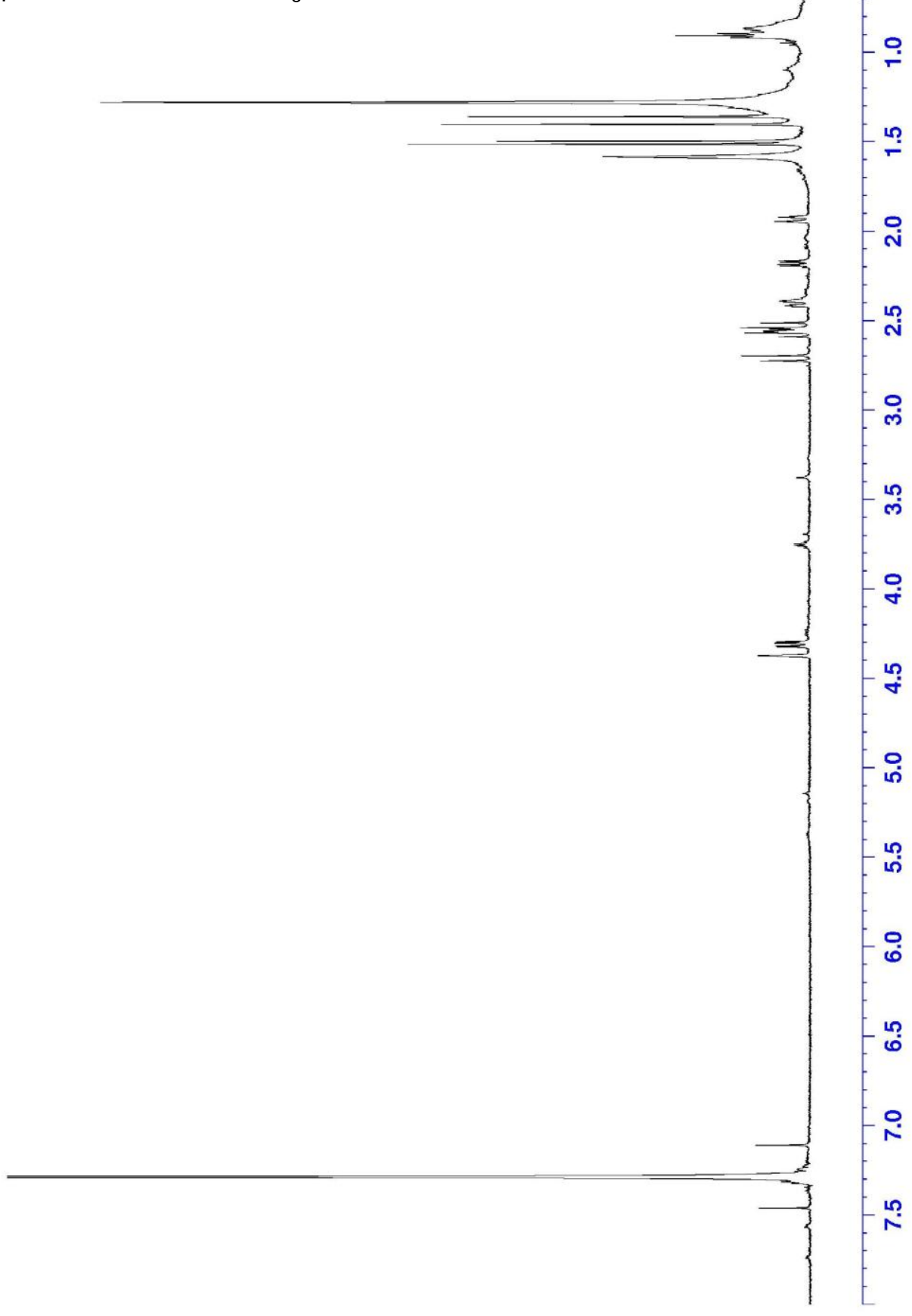




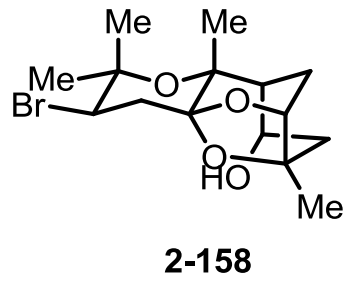

${ }^{1} \mathrm{HNMR}$ Spectrum, $600 \mathrm{HMz}, \mathrm{CDCl}_{3}$

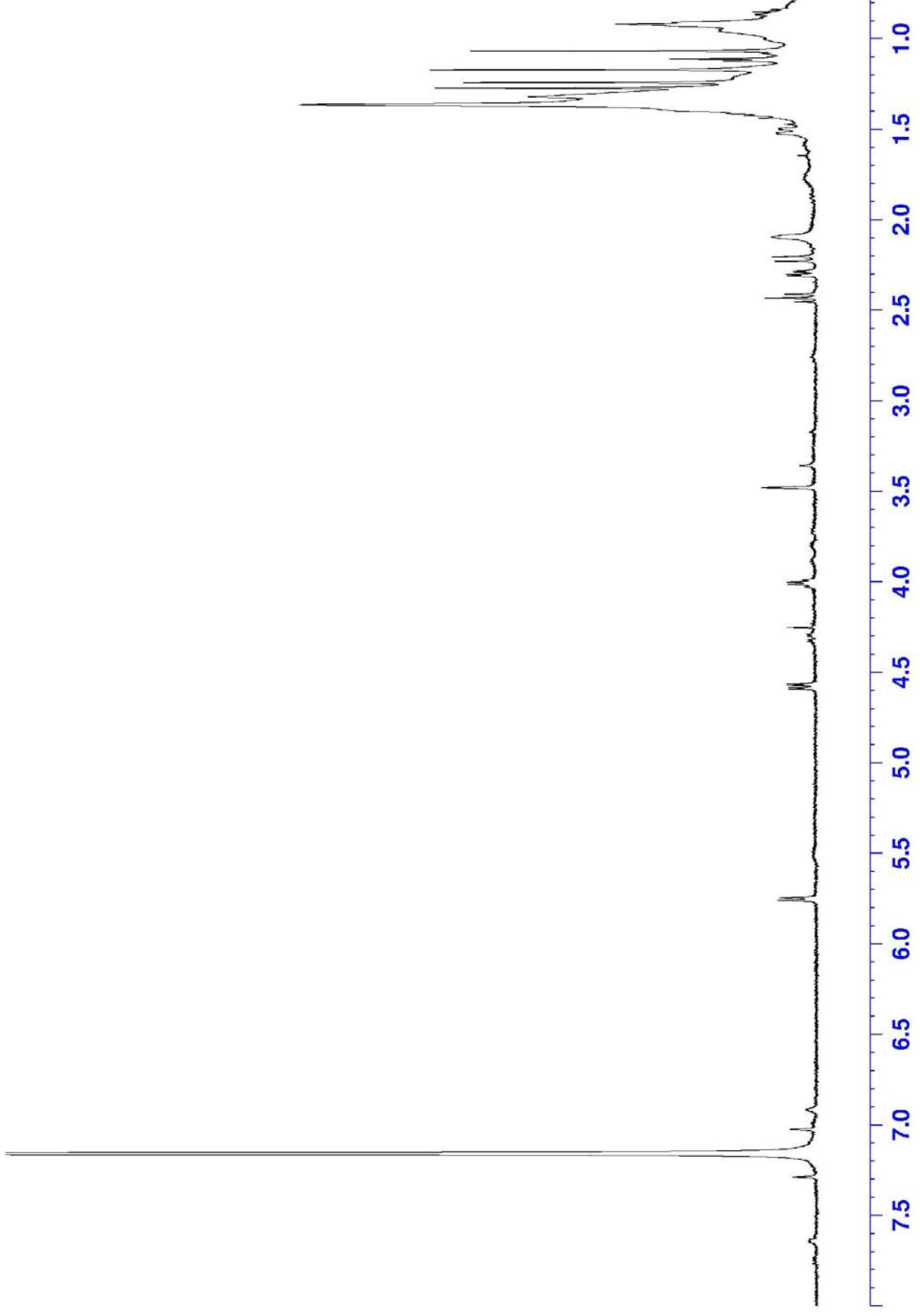




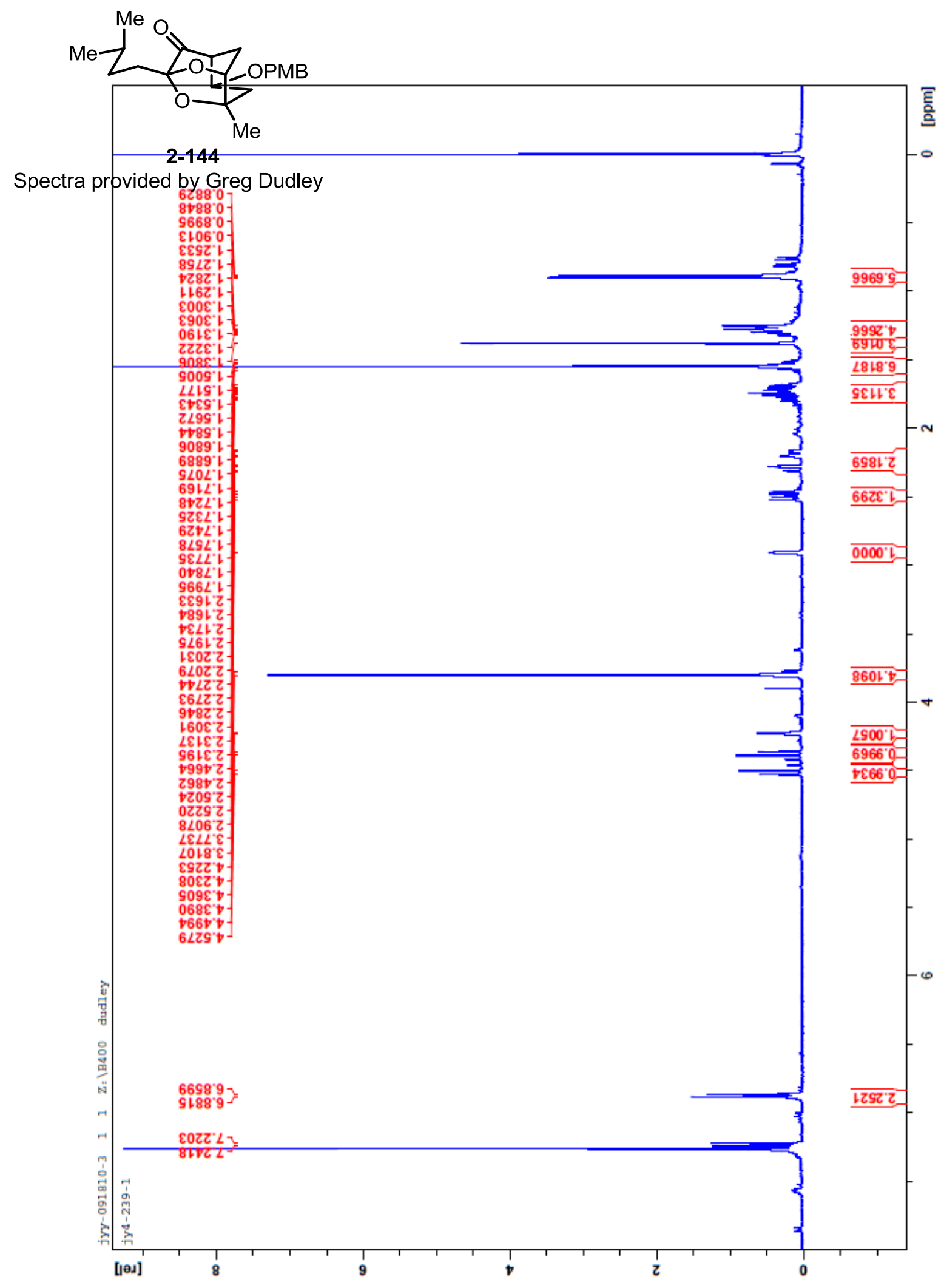




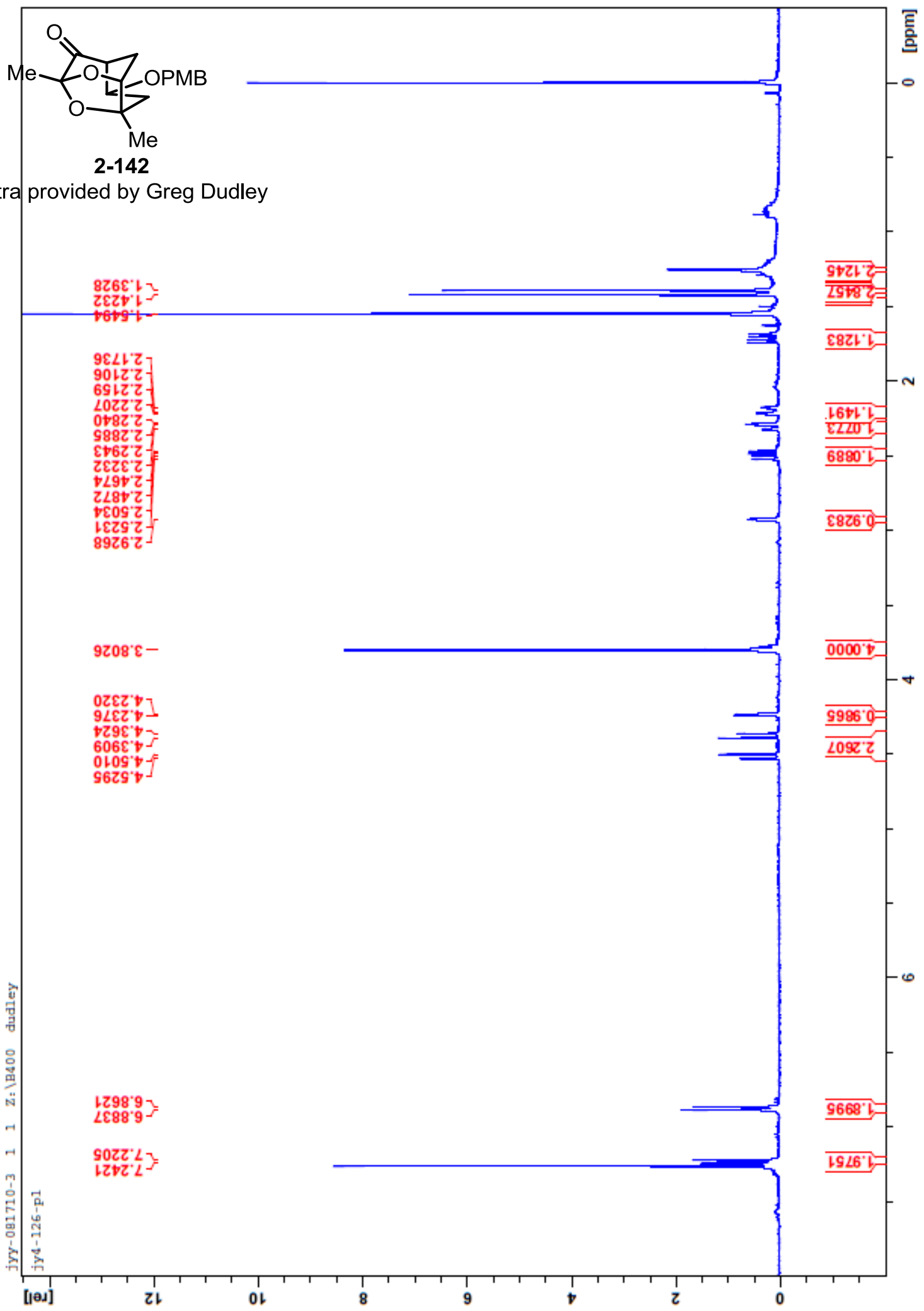


The following are copies of spectra of the natural sample kindly provided by Professor Lago. 


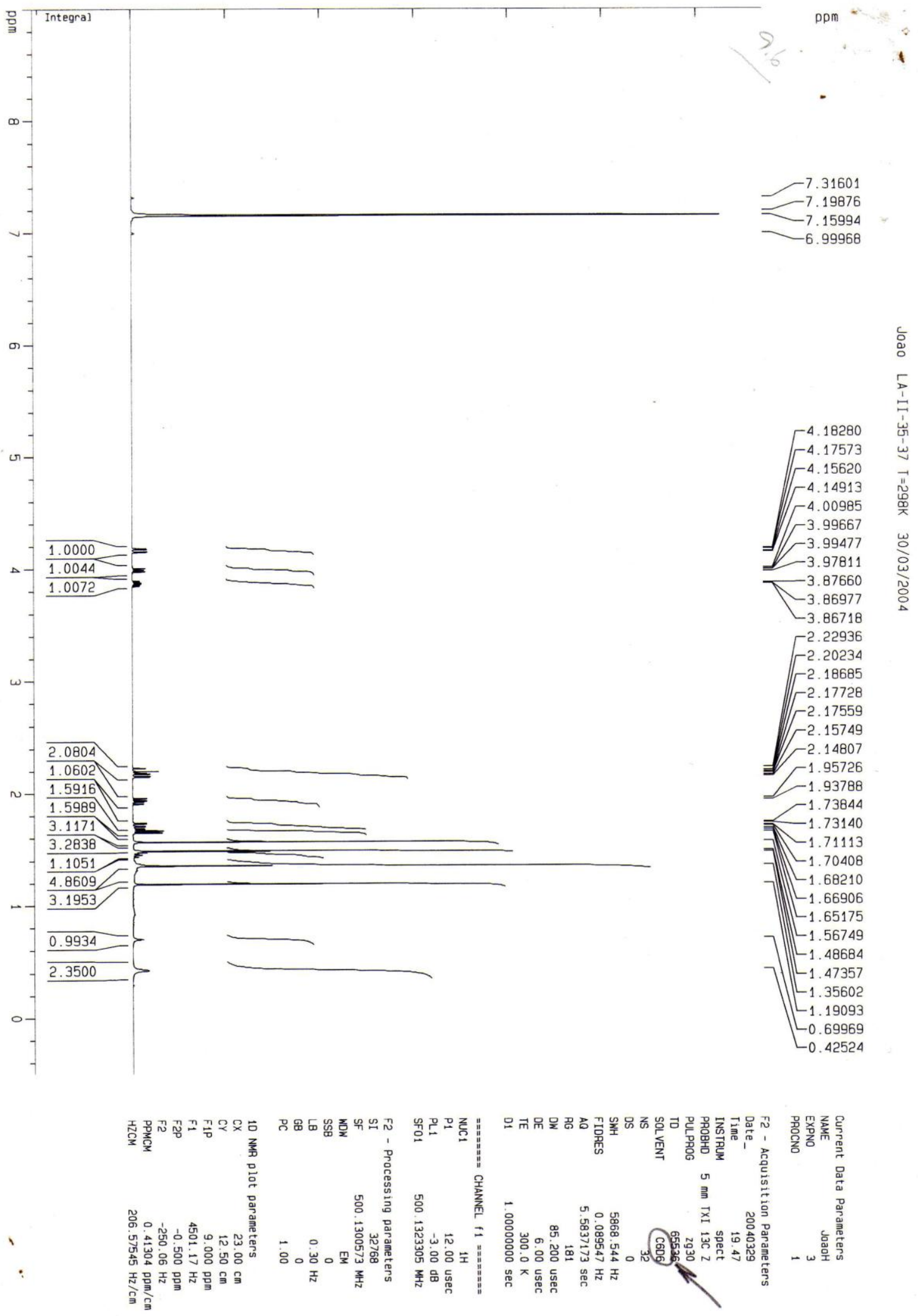

193 


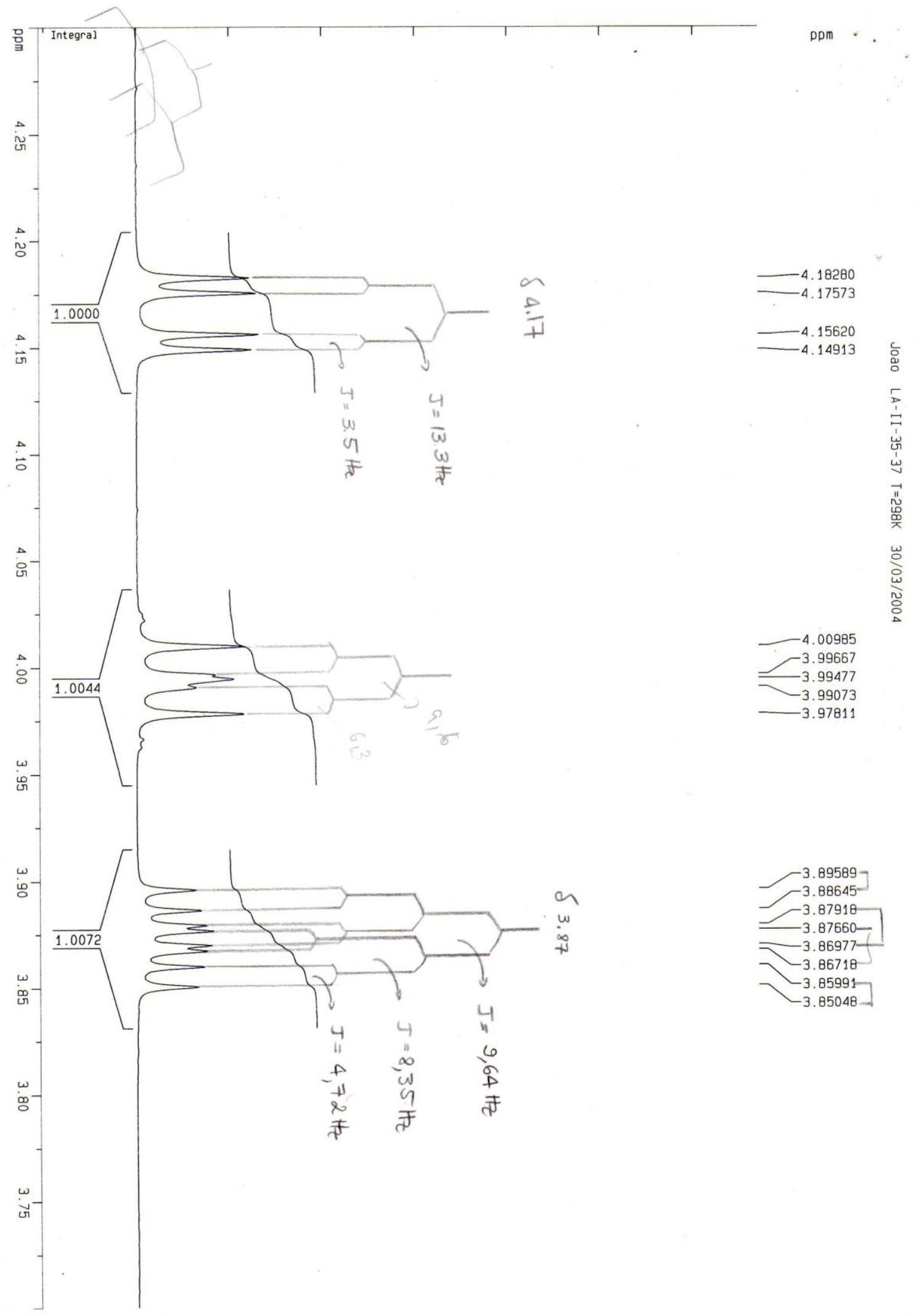




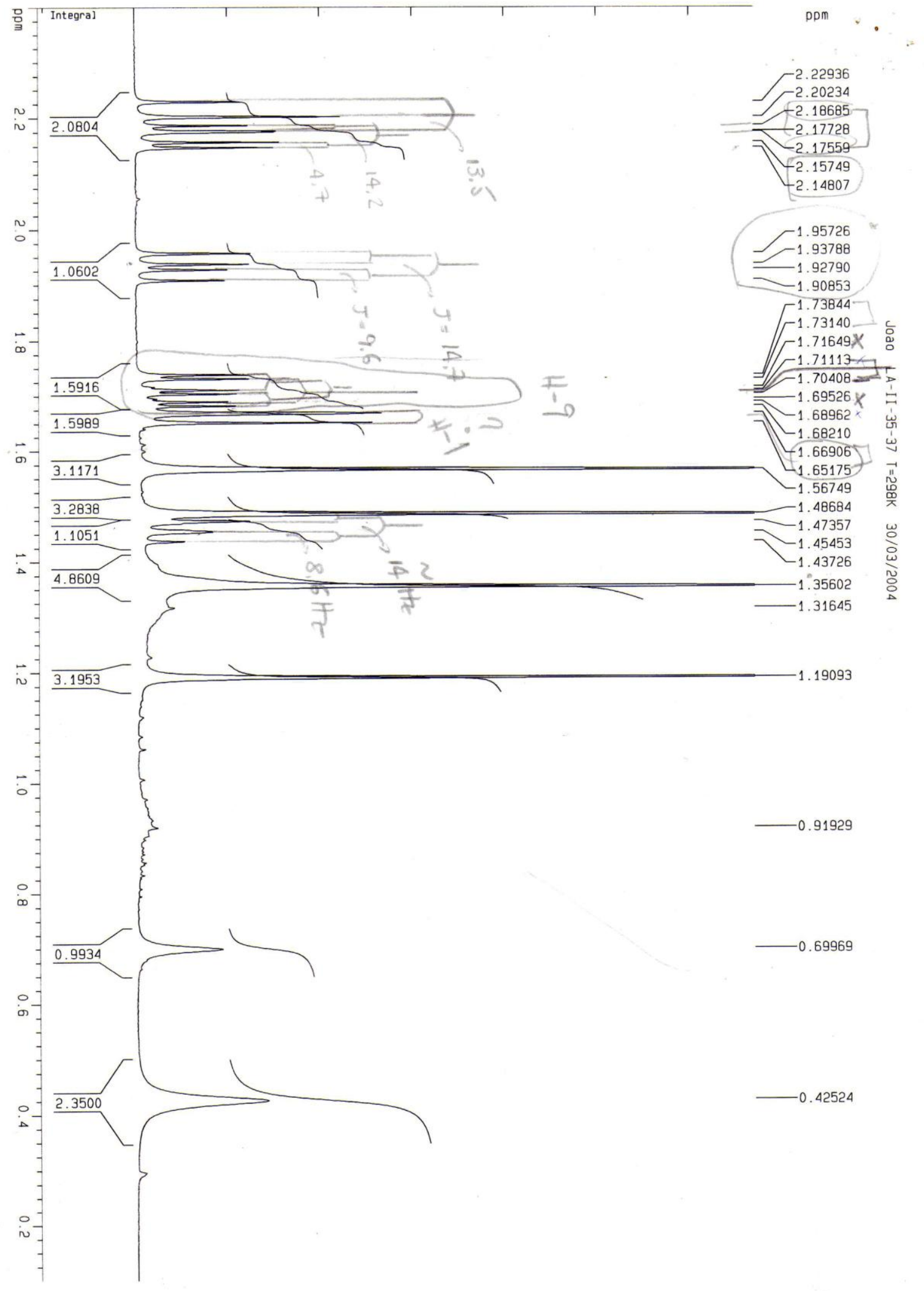




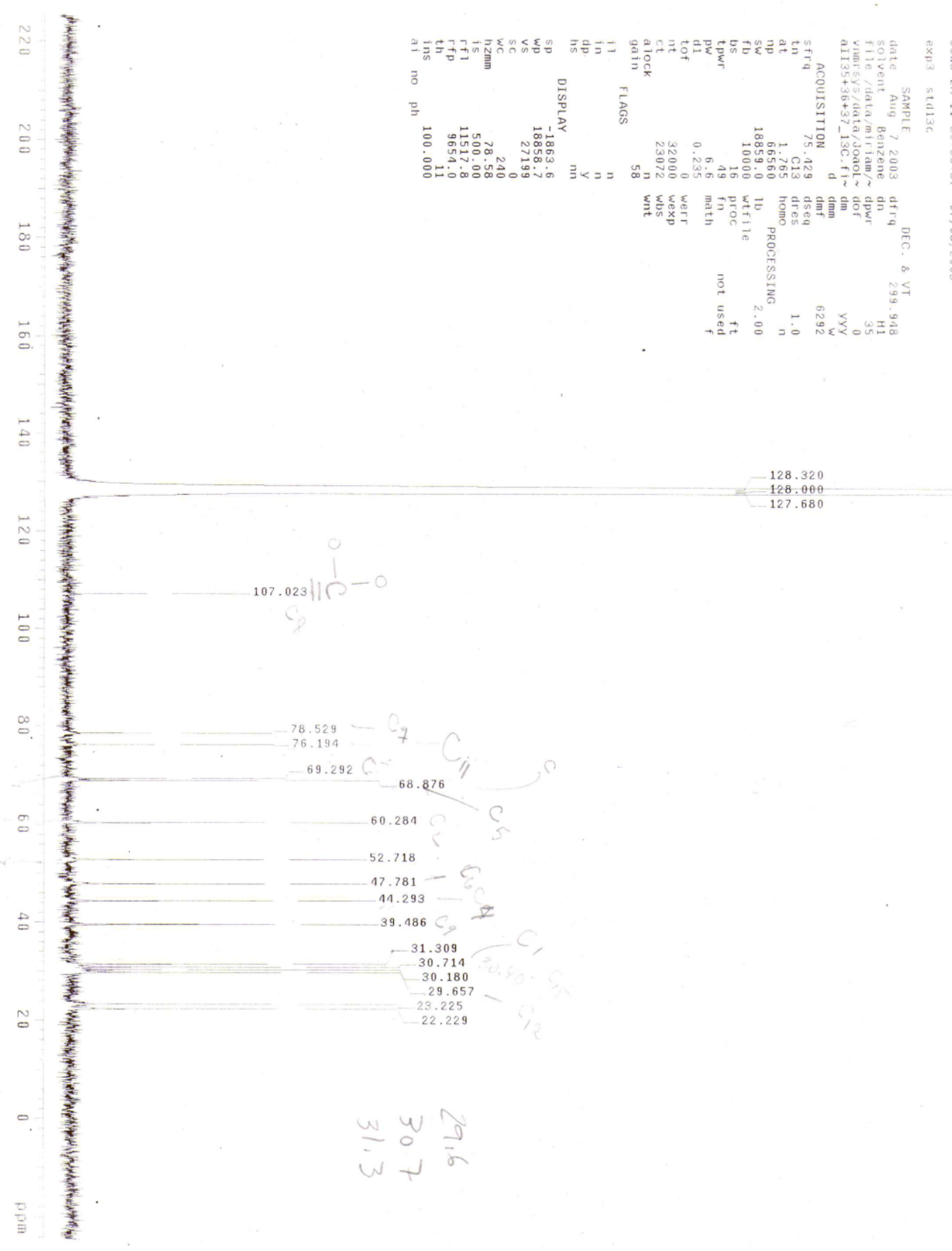




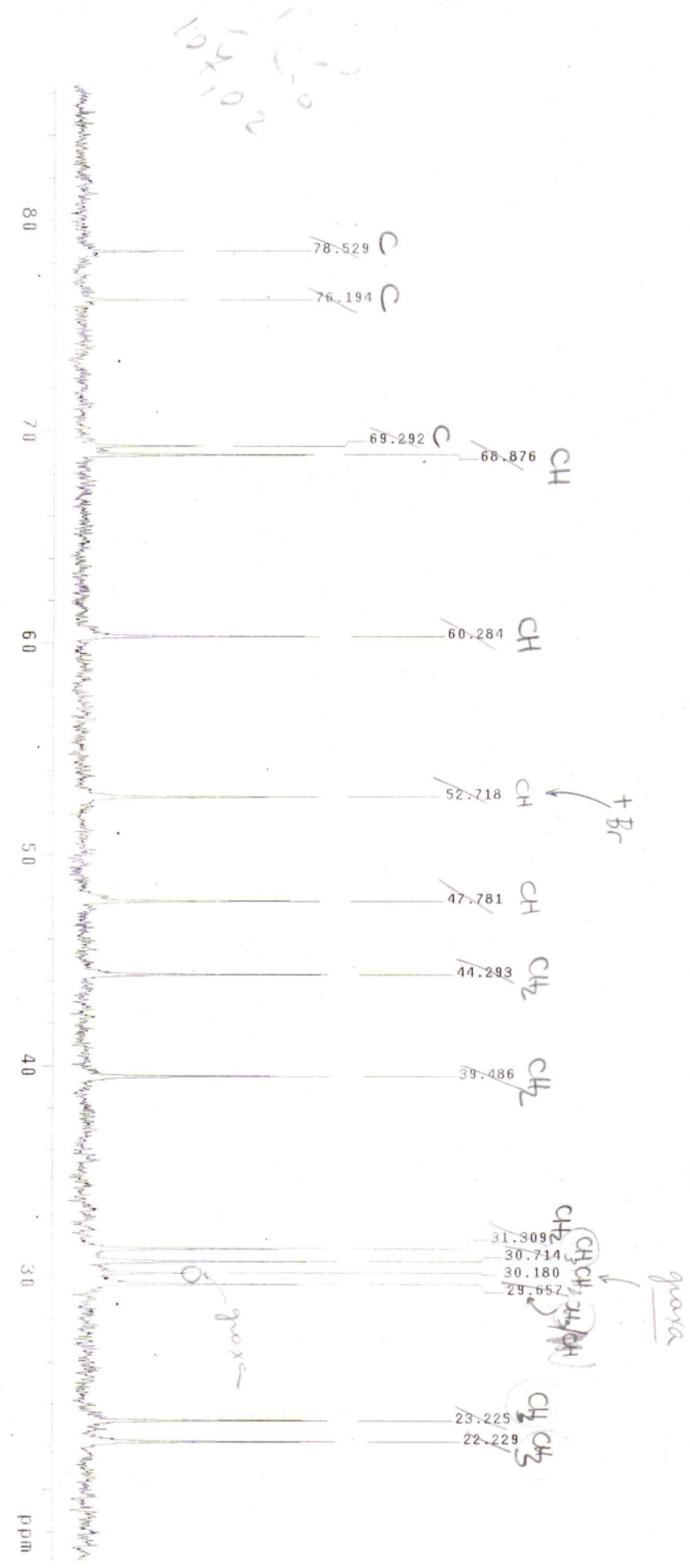


COSY on the following three pages 


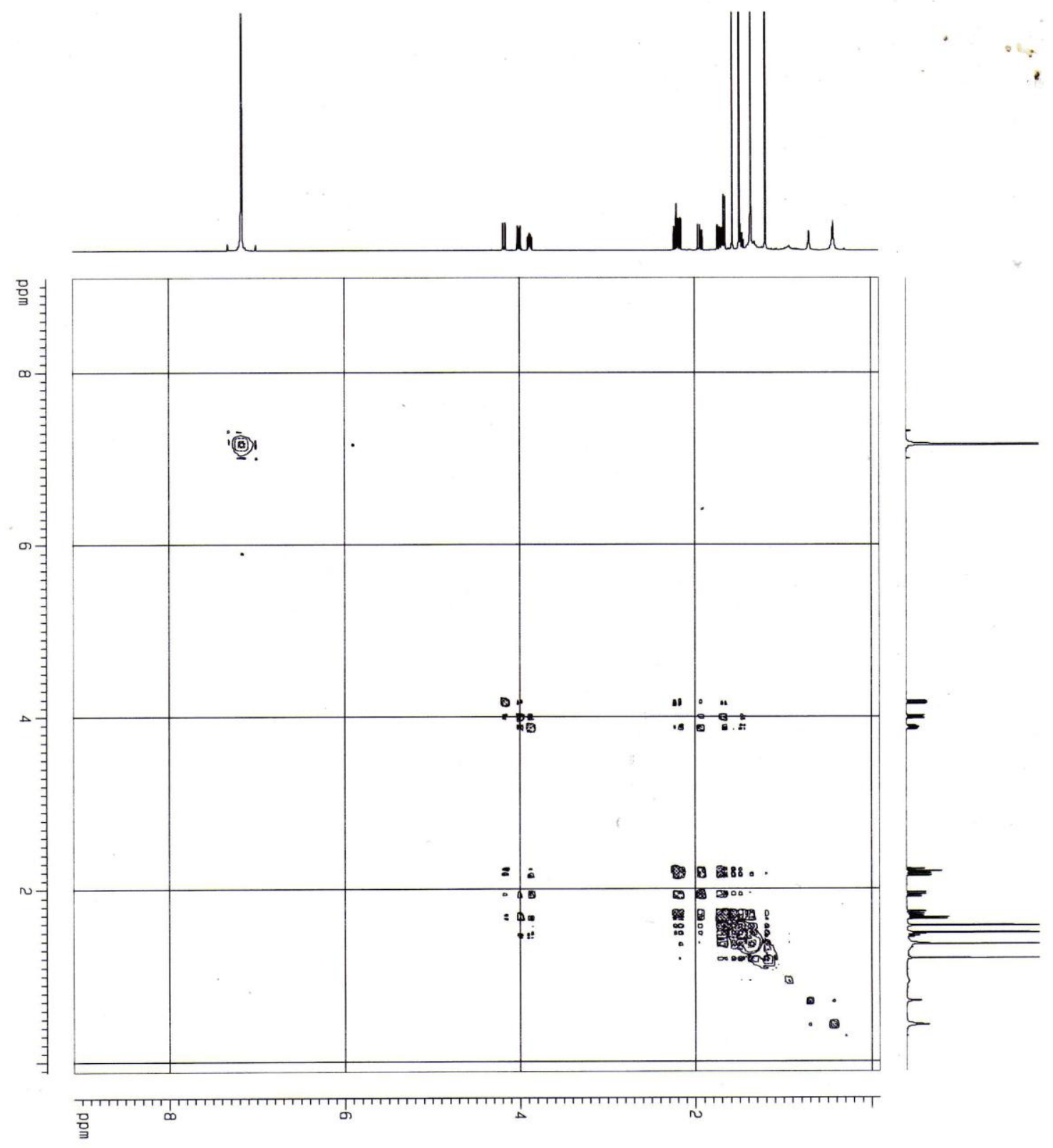

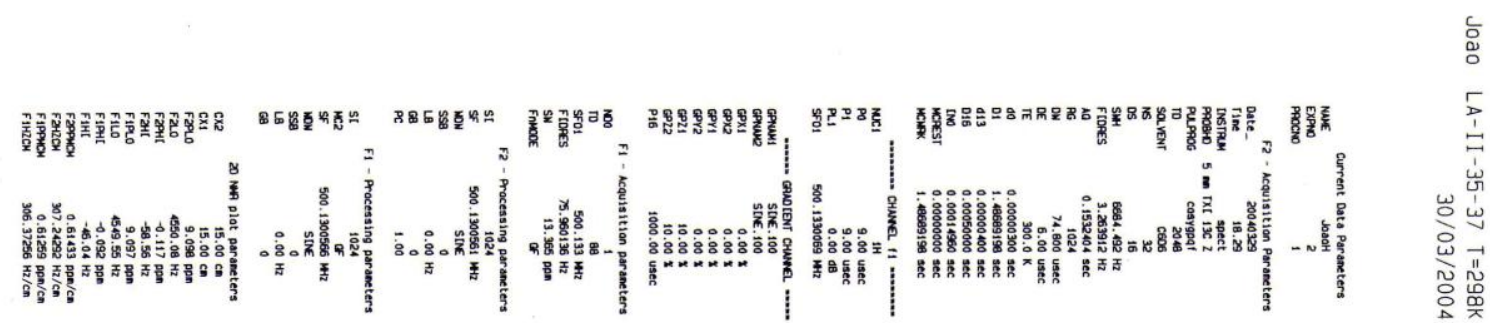




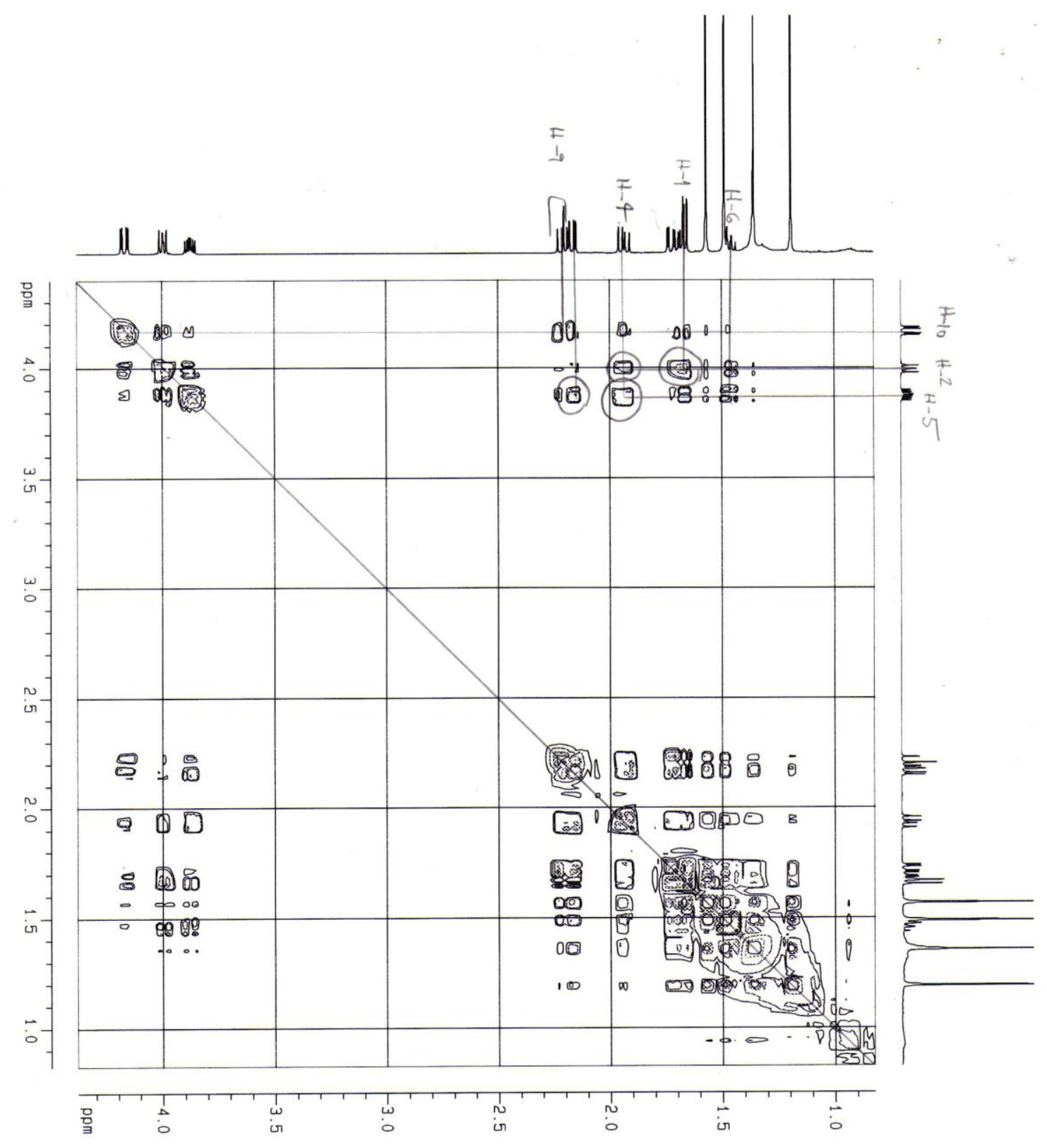

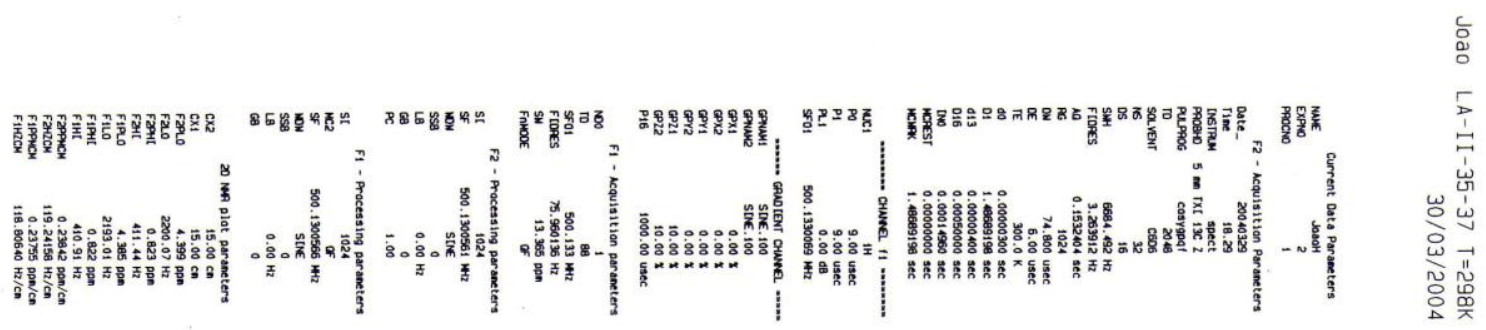



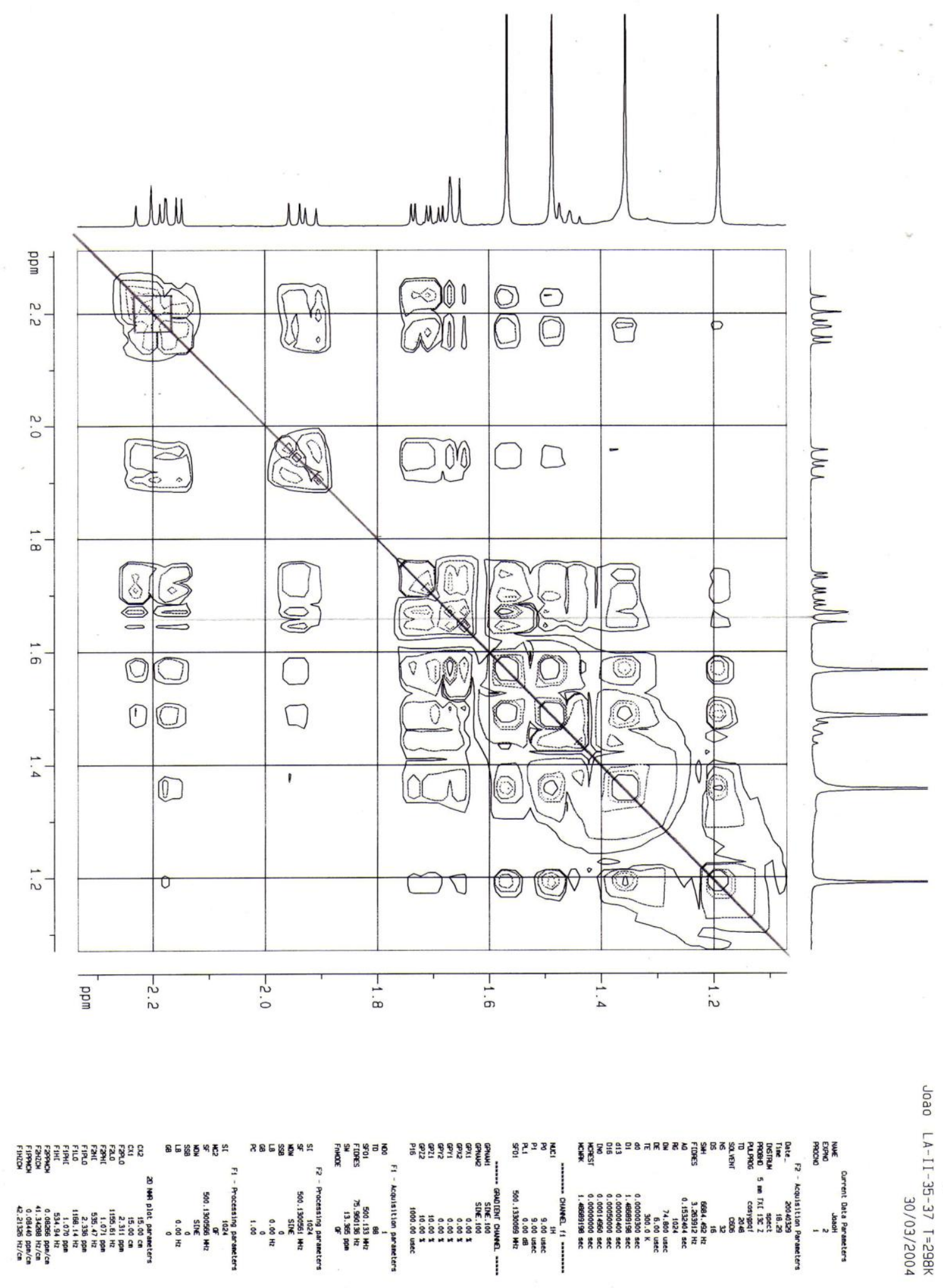
$\mathrm{HMBC}$ on the following three

pages 


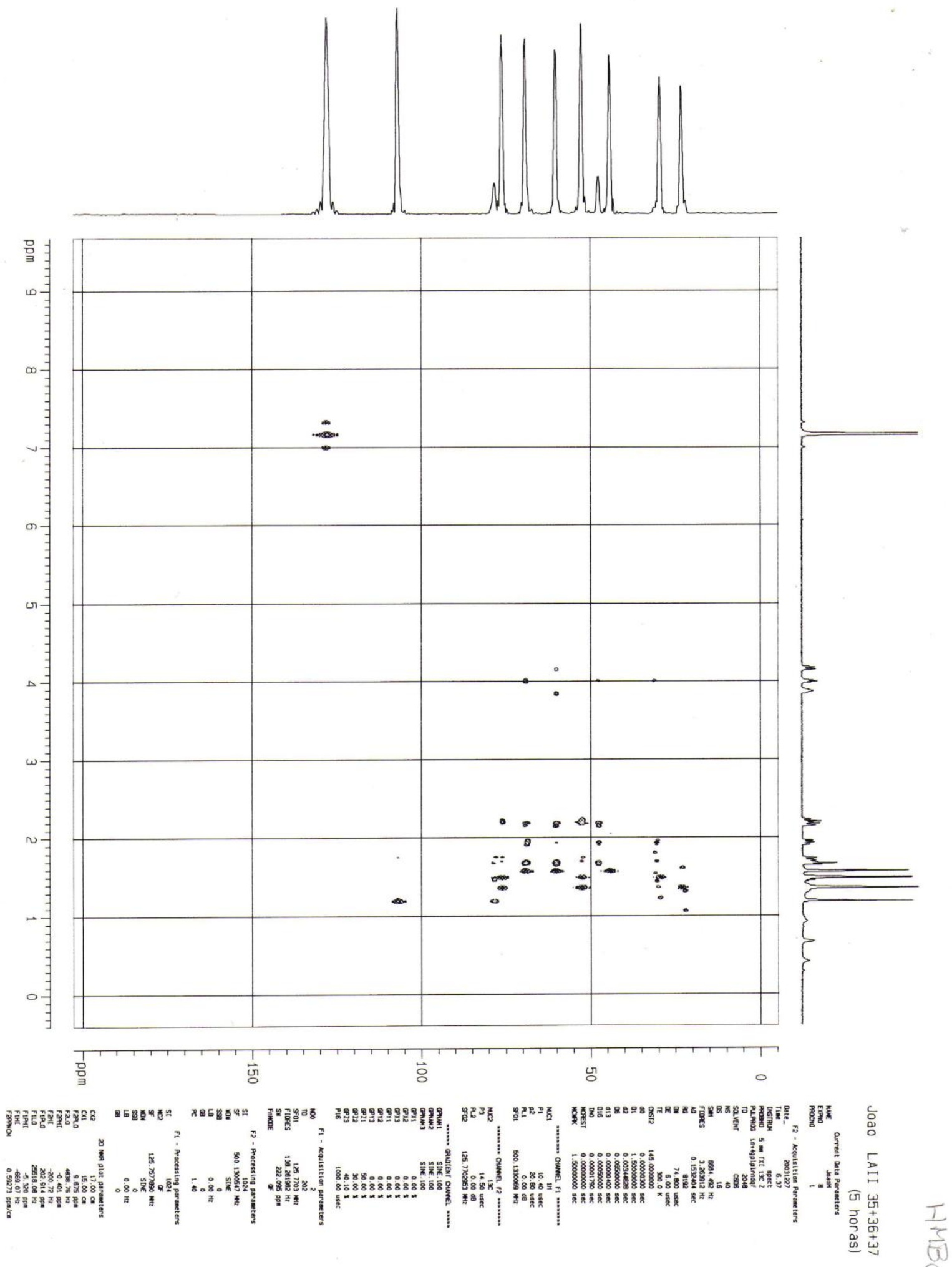




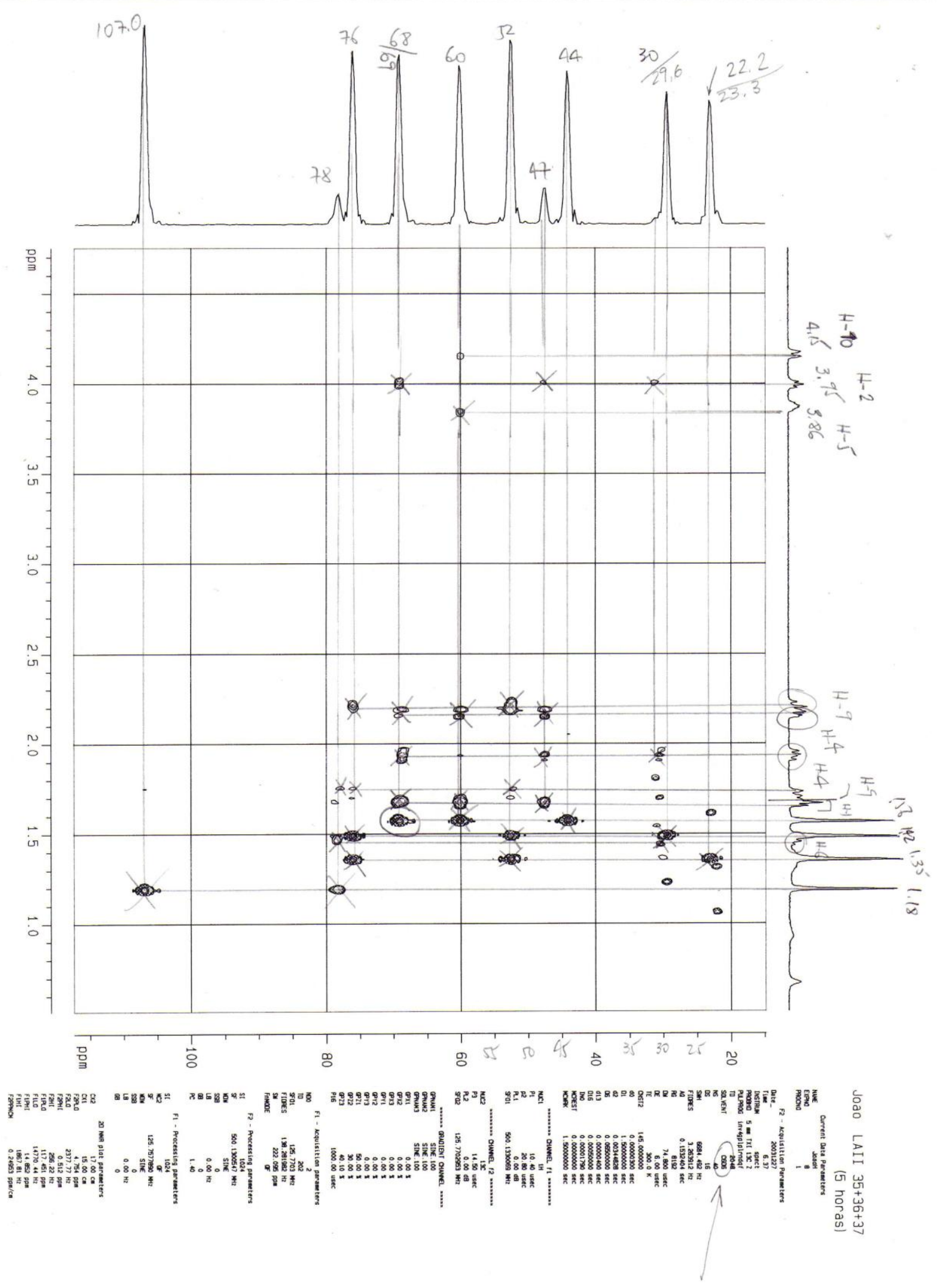




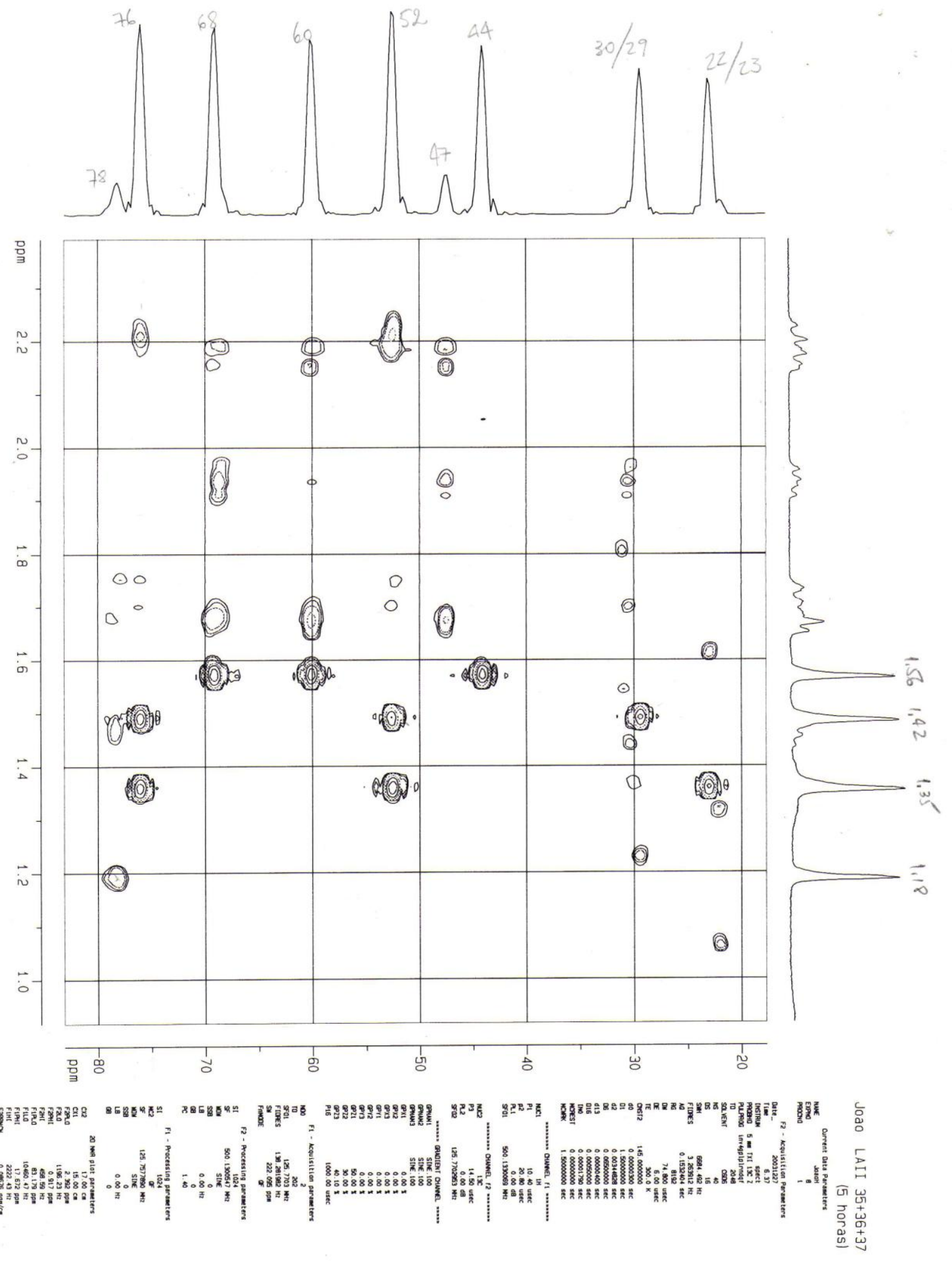


HMQC on the following three

pages 


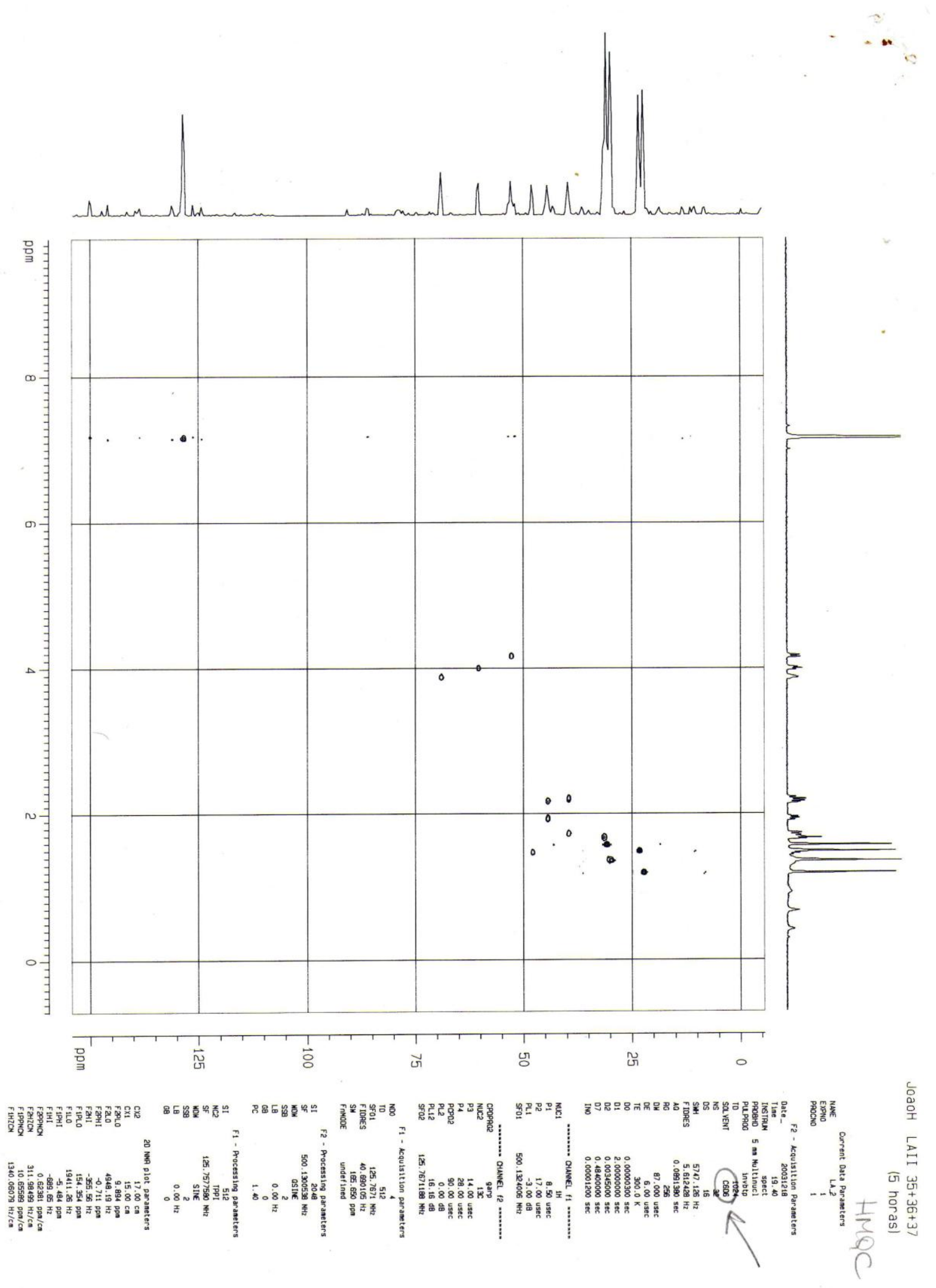




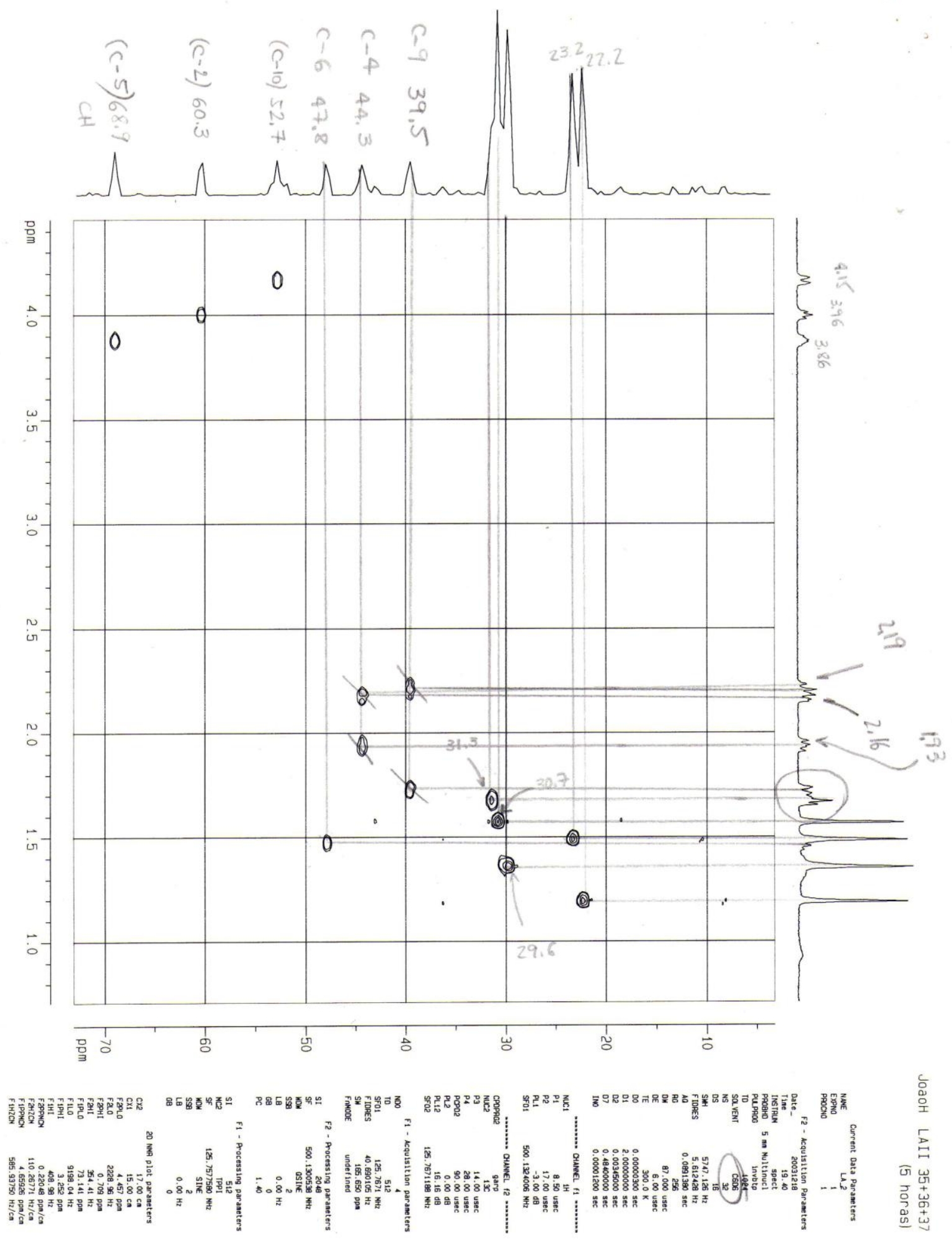



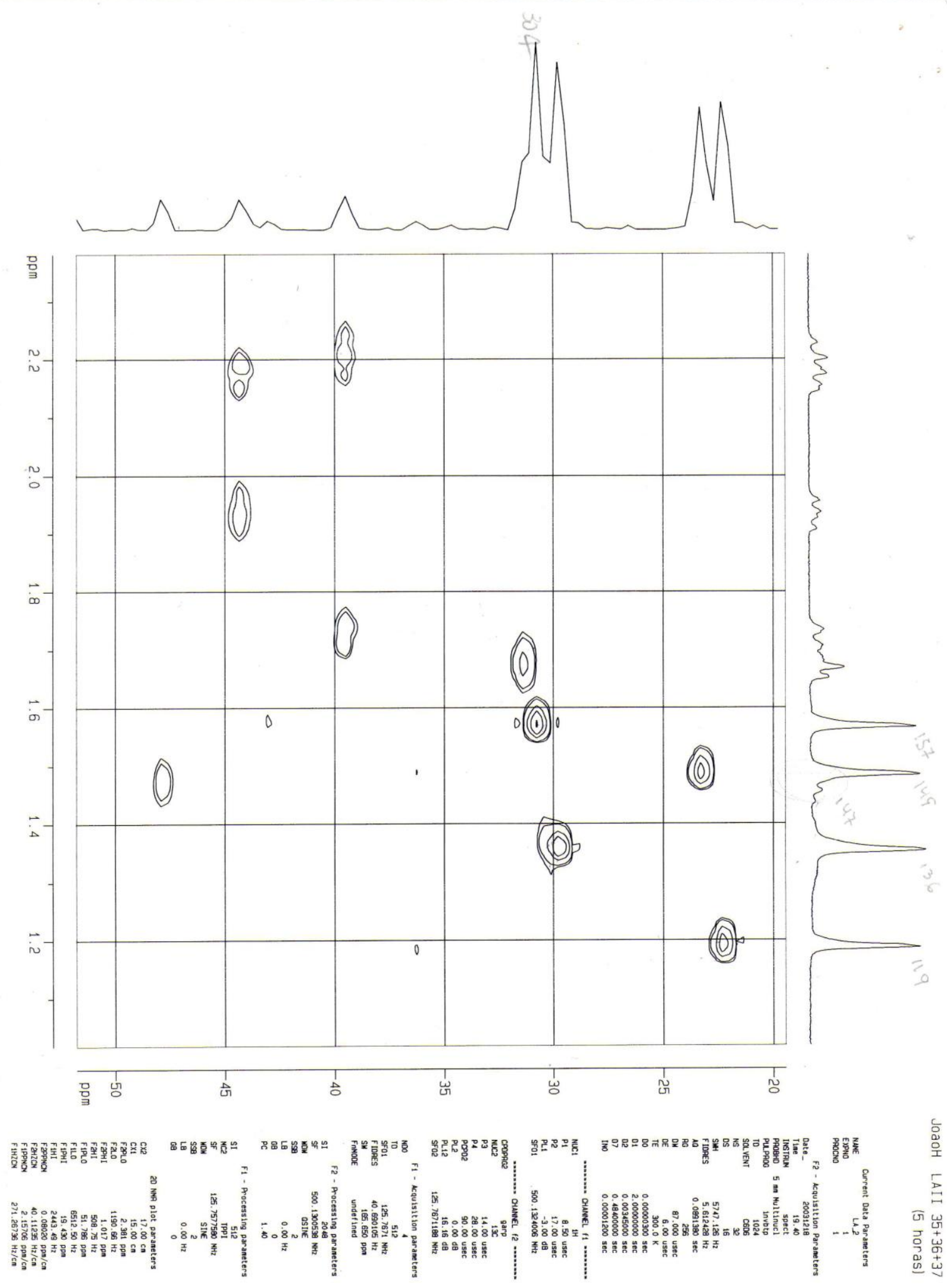


\section{References}

1) Crimmins, M. T.; Hughes, C. O. Org. Lett. 2012, 14, 2168. 